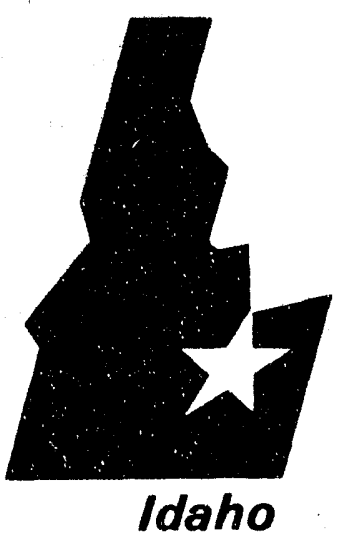

Nationa!

Engineering Laboratory

Managed

by the U.S.

Department

of Energy
EGG-WTD-10254

August 1992

\title{
Alpha Low-Level Stored Waste Systems Design Study
}

\author{
F. Feizollahi \\ B. Teheranian \\ W. J. Quapp
}

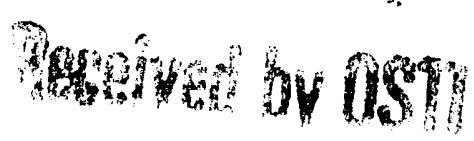

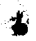

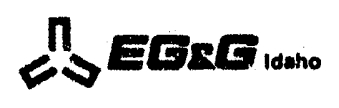

Work performed under DOE Contract No. DE-AC07-761D01570 
This document contains new concepts or the author(s) interpretation of new calculations and/or measurements; accordingly, EG\&G Idaho, inc. is required by the United States Government to include the following disclaimer:

\section{DISCLAIMER}

This report was prepared as an account of work sponsored by an agency of the United States Government. Neither the United States Government nor any agency thereof, nor any of their employees, makes any warranty, express or implied, or assumes any legal liability or responsibility for the accuracy, completeness. or usefulness of any information, apparatus, product or process disclosed. or represents that its use would not infringe privalely owned rights. References herein to any specific commercial product. process, or senvice by trade name, trademark, manufacturer. or otherwise, does not necessanily constitute or imply its endorsement. recommendation, or tavoring by the United States Govemment or any agency thereof. The views and opinions of authors expressed herein do not necessarily state or reflect those of the United States Govemment or any agency thereof. 


\title{
Alpha Low-Level Stored Waste Systems Design Study
}

\author{
F. Feizollahi
}

B. Teheranian"

W. J. Quapp

Published August 1992

\section{Idaho National Engineering Laboratory \\ EG\&G Idaho, Inc. \\ Idaho Falls, Idaho 83415}

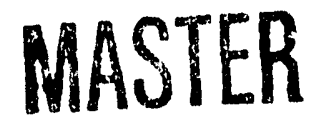

DISTRIBUTION OF THIS DOCUMENT IS UNLIMTTED

Prepared for the

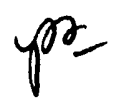

U.S. Department of Energy

Office of Environmental Restoration and Waste Management

Under DOE Idaho Fleld Office

Contract DE-AC07-76ID01570

a. Morrison Knudson Corporation, Environmental Services Division, 180 Howard Street, San Francisco, California, 94105. 


\section{Alpha Low-Level Stored Waste Systems Design Study}

EGG-WTD-10254

Prepared by:

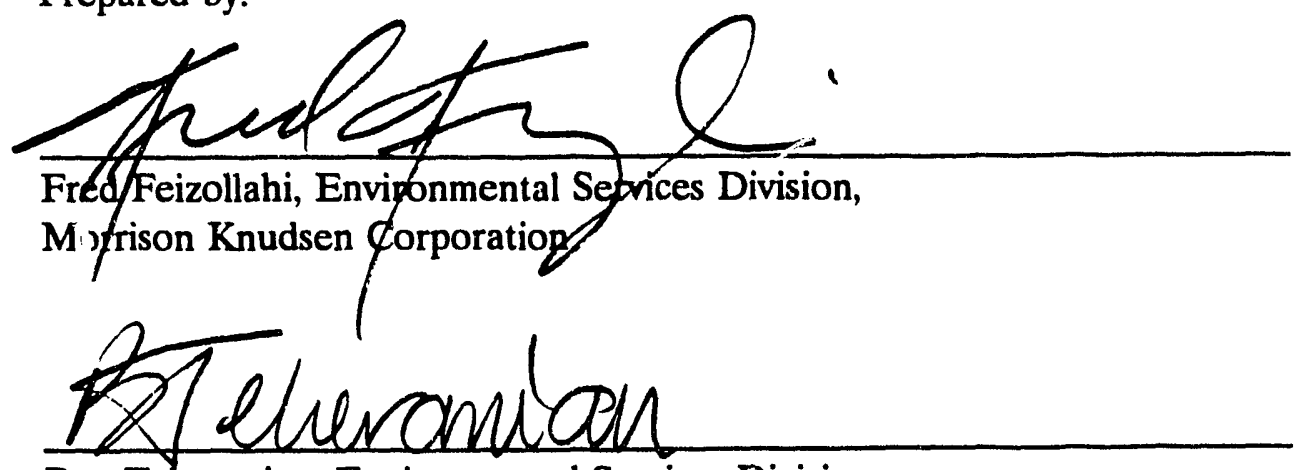

Ben Teheranian, Environmental Services Division,

$8 / 17 / 92$

Fred/Feizollahi, Enviponmental Setrices Division,

Date

Morrison Knudsen Corporation

Reviewed by:

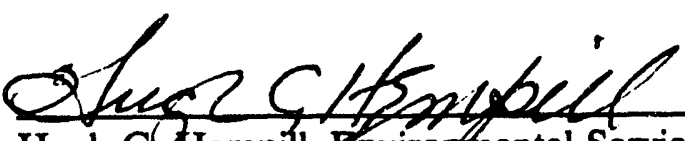

Hugh GCHempill, Enviromental Services Division,

Morrison Knudsen Corporation

Date

Reviewed and Approved by:

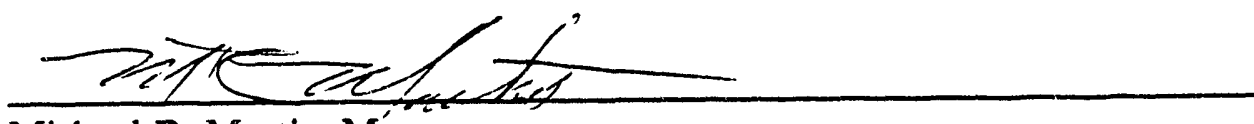

Michael R. Martin, Mánager

$8 / 18 / 92$

Date

Waste Management Facility Projects

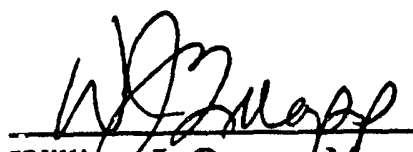

William J. Quapp/Manager

$8 / 18 / 92$

Date

Private Sector Participation Initiative 


\begin{abstract}
The Stored Waste System Design Study (SWSDS), commissioned by the Waste Technology Development Department at the Idaho National Engineering Laboratory (INEL), examines relative life-cycle costs associated with three system concepts for processing the alpha low-level waste (alphaLLW) stored at the Radioactive Waste Management Complex's Transuranic Storage Area at the INEL. The three system concepts are incineration/melting; thermal treatment/solidification; and sort, treat, and repackage. The SWSDS identifies system functional and operational requirements and assesses implementability; effectiveness; cost; and demonstration, testing, and evaluation (DT\&E) requirements for each of the three concepts.
\end{abstract}




\title{
EXECUTIVE SUMMARY
}

\author{
Introduction
}

The waste stored at the Idaho National Engineering Laboratory (INEL) Transuranic Storage Area (TSA) is classified in two general categories: transuranic (TRU) waste and alpha low-level waste (alpha-LLW). The TRU waste has a transuranic element contamination level greater than 100 nanocuries per gram (nCi/g), and the U.S. Department of Energy (DOE) plans to dispose of this waste in the Waste Isolation Pilot Plant (WIPP). The alpha-LLW has a TRU contamination level of less than $100 \mathrm{nCi} / \mathrm{g}$ but greater than $10 \mathrm{nCi} / \mathrm{g}$, and no specific method for its disposal has been established. The stored alpha-LLW falls under the low-level waste (LLW) category as defined by DOE Order 5820.2A and the U.S. Nuclear Regulatory Commission (NRC) regulation for shallowland disposal of radioactive waste, Title 10, Code of Federal Regulations, Part 61. It is also assumed that most of the alpha-LLW has components controlled under the Resource Conservation and Recovery Act (RCRA).

\section{Purpose and Scope}

The primary purpose of the Stored Waste System Design Siudy (SWSDS) is to compare relative life-cycle costs of facilities representing different levels of technological sophistication when processing alpha-LLW. The SWSDS investigates three system concepts that were found to be most preferable by a previous EG\&G Idaho, Inc., system screening effort, the Buried Waste System Design Study (BWSDS). ${ }^{1}$ This screening effort consisted of an original set of 73 system coricepts, of which 12 were selected for detailed evaluation. The three systems are based on three final product waste forms-vitreous, ${ }^{a}$ solidified, and repackaged with minimal processing. As a minimum requirement, the first two waste forms must meet the Environmental Protection Agency's (EPA's) land disposal restrictions (LDR) and the DOE regulations and requirements for shallow land burial. The third waste form is assumed only to be suitable for disposal in a deep geologic repository (similar to WIPP) that receives an EPA approval of a no-migration petition for variance from the LDR regulations.

\section{Systems Description}

The three system concepts studied are incineration/melting; thermal treatment/solidification; and sort, treat, and repackage. A brief description of each system is presented below.

The incineration/melting system concept (shown in Figure 1) produces a vitrified (glass/ceramic) waste form. To produce a vitrified waste, combustibles and semi-combustibles ${ }^{b}$ are first processed in an incinerator, the incinerator ash is then mixed with other noncombustibles and an additive soil,

a. The term vitreous, or vitrified, is used in this report to mean a final waste form having either glassy, glass ceramic, rocky (glass with crystalline phases or totally crystalline), or iron-enriched basalt (which is in a devitrified state) structure.

b. Semi-combustibles is used in this study to denote a mixture of non-combustibles and combustibles in which the quantity of combustible material is greater than $5 \%$ of the total mixture weight. 


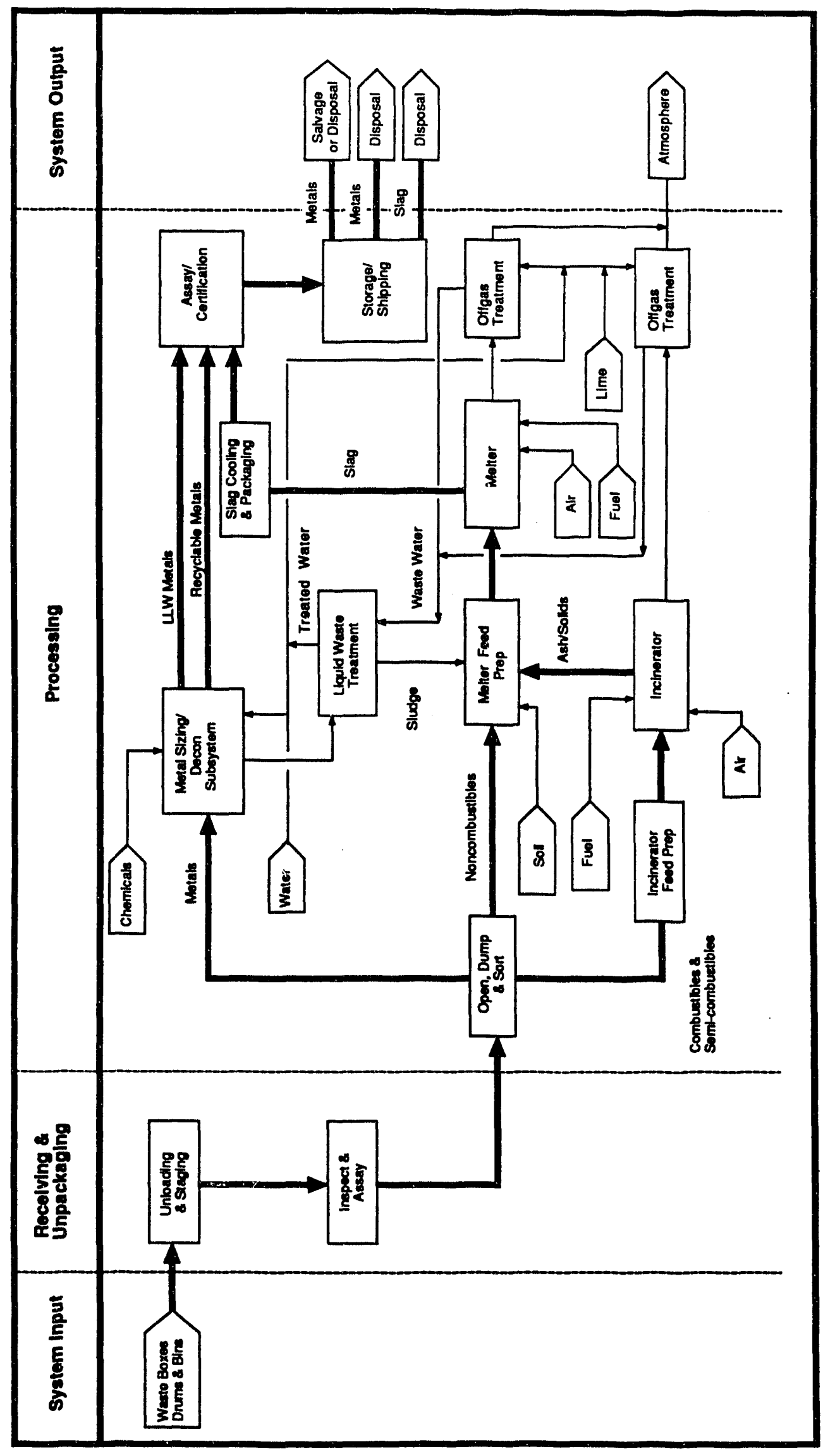

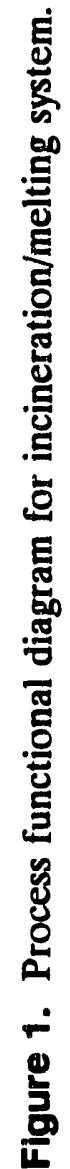


and the mixture is fed to a melter. The melter produces a molten slag which, upon cooling and annealing, becomes a high-integrity, leach-resistant glass- or rock-like material. Metals are presorted up front and processed in a separate unit operation called the metal sizing and decontamination (decon) subsystem. This subsystem converts the metals into either low-level disposable (less than $10 \mathrm{nCi} / \mathrm{g}$ ) waste or a poientially recyclable material.

The second system, thermal treatment/solidification (shown in Figure 2), produces a solidified (cementitious) waste form. This system is similar to the first concept with the exception that the ash and inerts from the incinerator are solidified. Noncombustible materials, such as soil, concrete, and glass, having organic contamination are treated by a thermal desorber to remove organics before they are solidified. All inorganic noncombustibles are fed directly to and processed by the solidification and packaging unit operations of the system.

The third system, sort, treat, and repackage (shown in Figure 3), is based on a minimum processing philosophy and produces a dry solids (unstabilized) waste form, which contains approximately 3 to 5 percent solidified liquids and fines. This system sorts and solidifies liquids and fines (as required by WIPP), while the remaining dry solids (except metals) are size reduced and then repackaged. As with the other two systems, the sort, treat, and repackage system has a metal sizing/decon subsystem which treats all metals presorted at the initial step of the process.

\section{Relative Costs}

Rough-order-of-magnitude (ROM) life-cycle cost estimates for the three systems are summarized in Figure 4. The ROM cost estimates include demonstration, testing, and evaluation (DT\&E), facility construction costs, operating and maintenance costs, operating budget funded activities, decommissioning, disposal, and transportation costs. As shown in Figure 4, the ROM lifecycle cost difference between the most and the least expensive system is approximately 10 percent. At this point of the system analysis, the cost differences are not significant enough to be a factor in selecting a preferred option.

Building costs are derived by first estimating the square footage needed to house each unit operation and then multiplying the square footage by the building unit rate costs. Four different categories of building unit rates are considered: low-hazard buildings at $\$ 150 / \mathrm{ft}^{2}$, moderate-hazard buildings at $\$ 350 / \mathrm{ft}^{2}$, double-barrier confinement alpha cells at $\$ 1000 / \mathrm{ft}^{2}$, and triple-barrier confinement alpha cells at $\$ 1200 / \mathrm{ft}^{2}$. The building costs are based on the assumptions that waste handling, processing, and equipment maintenance functions are accomplished in alpha cells; operating rooms are in moderate-hazard areas; and support functions are in low-hazard areas of the facility. The offsite utility cost of power, water, and sewer facilities was not included in the estimate.

The initial DT\&E costs and the annual operating and maintenance costs are derived by developing the size of the operating and maintenance staff, utility costs, and material costs for each unit operation.

Costs for design, construction, construction management, and testing are estimated by multiplying the equipment and building costs by a given set of factors which are uniformly applied

to each of the three options. These factors are basec on EG\&G Idaho's experience on similar projects. All costs are in 1992 dollars. 


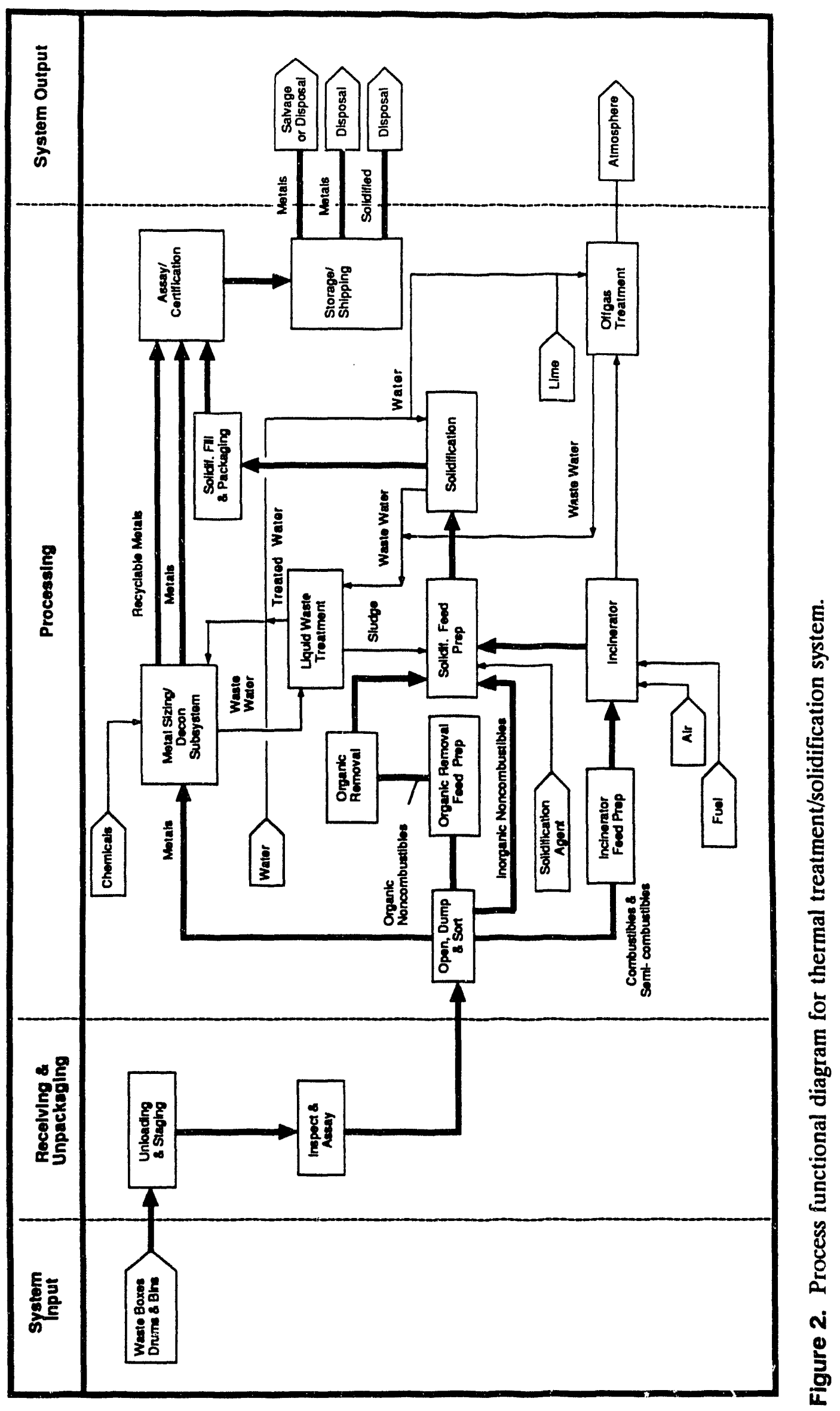




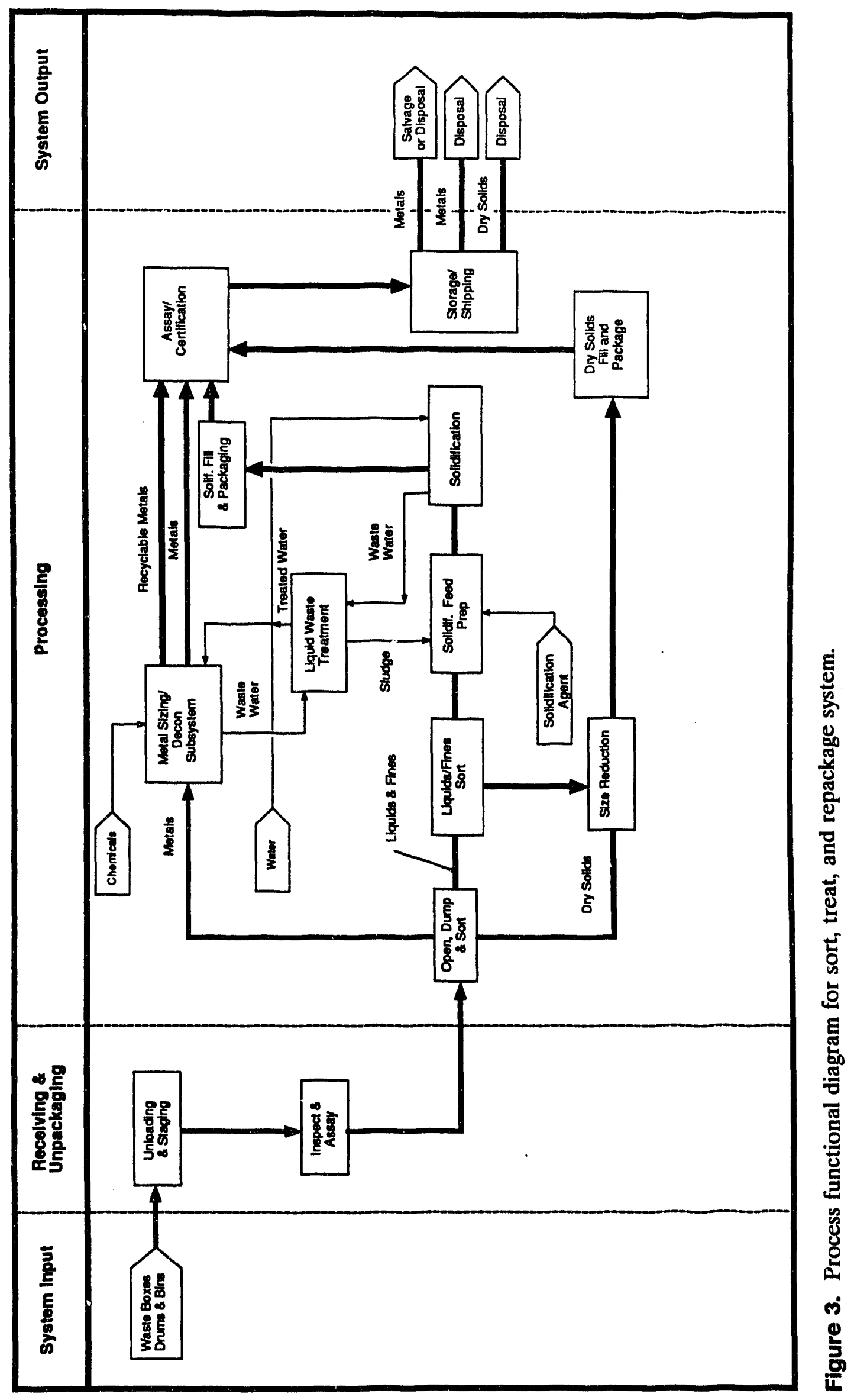




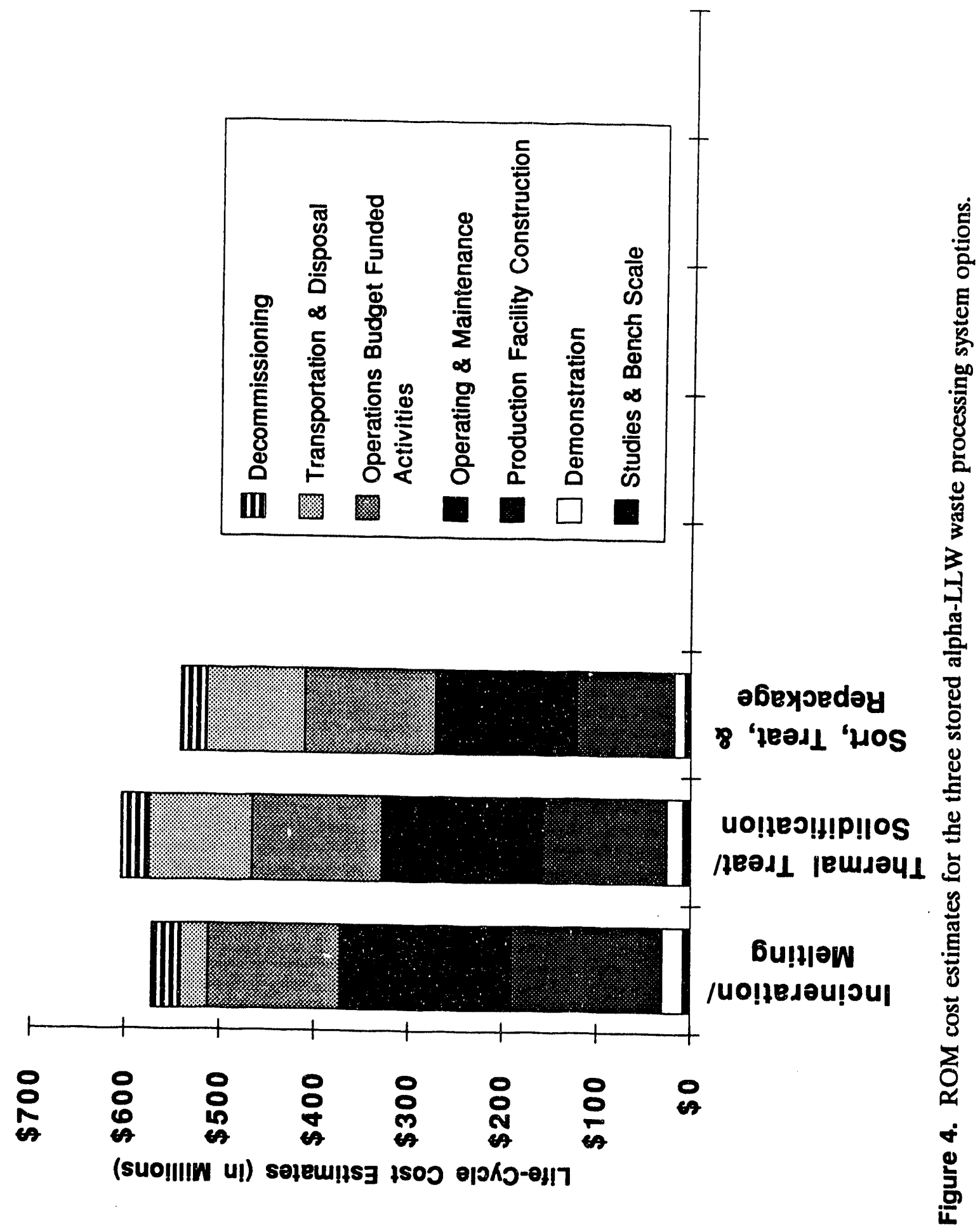


In accordance with DOE orders, there are a number of activities which can not be charged to the Line Item Construction Projects (LICP) funds. These include conceptual design, program management and administration planning prior to conceptual design, environmental and permitting, safety documentation, and preparation for operation. Budgeted cost for these activities are obtained from the current IWPF estimates and are added to the system ROMLC cost estimates. Furthermore, it is assumed that these costs are the same for all system options.

Decontamination and decommissioning costs are based on a recent cost study conducted by EG\&G Idaho for the buried TRU waste. ${ }^{2}$ Based on this study, a cost of $\$ 450 / \mathrm{ft}^{2}$ average unit rate is used. Transportation and disposal costs are obtained from the same reference. Accordingly, \$1.71 and $\$ 450$ per cubic foot unit rates are used for transforation and disposal, respectively. The disposal cost includes allowances for facility monitoring and care during the long-term post closure period, usually 100 years.

Cost sensitivity analyses are performed to determine the impact of the equipment, building and disposal costs, and the alpha-cell area variations on the overall system costs. Key conclusions of the cost assessment effort are:

- The overall system cost is significantly impacted by the size of the alpha cells required for waste processing. Therefore, a detailed design study is required to optimize the facility layout and to adequately define the alpha-cell space requirements and evaluate options such as glove-box versus remote alpha-cell waste handling.

- Building cost differences are minimal for the three systems (see Figure 5). This is due to an alpha facility high baseline cost, which is independent of the processes chosen.

\section{Key Advantages and Drawbacks of the Systems}

The three systems are each sized to process approximately one million cubic feet of alpha-LLW weighing about 13,120 tons. The volume of the packaged waste produced by each system is shown below. As shown, the incineration/melting system has the lowest waste volume which is a significant advantage of the system.

$\begin{array}{ll}\text { Incineration/melting } & 155,800 \mathrm{ft}^{3} \\ \text { Thermal treatment/solidification } & 573,400 \mathrm{ft}^{3} \\ \text { Sort, treat, and repackage } & 546,000 \mathrm{ft}^{3}\end{array}$

Other significant advantages of the incineration/melting system concept are that the thermal processes effectively destroy hazardous organic compounds and the noncombustible portion of the input waste is converted into a benign glass/ceramic material suitable for retention of the TRU elements for geological time frames. The significant disadvantages are the potential for large volumes of offgas ${ }^{c}$ and the need for secondary burners and pollution control devices to treat the offgas.

c. The use of incinerators that minimize offgas (such as pyrolysis technique with oxygen burning) and melters that use little air (such as arc melters with a little oxygen for redox control and/or metal decontamination) will alleviate the high offgas discharge concerns. 


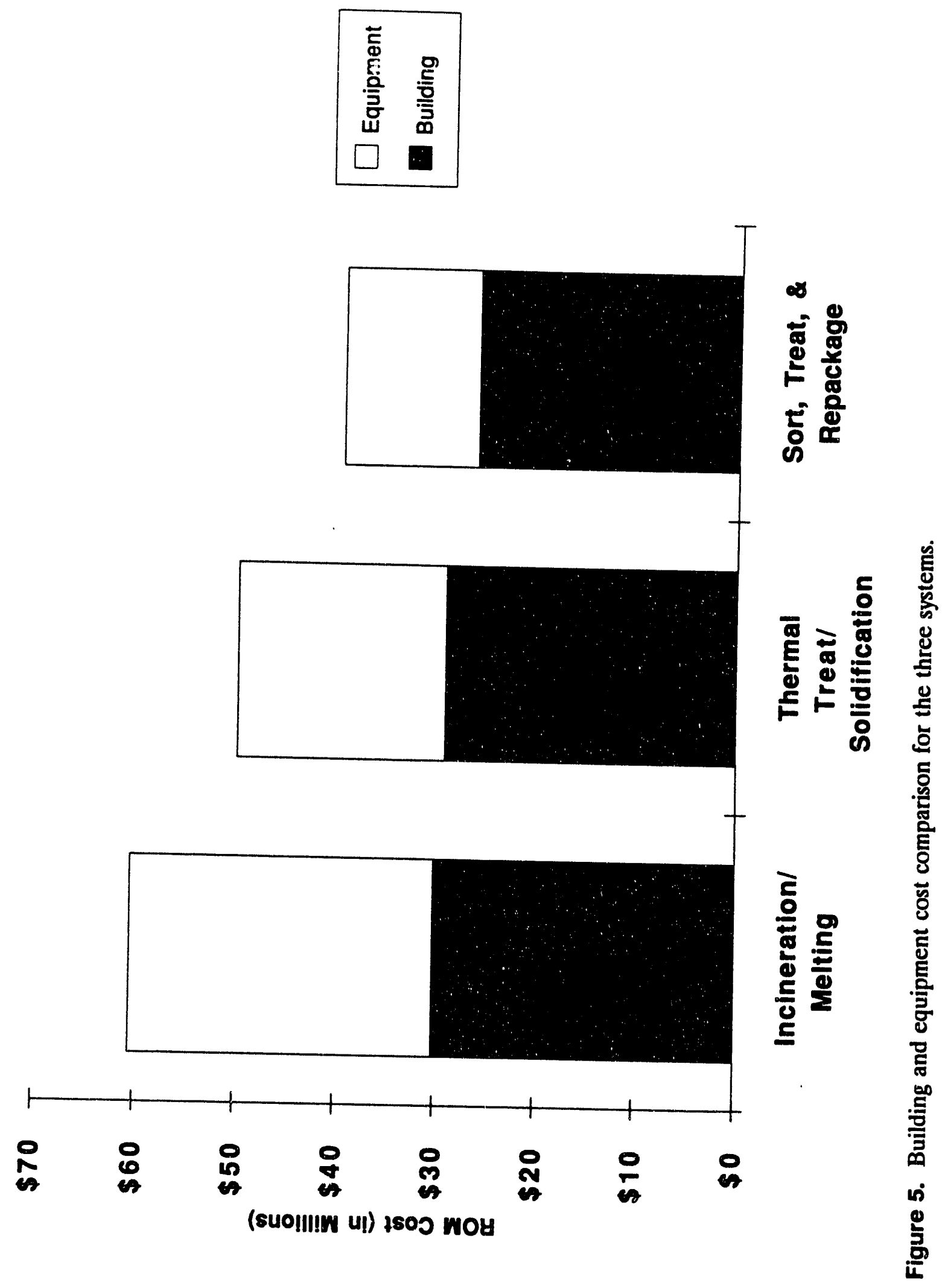


The thermal treatment/solidification system, which also uses an incinerator, has the same advantages relative to combustibles as the incinerator/melting system. The final solidified (cementitious) waste form is, however, less leach-resistant than the incineration/melting system and may be unable to stabilize TRU elements contained in alpha-LLW for the long-term period ( $>300$ years).

A significant advantage of the sort, treat, and repackage system is that it does not have complex processing techniques, as do the other two systems. Only a small solidification process is used and most of the incoming wastes are repackaged by material handling equipment. Thi, disadvantage is that the system produces a fiual waste form material that can be used only if a deep geological disposal facility becomes available.

\section{Demonstration, Testing, and Evaluation Needs}

Demonstration, testing, and evaluation (DT\&E) of the incineration/melting system has already been started and several paper studies and bench-scale tests have been completed. The remaining DT\&E is estimated to require approximately four years. The estimated DT\&E lead time for the thermal treatment/solidification system concept is approximately three years, taking into account the present paper studies and bench-scale tests. The sort, treat, and repackage system, which utilizes mostly material handling technologies, is estimated to require a 2.5 year lead time for DT\&E to adopt material handling technologies in an alpha-cell envirunment.

\section{Implementation Risk Assessment}

A qualitative assessment of the implementation risks for each of the system concepts is performed. Implementation risks are uncertainties related to the ability of the treatment systems to comply with the stated objectives. The assessment is helpful in identifying areas requiring focused work and attention. Accordingly, the project objectives are divided into technical, environmental, health and safety, institutional, schedule, and cost. The main concerns related to the technical performance objective are the maturity/complexity of the processes employed and the ability of the systems to produce an acceptable waste form.

The assessments indicated that the incineration/melting system has a low technical risk with regard to waste form. This is because initial studies on the resultant waste form (iron-enriched basalt) and a preliminary performance assessment have shown that this waste form meets all the criteria for permanent shallow-land burial. The thermal treatment/solidification system receives a moderate ranking in the technical area because the stabilized waste form material may not have the required long-term ( $>500$ years) integrity. The sort, treat, and repackage system has a high technical risk ranking due to the poor final waste form produced by this system; most of the waste (dry solids) is simply repackaged, has no stability, and is probably suitable only for disposal in a deep geological repository.

From the processing technology maturity/complexity standpoint, the incineration/melting system has a moderate risk while the thermal treatment/solidification and the sort, treat, and repackage systems have low technical risk. It is believed that all of the concerns relative to the processing 
technology maturity/complexity are engineering solvable issues and, hence, factors dominating the ranking of the technology risks are the waste form compliance issues.

The risk for complying with institutional objectives for the incineration/melting and thermal treatment/solidification systems are believed to be moderate because they both use thermal processes, which historically have had limited public support at DOE sites (though this has not been a problem at the INEL thus far and there are some indications of public support for vitrified waste forms). These two systems also receive a moderate ranking for compliance with schedule objectives because of the unforeseen delays that are typical for all thermal processes requiring RCRA, Clean Air Act, and other air discharge requirements and permits. The institutional and schedule objectives compliance risk for the sort, treat, and repackage system is believed to be low. The cost objectives compliance risk for all systems are believed to be moderate because cost uncertainties are anticipated until design, based on DT\&E, is well into maturity. The "in-process" environment, safety, and health protection objectives compliance risk for all systems is believed to be low.

\section{Conclusions}

Both the incineration/melting and thermal treatment/solidification systems are technically feasible. The implementation risks are also considered acceptaible. Selection of either system depends on the waste form acceptability. Waste form accep $:$ bility cannot be determined until further DT\&E on melter slag and solidified waste is conducted. Waste form acceptability also depends on the chosen disposal method. Until such information is available, DT\&E to allow concept exploration is recommended for both systicms.

The sort, treat, and repackage system assumes that the final disposal place for alpha-LLW will be a deep geologic repository, exempted from the LDR requirements. Since it is unlikely that a deep geologic repository will become available for this waste, significant DT\&E on the sort, treat, and repackage system is not justified.

\section{Future Activities}

Future front-end engineering activities are needed to support the alpha-LLW decision making process and include:

- Trade-off studies to optimize flow sheet for a thermal train in the incineration/melting system.

- Trade-off studies to optimize process capacity for maximized operating efficiency and resource utilization. Processing of waste from other DOE sources (such as the TRU stored waste) may have to be considered in the sizing of the overall facility.

- Trade-off studies to compare remote alpha-cell versus glove box approach to waste handling.

- Performing DT\&E on the melter, incinerator, offgas, remote waste handling, TRU assay, and decontamination equipment. 
- System design studies to evaluate options for the stored TRU waste, which will require some processing prior to shipment to meet WIPP waste acceptance criteria, and newly generated wastes. The system design study results for the four waste streams (stored TRU, stored alpha-LLW, buried TRU/alpha-LLW, and newly generated) should be used to integrate system options for the Idaho Waste Processing Facility (INPF).

- Performing systems engineering to support components requirements development and concept explorations leading to development of demonstration test plans for the melter, incinerator, offgas, material handling, and decontamination equipment.

- Continuation oî waste characterization efforts.

- Bench-scale test studies on vitrification and solidification formulations and process rohustness based on the range of incoming waste materials identified from waste characterization efforts. 


\section{ACKNOWLEDGMENTS}

The authors would like to acknowledge the efforts of those who contributed to this report, specifically, G. L. Anderson, A. L. Ayers Jr., L. G. Gale, J. E. Langford, M. R. Martin and R. A. Hyde of EG\&G Idaho, Inc.; B. L. Stevens, J. Ansted, and J. T. Foldyna of Environmental Services Division, Morrison Knudsen Corporation; and J. Nelson of EG\&G Idaho and V. Rose of Morrison Knudsen Corporation for the extra effort required in editing this report. 


\section{CONTENTS}

ABSTRACT $\ldots \ldots \ldots \ldots \ldots \ldots \ldots \ldots \ldots \ldots \ldots \ldots \ldots \ldots \ldots \ldots \ldots \ldots \ldots \ldots \ldots \ldots \ldots$

EXECUTIVE SUMMARY $\ldots \ldots \ldots \ldots \ldots \ldots \ldots \ldots \ldots \ldots \ldots \ldots \ldots \ldots$

ACKNOWLEDGMENTS $\ldots \ldots \ldots \ldots \ldots \ldots \ldots \ldots \ldots \ldots \ldots \ldots \ldots \ldots \ldots \ldots$

ACRONYMS $\ldots \ldots \ldots \ldots \ldots \ldots \ldots \ldots \ldots \ldots \ldots \ldots \ldots \ldots \ldots \ldots \ldots \ldots \ldots \ldots$

1. INTRODUCTION AND SUMMARY $\ldots \ldots \ldots \ldots \ldots \ldots \ldots \ldots \ldots \ldots \ldots \ldots$

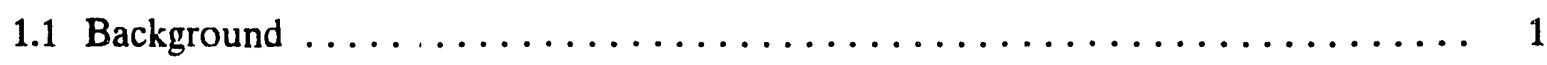

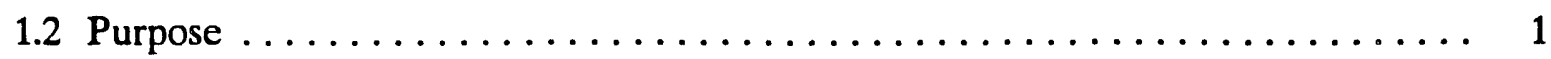

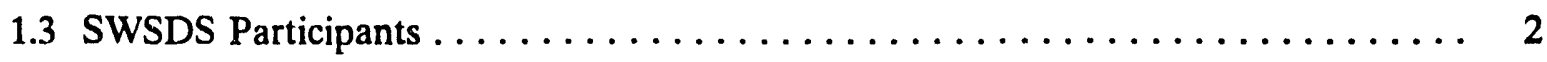

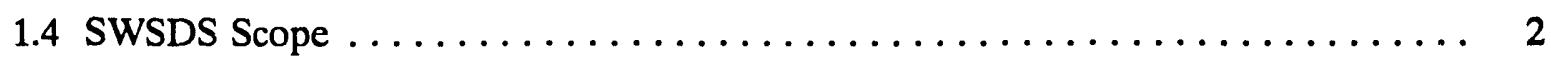

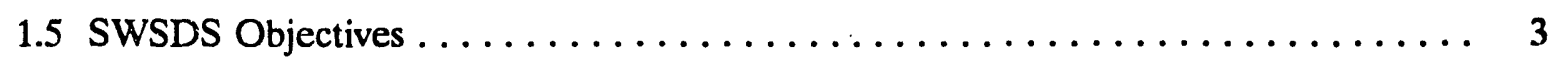

1.6 Systems Engineering $\ldots \ldots \ldots \ldots \ldots \ldots \ldots \ldots \ldots \ldots \ldots \ldots \ldots \ldots \ldots$

1.7 System Boundaries $\ldots \ldots \ldots \ldots \ldots \ldots \ldots \ldots \ldots \ldots \ldots \ldots \ldots \ldots \ldots \ldots$

1.8 Study Summary $\ldots \ldots \ldots \ldots \ldots \ldots \ldots \ldots \ldots \ldots \ldots \ldots \ldots \ldots$

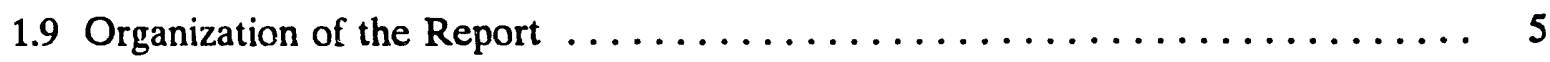

2. MISSION AND OBJECTIVES $\ldots \ldots \ldots \ldots \ldots \ldots \ldots \ldots \ldots \ldots \ldots \ldots \ldots \ldots$

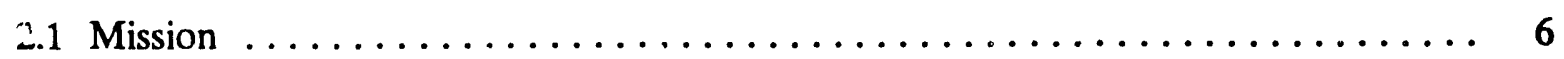

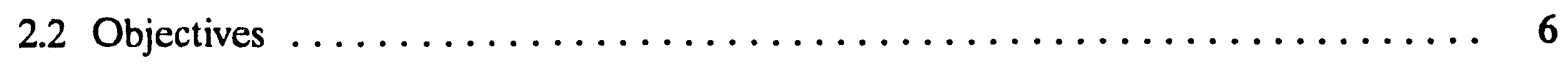

2.2.1 Technical Objectives $\ldots \ldots \ldots \ldots \ldots \ldots \ldots \ldots \ldots \ldots \ldots \ldots \ldots$

2.3 Environmental, Safety, and Health Objectives $\ldots \ldots \ldots \ldots \ldots \ldots \ldots$

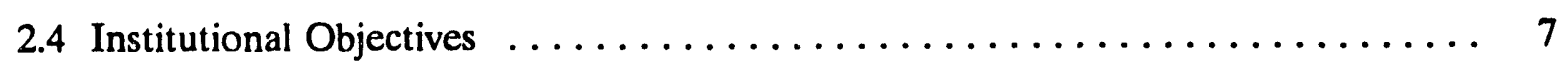

2.5 Schedule Objectives $\ldots \ldots \ldots \ldots \ldots \ldots \ldots \ldots \ldots \ldots \ldots \ldots \ldots \ldots \ldots$

2.6 Cost Objectives $\ldots \ldots \ldots \ldots \ldots \ldots \ldots \ldots \ldots \ldots \ldots \ldots \ldots \ldots \ldots \ldots \ldots$

xix 
3. SYSTEMS ENGINEERING APPROACH $\ldots \ldots \ldots \ldots \ldots \ldots \ldots \ldots \ldots \ldots \ldots$

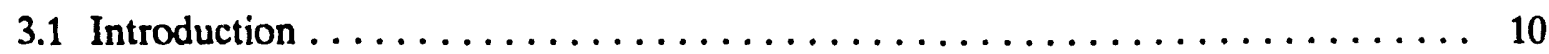

3.2 Systerns Engineering Approach for SWSDS $\ldots \ldots \ldots \ldots \ldots \ldots \ldots \ldots \ldots \ldots$

3.2.1 Requirement Development $\ldots \ldots \ldots \ldots \ldots \ldots \ldots \ldots \ldots \ldots \ldots \ldots \ldots$

3.2.2 System Concept Exploration $\ldots \ldots \ldots \ldots \ldots \ldots \ldots \ldots \ldots \ldots \ldots \ldots \ldots \ldots \ldots \ldots$

3.2.3 System Concept Assessment ..................... 13

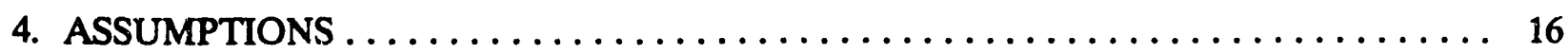

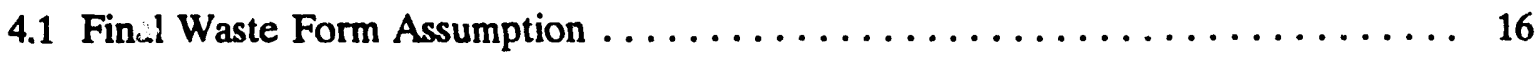

4.2 Waste Property Assumptions $\ldots \ldots \ldots \ldots \ldots \ldots \ldots \ldots \ldots \ldots \ldots \ldots \ldots \ldots \ldots \ldots$

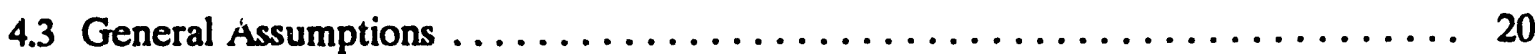

4.4 Criteria and Assumptions for Program Implementation
Risk Assessment $\ldots \ldots \ldots \ldots \ldots \ldots \ldots \ldots \ldots \ldots \ldots \ldots \ldots \ldots \ldots \ldots \ldots \ldots \ldots$

4.4.1 Technical and Performance Risk Considerations ............. 21

4.4.2 Health and Safety Risk Considerations .................. 21

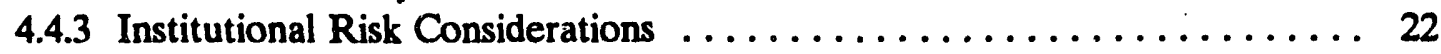

4.4.4 Schedule Risk Considerations ...................... 22

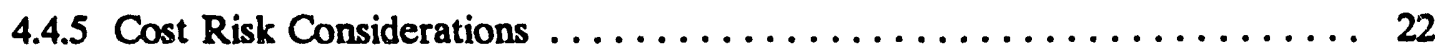

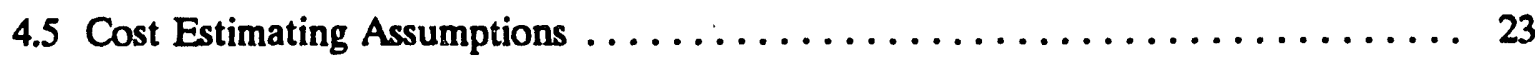

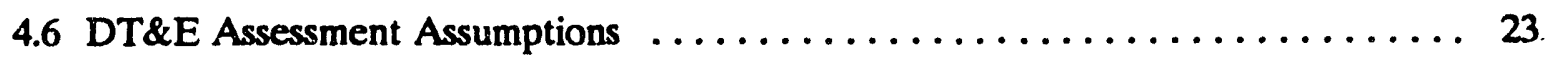

5. INCINERATION/MELTING SYSTEM $\ldots \ldots \ldots \ldots \ldots \ldots \ldots \ldots \ldots \ldots \ldots \ldots \ldots \ldots$

5.1 Functional and Operational Requirements $\ldots \ldots \ldots \ldots \ldots \ldots \ldots \ldots$

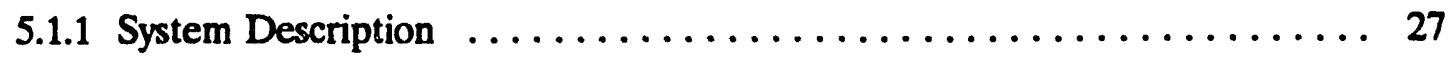

5.1 .2 System Requirements ............................ 31

5.1.3 Unit Operations Functional Requirements ................ 34

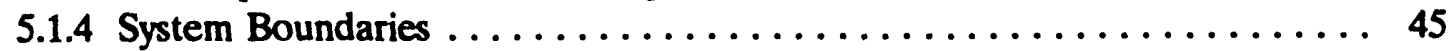

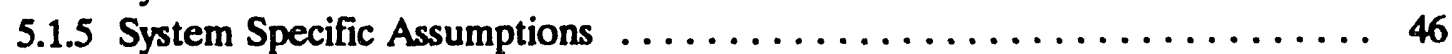

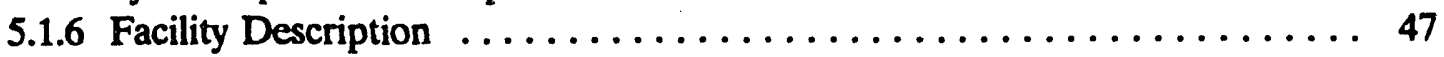

5.1.7 Interface Requirements $\ldots \ldots \ldots \ldots \ldots \ldots \ldots \ldots \ldots \ldots \ldots \ldots$. 47

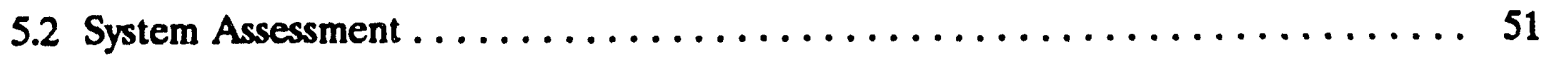

5.2.1 Evaluation of Unit Operation Technologies $\ldots \ldots \ldots \ldots \ldots \ldots \ldots \ldots$. 51

5.2.2 Program Implementation Risks $\ldots \ldots \ldots \ldots \ldots \ldots \ldots \ldots \ldots \ldots \ldots$ 
5.2.3 Unit Operations DT\&E Lead-Time Estimates $\ldots \ldots \ldots \ldots \ldots \ldots \ldots 71$

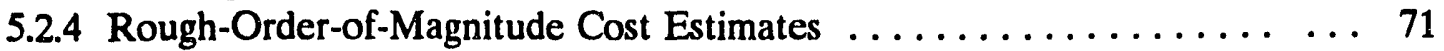

5.2.5 System Evaluation Results . . . . . . . . . . . . . . . 73

5.2.6 Summary of Demonstration, Testing, and Evaluation Needs . . . . . . 77

5.3 Recommendation for the System $\ldots \ldots \ldots \ldots \ldots \ldots \ldots \ldots \ldots \ldots \ldots \ldots$

6. THERMAL TREATMENT/SOLIDIFICATION SYSTEM $\ldots \ldots \ldots \ldots \ldots \ldots \ldots \ldots$

6.1 Functional and Operational Requirements $\ldots \ldots \ldots \ldots \ldots \ldots \ldots \ldots$

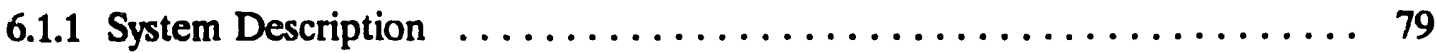

6.1.2 System Requirements ........................ 83

6.1.3 Unit Operations Functional Requirements ............... 83

6.1.4 System Boundaries . . . . . . . . . . . . . . . . 90

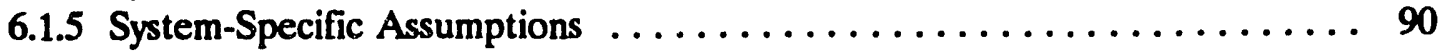

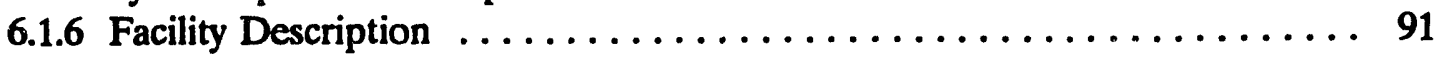

6.1.7 Interface Requirements $\ldots \ldots \ldots \ldots \ldots \ldots \ldots \ldots \ldots \ldots \ldots \ldots$. 95

6.2 System Assessment $\ldots \ldots \ldots \ldots \ldots \ldots \ldots \ldots \ldots \ldots \ldots \ldots \ldots \ldots \ldots \ldots$

6.2.1 Evaluation of Unit Operation Technologies $\ldots \ldots \ldots \ldots \ldots \ldots \ldots$

6.2.2 Program Implementation Risks . . . . . . . . . . . . . . 101

6.2.3 Unit Operations DT\&E Lead-Time Estimates $\ldots \ldots \ldots \ldots \ldots \ldots \ldots \ldots$

6.2.4 Rough-Order-of-Magnitude Cost Estimates ............... 103

6.2.5 System Evaluation Results . . . . . . . . . . . . . . . . . 103

6.2.6 Summary of Demonstration, Testing, and Evaluation Needs . . . . . . . 108

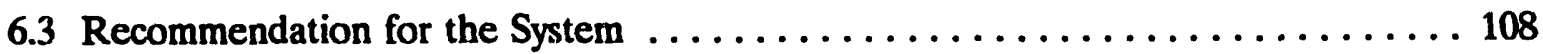

7. SORT, TREAT, AND REPACKAGE SYSTEM $\ldots \ldots \ldots \ldots \ldots \ldots \ldots \ldots \ldots \ldots$

7.1 Functional and Operational Requirements $\ldots \ldots \ldots \ldots \ldots \ldots \ldots \ldots \ldots$

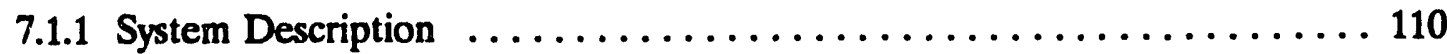

7.1 .2 System Requirements . . . . . . . . . . . . . . . . . . 113

7.1.3 Unit Operations Functional Requirements ............... 113

7.1.4 System Boundaries . . . . . . . . . . . . . . . . . . . 119

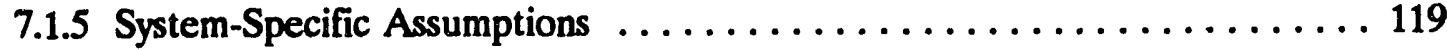

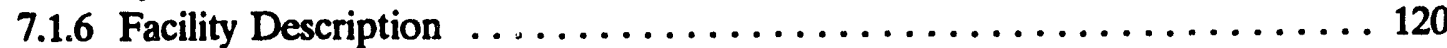

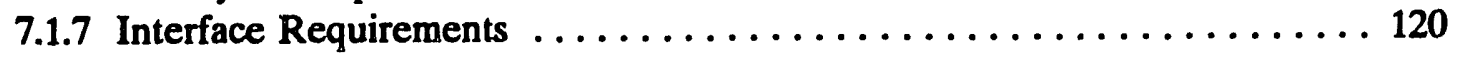

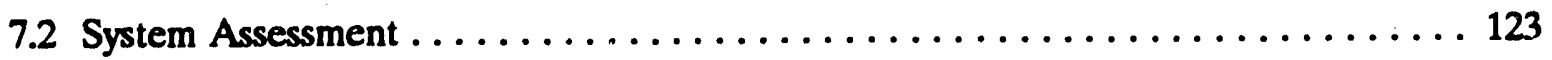

7.2.1 Evaluation of Unit Operations Technologies $\ldots \ldots \ldots \ldots \ldots \ldots \ldots \ldots$

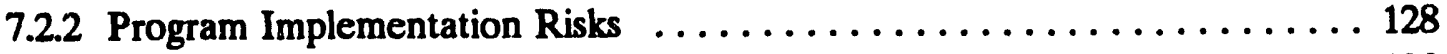

7.2.3 Unit Operations DT\&E Lead-Time Estimates . . . . . . . . . . . 130 
7.2.4 Rough-Order-of-Magnitude Cost Estimates . . . . . . . . . 130

7.2 .5 System Evaluation Results . . . . . . . . . . . . . . . . 130

7.2.6 Summary of Demonstration, Testing, and Evaluation Needs . . . . . . 134

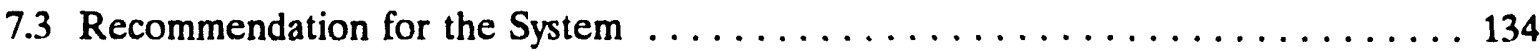

8. METAL SIZING/DECONTAMINATION SUBSYSTEM $\ldots \ldots \ldots \ldots \ldots \ldots \ldots \ldots$

8.1 Functional and Operational Requirements $\ldots \ldots \ldots \ldots \ldots \ldots \ldots \ldots \ldots$

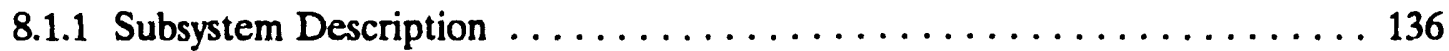

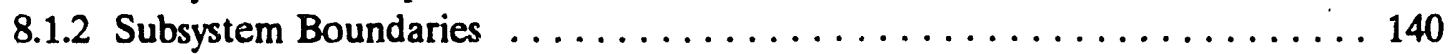

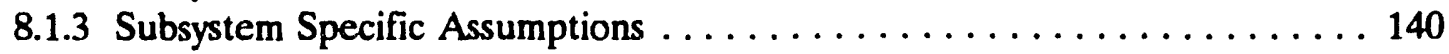

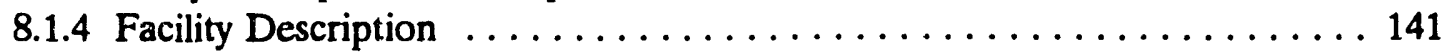

8.1.5 Subsystem Design Requirements $\ldots \ldots \ldots \ldots \ldots \ldots \ldots \ldots \ldots \ldots \ldots \ldots \ldots$

8.1.6 Interface Requirements . . . . . . . . . . . . . . . . 142

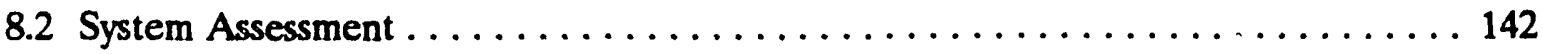

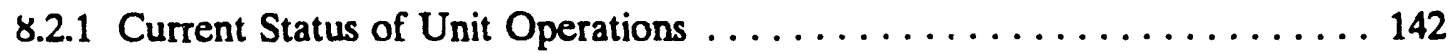

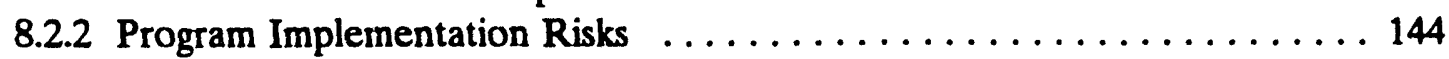

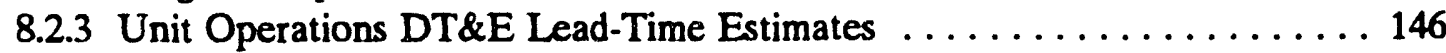

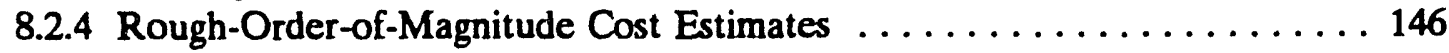

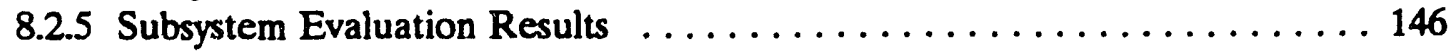

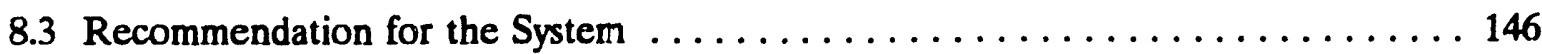

9. SUMMARY AND CONCLUSIONS $\ldots \ldots \ldots \ldots \ldots \ldots \ldots \ldots \ldots \ldots \ldots \ldots \ldots$

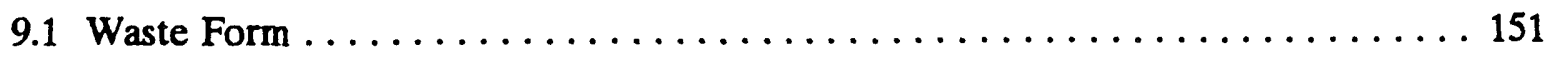

9.2 System Concepts Summary $\ldots \ldots \ldots \ldots \ldots \ldots \ldots \ldots \ldots \ldots \ldots \ldots \ldots \ldots \ldots$

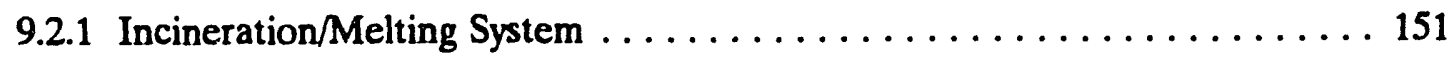

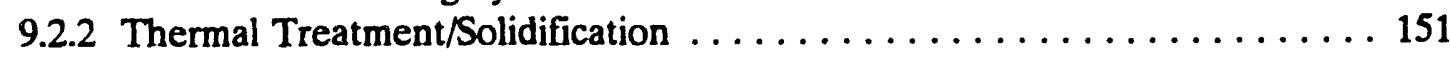

9.2.3 Sort, Treat, and Repackage System . . . . . . . . . . . . 152

9.3 System Implementation Risk Assessment Summary $\ldots \ldots \ldots \ldots \ldots \ldots \ldots$

9.4 Summary of ROM Life-Cycle Cost Estimates . . . . . . . . . . . . 154

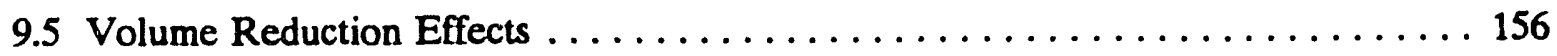

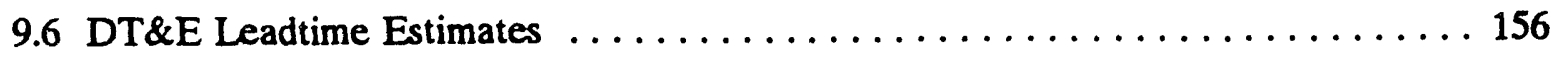

9.7 Performance Measurable Summary $\ldots \ldots \ldots \ldots \ldots \ldots \ldots \ldots \ldots \ldots \ldots$ 


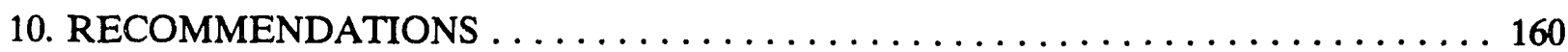

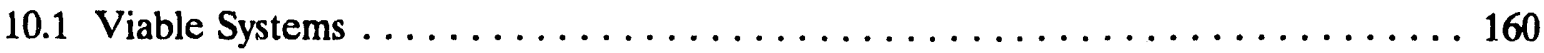

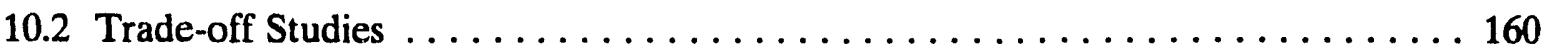

10.2.1 Incineration/Melting Flow Sheet $\ldots \ldots \ldots \ldots \ldots \ldots \ldots \ldots \ldots \ldots \ldots$

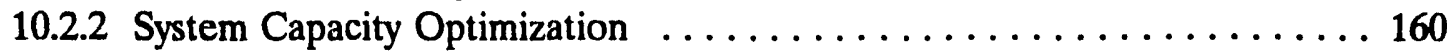

10.2.3 Remotely Operated Alpha-Cell Versus Glovebox ............ 160

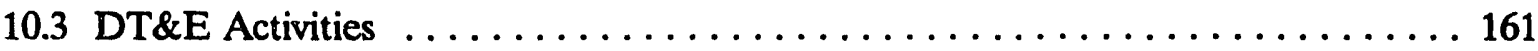

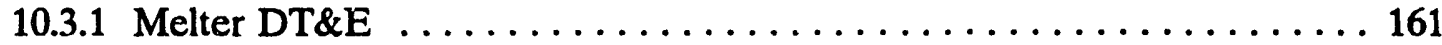

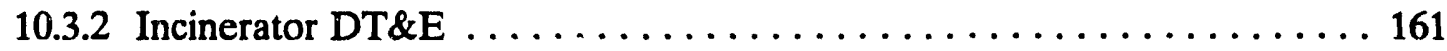

10.3.3 Waste Handling Devices DT\&E ... . . . . . . . . . . 161

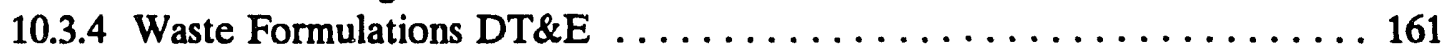

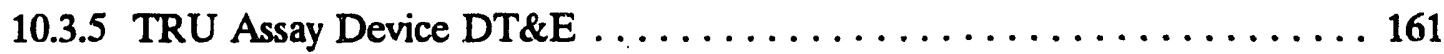

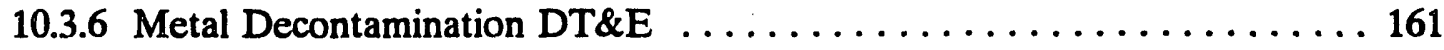

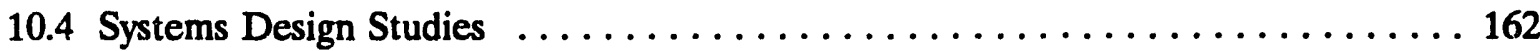

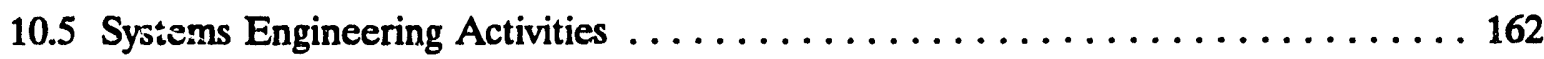

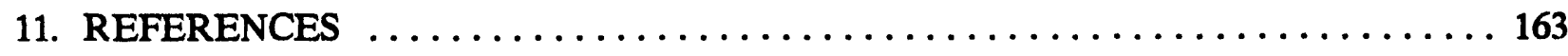

APPENDIX A-Waste to be Treated in the IWPF Engineering Design File

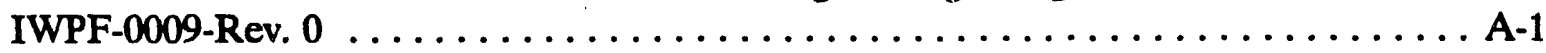

APPENDIX B-Cost Estimating Model $\ldots \ldots \ldots \ldots \ldots \ldots \ldots \ldots \ldots \ldots \ldots \ldots \ldots$

\section{FIGURES}

1. Process functional diagram for incineration/melting system. $\ldots \ldots \ldots \ldots \ldots \ldots \ldots \ldots$ vi

2. Process functional diagram for thermal treatment/solidification system. $\ldots \ldots \ldots \ldots$ viii

3. Process functional diagram for sort, treat, and repackage system. $\ldots \ldots \ldots \ldots \ldots \ldots$ ix

4. ROM cost estimates for the three stored alpha-LLW waste processing system options. ... $x$

5. Building and equipment cost comparison for the three systems. $\ldots \ldots \ldots \ldots \ldots \ldots \ldots$ xii

6. Preliminary schedule for IWPF. $\ldots \ldots \ldots \ldots \ldots \ldots \ldots \ldots \ldots \ldots \ldots \ldots \ldots \ldots$

7. Application of the systems engineering process to the SDS. $\ldots \ldots \ldots \ldots \ldots \ldots \ldots \ldots$

8. Categories of work effort and research and development and acquisition phases. . . . . 24 
9. Assumed phases of demonstration, testing, and evaluation during advanced

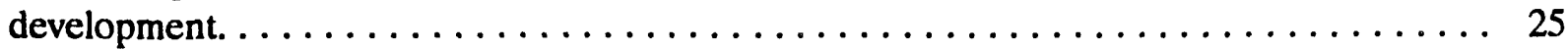

10. Process functional diagram for incineration/melting system $\ldots \ldots \ldots \ldots \ldots \ldots \ldots \ldots$

11. Unit operations subfunctional flow diagram for incineration/melting system $\ldots \ldots \ldots 35$

12. General arrangements for the incineration/melting system $\ldots \ldots \ldots \ldots \ldots \ldots \ldots \ldots$

13. Process functional diagram for the thermal treatment/solidification system $\ldots \ldots \ldots . \ldots 81$

14. Unit operations subfunctional flow diagram for the thermal

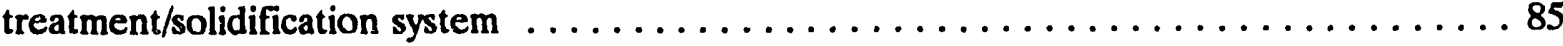

15. General arrangments for the thermal treatment/solidification system $\ldots \ldots \ldots \ldots \ldots$

16. Process functional diagram for the sort, treat, and repackage system $\ldots \ldots \ldots \ldots \ldots \ldots$

17. Unit operations subfunctional flow diagram for the sort, treat, and repackage system $\ldots 115$

18. General arrangments for the sort, treat, and repackage system $\ldots \ldots \ldots \ldots \ldots \ldots \ldots 121$

19. Functional flow diagram for the metal sizing/decontamination subsystems $\ldots \ldots \ldots 137$

\section{TABLES}

1. Definition of system performance measurables $\ldots \ldots \ldots \ldots \ldots \ldots \ldots \ldots \ldots \ldots$

2. Stored alpha-LLW type description $\ldots \ldots \ldots \ldots \ldots \ldots \ldots \ldots \ldots \ldots \ldots \ldots \ldots \ldots$

3. Composition of the combustible portion of the stored alpha-LLW . . . . . . . . 19

4. DT\&E for the incineration/melting system with LLW presort $\ldots \ldots \ldots \ldots \ldots \ldots \ldots \ldots$

5. Summary of incineration/melting systems implementation risks and major

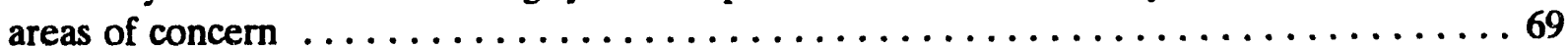

6. DT\&E lead-time estimate for the incineration/melting system $\ldots \ldots \ldots \ldots \ldots \ldots \ldots \ldots 72$

7. Rough order-of-magnitude cost estimates for the incineration/melting system $\ldots \ldots \ldots 73$

8. Performance measurable scores for the incineration/melting system $\ldots \ldots \ldots \ldots \ldots \ldots$

9. DT\&E needs for the thermal treatment/solidification system $\ldots \ldots \ldots \ldots \ldots \ldots \ldots$ 
10. Summary of thermal treatment/solidification system implementation risks and

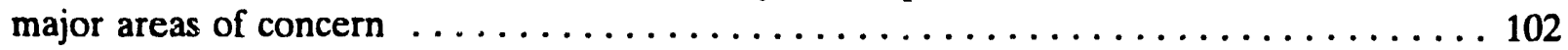

11. DT\&E lead-time for the thermal treatment/solidification system $\ldots \ldots \ldots \ldots \ldots$

12. Rough order-of-magnitude cost estmates for the thermal

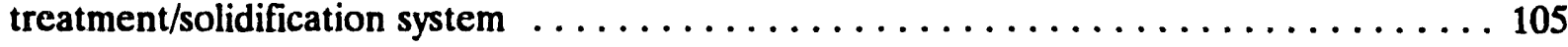

13. Performance measurable scores for the thermal treatment/solidification system $\ldots \ldots \ldots 107$

14. DT\&E needs for the sort, treat, and repackage system $\ldots \ldots \ldots \ldots \ldots \ldots \ldots \ldots$

15. Summary of sort, treat, and repackage systems implementation risks and

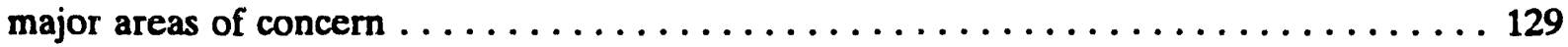

16. DT\&E lead-time estimate for the sort, treat, and repackage system $\ldots \ldots \ldots \ldots \ldots 131$

17. Rough order-of-magnitude cost estimate for the sort, treat, and repackage system $\ldots \ldots 132$

18. Rating measurables for the sort, treat, and repackage system $\ldots \ldots \ldots \ldots \ldots \ldots$

19. DT\&E assessment summary for the metal sizing/decontamination subsystem $\ldots \ldots \ldots 147$

20. DT\&E needs for the metal sizing/decontamination subsystem $\ldots \ldots \ldots \ldots \ldots \ldots \ldots$

21. Program implementation risk summary $\ldots \ldots \ldots \ldots \ldots \ldots \ldots \ldots \ldots \ldots \ldots \ldots$

22. Stored alpha-LLW processing systems ROM life-cycle cost estimates summary $\ldots \ldots \ldots 155$

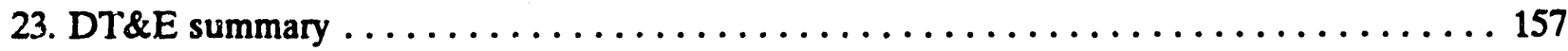




\section{ACRONYMS}

AEA

AEC

ALARA

ARAR

BWSDS

BDAT

$\mathrm{CCW}$

CCWE

CERCLA

DOE

DOE-ID

DOT

DT\&E

EOF

EPA

F\&OR

FOM

HEPA

HOC

HVAC

I/O

INEL
Atomic Energy Act

U.S. Atomic Energy Commission

as low as reasonably achievable

applicable or relevant and appropriate requirement

Buried Waste System Design Study

best demonstrated available technology

Constituent Concentration of the Waste

Constituent Concentration of the Waste Extract

Comprehensive Environmental Response, Compensation, and Liability Act

U.S. Department of Energy

Department of Energy Idaho Field Office

U.S. Department of Transportation

demonstration, testing, and evaluation

energy optimizing furnace

U.S. Environmental Protection Agency

functional and operational requirement

Figure of Merit

high-efficiency particulate air (filter)

halogenated organic compound

heating, ventilating, and air conditioning

input/output

Idaho National Engineering Laboratory

xxvii 


\begin{tabular}{ll} 
ISV & in situ vitrification \\
IWPF & Idaho Waste Processing Facility \\
LANL & Los Alamos National Laboratory \\
LDR & land disposal restriction \\
LICP & Line Item Construction Project \\
LLNL & Lawrence Livermore National Laboratory \\
LL-TRU & Low-level transuranic \\
LLW & low-level waste \\
NDE & Nondestructive examination \\
NEPA & National Environmental Policy Act of 1969 \\
NPL & National Priorities List \\
NRC & U.S. Nuclear Regulatory Commission \\
NWCF & New Waste Calcining Facility \\
ORNL & Oak Ridge National Laboratory \\
PAN & passive neutron counting \\
PCB & polychlorinated biphenyl \\
PCR & plasma centrifugal reactor \\
PEC & Plasma Energy Corporation \\
PFD & process functional diagram \\
PLC & programmable logic controller \\
PLPF & Plutonium Processing Facility \\
PPF & plasma pyrolysis furnace \\
PSAPP & Priii \\
\hline
\end{tabular}




\begin{tabular}{|c|c|}
\hline PVC & polyvinyl chloride \\
\hline R\&D & research and development \\
\hline RAM & reliability, availability, and maintainability \\
\hline RCRA & Resource Conservation and Recovery Act \\
\hline RDDT\&E & Research, development, demonstration, testing, and evaluation \\
\hline ROD & Record of Decision \\
\hline ROM & rough-order-of-magnitude \\
\hline ROV & remotely operated vehicles \\
\hline RTR & real-time radiography \\
\hline RWMC & Radioactive Waste Management Complex \\
\hline SAIC & Science Applications International Corporation \\
\hline SDS & System Design Study \\
\hline SE & systems engineering \\
\hline SEG & Scientific Ecology Group \\
\hline SGS & gamma spectroscopy \\
\hline SWEPP & Stored Waste Examination Pilot Plant \\
\hline SWSDS & Stored Waste System Design Study \\
\hline TEC & total estimated cost \\
\hline $\mathrm{T} / \mathrm{O}$ & tradeoff \\
\hline TRAMPAC & transportation package \\
\hline TRU & transuranic \\
\hline TSA & Transuranic Storage Area \\
\hline TVR-III & Transportable Volume Reduction and Solidification System \\
\hline $\mathbf{U} / \mathbf{R}$ & utilization of resources \\
\hline
\end{tabular}

xxix 
UCRL University of California Research Laboratories

VOC volatile organic compound

WAC waste acceptance criteria

WERF Waste Experimental Reduction Facility

WIPP Waste Isolation Pilot Plant 


\section{Alpha Low-Level Stored Waste Systems Design Study}

\section{INTRODUCTION AND SUMMARY}

\subsection{Background}

In the early 1970 s the Idaho National Engineering Laboratory (INEL) began retrievable storage of low-level alpha emitting waste, ${ }^{a}$ such as plutonium $(\mathrm{Pu})$-contaminated waste produced in national defense programs. Most of the waste stored at the INEL came from the Rocky Flats Plant near Golden, Colorado. This waste was placed on aboveground asphalt pads, which when full, were covered with protective fabric covers and a soil cap. In the early 1980s, the INEL began placing waste containers in warehouses. Both the asphalt pad and warehouse storage units are in the Transuranic Storage Area (TSA) located within the Radioactive Waste Management Complex (RWMC).

The alpha-contaminated wastes are stored in drums, wooden boxes, metal boxes, and metal bins. Approximately 99.7 percent of the stored containers are contact handled (i.e., having less than $200 \mathrm{mR} / \mathrm{hr}$ radiation dose on the surface) and contain material such as discarded debris, rags, paper, clothing, metals, glassware, and sludges. It is also believed that most of the waste is contaminated with hazardous components controlled under the Resource Conservation and Recovery Act (RCRA).

The stored waste is classified in two categories according to its transuranic (TRU) element concentration. The first category, referred to as TRU, has a transuranic element concentration of greater than 100 nanocuries per gram (nCi/gm). Currently, the U.S. Department of Energy (DOE) plans to dispose of this category of waste at the Waste Isolation Pilot Plant (WIPP). The second category, referred to as alpha low-level waste (alpha-LLW), has a transuranic elements concentration of between 10 and $100 \mathrm{nCi} / \mathrm{gm}$. A disposal method for this waste has not been identified.

Alpha-LLW falls under the low-level radioactive waste (LLW) classification as defined by the DOE Order 5820.2A and the Nuclear Regulatory Commission (NRC) regulation for LLW disposal, Title 10 of Code of Federal Regulation, Part 61. Since alpha-LLW falls under the LLW category, it is most suitable for burial in shallow-land disposal sites if the final waste form and disposal facility can be shown to meet the performance assessment objective of DOE Order 5820.2A.

\subsection{Purpose}

The selection, design, construction, and operation of processing systems for the stored alphaLLW is managed under the Waste Management Facility Projects Unit of EG\&G Idaho, Inc. The Idaho Waste Processing Facility (IWPF) is a proposed line item (FY 1997) which will be used to process the alpha-LLW stored at the INEL. Accordingly, an integrated set of technologies will be needed for safe treatment and disposal of the waste. A key question for the IWPF project is which feasible and cost-effective technologies could be used to satisfy the INEL waste management

a. Referred to as either alpha or transuranic (TRU) wastes. 
objectives and strategies. To provide an answer to this question, this Stored Waste System Design Study (SWSDS) similar to the Buried Waste System Design Study (BWSDS), ${ }^{1, b}$ was commissioned by EG\&G Idaho in January 1992. As with the BWSDS, the SWSDS uses systems engineering (SE) principles advocated by DOE Order 4700.1 to examine three of the system concepts evaluated in the BWSDS. The intent of the SWSDS is to identify a set of cost-effective, practical, and acceptable treatment strategies; develop system concepts encompassing these strategies; estimate a rough-orderof-magnitude (ROM) cost for the concepts; and identify those component technologies within these concepts that will require demonstration, testing, and evaluation (DT\&E).

\subsection{SWSDS Participants}

The SWSDS was performed by a project team consisting of personnel from EG\&G Idaho and the Environmental Services Division of Morrison Knudsen Corporation. EG\&G Idaho provided the overall project management and technical guidance for the study and coordinated preparation of the final report. Morrison Knudsen Corporation developed the system preconceptual design packages and performed the related assessments.

\subsection{SWSDS Scope}

Practicable and cost-effective technologies that can satisfy the objectives of the IWPF Project for alpha-LLW processing are studied to address issues such as:

- $\quad$ Life-cycle cost estimates for the process system methods and final waste form

- Process systems technology availability and practicability

- Technologies that promise significant cost reduction and high performance but require DT\&E before they can be used in an integrated system.

Since no single technology can accommodate the overall processing requirements, the use of several technologies integrated as a system are addressed. While examining the technology options, the SWSDS considers the above issues and focuses on the technology requirements of the systems engineering process. The intent is to identify three different cost-effective, practicable, and acceptable treatment strategies; develop system concepts encompassing these strategies; and identify technologies within these concepts which will require DT\&E.

In addition to their role in developing component technology requirements, the SWSDS results can be used to establish detailed (derived) system requirements for future studies. Such as:

b. In 1991 the Waste Technology Development Department of EG\&G Idaho, Inc., conducted a BWSDS to perform a preliminary evaluation of the options to remediate the Pu-contaminated waste buried at the INEL's Subsurface Disposal Area (SDA) located at the RWMC. The BWSDS analyzed twelve different system concepts for in situ and ex situ remediation of Pu-contaminated waste, taking into account the overall system point of view. The SWSDS is modeled after the BWSDS, and the three stored LL-TRU waste treatment system concepts are developed in parallel with similar concepts examined in the BWSDS. 
- Input/Output (I/O) Requirements: Currently the top-level system input is the stored alpha-LLW at the TSA; the top-level output is the processed waste in a form that is suitable for permanent disposal. However, a specific method of disposal, which is a key requirement effecting the system, has not been selected at this time, and as a result, the system output could encompass a broad range of choices. Three specific choices for the system output waste form have been considered: a high-integrity, leach-resistant (vitreous) product; a product that meets the U.S. Environmental Protection Agency (EPA) Land Disposal Restrictions (LDR); and a product that meets WIPP waste acceptance criteria (WAC). Before disposal, all products when combined with the disposal facility must meet the performance assessment requirement of DOE Order 5820.2A for low-level waste.

- Utilization of Resource (U/R) Requirements: The current top-level requirements are specified in terms of the most cost-effective approach and an approach having the least environmental, social, and economic impact. The establishment of more specific cost objectives will be needed to facilitate DOE's formal budget approval process. The SWSDS gives a rough-order-of-magnitude $(\mathrm{ROM})^{c}$ cost estimate for each of the concepts. These costs can be used as the starting point to establish a more specific program cost objective.

The scope of the SWSDS does not include retrieval of the st:red waste, study of disposal options, selection of an optimum waste form, or s slection of an optis: atment strategy. While the U/R limitations on the allowable environmental, social, and econu. : impacts will be decided through the National Environmental Policy Act (NEPA) process, the SWSDS results provide preliminary data so that interim allowable environmental, social, and economic impacts for the system may be established.

\subsection{SWSDS Objectives}

The SWSDS has two primaty objectives. The first objective is to compare relative life-cycle costs of processing facilities representing different levels of technological sophistication. The second objective is to provide a basis for deciding which waste processing component technologies are feasible and should be further developed to facilitate the selection of a waste processing option for IWPF and identify the requirements, from a system standpoint, for DT\&E of these supporting technologies. Accordingly, the following questions are addressed by this study:

- Is there a significant difference in cost among the various systems for the different output waste forms?

- Are there process energy requirements that make systems or final waste forms nonviable?

- Which treatment technologies need further development and in what areas?

c. The goal of rough-order-of-magnitude cost estimates in this study is to be plus or minus 50 percent of the actual cost. 
- What are the technical, safety, cost, and schedule risks associated with the viable systems?

- For a given final waste form, how much time whi be required for demonstration or pilotscale testing prior to the start of final design of the processing systems?

- What are the preliminary requirements for the viable system?

- Is extensive sorting before the process (to make the input controlled and more homogeneous) more desirable than bulk heterogeneous mass processing?

\subsection{Systems Engineering}

The systems engineering process is a sequence of activities and decisions that transforms an identified mission objective into a description of system performance parameters and preferred system configuration. The process is applied to ensure that project activities are carried out in a technically acceptable and cost-effective manner so that the result meets the defined need. Accordingly, the system configuration is derived through an iterative process which examines alternate approaches by synthesis, analysis, design, and test, as applicable. Systems engineering integrates relevant technical parameters and ensures that all physical and functional interfaces are fulfilled. Systems engineering also ensures that all applicable special engineering requirements, such as safety, reliability, availability, operability, maintainability, and human factors have been appropriately factored into a cosi-effective system configuration.

Although systems engineering covers all phases of a project life cycle, this SWSDS focuses only on the two early life-cycle phases of the system, i.e., requirements development and concept exploration (during the requirements development phase, requirements which address all problems to be resolved by the system are derived from the project top-level requirements, and during the concept exploration phase a set of system design concepts is identified, a basis for their evaluation is provided, and a feasible design concept is recommended).

\subsection{System Boundaries}

The stored-waste processing system boundaries used in the SWSDS encompass the input waste, which is the alpha-LLW stored at the TSA and delivered at the truck bay entrance door of the waste treatment facility, and the output, which is the packaged waste at the shipping door. Offsite transportation and disposal of waste is not included in the system boundary. However, a cost estimate has been included for these activities based on the results of prior work.

\subsection{Study Summary}

Characteristics of the alpha-LLW stored at the TSA are based on shipment data (see Appendix A). These data, in conjunction with the IWPF Mission Requirement document (currently in draft stage), are used to develop top-level requirements. Three of the viable system concepts considered in the BWSDS are modified to meet the alpha-LLW processing needs. 
The three systems considered for the treatment of alpha-LLW treatment are categorized according to their output: (a) Waste Form $2^{d}-$ a leach-resistant, high-integrity (i.e., glass or rock) product, (b) Waste Form 3-a product that meets land disposal restriction (LDR) requirements and limits the hydrogen generation potentials from metals, and (c) Waste Form 4-a product that meets the current WIPP requirements for TRU wastes. ${ }^{e}$

A system concept was considered for each of the three waste forms:

- Waste Form 2 - Incineration/melting system

- Waste Form 3 - Thermal treatment/solidification system

- Waste Form 4 - Sort, treat, and repackage.

In addition, a unit operation (e.g., a system component that accomplishes a given function) that is common in all of the above systems was studied as a separate subsystem. This common subsystem is metal sizing/decontamination.

\subsection{Organization of the Report}

The SWSDS report is organized into 10 sections consisting of an introduction in section 1, missions and objectives in Section 2, systems engineering approach in Section 3, assumptions in Section 4, three system concepts and a common subsystem in Sections 5 through 8, significant findings of the SDS in Section 9, and recommendations in Section 10. Sections 5 through 8 give a description of each overall system concept and its functional and operational requirements (F\&OR), boundaries, process functional diagram, facility scoping layout, and design and interface requirements. Each system description is followed by a system assessment subsection consisting of the current status of unit operations, system implementation risks, unit operations lead-time estimates, DT\&E requirements, and a ROM cost estimate.

d. Waste form designations used in this report are consistent with the numbering system used in the BWSDS report. Waste Form 1, a product of in situ treatment techniques, is not applicable to the SWSDS.

e. This waste form would be suitable for disposal in WIPP assuming the no migration petition is granted, and the WIPP acceptance criteria based on TRU content were lowered to $10 \mathrm{nCi} / \mathrm{g}$. Presently, this waste is precluded from disposal at WIPP because of TRU content below $100 \mathrm{nCi} / \mathrm{g}$. 


\section{MISSION AND OBJECTIVES}

Preliminary mission and objective statements for the stored alpha-LLW are derived from the Idaho Waste Processing Facility Mission document, which is in the draft stage. The mission and objectives, presented below, will be finalized as the project approaches its funding approval phase.

\subsection{Mission}

The U.S. Department of Energy Idaho Field Office (DOE-ID) is responsible for conducting the INEL waste management activities in a manner that protects the environment and the health and safety of both the workers and the general public. The INEL waste is comprised of stored alphaLLW and mixed alpha-LLW contaminated with up to $100 \mathrm{nCi} / \mathrm{gm}$ of TRU elements; contact and remote-handled TRU waste; newly-generated TRU waste; and waste buried at the RWMC which includes TRU waste, alpha-LLW, and mixed wastes. In order to limit the initial design efforts and reduce risk associated with processing INEL wastes, the IWPF ${ }^{f}$ will be designed to process waste having well-defined waste form requirements and relatively few unique processing problems. Since the stored alpha-LLW is well characterized and relatively easy to process, the mission of the IWPF is to process this waste stream.

\subsection{Objectives}

\subsubsection{Technical Objectives}

The following technical objectives for the system concepts considered in this SWSDS are derived from the preliminary IWPF mission document.

- Waste Form Standards: The chemical and physical properties of the output product (the waste form) for the alpha-LLW stored at the RWMC shall be based on process safety, transportation, and disposal requirements. The alpha-LLW is to be disposed of in a permitted engineered facility regulated by DOE and EPA. The final form of the waste must conform to the applicable DOE and EPA regulations, including the RCRA LDR (40 CFR 268). These requirements will be used to develop design criteria for the LL-TRU processing system.

- Additional Waste Form Requirements: Performance assessment techniques in conjunction with the statutory and regulatory requirements and guidelines will be used to establish waste form standards as a means of ensuring environmental, safety, and health compliance.

- Disposal Criteria: The combination of the final waste form and the disposal facility must meet the performance assessment requirements of DOE Order 5820.2A. No disposal site

f. Processing of TRU waste will be limited to those TRU wastes that are found to not meet the WIPP waste acceptance criteria or TRAMPAC shipping requirements. Processing of the retrieved buried waste is dependent on the outcome of the CERCLA remedial investigation/feasibility study and Record of Decision. 
currently exists for treated alpha-LLW. A permitted alpha-LLW facility for either storage or disposal must be available when the system starts operation. Development of the disposal facility is currently in the planning stage.

- Transportation Requirement: The waste form must meet U.S. Department of Transportation (DOT), NRC, and EPA standards for transportation of radioactive and hazardous wastes. This includes the TRAMPAC specifications for transportation of TRU wastes.

- Operational Requirements: Alpha-LLW processing operations shall be performed in a manner that is safe to the worker, the public, and the environment. The facility operation also must be in compliance with all applicable federal, state, and local statutes, regulations, and permits, and with applicable DOE orders.

\subsection{Environmental, Safety, and Health Objectives}

The overall environmental, safety, and health objectives of the alpha-LLW processing system are to ensure that all waste treatment, storage, and transportation activities will be performed in a manner that will protect the environment and the health and safety of the workers and the general public.

- Safety and Health: Key health and safety objectives during the concept definition are to identify hazards of the waste processing and associated operations, and to provide measures to eliminate, control, or mitigate identified hazards.

- Environmental Standards: System operation must be in compliance with standards from all applicable environmental statutes such as the RCRA, the Toxic Substances Control Act, the Safe Drinking Water Act, the Clean Air Act, and the Clean Water Act.

\subsection{Institutional Objectives}

Institutional objectives ensure public involvement and adherence to NEPA environmental regulations.

- Public Involvement: The public involvement objective is to implement a public participation plan that encourages public input into the program decision-making process in accordance with NEPA and DOE requirements.

- NEPA Compliance: NEPA compliance objectives are to ensure that environmental concerns are adequately addressed in the selection and implementation of an alternative and that provisions of NEPA, as implemented by the Council of Environmental Quality (CEQ) regulations and DOE requirements, are satisfied. 


\subsection{Schedule Objectives}

The schedule objective is to reach approval for Title I by Fiscal Year 1997. This is based on the assumption that the facility will start operations by FY 2005. The schedule for the alpha-LLW processing system is assumed to be the same as the IWPF project schedule, which is shown in Figure 6.

\subsection{Cost Objectives}

A baseline total estimated cost (TEC) for the stored alpha-LLW processing has not been established. TEC will be developed after cost-effective solutions have been defined. At this stage, the cost objective is "cost-effectiveness." 


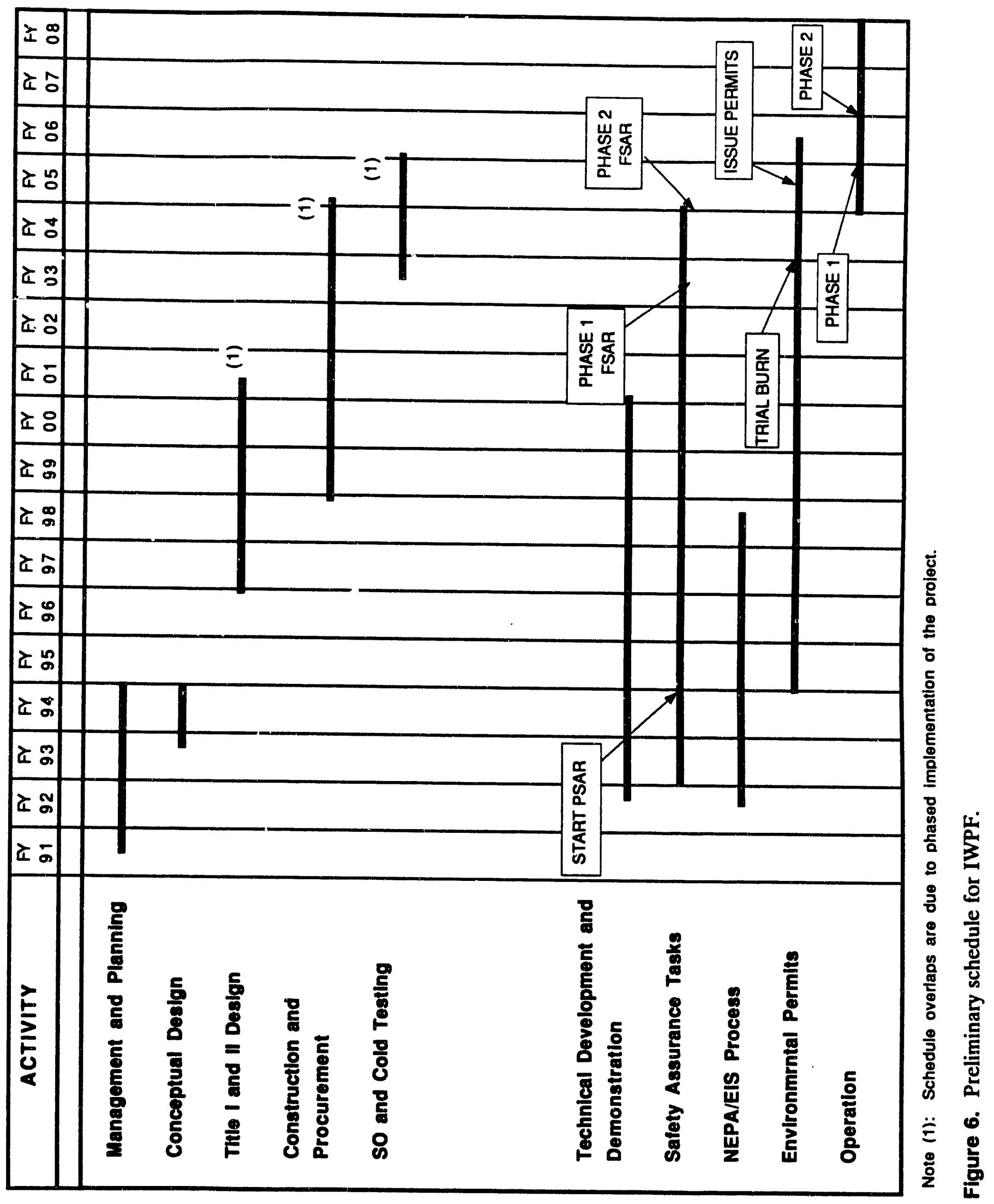




\section{SYSTEMS ENGINEERING APPROACH}

\subsection{Introduction}

The application of systems engineering management tools to define and implement the most cost-effective solution to meeting the program mission and objectives is encouraged by DOE Order 4700.1. Systems engineering covers the entire life cycle of a project, which includes the following six stages:

1. Advanced development (including requirement development and concept exploration)

2. Engineering development

3. System construction

4. System test

5. System operation

6. Retirement (decontamination and decommissioning).

Systems engineering places significant emphasis on advanced development, which includes the tasks of requirements development and concept exploration. This phase is crucial in the project life cycle because the decisions made during this phase, which represents the first $10 \%$ of the life cycle, commit approximately $90 \%$ of the project resources. Furthermore, the cost of correcting system design errors increases expor entially as the system life cycle proceeds.

Advanced development involves a requirements development task. This includes a comprehensive statement of the problem and places the system requirements into the following categories:

- I/O Requirements: What is the system supposed to do in terms of $I / O$ and system function?

- Performance Requirements: How well must the system perform the function specified in the I/O and functional requirements? (how fast, how accurately, and how reliably?)

- Technology Requirements: What technology is available to build the system? Are components available? What technologies should be excluded?

- U/R Requirements: What are the system life cycle cost limitations (how much money can be spent)? What are the allowable environmental, social, and economic impacts?

- Tradeoff (T/O) Requirements: What are the tradeoffs among performance criteria and cost criteria and between performance and cost? 
- System Test Requirements: How well can the system test be specified for observance, conformance, compliance, and acceptance? What are the requirements and procedures of the real system in terms of observed data and conformance, compliance, and acceptance and as compared to the model?

The second task in the advanced development phase is concept exploration. This task identifies a set of system design concepts, evaluates each concept, and recommends those which are feasible. A value for each $I / O, U / R$, and T/O Figure of Merit (FOM) is recorded for each design concept. Concept exploration for the system also includes functional analysis and allocation. This involves dividing the requirements associated with each top-level system function and allocating them to several subfunctions. Through this process of concept exploration, a recommendation is made for the most viable system design concepts.

\subsection{Systems Engineering Approach for SWSDS}

To focus on the technology requirement aspect of the LL-TRU stored waste treatment project, the project mission and objectives (top-level requirements) are identified first (see Figure 7; then available and emerging technologies are identified and used to develop a set of treatment strategies and associated system concepts. Concept development uses system engineering principles of functional analysis and allocation. System concepts are assessed in terms of their current status and DT\&E needs, lead time, and ROM cost estimate. The system concept development and assessment results are used to develop preliminary system requirements for the LL-TRU stored waste treatment project.

\subsubsection{Requirement Development}

Mission and objectives for the alpha-LLW treatment project are extracted from the IWPF Mission Requirement Document and are presented in Section 2. These top-level requirements are the only firm requirements at this time. Several assumptions are made to develop the system concepts and to conduct an assessment, and these assumptions are presented in Section 4 of this report.

\subsubsection{System Concept Exploration}

Based on the top-level requirements (defined need, objectives, and constraints), three interrelated activities are used to develop processing concepts: functional identification, functional performance requirements analysis, and functional allocation.

Functions that carry out activities to meet the defined need are identified in an F\&OR section. Function identification was accomplished by using process functional diagrams (PFDs) that depict the relationships among functions. Each function is displayed as a block in the PFDs. The blocks show the sequential relationship of all functions of a system that meets the defined need.

A rough estimate of performance requirements is identified for the system and is presented in the F\&OR sections. These are qualitative values assigned to the system. The inputs and outputs of each function are also identified to better understand the interrelationships of all system functions. Requirement allocations are performed to divide the requirements until a level is reached at which 


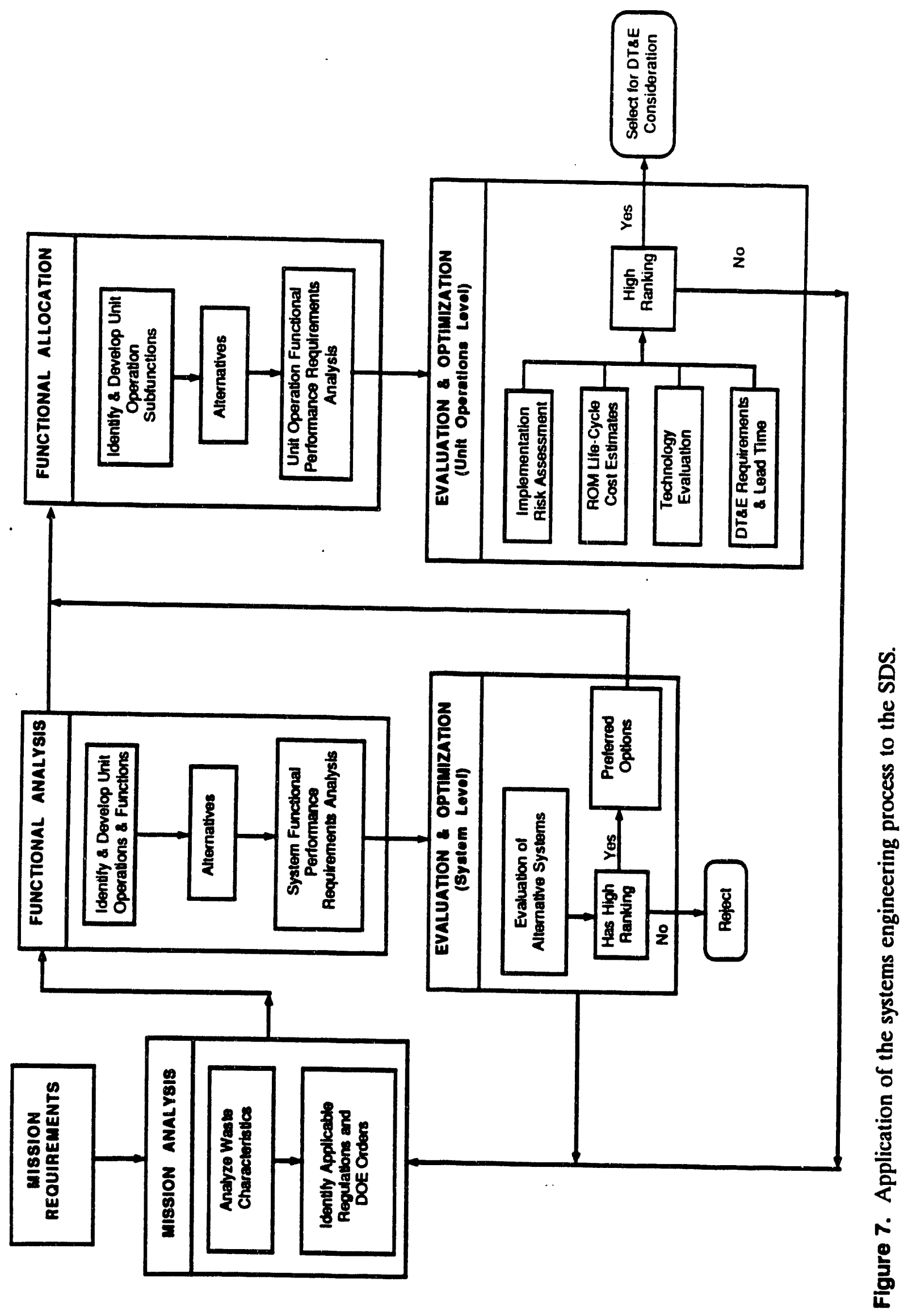


a specific technology fulfills the needed functional/performance requirements. The results of the requirement allocation are depicted in the unit operation subfunctional flow diagram (see Sections 5 through 8).

\subsubsection{System Concept Assessment}

After selecting unit operations (system components that accomplish a given function) of the system concept, two different evaluations are performed to determine the degree to which the system functional requirements are satisfied:

Performance Measurables Assessment. A set of matrices are used to subjectively score the degree to which a unit operation achieves a performance measurable. Each unit operation is scored from one to ten, with ten indicating the highest compliance or concurrence with the measurable performance criteria. The ranges of scoring considered during subjective evaluation of the performance measurables are as follows:

$\begin{array}{lll}\text { - } & \text { High } & 9-10 \\ \text { - Moderately high } & 7-8 \\ \text { - Moderate } & 5-6 \\ \text { - Moderately low } & 3-4 \\ \text { - Low } & 1-2\end{array}$

Table 1 defines the performance measurables applied in the Systems Design Study (SDS).

Weighting factors are used to ensure that the importance of each measurable performance as unit operation is considered in the overall system score. Weighting factors are used for each measurable performance according to its importance. Weighting factors are also used for each unit operation in the system. Accordingly, a weighting factor of 2 is given to the main process unit operations, a factor of 1.5 is given to the unit operations processing secondary waste, and a factor of 1 is used for supporting unit operations.

The score for each measurable is multiplied by the weighting factor and the resultant numbers are added for each unit operation. The total score for the unit operation is then multiplied by the weighting factor assigned to that unit operation. The score for the system, expressed in percentage of maximum available score, is obtained by dividing the sum of the unit operation weighted scores by the total maximum available score and multiplying this number by 100 .

Program Implementation Risk Assessment. Uncertainties and weaknesses of each concept are identified by performing a qualitative program implementation risk assessment. The programmatic risks associated with implementing the concept are assessed for each of the system concepts. This assessment identifies major uncertainties requiring focused work and attention and provides a degree of confidence that the program can be executed to meet the stated mission and objectives. The assessment is performed during the initial project phase in accordance with risk assessment guidelines given in DOE Order 4700.1. 


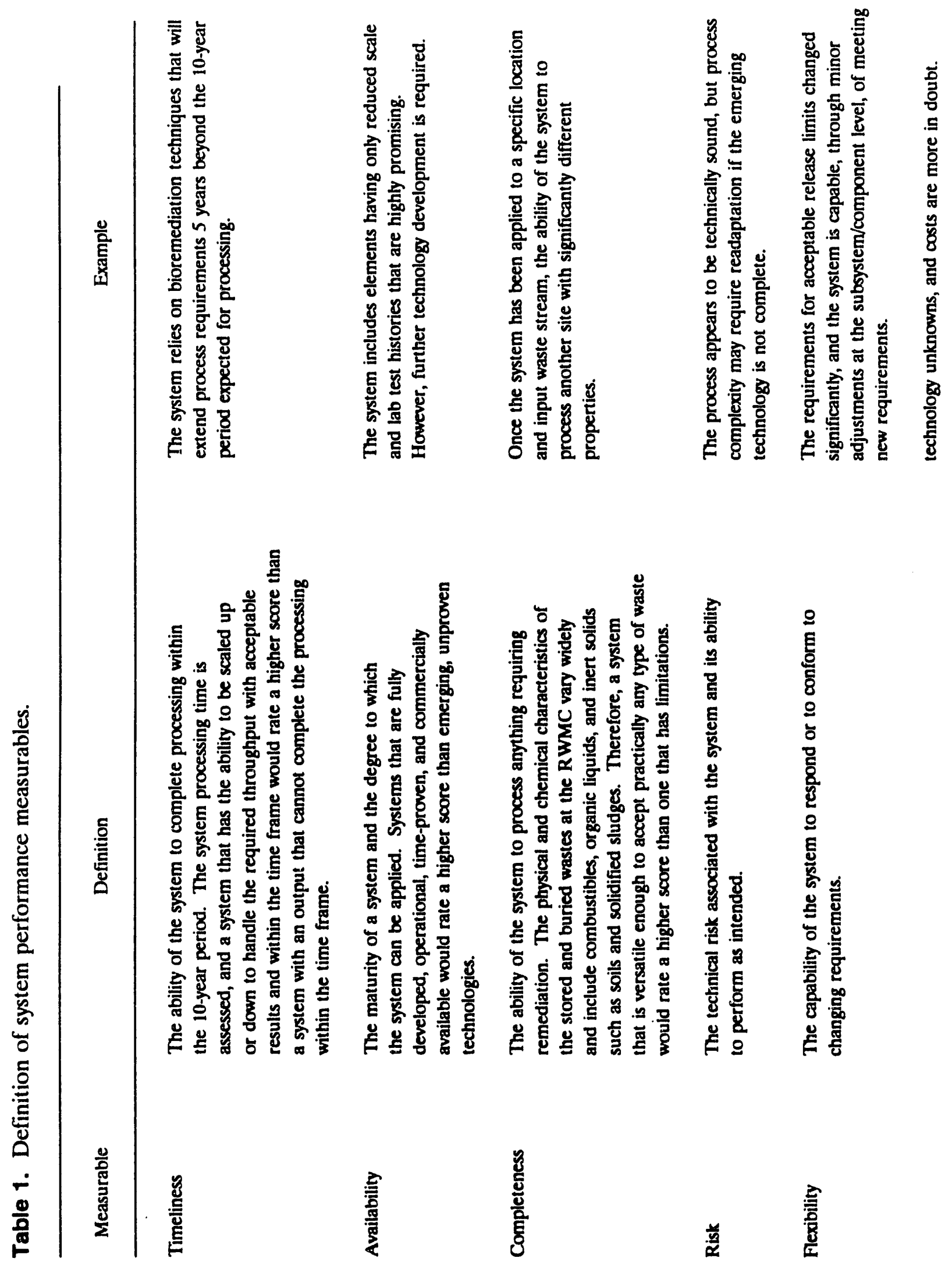




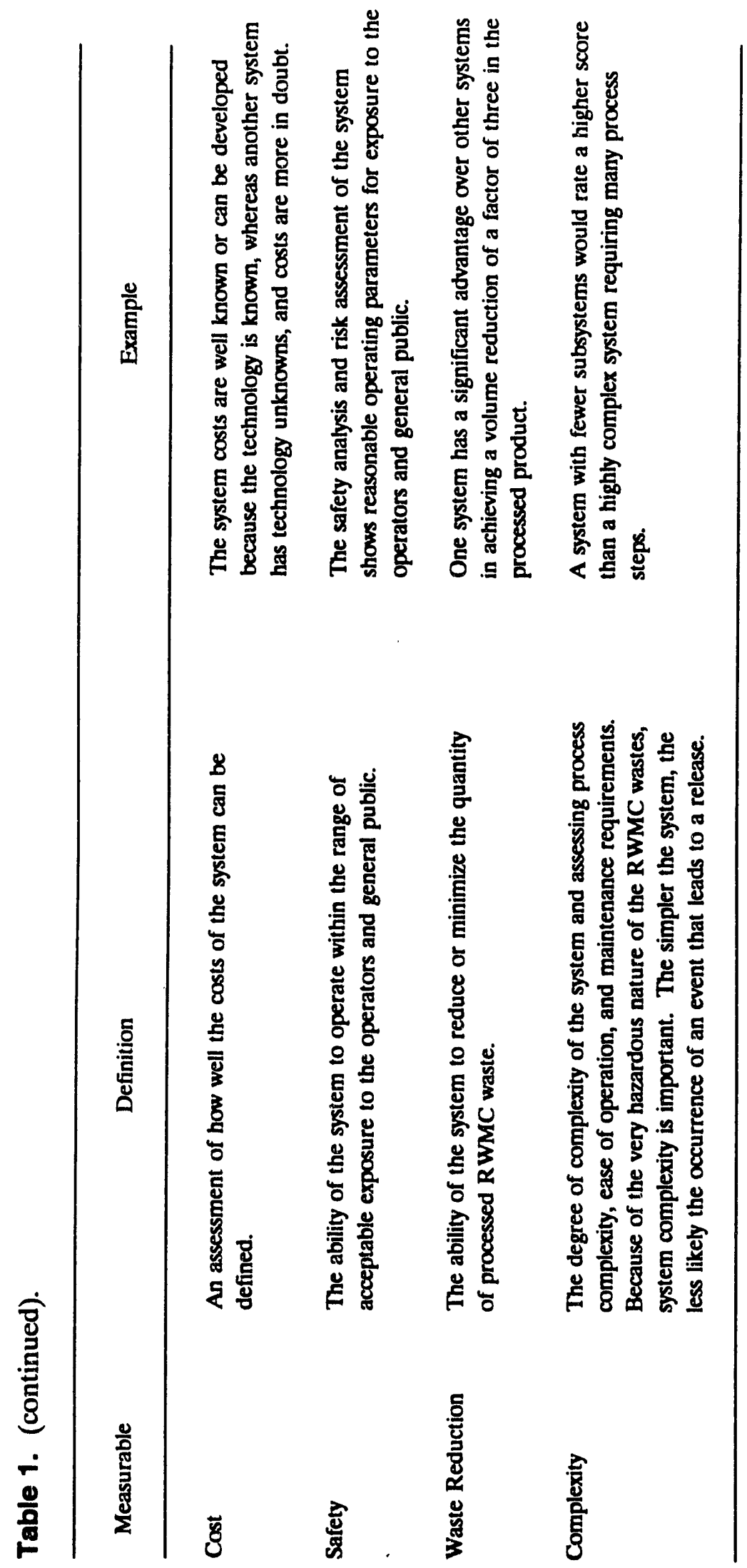




\section{ASSUMPTIONS}

The following assumptions apply to all system concepts developed under this study.

\subsection{Final Waste Form Assumption}

The physical and chemical properties imposed on the output of the system (the waste form) is the single most important factor affecting the study and selection of a system concept. Although a specific waste form for the stored LL-TRU waste cannot be established until a disposal strategy is selected, as a minimum requirement, the LDR in conjunction with the EPA and DOE regulations and requirements for LLW are imposed on this waste.

The system concepts investigated in the SWSDS are based on waste forms that are suitable for the alternative disposal methods established as the objectives for disposal of the stored LL-TRU waste. The assumed waste form requirements that meet the alternative disposal methods are given below. The system concepts and waste form numbering systems used in this study are parallel to those considered in the BWSDS.

- Waste Form 1, In-Place Confinement of Buried Waste: This form is for in situ treatment concepts for buried waste as considered in the BWSDS and is not applicable to the system concepts considered in the SWSDS.

- Waste Form 2, Leach Resistant, High Integrity: This waste form is a leach-resistant, highintegrity glass-or ceramic-like material and meets the general requirements established for high-level nuclear waste to be disposed of in a deep geologic repository. However, it is not suggested that this waste needs to be disposed of in a deep geologic repository. The waste form also complies with transportation package (TRAMPAC) TRU criteria. Because of its high quality, this waste form also meets the less stringent requirements for waste forms 3 and 4 , discussed below.

- Waste Form 3 - LDR Compliance Required, Hydrogen Generation Restricted: This waste form complies with the LDR requirements (i.e., destroy organics and fix inorganics), restricts the hydrogen generated from metals, and complies with the TRAMPAC TRU transportation packaging criteria. It is assumed that this waste form will be suitable for a RCRA shallow land disposal facility. Waste Form 3 does not meet the requirements of Waste Form 2 (i.e., it is not a glass or ceramic) but will meet Waste Form 4 requirements, which are discussed below.

- Waste Form 4 - WIPP Compliance Required: This waste form complies with the current WIPP WAC and the TRAMAC TRU transportation packaging criteria. It is assumed that this waste form will be suitable for a disposal facility similar to WIPP. Waste Form 4 does not meet any of the above waste form requirements. 


\subsection{Waste Property Assumptions}

It is assumed that the general properties of the stored LL-TRU waste are the same as those given in the EG\&G Idaho Engineering Design File, IWPF-0009, Rev. 0 (see Appendix A). The following is additional information concerning the input waste criteria:

- The total input is 36,576 55-gal drums; 3792 wooden boxes; and 536 metal bins. The total volume of the waste is approximately one million $\mathrm{ft}^{3}$.

- The category and composition of the input waste (from Appendix A) are shown in Tables 2 and 3.

- The transuranic concentration of any drum, box, or bin is less than $100 \mathrm{nCi} / \mathrm{g}$.

- Waste containing materials that can jeopardize the safety of processing operations either exist in small quantities and can be safely handled or can be segregated for handling and processing as special material. Waste material in this category may include high radiation objects requiring remote handling, containers having free liquids, and compressed gas cylinders.

- All of the alpha-LLW waste is assumed to be mixed waste, which is defined as waste that is both hazardous waste subject to the requirements of the RCRA and radioactive waste subject to the requirements of the Atomic Energy Act (AEA). The determination that the processes employed by the systems considered in SWSDS meet the LDR treatment standards and/or the specified technologies (per EPA regulation 40 CFR 268) are made based on the following assumptions. The joint EPA and NRC guidance on identifying and sampling mixed waste is provided in References 3 and 4, 40 CFR 268.1(d), and 40 CFR 268.2, Table 3.

- Lead shielding: It is assumed that input waste classified in this category will be separated during the initial handling steps and will be treated according to the specified technology - macroencapsulation. This technology is provided in the metal sizing and decontamination subsystem. After treatment by the specified technology, the waste can go to a mixed waste disposal facility licensed under EPA Subtitle C/AEA requirements.

- Waste containing elemental mercury: If found, elemental mercury will be separated during the initial handling steps and will be treated by a portable skid mounted selfsufficient treatment system equipped with the EPA specified technology amalgamation of liquid. After treatment, the waste can go to a mixed disposal facility.

- Waste contaminated with polychlorinated biphenyls (PCBs) and halogenated organic compounds (HOCs) as specified in 10 CFR 268.42(a)(1) and (a)(2): These wastes will be treated by incineration, which is the EPA specified technology. After incineration, the residue (ash) will be further treated by either vitrification or solidification process. The treated waste can go to a mixed waste disposal facility. 
Table 2. Stored alpha-LLW type description (see Appendix A).

\begin{tabular}{lcr}
\hline \multicolumn{1}{c}{ Description } & Percent & $\begin{array}{c}\text { Weight } \\
\text { kg }\end{array}$ \\
\hline Combustibles & 17.55 & $2,075,159$ \\
Metal (steel/structural) & 26.28 & \\
Metal - special & .12 & $3,107,434$ \\
Glass & 1.66 & 13,919 \\
Graphite molds and crucibles & .10 & 196,139 \\
Molds and crucibles: other non-metallic & .03 & 11,386 \\
Uncemented inorganic sludge & 10.90 & 3,465 \\
Uncemented organic sludges & 9.50 & $1,192,844$ \\
Cemented sludges and absorbed liquids & 15.55 & $1,123,503$ \\
Concrete and brick & 4.85 & $1,838,517$ \\
Salts & .09 & 573,680 \\
Leaded rubber & .03 & 10,645 \\
Benelex and plexiglass & .31 & 3,653 \\
Resins & .04 & 37,145 \\
Mixed waste: paper, metals, glass & 6.85 & 4,521 \\
Insulation and filter & 3.54 & 809,535 \\
Soil, asphalt, sand, and ash & 4.00 & 418,040 \\
Total & 100.00 & 472,525 \\
& & $11,822,769$ \\
& & \\
\hline
\end{tabular}


Table 3. Composition of the combustible portion of the stored alpha-LLW. ${ }^{1}$

\begin{tabular}{lrr}
\hline \multicolumn{1}{c}{ Waste Type } & Percent & $\begin{array}{r}\text { Heating } \\
\text { Value } \\
\text { BTU/b }\end{array}$ \\
\hline Wood & 0.87 & 8,420 \\
Paper & 61.87 & 7,709 \\
Polyethylene & 15.60 & 19,949 \\
Cloth & 14.70 & 7,200 \\
Graphite & .15 & 10,000 \\
Rubber & 1.02 & 12,800 \\
Cardboard & .29 & 8,374 \\
Teflon & .09 & 0 \\
Metal & 1.00 & 2,869 \\
Cement & .29 & 0 \\
Sand & 1.06 & 0 \\
PVC Plastic & 2.49 & 8,831 \\
\hline
\end{tabular}


- Compressed gases: If found, input waste classified in this category will be separated during the initial handling steps and will be treated according to the specified technology, which is deactivation to remove the hazardous characteristics of waste due to ignitability, corrosivity, and/or reactivity. This technology is provided in the metal sizing and decontamination subsystem. After treatment, the waste can go to a mixed waste disposal facility.

- All other wastes classified as RCRA characteristics or RCRA listed (Subpart D) wastes. All other waste are assumed to be subject to either incineration as the LDR required treatment technology, or LDR required treatment standard based on constituent concentration of the waste (CCW) or constituent concentration of the waste extract (CCWE). In the latter case, it is assumed that incineration followed by either vitrification or solidification will meet the specified treatment standards. After meeting the treatment standards, the solidified or vitrified waste can go to mixed waste disposal facility.

\subsection{General Assumptions}

The assumptions include several provisions that may not be consistent with the latest criteria used by the IWPF project. These assumptions are being retained to allow a comparison between the systems considered in the SWSDS with those in the BWSDS.

- All LL-TRU contaminated waste metals will be decontaminated, where possible, for disposal as LLW in less restrictive environs or potentially reuse and recycle, if allowed by regulations.

- The processing buildings for alpha-LLW are classified as a Solid Radioactive Solid Waste Facility per Section 1324 of DOE Order $6430.1 \mathrm{~A}$ and as a moderate hazard facility per University of California Research Laboratories (UCRL) 15910. The current plans are to design the IWPF as a plutonium facility per Section 1304 of DOE Order 6430.1A.

- The time allowed for processing alpha-LLW is 10 years.

- Operational assumptions: 24 hours/day, 5 days/week, 240 days/year, and $70 \%$ plant availability during operation. This is equal to 168 days/year or 4032 hours/year of operation.

The scoping layout of the facilities for each concept is based on the following assumptions:

- Incoming Waste Surge Capacity: Surge capacity for indoor storage of the incoming drums, boxes, and bins is $3-4$ months.

- Outgoing Packaged Waste Storage Capacity: Capacity for the indoor storage of the packaged waste is 6-8 months. 
The current basis for IWPF is that the inspection and assay of the incoming waste will be performed in the Stored Waste Experimental Pilot Plant (SWEPP), and the waste will be stored in separate storage modules.

\subsection{Criteria and Assumptions for Program Implementation Risk Assessment}

The programmatic risks associated with implementing the concept are assessed for each of the system concepts. This assessment should identify major uncertainties requiring focused work and attention and provide a degree of confidence that the program can be executed to meet the objectives stated in Section 2. The assessment is performed during the initial project planning phase in accordance with the guidelines given in DOE Order 4700.1 for risk assessment. Program implementation risk assessments in this report are qualitative and are based on the judgement of the study team members. Because the stored alpha-LLW treatment project is still in the initial phase of the acquisition process, detailed information for a full analysis does not yet exist. Therefore, the qualitative judgements are based on the following methodology.

Each of the unit operations are considered during an initial implementation risk assessment of the system concepts. This is done by applying the knowledge of experienced personnel and using this knowledge to rank each of the program objectives as low, moderate, or high risk. Then, a composite implementation risk level for the overall system concept is assigned based on the risk associated with the unit operations. In most cases, only the overall system implementation risks are presented in this report. A low ranking implies that the system could be implemented at the present time with virtually no risk. A moderate ranking implies that although the implementation of the system concept is feasible, certain aspects of implementation still need to be resolved. A high ranking implies that a system concept has a considerable amount of uncertainty that a given objective will be achieved.

\subsubsection{Technical and Performance Risk Considerations}

The stored alpha-LLW cnaracteristics considered in this study are based on a preliminarily characterization performed for the IWPF design (see Appendix A). The risk assessmerit of the ability to comply with the performance objectives is based on these waste characteristics. However, detailed and accurate information on the materials stored at the TSA was not available at time this study was performed. Any pyrophoric materials and large compressed gas cylinders containing volatile and toxic gases can have a significant impact on the performance compliance risk characterization.

\subsubsection{Health and Safety Risk Considerations}

The following considerations are used in characterizing the health and safety risks:

- General Construction-Related Concerns: As with any construction-related activity, there will be general health and safety concerns associated with the stored waste processing facility construction. Risk associated with the ability of the program to define and mitigate these health and safety concerns is considered to be low. 
- Radioactive and Hazardous Material Handling Concerns: Because of radioactive, hazardous, and mixed waste contamination of the material handled during operations, the program will be subject to health and safety risks associated with low-level radiation, alpha particles, and hazardous material exposures. Because of extensive DOE and commercial power reactor experience, the risk associated with the ability of the program to define and mitigate these health and safety concerns is considered to be low for all system options.

- Criticality. Because of the low concentration of plutonium in the stored LL-TRU waste, the program will not be subject to health and safety risks associated with criticality.

- Pyrophoric and Flammable and Toxic Gas: Since the SWSDS waste characteristics document (see Appendix A) does not identify pyrophoric material or compressed gas cylinders containing flammable and toxic gases, the ability of the program to define and mitigate health and safety risks associated with these wastes is not believed to be a significant concern.

\subsubsection{Institutional Risk Considerations}

In the past, DOE projects involving large thermal processes (e.g., Rocky Flats and Los Alamos National Laboratory) have received low levels of public and institutional sipport. However, this has not been the case at INEL. Therefore, systems employing large thermal processes receive moderate ranking in the area of institutional risk.

\subsubsection{Schedule Risk Considerations}

The following considerations were used in characterizing schedule risks:

- Time Available for DT\&E: As indicated previously, the schedule objective is to reach Title I design by FY 97 . To achieve this objective, it is assumed that detailed information to select a treatment alternative is needed by FY 96 . Therefore, any system unit operation requiring a DT\&E leadtime longer than 4 years for its main process is considered to be high risk.

- Thermal System Burn Test Requirements: Because of past experience in lengthy burn tests and EPA approval processes at other DOE sites (e.g., Rocky Flats and Oak Ridge National Laboratories), system options involving the incineration process are characterized as a moderate risk for compliance with the schedule objectives.

\subsubsection{Cost Risk Considerations}

Since a baseline cost estimate has not been established at this time, the assessment of cost risk is based on the ability of the program to define the cost of the given system. The cost risk

f. High pressure ( $>15 \mathrm{psi}$ ) gas cylinders and pyrophorics have been prohibited by the TSA waste acceptance criteria since the waste storage began. 
characterization will be impacted if materials and contaminants that can have a significant impact on the technical performance risk are found.

\subsection{Cost Estimating Assumptions}

Cost estimating assumption are presented in Appendix B of this report.

\subsection{DT\&E Assessment Assumptions}

Major unit operations in each of the system and subsystem concepts are evaluated to estimate DT\&E needs, lead time, and resource requirements. Following are some of the criteria and assumptions used as the basis for these estimates.

- Project Execution: It is assumed that the stored LL-TRU waste processing project will be conducted in accordance with the project management system advocated by DOE Order 4700 .1. Figure 8 shows the various categories of work and the various phases of research and development in a typical project implemented under the DOE Order 4700.1.

- Research and Development (R\&D) Categories of Technologies: The three system options and the one subsystem considered in the SWSDS will not use technologies that fall in the categories of basic research, applied research, or technology or exploration development as defined in DOE Order 4700.1. Only technologies that have passed the technology or exploration development stage are assessed. Under the EG\&G Idaho research, development, demonstration, testing, and evaluation (RDDT\&E) program definitions, technologies considered are assumed to have completed R\&D activities and require only DT\&E activities to compare the effectiveness of alternative processes; determine the applicability of a technology to a site-specific use; establish a level of confidence in a treatment process; yield information such as process results, design criteria, and operational sensitivities; and obtain regulatory agency concurrence or approvals, as needed. The EG\&G Idaho DT\&E activities are considered to be comparable to the advanced development activities defined in DOE Order 4700.1.

- DT\&E Output Assumptions: When a DT\&E program is proposed for a given unit operation, the intent is to identify a series of activities to develop the unit operation to a point where the results will support DOE key decision 2, (start of the Title II design) for the stored LL-TRU waste treatment program.

- DT\&E Steps: To allow a consistent assessment of DT\&E needs, the activities are divided into the following logical steps (see Figure 9).

Primary Paper Evaluation: The primary paper evaluation studies the various options using existing information. This evaluation defines the scope and conceptual design for the next steps of the DT\&E phase. It will eliminate from further consideration those options that are not likely to be cost effective. 


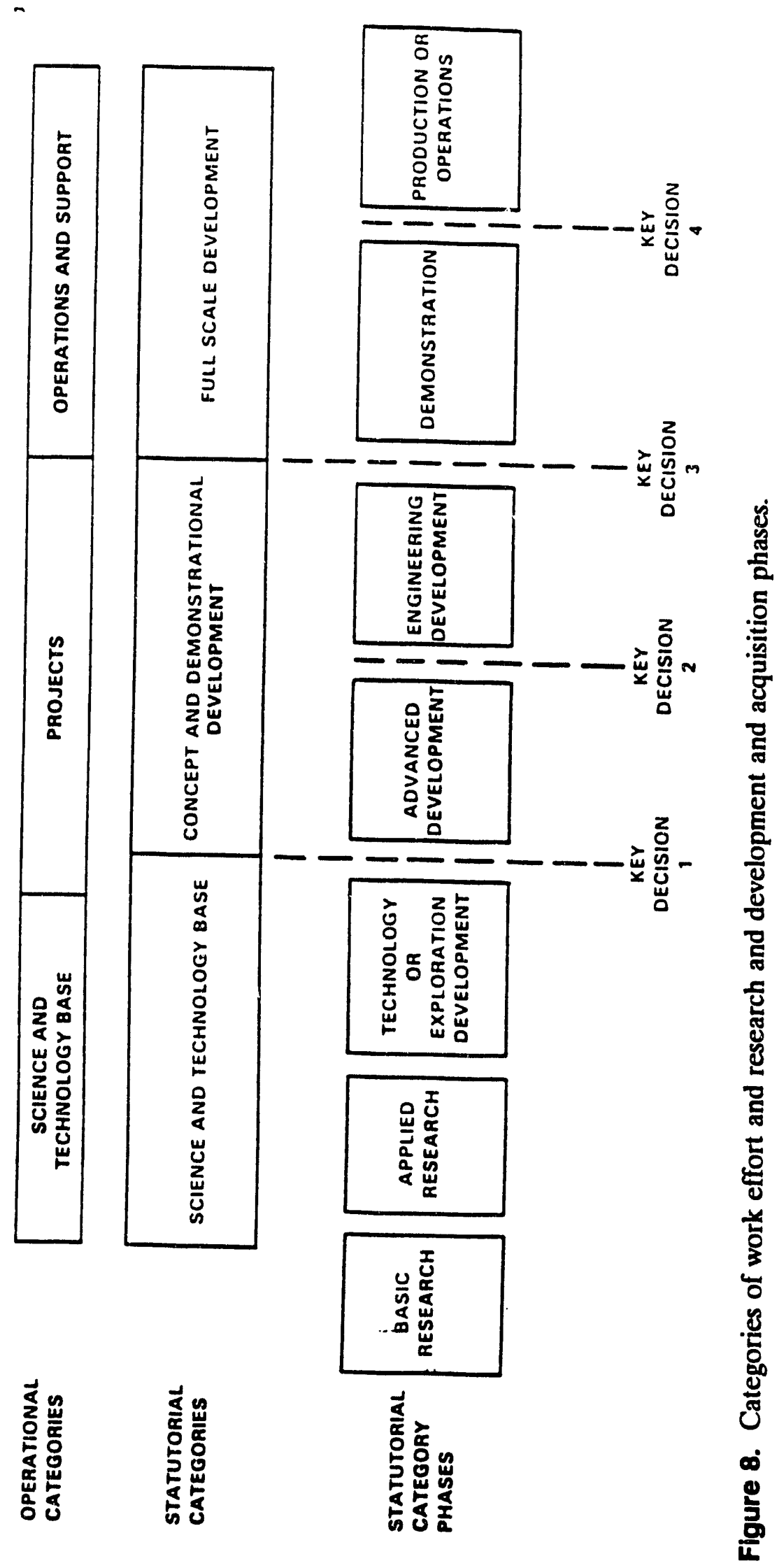




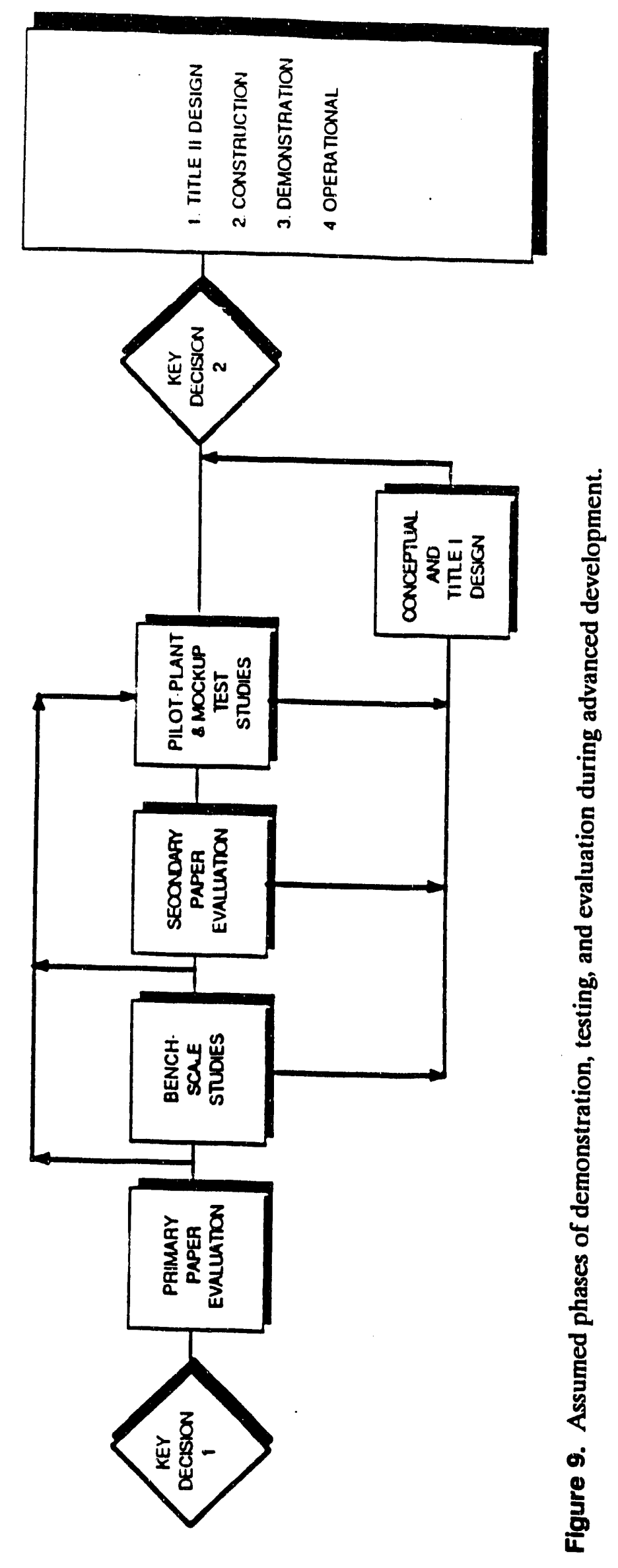


- Bench-scale studies: Bench-scale studies are the next logical step, but in some cases it is assumed that the DT\&E efforts can move directly from initial paper evaluation to the pilot-plant/prototype test studies. For example, evaluating a robotics operation in waste segregation would not be conducive to bench-scale studies, but bench-scale tests would be a necessary part of solidification process and formulation development.

- Secondary paper evaluation: When further pilot-plant studies are necessary, a secondary paper including more detailed concept development may be needed. This will eliminate options that are not cost-effective and focus the pilot or prototype test study on essential issues, normally using a single technology option.

- Pilot-Plant and Prototype Test Studies: The pilot-plant and prototype test studies provide reliable information for developing design criteria including scale-up limitations and cost estimates for processes and ancillary equipment. Full-scale prototype tests are assumed to be necessary for nonprocess equipment such as robotics development. Pilot-plant and prototype studies typically cover only the critical portions of the equipment requiring advanced development.

- Number of Technology Options Studied in Typical DT\&E Program: It is assumed that primary paper evaluation, bench-scale studies, and secondary paper evaluation steps will result in narrowing the alternatives to a single option. Pilot-plant and prototype studies are assumed to be applied only to the selected option and are proposed only if necessary.

- DT\&E Lead Times: To provide a consistent estimate of the DT\&E lead times, the time spans listed below are assumed for the DT\&E steps. Based on the complexity of the technologies being considered, the time span is narrowed to a specific duration in the assessment sections of the system concept. The time spans include allowances for a 1 month procurement process and 1-month report preparation for bench-scale and paper studies. For pilot-plant and mock-up studies, a 2-month procurement process, 2-12 month design, 4-12 month fabrication, and 6-24 month test and report preparation are assumed to be necessary.

- Primary paper evaluation

- Bench-scale studies

- Secondary paper evaluation

- Pilot-plant/mock-up test studies
5-6 months

5-18 months

5-6 months

14-60 months 


\section{INCINERATION/MELTING SYSTEM}

This section describes an incineration/melting system devised to convert the stored alpha-LLW into a physical and chemical form that is a high-integrity, leach-resistant solid similar to glass, ceramic, or rock.

\subsection{Functional and Operational Requirements}

\subsubsection{System Description}

The incineration/melting system, shown in Figure 10, is comprised of several unit operations and a metal sizing and decontamination subsystem. The metal sizing and decontamination subsystem is described in Section 8.

The waste containers (drums, boxes, and metal bins) arrive at the incineration/melting facility on a transport vehicle. Containers are removed from the transport vehicles and placed in a staging/storage area. The containers are visually examined, labeled, logged, recorded, and sent to an inspection and assay unit operation.

The inspection and assay results allow segregation of the containers to expedite processing. Based on the inspection and assay results, the waste containers are grouped either as bulk metals, combustibles, organic sludges, semicombustibles, ${ }^{8}$ inorganic sludges, or special waste. The special waste category includes any container that requires a special sorting operation.

At the open, dump, and sort unit operation, the categorized waste containers are uncapped and their contents emptied on either a sorting device or on transport devices that carry the waste directly to the various process unit operations. When dumped on the sorting device, the various waste types are first separated into various categories as needed by the process and then placed on the transport devices. The open, dump, and sort unit operation also has the capability to size reduce empty nonmetal containers. Empty metal containers are transported to the metal sizing and decontamination subsystem for processing (discussed in Section 8). From the open, dump, and sort operation the waste goes to the main processing streams, incineration and melting.

Waste is fed to the incinerator by the input preparation and feed unit operation that shreds and pulverizes the incoming material. All combustible materials burn while inert materials pass through with the ash. The solids discharged from the incinerator are cooled and sampled and then fed to the melter.

The melter receives four different feeds: incinerator ash and solids, inorganic sludges, wet sludges, and an additive soil that is needed to produce a high-integrity vitrified product. An input preparation and feed unit operation shreds, pulverizes, and blends the incoming waste, as needed, before it is fed to the melter. The melter turns the four input streams into a molten slag. The slag

g. Semi-combustibles term is used in this study to denote a mixture of non-combustibles and combustibles in which the quantity of combustible material is greater than 5 percent of the total mixture weight. 


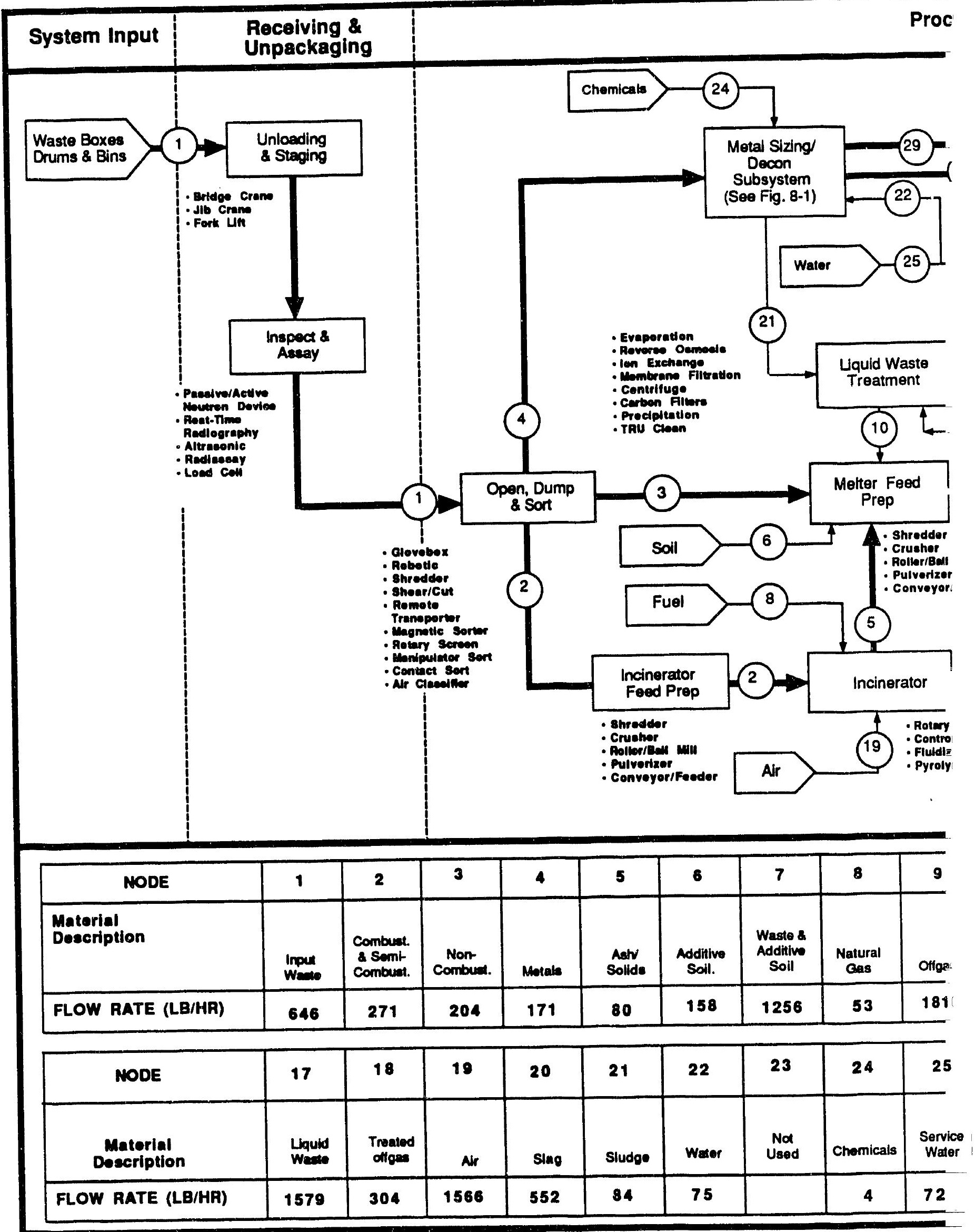

Figure 10. Process functional diagram for incineration/melting system. 


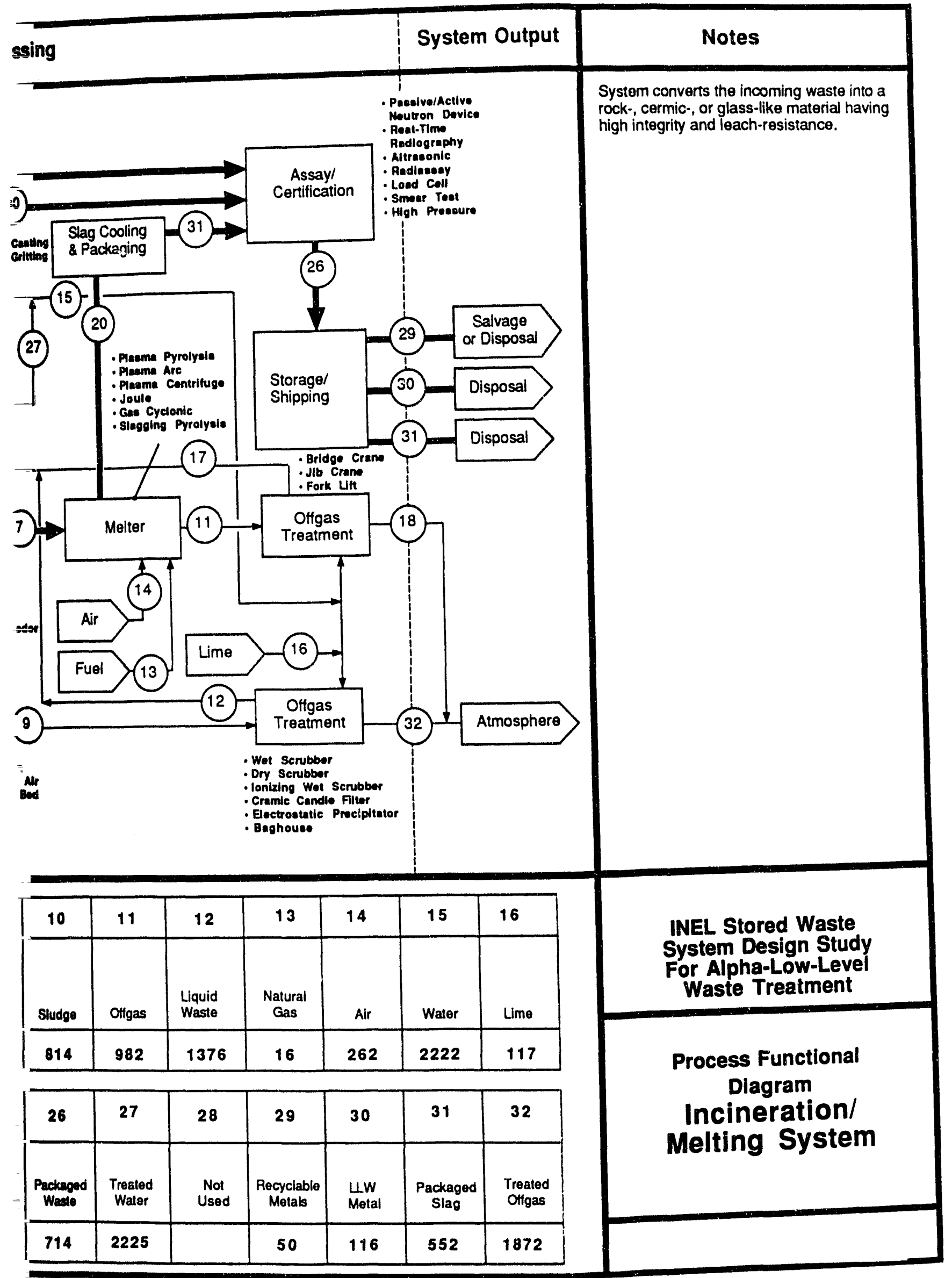


is poured into an ingot mold, cooled, and packaged. The ingot cooling step is designed to provide a precise annealing rate to achieve the highest quality waste form.

The system's major product is the vitreous waste. Other system products include decontaminated metals (suitable for shallow-land disposal or potential recycle and reuse) discharged from the metal sizing and decontamination subsystem. All system products are containerized and processed through a radio-assay and a final certification process. Certified containers are sent to an interim storage facility and shipped, when needed, to long-term storage and disposal facilities.

The system has two secondary waste streams, liquid and offgas. Both the melter and incinerator unit operations are equipped with a secondary combustion or retention chambers that complete the volatile gas destruction process. The secondary combustion effluent is fed to air pollution control equipment designed to remove particulates, heavy metals, $\mathrm{SO}_{2}, \mathrm{HCl}$, and $\mathrm{NOx}$. A surge tank allows retention for reprocessing in the event of a process upset.

Secondary liquid waste from the offgas and the metal sizing and decontamination operations is processed by a liquid waste-treatment unit operation. This unit operation removes dissolved and suspended solids (organic and inorganic) from the liquid waste. Treated waste water is recycled and reused. Sludge and other wet solids are fed to the melter for processing.

\subsubsection{System Requirements}

5.1.2.1 System Functional Requirements. The system includes all facilities, processes, equipment, devices, and accessories required for processing and packaging the alpha-LLW stored at the RWMC. The system converts the waste into a physical and chemical form that is a high-integrity, leach-resistant solid similar to glass, ceramic, or rock.

System support functions consist of, but are not limited to, the following:

- Security

- Work control/personnel support

- Contaminated equipment maintenance

- Noncontaminated maintenance

- Heating, ventilating, and air conditioning (HVAC)-nonprocess

- Fire protection

- Safety (equipment and training)

- $\quad$ Health physics

- Sanitary facilities 
- Electrical (including emergency)

- Process control and data logging

- Environmental regulatory reporting and records management

- Criticality control and monitoring

- Radiation instrumentation

- Personnel decontamination (radioactive and hazardous)

- Bulk chemical and additive supply and storage

- Storm water runoff control

- Wastewater treatment (hazardous, radioactive, and sanitary)

- Interior and external (public relations) communications

- Spill or emergency response provisions (hazardous and radioactive)

- Analytical laboratory

- Environmental field sampling.

5.1.2.2 System Performance Requirements. The system will meet the following performance requirements:

- Capacity: The system processes and packages the alpha-LLW over a 10-year period, assuming 24 hours/day, 5 days/week, and 240 days/year operation with $70 \%$ availability.

- Input waste: The system has the capability to receive diverse types of waste material. At a minimum, the system will process the following categories of waste:

- Bulk metals include containers having the content codes "metal - steel," "metal special," and "leaded - rubber." (Appendix A of this report provides more information on the composition of the 19 waste-stream content code groups.)

- Combustibles include containers having the content codes "combustibles" and "mixed waste paper, metal, glass."

- Organic sludge includes containers having content codes "uncemented organic sludge" and "resins." 
- Semicombustibles include containers having content codes: "benelex and plexiglass," "soil, asphalt, sand and ash," "graphite, molds, and crucibles," "insulation and filters," and "molds, crucibles -others."

- Inorganic sludge and others include containers having content codes "salts," "glass," "concrete and brick," "cemented sludge/liquids," and "uncemented inorganic sludge."

- Special waste includes any container that requires a special sorting operation. For example, a box containing a combination of large metal objects, soil, and concrete may require separation of the bulk metals for efficient and cost-effective processing. Similarly, a container with contents that include compressed gas cylinders will require removal of the cylinders to meet safety requirements.

Note: Certain special items received from the TSA will have a size or nature incompatible with the normal processing units' capabilities. Treatment of these items to meet the waste form requirements is outside the scope of the normal process and will be handled by special treatment schemes devised on a case-by-case basis.

- Form for packaged nonmetal waste is a glass-ceramic or rock-like material that has high structural integrity. The product is highly leach resistant and meets the DOE, EPA, and DOT requirements for transportation and long-term disposal as LLW.

- Form for metals includes the decontaminated metals produced by the facility are either suitable for uncontrolled release (recycle or reuse as permitted by regulation) or for disposal in a LLW burial facility.

- Efficient systems minimize the volume of waste requiring disposal and the quantity of secondary waste and other discharges to the environment.

- Exposure of hazardous and radioactive materials to the public, workers, and environment will be as low as reasonably achievable (ALARA).

5.1.2.3 System Design Requirements. The system is classified as a moderate hazard facility per UCRL 15910 and meets the requirements for a solid radioactive waste facility per DOE Order 6430.1A.

The system is designed in accordance with applicable regulations. Specifically, RCRA places design conditions on the storage and treatment process and performance specifications on the thermal and waste stabilization processes. All equipment has high-quality, low-maintenance items to keep personnel exposure ALARA. Remote operations are used to the greatest extent practical. The facility design is compatible with DOE requirements including the DOE Idaho Architectural Engineering Standard and DOE Order 6430.1A, "DOE General Design Criteria Manual."

Adding soil to the melter is designed to prolong the retention of TRU in the waste form, buffer the process and dampen out the effects of the incoming waste material variations, and ensure a uniform output. The soil addition produces a better performing final waste form and a more robust uniform process and product. 
The individual unit operations are sized to handle at least $125 \%$ of the mass flow rates shown on the process functional diagram.

\subsubsection{Unit Operations Functional Requirements}

Each unit operation has the facilities, equipment, devices, and accessories needed to accomplish the following functional and subfunctional iequirements. Detailed performance requirements for the unit operations will be developed in future 'cudies. Figure 11 depicts the preliminary unit operations process subfunctional diagram for the system.

\subsubsection{Unloading and Staging.}

- Unit operation functions summary. The unloading and staging unit operation unloads the transportation vehicles; places containers in the staging area and provides surge storage; moves containers within the unloading, staging, and surge storage areas; and transports containers to and from the various interfacing unit operations. The unit operation can interface with a transportation vehicle mounted with a radiation overpack.

- Allocated functions: Unit operation functions are allocated to the following subfunctions:

- Onsite transportation: A transportation vehicle (with an overpack, if needed) is used to ship the containers from the TSA to the alpha-LLW processing facility, providing this vehicle is outside the scope of this study.

- Unload and transfer: A container handling device unloads the containers from the vehicle and moves them to the staging and storage areas. As needed, the container handling device moves the containers from the staging and storage areas to the assay or the open, dump, and sort unit operations.

- Stage/store: Containers are unloaded in an enclosed truck bay and placed in an indoor staging area, which has sufficient space to allow maneuvering of the containers and sufficient surge storage capacity to provide the desired operational reliability.

\subsubsection{Inspect/Assay.}

- Unit operation functions summary: The inspect/assay unit operation determines radioactivity and physical properties and parameters needed to categorize waste containers before processing. Various container waste categories are given in Section 5.1.2.2.

- Allocated functions: Unit operation functions are allocated to the following subfunctions:

- Alpha radio-assay: Waste containers are examined by radio-assay devices to allow alpha radiation classification of waste in accordance with the criteria established by the processing unit operations. Various devices, such as passive/active neutron (PAN) counting instruments, may be used. Containers are examined to ensure that they are alpha-LLW. Containers classified as other than LLW or alpha-LLW are transported back to the TSA. 


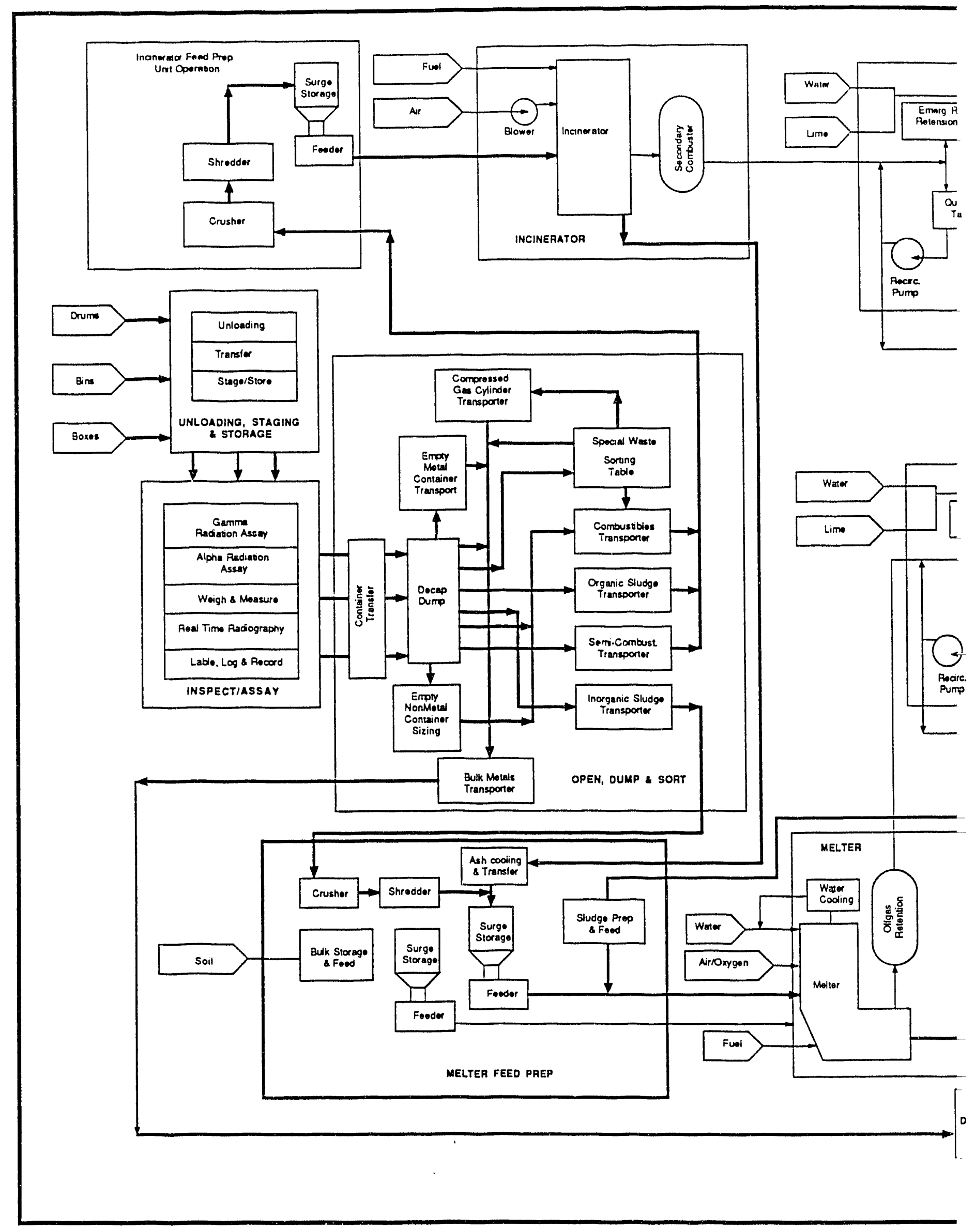

Figure 11. Unit operations subfunctional flow diagram for incineration/melting system. 
- Gamma radio-assay: Waste containers are examined by radio-assay devices to allow gamma radioactivity classification in accordance with the criteria established by the processing unit operations. Various devices, such as gamma spectroscopy Segmented Gamma Scan (SGS) instruments may be used. Containers are examined to ensure that they are suitable for contact handling (less than $200 \mathrm{mR} / \mathrm{hr}$ on surface) and treatment by the given process units. Containers not meeting the criteria are transported back to the TSA.

- Weighing and measuring: Containers are weighed and measured to determine waste density.

- Nondestructive physical (real-time radiography) examination: Contents (such as metals, paper, glass, sludge, gas cylinders, and liquids) of each container are determined by nondestructive examination. At a minimum, each container is examined using a nondestructive assay equipped with a real-time radiography (RTR) device. Ultrasonic devices are also used. Using data from the RTR and other devices, the containers are classified according to one of the categories discussed in Section 5.1.2.2.

- Label, log, and record: Each container is labeled, and its properties are logged and recorded into a computerized database program.

\subsubsection{Open, Dump, and Sort.}

- Unit operation summary. The open, dump, and sort unit operation prepares waste containers (drums, boxes, and metal bins) for processing by other unit operations. All operations are accomplished in a radiation- and hazardous-chemical controlled cell. The unit operation decaps the waste containers and dumps the waste onto either sorting devices or transport devices that carry the waste to the next unit operations. The unit operation's sorting function is to separate bulk metals, combustibles, noncombustibles, special wastes, ${ }^{\text {b }}$ and gas cylinders. The unit operation also size reduces empty nonmetallic containers.

- Allocated functions: Unit operation functions are allocated to the following subfunctions:

- Controlled environment: Open, dump, and sort operations are accomplished remotely in a controlled environment with a multiple confinement barrier. Containers enter this environment through airlock doors. Equipment maintenance is accomplished manually in a controlled environment. Features are provided for equipment pull out and decontamination before maintenance.

h. Special wastes are those material that are not treatable and compatible with the processing trains included in the system (e.g., $\mathrm{Hg}$ ). After identification and removal, special wastes are handled on a case-by-case basis. 
- Container transfer: Containers are transferred to the controlled environment through airlock doors and are brought to the decap/dump device.

- Decap/dump: After entering the controlled environment through the airlock, the containers caps are removed and their contents are dumped on devices that transport the waste to the next unit operations. Containers designated as special waste are dumped on a sorting device. Open and dump devices have features that control spread of liquids and loose particulates. Any spilled liquid is collected and sent to other unit operations for treatment.

- Sorting: Special waste is sorted to remove bulk metals, noncombustibles, combustibles, and gas cylinders. Various sorting technologies, such as vibratory tables and air classifiers, may be used. The sorted waste materials are placed in transfer devices. The sorting device has features to control the spread of liquids or loose particulates. Any spilled liquid is collected and sent to other unit operations for treatment.

- Nonmetal container sizing: Nonmetallic containers are cut into smaller sizes as needed for processing by the next unit operations.

- Transporters: After dumping and segregation operations, the waste, including the sized nonmetallic containers, is conveyed to the next unit operations.

\subsubsection{Incinerator Feed Preparation.}

- Unit operation functions summary. The incinerator input preparation and feed unit receives, stores, prepares the incoming waste streams into a proper size and mixture, and feeds at a rate that is required for the incinerator unit operation.

- Allocated functions: Unit operation functions are allocated to the following subfunctions:

- Controlled environment: Operation and maintenance are accomplished remotely in a controlled environment as discussed in Section 5.1.3.3.

- Crusher: The larger waste pieces (e.g., cemented sludge) are size reduced by crushing.

- Shredder: After crushing, the waste is further reduced in size to facilitate complete combustion.

- Surge storage: Size reduced waste is stored in hoppers that have sufficient capacity to provide the required incineration feed surge capacity.

- Feeder: The feeder conveys the waste to the incinerator at the desired feed rate. 


\subsubsection{Incineration.}

- Unit operation function summary. The incinerator performs the following functions:

- Thermal destruction of the combustible solids, gases, and volatile liquids.

- Discharges any inert material (such as soil, glass, and metals) that accompanies the input waste.

- Allocated functions: Unit operation functions are allocated to the following subfunctions:

- Controlled environment: Operation and maintenance are accomplished remotely in a controlled environment as described in Section 5.1.3.3.

- Incinerator. The incinerator uses a high-temperature thermal process (combustion oxidation) to treat incoming combustible (organic) waste streams in the form of solids, sludges, or liquids. Noncombustible (inert) waste components, such as soil or some metals, are also tolerated. Incineration of waste typically occurs at a temperature (ranging from $1800^{\circ} \mathrm{F}$ to $2200^{\circ} \mathrm{F}$ ) sufficient for complete oxidation (or pyrolization in the absence of sufficient oxygen) and destruction of toxic organic material. Unburned materials, such as inerts, remain as an ash. Noncombustibles typically pass through the incinerator unchanged. Various incinerator designs such as rotary kiln, controlled air (stationary), and starved air incinerators may be used. The ash from the incinerator is the primary waste stream requiring further treatment and is processed by the next downstream unit operation. The incinerator secondary waste is flue gas, which requires further treatment at higher temperatures with a sufficient residence time for destruction.

- Secondary combuster: Flue gas from the incinerator is treated in a high temperature $\left(2000^{\circ} \mathrm{F}\right.$ to $\left.2500^{\circ} \mathrm{F}\right)$ combusting unit. The gases remain at the high temperature for at least 2 seconds.

- Combustion air: A blower provides the air required for the combustion process.

- Combustion fuel: Natural gas or other fuel used by the incinerator are supplied by a fuel storage and feed unit.

- Rejected ash: Rejected ash is collected and sent to the melter feed preparation unit operation.

\subsubsection{Incinerator Offgas.}

- Unit operation functions summary. The incinerator offgas unit operation treats the incinerator offgas to meet the emission standards and requirements for discharged gas. The treated gas is monitored and released to the atmosphere. Liquid residues are collected and transferred to other unit operations for treatment and disposal. 
- Allocated functions: Unit operation functions are allocated to the following subfunctions:

- Controlled environment: Operation and maintenance are accomplished remotely in a controlled environment as discussed in Section 5.1.3.3.

- Gas cooling: High-temperature flue gas from the secondary combuster is sent to the gas cooling device, which reduces the temperature with water spray. The cooling water is supplied by the make-up water equipment and is collected in a quench tank.

- Particulate removal: Gas scrubbing techniques remove the particulates from the flue gas.

- Neutralization: Volatile metals, acid gases, and other material are also removed from the gas as it is cooled and scrubbed. Since this removal increases the water acidity, a neutralizing agent (such as lime) is added to the spray water.

- Chemical agent preparation and feed: Bulk storage, mixing, and feed capability for the neutralizing agent are provided as needed to support the offgas unit operation.

- Entrained liquid separation: Gas discharged from the cooling and particulate removal process contains entrained liquid. This entrained liquid is removed by demisters and separators or other techniques.

- Drying: The gas exhausted from the entrained liquid separation step is dried to decrease the relative humidity as needed for the filtration step. A combination of air-to-gas heat exchangers and alumina desiccant dryers may be used.

- Filtration: Filtration removes particulates from the dried gas and any remaining volatile and toxic compounds or elements that can be adsorbed by adsorbent filters. A combination of high efficiency particulate air (HEPA) prefilters and carbon absorption beds may be used.

- Gas flow: Blowers move the flue gas through the offgas train.

- NOx removal: The filtered gas is treated to remove NOx as required by emission standards and discharge permits.

- Emergency relief: The emergency relief is located at a strategic location in the offgas system and prevents potential over-pressurization in the offgas line. It also operates in the event of a process upset. The emergency relief could result in releasing partially treated gas to the environment; therefore, a high-temperature HEPA filtration device followed by a surge tank is provided downstream of the emergency relief point. Any untreated gas is collected for reprocessing.

- Liquid residues: Liquid residues from the offgas unit operation are collected and conveyed to other unit operations for treatment. 
- Monitoring: Gas effluent is sampled and monitored for radioactivity and other hazardous characteristics as required by the facility permits.

\subsubsection{Melter Feed Preparation.}

- Unit operation functions summary: The melter feed preparation receives, stores, prepares the incoming waste streams into a proper size and mixture, and feeds at a rate that is required for the melter unit operation.

- Allocated functiors: Unit operation functions are allocated to the following subfunctions:

- Controlled environment: Operation and maintenance are accomplished remotely in a controlled environment as discussed above in Section 5.1.3.3.

- Crushing: The larger waste pieces (e.g., cemented sludge, concrete, brick, rejected slag) are reduced in size by crushing.

- Shredder: After crushing, the waste is further reduced in size to facilitate more rapid and complete vitrification.

- Ash cooling and transportation: Ash is collected from the incinerator discharge, cooled, and transported to the surge storage container.

- Waste surge storage: Waste and ash is stored in a storage container that is sized to provide the required melter feed surge capacity. The surge-storage container is equipped for ash sampling.

- Waste feeder: The feeder conveys the waste to the melter at the desired feed rate.

- Additive soil bulk storage and transfer: Soil is stored in piles and transferred to the soil surge storage unit as needed. Bulk storage capacity and transfer rate are sufficient to support the system availability requirements.

- Liquid residue feed: Liquid residue from the liquid waste treatment unit operation is fed to the melter.

- Soil surge storage: Soil transferred from the bulk storage area is stored in a container with sufficient capacity to meet the melter feed surge-capacity needs.

- Soil feeder: The feeder conveys the soil to the melter at the desired feed rate.

\subsubsection{Melting.}

- Unit operation function summary: The melter performs the following functions:

- Thermal destruction of combustible solids, gases, and volatile liquids. 
- Melting of the inert feed material including inorganic sludges, solids and ash from the incinerator, liquid residues from the liquid waste treatment unit operation, and an additive soil. The melter converts the feed material into a homogenous molten slag. The slag is discharged to the next unit operation where it is molded into ingots, cooled, and annealed. Melt chemistry may also allow for separations of clean "reduced" metals.

- Allocated functions: Unit operation functions are allocated to the following subfunctions:

- Controlled environment: Operation and maintenance are accomplished remotely in a controlled environment as described above in Section 5.1.3.3.

- Melter: The melter uses high-temperature (generally about $3000^{\circ} \mathrm{F}$ ) thermal slagging or vitrification processes to treat the feed material, which includes a wide variety of wastes such as solids, liquids, metals, sludges, or soils. The melter produces a glassy slag that, when cooled, forms a glass-, ceramic-, or rock-like material that is leach resistant and suitable for long-term storage or disposal. Various melters, such as electric arc, plasma torch, or joule melter designs, may be used. The secondary waste from the melter is a flue gas that requires further treatment at high temperatures with a sufficient residence time for destruction.

- Secondary combuster or retention chamber: Flue gas from the melter is treated by a high temperature $\left(2000^{\circ}-2500^{\circ} \mathrm{F}\right)$ combusting unit if needed. The gases remain at the high temperature chamber for a minimum of 2 seconds.

- Melter cooling: The melter jacket is cooled by air, gas, or water, if needed.

5.1.3.9 Metter Offgas. The melter offgas description is the same as the incinerator offgas described in Section 5.1.3.6.

\subsubsection{Lquid Waste Treatment.}

- Unit operation functions summary. The unit operation receives, stores, treats, and disposes of the radioactive, hazardous, and mixed liquid waste generated at the facility. The treatment removes dissolved and suspended organic and inorganic material. Treated liquid waste is sampled and reused. Treatment byproduct residues are sent to another unit operation for further treatment and disposal.

- Allocated functions: Unit operation functions are allocated to the following subfunctions:

- Controlled environment: Operation and maintenance are accomplished remotely in a controlled environment as discussed in Section 5.1.3.3.

- Incoming liquid waste collection: Incoming liquid waste is collected in tanks with sufficient storage capacity to meet the system availability requirements. 
- Solids precipitation: Impurities in the waste water are precipitated by chemical agents that promote precipitation of suspended and dissolved solids.

- Solids removal: Effluent from the solids precipitation unit is processed in a filtration unit.

- Organics removal: Effluent from the filter is passed through an organics removal device. Carbon filters or coalesers may be used for this function.

- Ion exchange: Effluent from the organics removal unit is processed through an ionexchange unit. The unit removes the remaining impurities and ensures that the effluent is in compliance with the discharge criteria.

- Sampling tank: The treated liquid from the ion-exchange unit is collected in a tank to allow sampling and analysis before the waste is reused.

- Sludge tank: Wet solids and sludge from the filtration, organics removal, and ionexchange units are collected in a sludge tank. The sludge tank contents are pumped to the melter feed preparation unit operation.

\subsubsection{Slag Cooling and Packaging.}

- Unit operation functions summary: The unit operation molds, cools, packages, and tests the molten slag discharged from the melter. After packaging, the waste container is cleaned (to remove any surface contamination) and sent to an assay/certification unit operation.

- Allocated functions: Unit operation functions are allocated to the following subfunctions:

- Controlled environment: Operation and maintenance are accomplished remotely in a controlled environment as discussed in Section 5.1.3.3.

- Ingot mold: The molten slag is poured into an ingot mold.

- Cooling/annealing: The ingot is cooled at a prespecified rate required for the annealing process and is set aside to allow complete cooling.

- Packaging: The cooled slag is containerized and packaged in accordance with disposal site requirements.

- Cleaning: The packaged waste is smear tested and, if needed, is cleaned to remove any loose exterior contamination. The liquid waste from the container wash-down operation is sent to the liquid waste-treatment unit operation. 


\subsubsection{Assay/Certification.}

- Unit operation functions summary. The assay/certification unit operation determines radioactive, physical, and chemical properties and parameters that are needed to classify and certify that the waste package is in compliance with transportation and disposal regulations.

- Allocated functions: Unit operation functions are allocated to the following subfunctions:

Alpha radio-assay: Packaged waste (i.e., filled waste containers meeting the ultimate waste form requirements) is examined by alpha radio-assay devices to allow alpha radiation classification of waste in accordance with the DOT, DOE, and NRC transportation and disposal requirements. Various devices, such as passive neutron counting instruments, may be used.

- Gamma radio-assay: Packaged waste is examined by gamma radio-assay devices to allow gamma emitting radionuclide classification of waste in accordance with DOT, DOE, and NRC transportation and disposal requirements. Various devices, such as gamma spectroscopy instruments, may be used.

- Exterior surface contamination assay: The containers are smear tested to determine the extent of any exterior contamination. If a container surface is contaminated, it is decontaminated with water.

- Weighing and measuring: Containers are weighed and measured to determine waste density.

- Nondestructive physical examination: The contents of each container are determined by nondestructive examinations (NDES). At a minimum, each container is examined by an ultrasonic device. Rejected slag is returned to the melter feed preparation unit operation for remelting.

- Labeling, logging, and recording: Examination and assay data are logged and recorded. Using the assay data, containers are first classified either as LLW or TRU waste. LLW containers are further classified according to DOT and NRC requirements and are certified as such. Containers classified as TRU are transported to the TRU storage area.

\subsubsection{Interim Storage and Shipping.}

- Unit operation functions summary: The unit operation loads the containers into shipping vehicles, places packaged containers in the storage area, provides surge storage for the outgoing containers, moves containers within the shipping and storage areas, and transfers containers to and from the various interfacing unit operations. The unit operation can interface with a shipping vehicle equipped with a radiation overpack. 
- Allocated functions: Unit operation functions are allocated to the following subfunctions:

- Shipping: A shipping vehicle (with an overpack, if needed) is used to ship containers from the facility to long-term storage and disposal facilities. Providing this vehicle is outside the scope of this study and will be by others.

- Container transfer: A container handling device loads the containers into the vehicle or within the storage areas, as needed. The container handling device also transfers the containers from the packaging area to the assay/certification unit operation and from there to the storage area.

- Interim storage: Containers are loaded into shipping vehicles in an enclosed truck bay. An indoor staging area with sufficient space to allow maneuvering of the containers and with sufficient interim storage capacity is provided.

\subsubsection{System Boundaries}

5.1.4.1 Physical Boundaries. The physical boundaries of the system include the following:

- The facility required for the system is located on a 5-acre site with its boundary defined by a site perimeter fence.

- The loading dock is the boundary for the input waste streams.

- The shipping dock is the boundary for the output streams from the facility. Output streams consist of packaged alpha-LLW or LLW shipments to disposal facilities, nonradioactive solid waste shipments to municipal disposal facilities, and nonradioactive chemical-hazardous waste to offsite chemical disposal facilities.

5.1.4.2 Utilities. The system requires services from the water system and electrical power supply. The system utility boundaries include the following:

- Service water shut-off valves located at the site fence.

- A 4-kV power supply pole located at the fence. Other utilities, such as service air and emergency power, are a part of the system.

- A natural gas shut-off valve/meter located at the site fence.

5.1.4.3 Environment. The system has the following physical interface with the environment:

- Incinerator and melter-offgas discharge stack.

- Building ventilation-system discharge duct.

- Treated liquid-waste evaporation pond. 
- Sanitary drain field.

\subsubsection{System Specific Assumptions}

The following system-specific assumptions have been made.

- Soil Additive: The vitrification process requires a $40 \%$ by weight soil additive. The density of the vitreous waste is assumed to be $187 \mathrm{lbs} / \mathrm{ft}^{3}$.

- Equipment: For energy and cost-scoping purposes, a plasma arc melter and a rotary kiln incinerator were selected for this processing system. This selection does not mean that these technologies are necessarily preferred.

- Waste characterization: The mass and composition of the input waste stream was based on the characterization of the waste at the TSA (see Appendix A).

- Mass flow rates: A summary of the estimated mass flow rates for the system is shown in Figure 10.

- The offgas from the incinerator is cooled, filtered, and processed through an offgas treatment system. The offgas system can handle radionuclides, particulate, and other air pollutants.

- Unit operation capacities: The unit operation c nacities are at least $125 \%$ of the design flow rates, based on the mass of waste that $m+$ be processed over a 10-year period. Because of the low input feed rate, the unit op i ion estimated capacities are sometimes larger than the required size. This is especially , se for the incineration and melting units.

- Key unit operation energy requirements:

- Incinerator: The energy requirements are based on the energy required to operate an incinerator with a mass flow rate as shown on process functional diagram. The energy requirement is approximately $40 \mathrm{~kW}$ for electrical power and $41 \mathrm{lb} / \mathrm{hr}$ for propane consumption.

- Melting furnace: The energy requirements, based on the necessary energy required to operate a melter with a mass flow rate shown on the process functional diagram, is estimated to be approximately $1000 \mathrm{~kW}$.

- Offgas system: Offgas system energy requirements are estimated approximately $93 \mathrm{~kW}$ for the incinerator and $30 \mathrm{~kW}$ for the melter.

- The preconceptual design for the process cells handling opened containers is based on a conservative assumption that errors in alpha radiation measurement will result in the processing of waste with higher than $100 \mathrm{nCi} / g m$ TRU content. 


\subsubsection{Facility Description}

A scoping-study layout for the system is shown in Figure 12. A single building houses the system, and incoming waste is unloaded at the truck bay in front of the building. A large open area adjacent to the truck bay is used for container staging, storage, and inspection and assay operations. From the open area, the containers are moved to the processing cells located in the center of the building.

Three parallel process cells are perpendicular to an open, dump, and sort cell with pipelines and conveyors passing over and under the operations and maintenance aisles. Each process cell is arranged with glass windows at the front so an operator is able to view the operations. The rear of each process cell joins a maintenance and decontamination cell. Work on equipment requiring repair or upkeep is accomplished by pulling out the equipment from the process cell and performing repair in the maintenance cell. The maintenance and decontamination cells are accessible through airlocks and have a confinement-barrier level commensurate with the hazards level established by the design criteria.

\subsubsection{Interface Requirements}

Following are the interface requirements for the overall system (see Section 8 for the metal sizing and decon subsystem). The flow rate values for the input, output, and intermediate points are given in the process functional diagram, Figure 10.

5.1.7.1 System Output. The system interface outputs include:

- LLW and alpha-LLW packages (from vitrification and metal decontamination operations) to a long-term storage or disposal facility.

- $\quad$ Exhaust gases from the stack discharged to atmosphere.

- Sanitary waste discharged to drainage field.

5.1.7.2 Input from Other Systems. System interface inputs include:

- Alpha-LLW from SWEPP and storage modules.

- Utilities including service water, normal and emergency power, natural gas, and communications.

- Consumables including personnel protective equipment, laboratory material, solidification materials, packaging materials, and disposable and reusable shipping containers.

5.1.7.3 Miscellaneous Systems. The system interfaces with the site communication and alarm systems including telephone, evacuation, fire, security alarm, and public address systems. The process automatically shuts down if the fire system or the evacuation alarm are activated. 


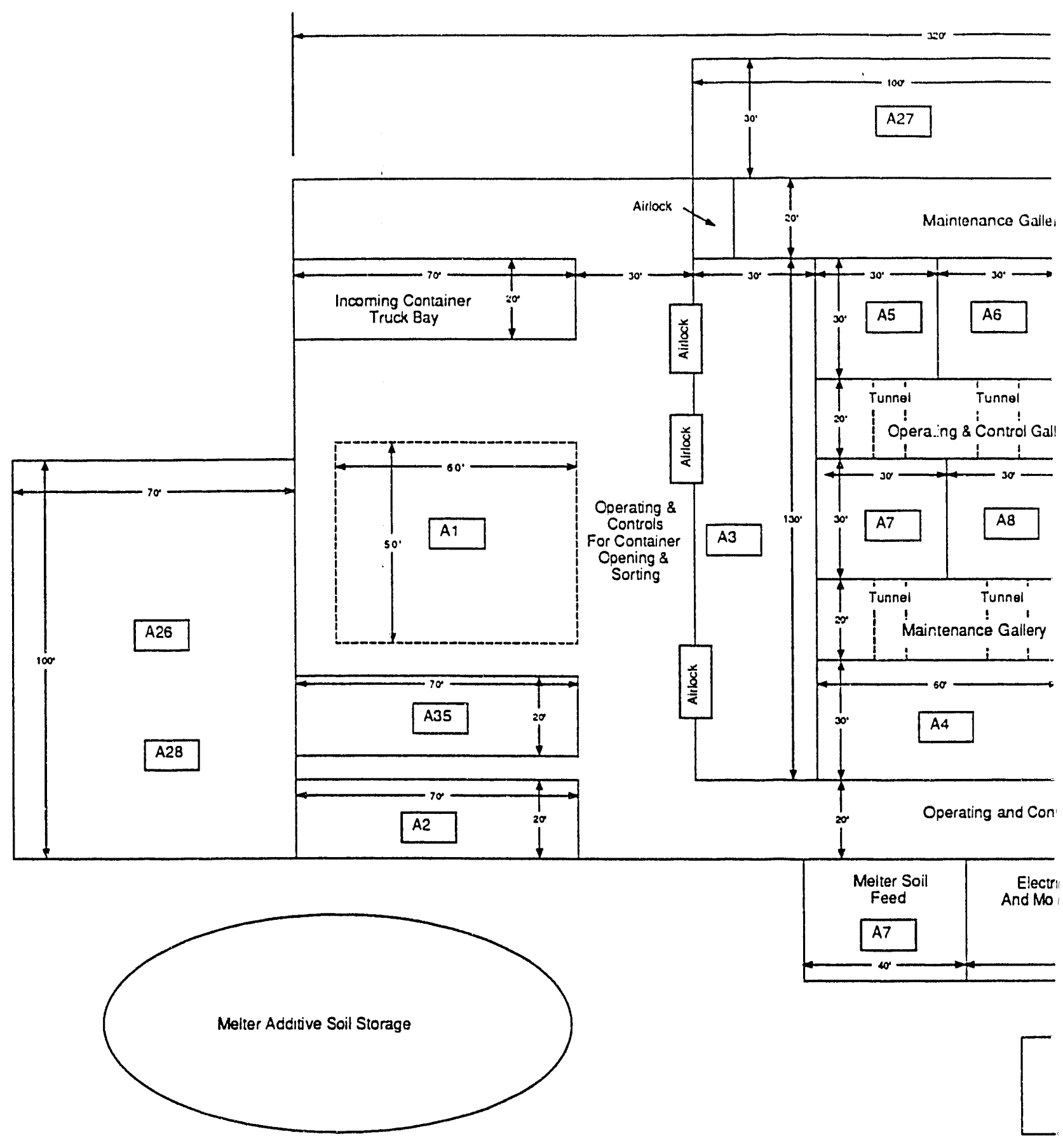

Figure 12. General arrangements for the incineration/melting system. 


\subsection{System Assessment}

This section presents an assessment of available system technologies based on the subjective judgment and knowledge of the authors. Additional technology evaluations are needed before the final selection of components and to identify detailed development and demonstration needs for selected technologies. Specifically, this section discusses the development level of some of the key unit operations and typical technologies available for performing the required functions. A qualitative assessment of the risks associated with the ability to achieve the required functions is given based on current knowledge and limitations of the available technologies. The strengths and weaknesses of the unit operations are also noted.

\subsubsection{Evaluation of Unit Operation Technologies}

To accomplish the functions specified for the unit operations, several unique devices, components, and processes are needed. These devices, components, and processes are identified and assessed in this section. Each unit-operation is evaluated individually to assess the overall feasibility of the system and identify areas requiring focused attention. The details of the evaluation are presented below while the assessment is summarized in Table 4.

5.2.1.1 Unloading and Staging. The function of this unit operation is to unload containers from transportation vehicles and transport them within the facility. These functions can be performed by standard handling equipment such as bridge or jib cranes and forklifts. Therefore, there are no unique technology acquisition requirements for this unit operation.

5.2.1.2 Inspect/Assay. The function of this unit operation is to categorize waste containers to determine their gamma and alpha radioactivity and physical properties and parameters. An evaluation of the various subfunctions in this unit operation is presented below.

- Alpha radio-assay: Alpha radio-assay is the most critical measurement in the system because it provides the data that determines whether the waste is $\mathrm{LLW}$ ( $<10 \mathrm{nCi} / \mathrm{gm}$ ), alpha-LLW ( $>10 \mathrm{nCi} / \mathrm{gm}$ and $<100 \mathrm{nCi} / \mathrm{gm}$ ), or TRU ( $>100 \mathrm{nCi} / \mathrm{gm})$. This waste classification is used for two purposes: to verify the level of TRU activity before processing operations and to comply with disposal requirements and regulations. The preconceptual design for process cells handling opened containers is based on a conservative assumption that errors in alpha radiation measurement could result in the processing of waste with a higher than $100 \mathrm{nCi} / \mathrm{gm}$ TRU element content.

Currently, several DOE sites use a waste classification technology based on a combined passive and active neutron approach developed by Los Alamos National Laboratory. This assay technique has been used since 1987 to assay drums of TRU waste, and to a lesser extent, boxes of waste. Two major DOE sites that routinely use the technique are the INEL and the Rocky Flats Plant. The INEL (SWEPP) facility uses the assay system to determine the fissile content of drums and classify the waste as LLW or TRU. It is also used to certify waste to the WIPP WAC. The Rocky Flats Plant assays both drums and boxes for fissile content. Measurement accuracy and long counting times can be a problem 


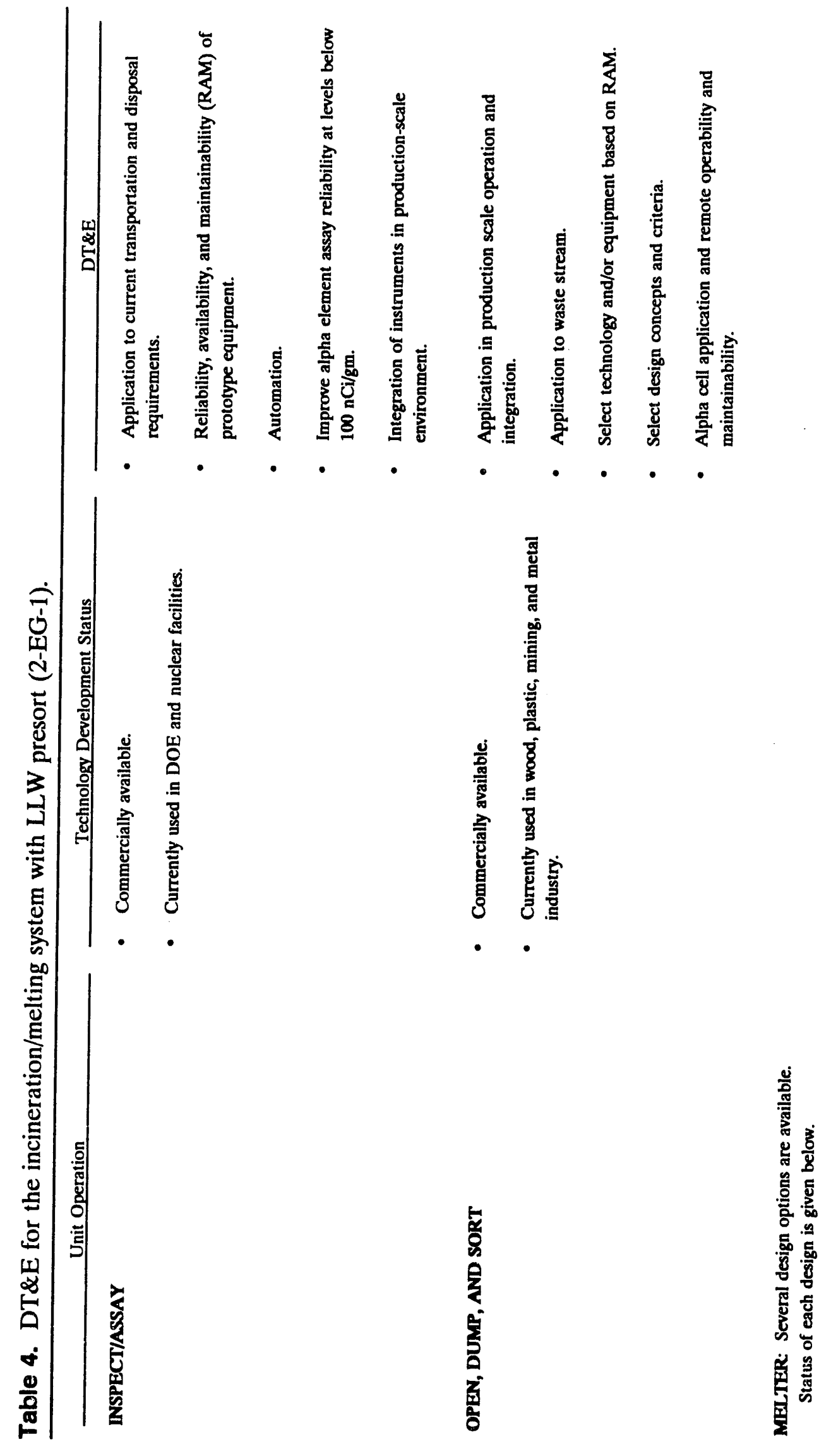




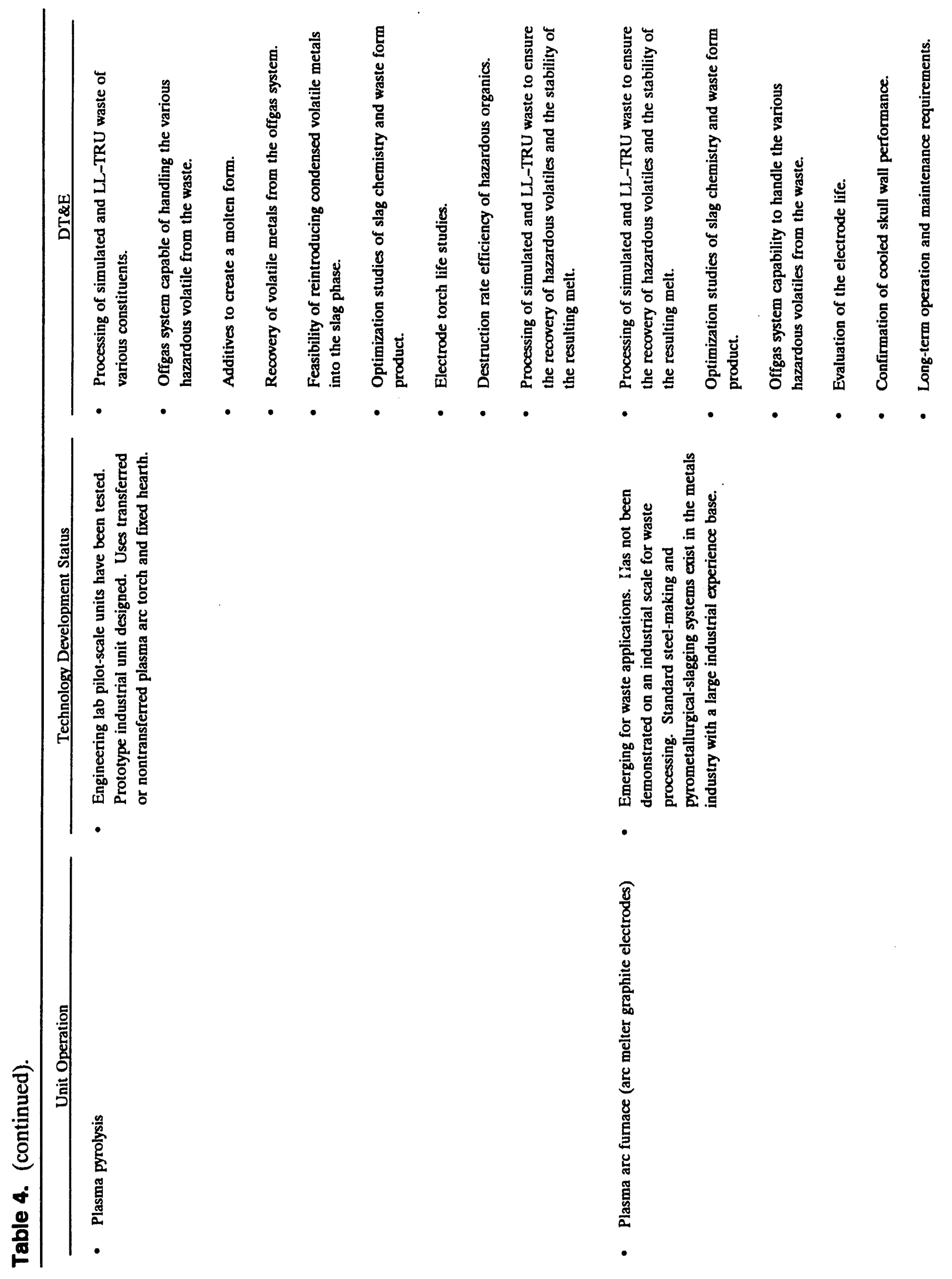




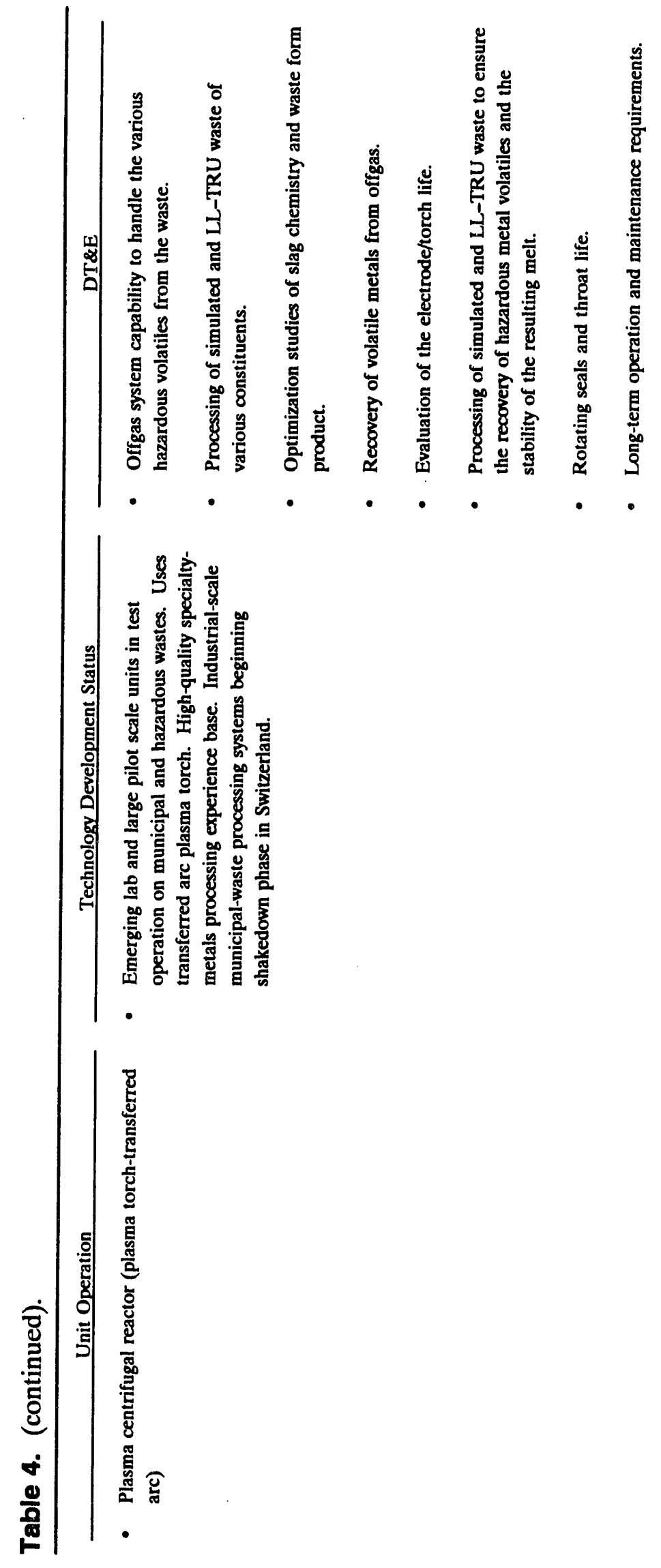




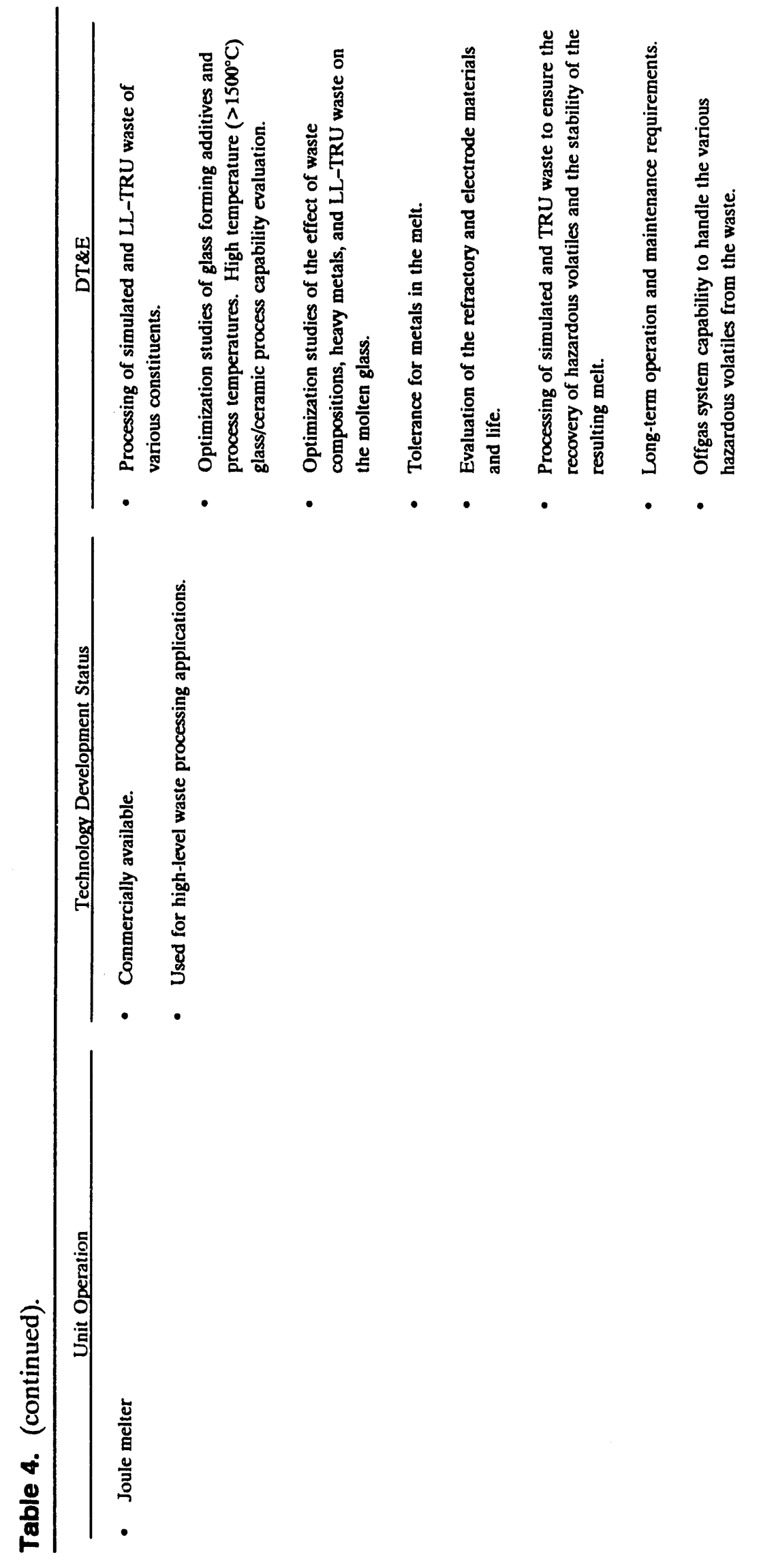




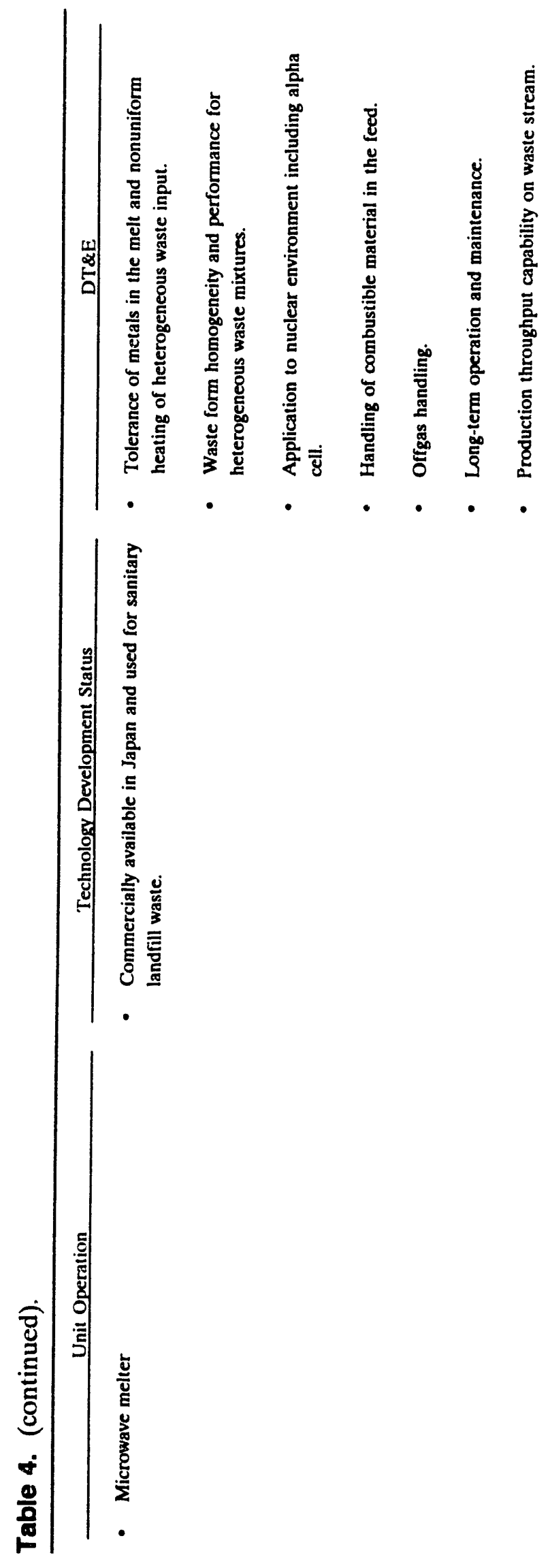




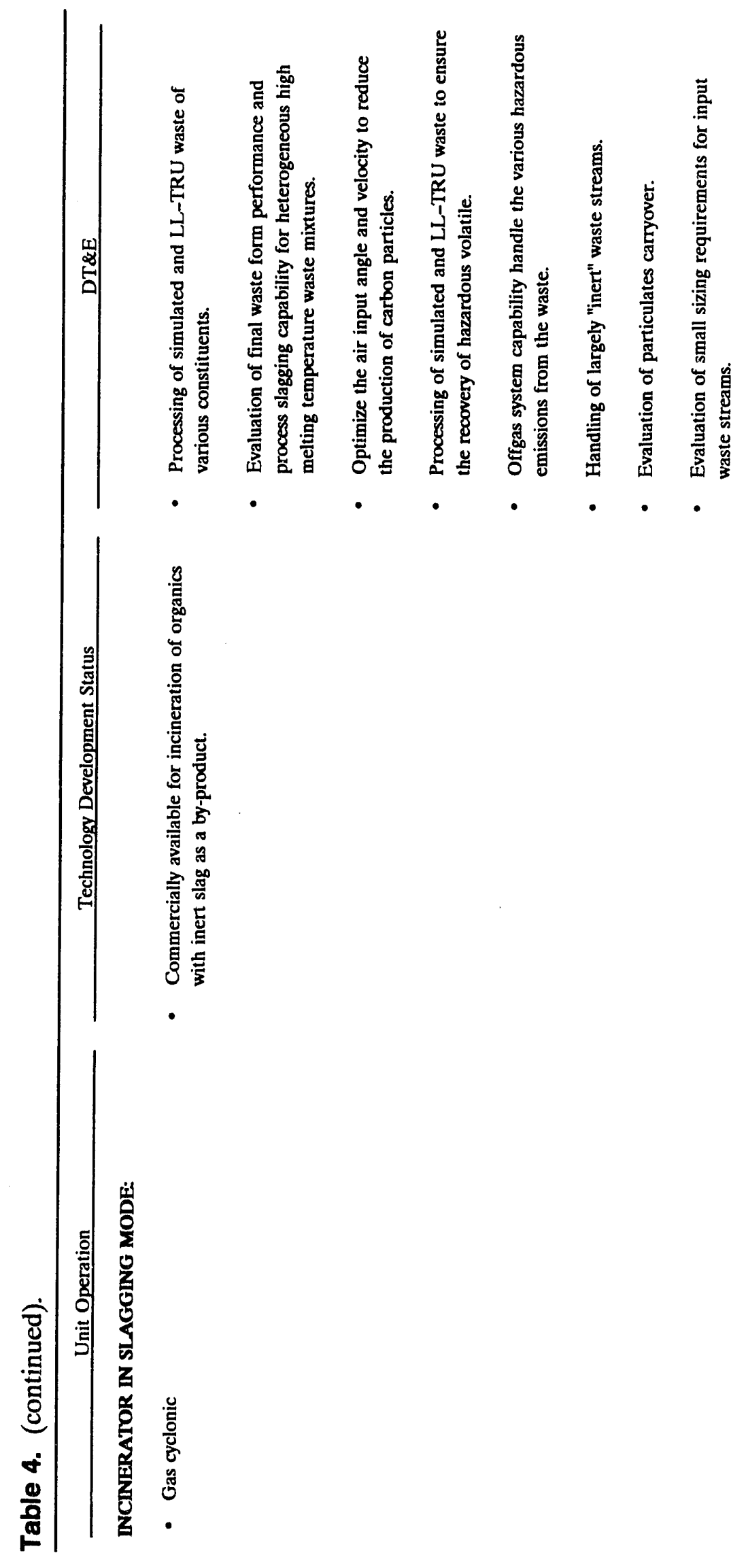




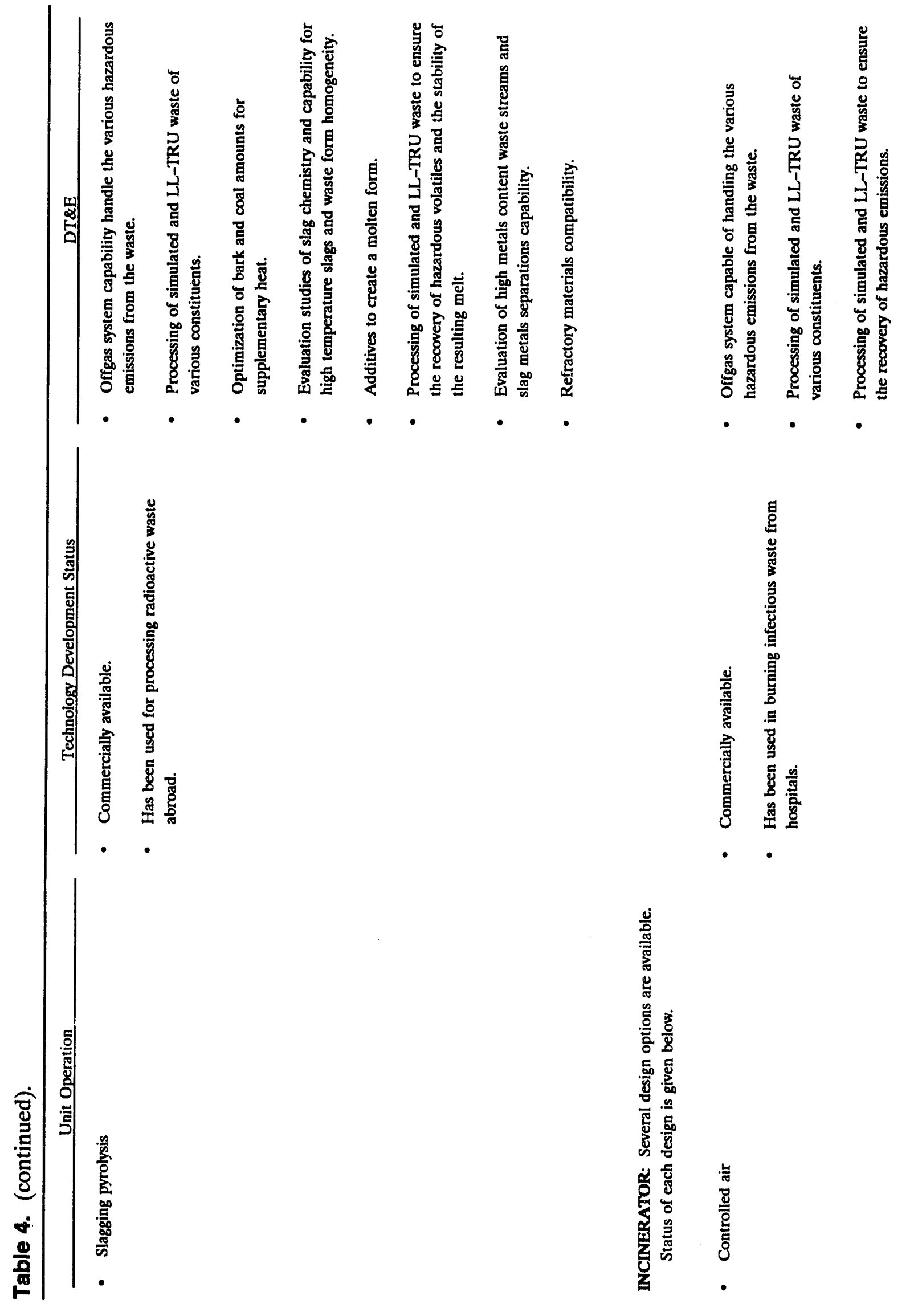




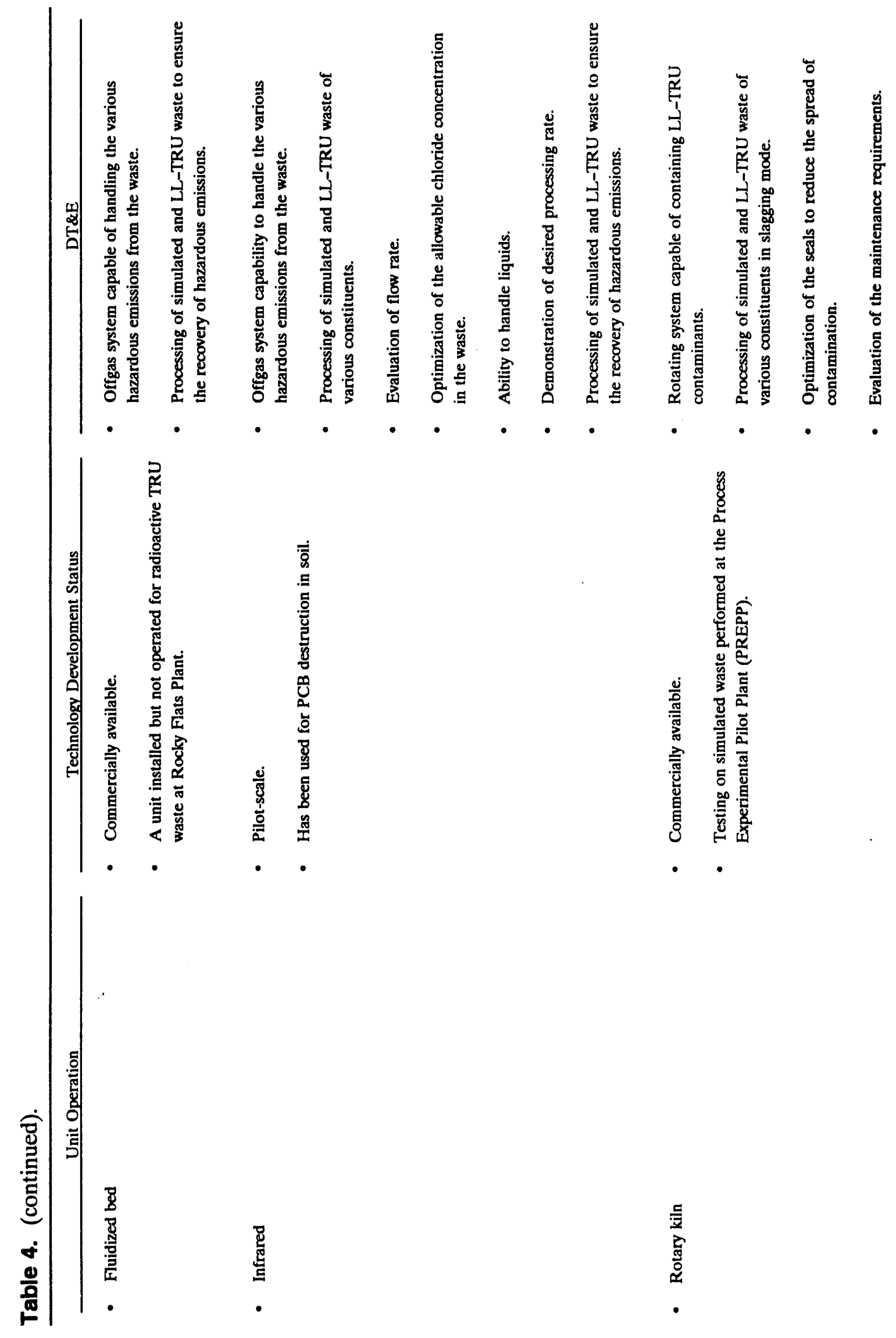




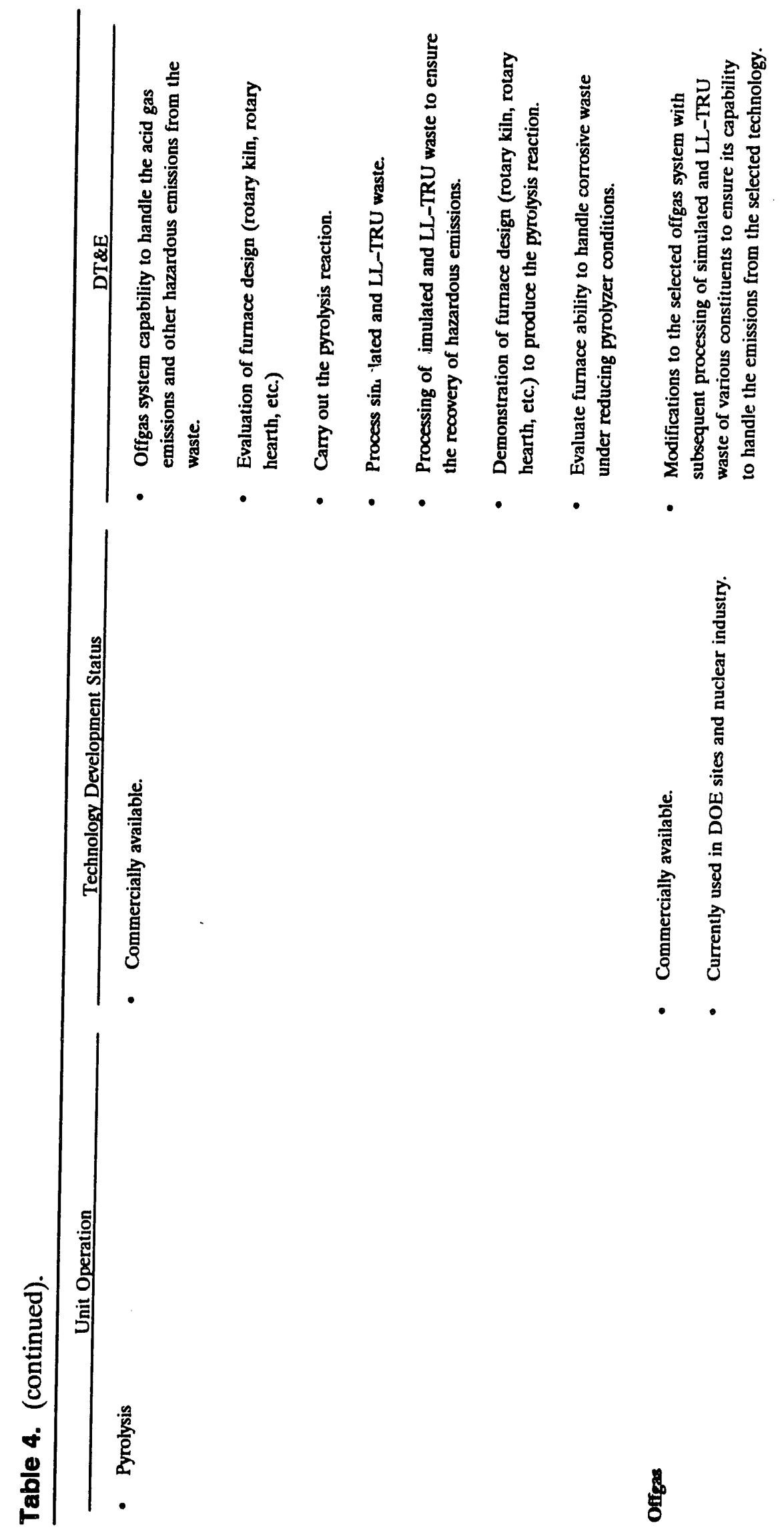




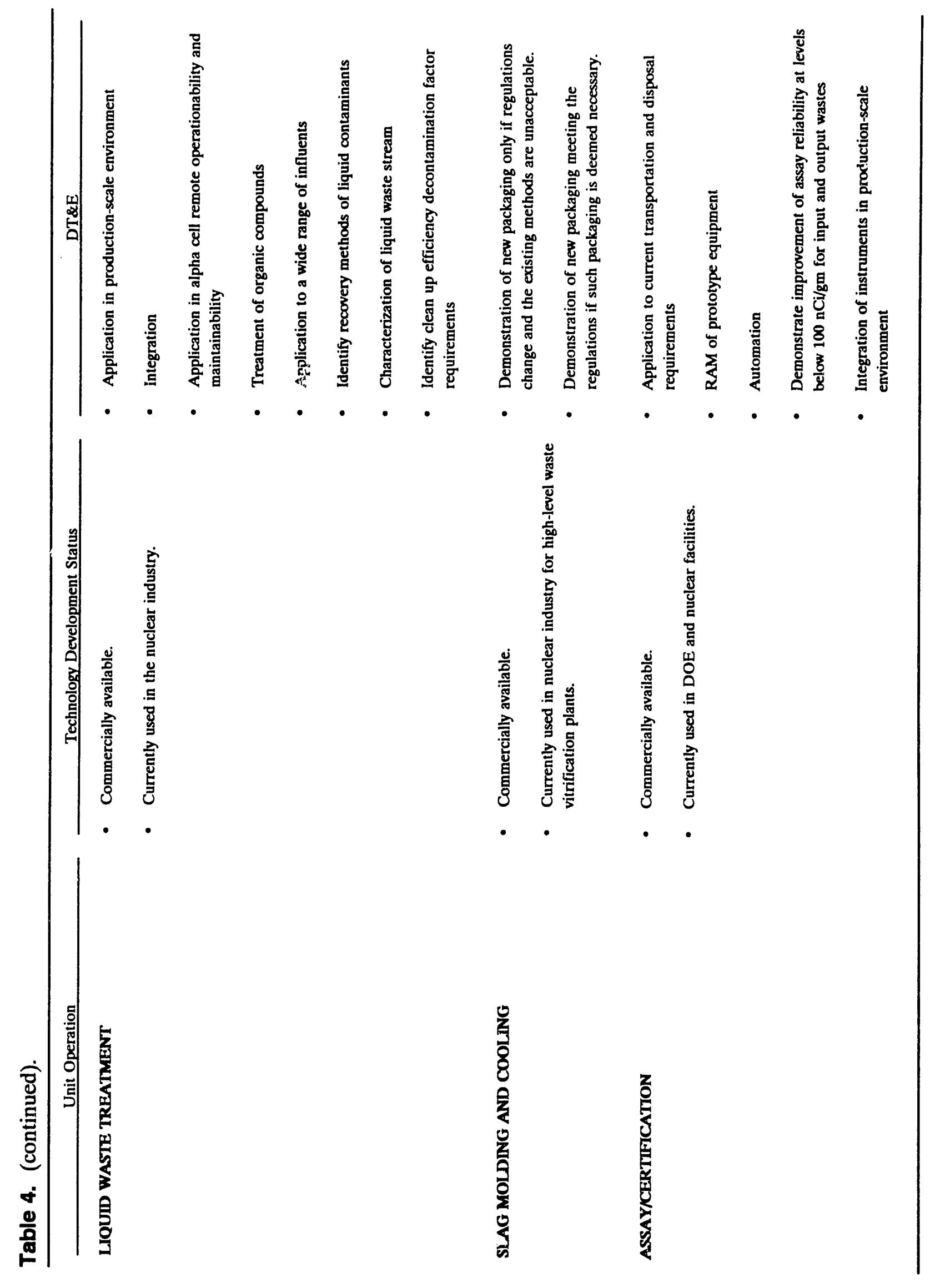


for TRU contamination below $100 \mathrm{nCi} / \mathrm{g}$. DT\&E efforts are needed to improve the process to support production rates and to improve the instrument's measurement sensitivity.

- Gamma radio-assay: Gamma scanning devices, such as gamma spectroscopy instruments, are well-developed technologies.

- Weighing and measuring: Weight and dimension measurement instruments, such as load cells and laser beams, are well developed and are commonly used in the industry.

- Non-destructive physical examination: NDE and testing is used to identify waste material such as bulk metals, liquids, and compressed gas cylinders that require special segregation and treatment. Currently, NDE is successfully conducted at the SWEPP using a real time radiography (RTR) device. Therefore, DT\&E is not required for the NDE function.

- Label, log and record: These functions can be performed using existing computerized database programs.

5.2.1.3 Open, Dump, and Sort. The function of this unit operation is to receive waste containers (drums, boxes, and metal bins), remove their caps, and dump their contents either on sorting devices or on transport devices, which carry the waste to the next unit operations. The unit operation's sorting functions are to sort bulk metals, combustibles, noncombustibles, and gas cylinders. The unit operation also reduces the size of empty, nonmetallic containers.

The container decapping, transfer, and dumping functions can be performed by standard industrial equipment with minor design modifications for remote operations and maintenance. However, sorting waste to the extent used in this system is considered unique because it is not widely practiced in other industries. This function may require DT\&E to optimize the process. Some of the remote dumping, sorting, and other materials handling operations can be performed using through-the-wall master/slave manipulators or floor and crane mounted robots. These techniques are widely used among various industries and only application engineering efforts are needed for their use in alpha-cell environment. Sorting of ferrous metals from nonmetals could be done remotely by magnetic separation and manipulators. Several of these magnetic devices are available and include magnetic-head pulleys, suspended magnets, magnetic drums, and plate magnets. To facilitate removal, the nonmagnetic metallic portion of the waste could be artificially magnetized by electrically produced currents.

The combustible and noncombustible wastes can be separated by visual inspection, density equipment, and air classification equipment. Visual inspection is performed by operators who use manipulators to segregate the waste. Density equipment using gravity to separate the combustible (less dense) waste from the noncombustible (more dense) waste may also be used if fine segregation is needed. Available density devices to separate waste include the cyclone separator, dense-media cone separator, revolving-drum type dense media separator, and the drag-tank separator. Most of these units are commercially available and have been proven in metallurgical processes.

Although many of the individual components used for open, dump, and sort functions are available commercially and have been proven industrially, they have not been used in a radioactive 
or an alpha cell environment. Therefore, most of the devices will be a first-of-a-kind application in an alpha cell environment, and special machine and tool design combined with DT\&E efforts is needed to resolve problems associated with remote operability, ease of decontamination, and alpha cell maintenance (i.e., by personnel suited in personnel protective equipment).

5.2.1.4 Incinerator Feed Preparation. This unit operation size reduces the incoming waste streams and feeds them into the incinerator. These functions can be performed by shredders, crushers, ball/roller mills and other material handling techniques used in the plastic, wood, metal, and mining industries. Shredders are available commercially and have proven to be feasible in a wide variety of applications. Cryofracture is a relatively new process that has been used in processing defense waste. Cryofracture would require development and demonstration on sample waste streams.

A variety of crushers have been used commercially for many years. Various industries, including mineral ore sizing and particulate sizing, have used such equipment for all types of minerals. Available crusher-type equipment includes jaws, gyrators, cones, pans, rolls, rotaries, anu hammer types. Pulverizers such as balls, ring rollers, hammers, disks, and fluid energy mills are readily available. Selection is a function of the desired feed size, hardness, and reduction ratio. Since most of this equipment can be operated closed circuit, modification for radioactive or alpha confinement is expected to require only engineering and demonstration.

Shredders of the counter rotation type are installed at the Savannah River Site and were previously installed in the INEL Process Experimental Pilot Plant (PREPP) facility. The PREPP used simulated TRU wastes to test a shredder feed that was prepared for an incineration/ solidification process. A shredder/compactor also exists at the Tennessee Valley Authority-Watts Bar Nuclear Plant. Other technologies also exist, such as the screw-type auger shredder (manufactured by KOMAR), which was tested at PREPP. In general, large shredders have been successfully demonstrated commercially and at municipal waste treatment plants.

Hardened steels and large pieces of material are difficult to shred. To eliminate this problem, metals will be separated from the waste and sent to a metal sizing and decontamination unit. It is anticipated that shredder maintenance in alpha-LLW processing may present some difficulties, but removal of metals from the waste should minimize maintenance. These are primarily engineering challenges that must be combined with DT\&E to place shredders into TRU waste processing.

In conclusion, most of the equipment is a first-of-a-kind application in an alpha cell environment; therefore, special machine and tool design combined with DT\&E efforts is required. Areas requiring focused attention are remote operability, ease of decontamination, and alpha cell mainınance (i.e., by using remote manipulator systems or personnel dressed in personnel protective equipment).

5.2.1.5 Incineration/Melter Process Flow Sheet. A critical design decision is the selection of an incinerator/melter process. The following processing options are available:

- Option A - Combined waste stream with a single thermal unit operation: This option would be used if it can be proven that both the incineration and slagging processes can be effectively executed in a single thermal unit operation. Combustible and noncombustible waste streams are combined and fed to the thermal vessel, and the vessel destroys the 
combustibles while converting the noncombustibles into a molten slag. The advantage of this appruach is that it minimizes waste sorting operations, and only single thermal process, feed preparation, and offgas units are needed. The disadvantages are the potential for incomplete combustion of the incoming waste and the difficulty of controlling the thermal and offgas treatment processes to ensure production of the desired final waste form material.

- Option B - Combined waste stream with cascading thermal vessels: This option combines combustible and noncombustible materials in a single waste stream that is fed to a closecoupled cascading incineration and melting train. Soil is also added at the incinerator inlet. The incinerator burns all combustible material while the additive soil passes through along with any other noncombustible material introduced at its inlet. Solids from the incinerator fall directly to the melter inlet that is located underneath the incinerator solids discharge port. The advantages of this option are that it minimizes the sorting operation and eliminates the ash cooling and the melter preparation and feed units. A disadvantage of this option is the complexity of controlling the thermal process in a closely coupled twovessel configuration. Another key disadvantage is that the melter and incinerator operations and controls: are interdependent and a failure in one unit can shut down the entire operation. Ancther disadvantage is more complex process control is required to ensure the quality of the vitrified final waste form.

- Option C - Fine-sorted waste stream with dual-thermal vessels: This option would be used only if the selected incinerator design cannot accept a high percentage (approximately greater than 5\%) of noncombustibles in its feed. Therefore, use of this option will require a fine-sorting device to separate noncombustibles from the combustibles with a relatively high degree of accuracy. After fine separation, the combustible waste stream is fed to a dedicated combustible material incinerator. The ash from the incinerator, along with additive soil and the noncombustibles waste stream, is fed to the melter. The advantage of this option is that it completely incinerates the combustibles and provides the capability to independently control the incineration and melting processes and the related offgas systems. This option also allows quality control of the vitrified waste. The disadvantages of this option are that it requires a complex set of components to execute the finesorting functions, and two thermal processing units and related feed preparation and offgas treatment units will be required.

- Option D - Rough-sorted waste stream with dual vessels: A key feature of this option is that it uses an incinerator (such as rotary-kiln) that can accept feed material containing a large percentage of noncombustibles (inerts) such as soil, glass, concrete, and small pieces of metals. If this option is used, only a coarse-sorting operation is needed. Any waste material suspected of containing combustibles can be fed directly to the incinerator; the combustibles burn while the noncombustibles pass through the unit and are discharged with the ash. The discharged solids must be cooled and ihen can be sampled to determine the correct additive soil formula. The incinerator solids can be combined with any other waste that is free of combustible material, mixed with additive soil, and fed to the melter vessel. The advantage of this option is that it minimizes the sorting operation, allows for complete incineration of combustibles, and provides the capability to control the incineration and melting processes and the related offgas systems. This option also 
provides capabilities to exert quality control of the waste form characteristics. A disadvantage of this option is that two different thermal processing units and related feed prepara'ion and offgas treatment units are needed.

Option $\mathrm{D}$ has been selected to facilitate the development of a preconceptual design package required by this study. This does not mean that the other options should be eliminated from further consideration. If options $A$ and $B$ prove feasible, they may result in a significant reduction of space, equipment, and waste handling steps. Therefore, it is recommended that further detailed investigations be conducted to establish a process flow sheet design for the melter/incinerator portion of the overall system.

5.2.1.6 Incineration Equipment. Incineration is a highly developed process in the hazardous waste industry. Additionally, over 80 radioactive waste incinerators have operated since 1949 . Los Alamos National Laboratory has demonstrated a controlled-air incinerator for reducing TRU-waste volume since 1976. Other LLW incinerators have been demonstrated at the Waste Experimental Reduction Facility (WERF) at the INEL, the K-25 facility at Oak Ridge National Laboratory (ORNL), and the Scientific Ecology Group (SEG) at Oak Ridge. Incinerators to reduce radioactive waste volume are used extensively in Europe and Japan. The Japanese have at least 18 operating radioactive waste incinerators.

Incinerator design and offgas and ash handling systems are influenced by both the combustible and noncombustible fractions of the feed. Waste compositions similar to alpha-LLW have been treated in municipal solid waste applications. No radioactive waste incinerator has been tested using the stored alpha-LLW mixture. Other technologies are the fluidized bed incinerators, used extensively at commercial facilities; pyrolysis units, used in other countries but not applied at DOE facilities; and the rotary kiln, which is commonly used in commercial applications and is particularly suited for large bulk, unsorted wastes. An experimental rotary kiln incinerator was installed at the INEL's PREPP. Thermal incinerator based treatment systems need DT\&E to demonstrate integrated performance of supporting systems such as feed prep and seal technology. An assessment of the various incinerator types are presented in Reference 5.

5.2.1.7 Incinerator Offgas. This unit operation treats the discharged gas to meet emission standards and requirements. The treated gas is monitored and released to the atmosphere. Liquid and solid residues are coliected and transferred to other unit operations for treatment and disposal.

Almost all the radioactive waste incinerators worldwide are equipped with offgas treatment systems to control release of radioactive or other hazardous material emissions, including radionuclides. Choice of an offgas system is determined by the amount and type of particulate and halogenated plastics in the feed material. Historically, wet offgas systems have been used, but newer applications are using dry scrubbing techniques. Dry systems employ sintered metal filters, HEPA filtration, and cooling dilution air. Offgas systems, with the HEPA filters employed for radioactive applications, have been demonstrated on a large scale. Radioactive waste incinerators use HEPA filters for final treatment, while HEPA filters are not commonly used on hazardous waste systems. Additionally, the INEL waste combination, which includes alkali sludges and chlorinated wastes, is unique. Factors such as these require careful design of the offgas system to remove acid gases and trap fine particulate. 
One offgas system that appears acceptable for both melting and incinerating offgases has been developed by Pacific Northwest Laboratories. This offgas system has handled radionuclides, particulate, and acids. Currently, this offgas system is being modified for use with the in situ vitrification (ISV) project testing at the INEL. A multistage offgas cleaning system will handle multiple volatile metals. The stages might consist of a first stage for volatile metal condensing, a second stage for metal fume recovery, and a third stage for acid gas correction, a wet or dry recovery system, and sludge or dust collection to cold stabilization.

Offgas treatment systems do not need significant DT\&E at this time; however, engineering development will be needed to identify an effective emission control technology for alpha-LLW incineration and melting processes. Improved handling to avoid or more efficiently treat secondary effluents could be necessary.

5.2.1.8 Melter Feed Preparation. The melter feed preparation functions are the same as the incinerator feed preparation. Therefore, evaluation results for the incinerator feed preparation also apply to this function.

5.2.1.9 Melting Equipment. This equipment melts the inert feed material which includes inorganic sludges, solids and ash from the incinerator, liquid residues from the liquid waste unit operations, and additive soil. It also thermally destroys any combustible or organic material that may be mixed with the incoming feed. The melter converts the feed material into a homogenous molten slag. The molten slag is discharged to the next unit operation where it is poured into molds, cooled, and annealed.

In general, the electrically heated arc, plasma, and Joule melter systems are preferred because of their low offgas levels and higher slagging temperature and mixing capabilities. Other systems involving fuel combustion are subject to major offgas treatment requirements and usually shorter residence times. The status of melting technologies considered for treating the INEL waste are discussed in Geimer ${ }^{5}$ and in more detail in Donaldson. ${ }^{6}$

Melter technology is generally well developed for industrial applications and has been tested for many decades. What has not been developed is the particular process to convert the incoming waste stream material within the quality constraints established for the product waste form. In this case, melter DT\&E efforts are similar to every other industrial process that is not a duplicate of an existing process and, hence, need to be developed (tailored) for the particular material to be processed.

5.2.1.10 Melter Offgas. Melter offgas evaluation is the same as the incinerator offgas evaluation in Section 5.2.1.7.

5.2.1.11 Liquid Waste Treatment. This unit operation receives, stores, treats, and disposes of the radioactive, hazardous, and mixed liquid waste generated at the facility. Treatment includes remuval of dissolved and suspended organic and inorganic material. These operations functions can be accomplished using existing radioactive and hazardous liquid waste treatment equipment such as precipitators, filters, carbon bed absorbers, evaporators, and demineralizers. All of these techniques are in operation to treat LLW in Spain, Japan, Taiwan, and U.S. nuclear power stations and have had many years of operation. Also, a process known as TRU/Clear (a proprietary process that removes TRU contamination) appears to be effective in eliminating alpha-emitting nuclide from aqueous 
solutions. This process results from research performed at LANL and is now exclusively licensed to the Analytical Development Corporation. Reverse osmosis has been used in some industrial applications, and high-level waste evaporators are used at the Hanford Site to solidify high-level tank wastes. Concentrating and solidifying low-level salt solutions using microwave heating has been demonstrated in Germany. Another technique demonstrated in the early 1980s by the Rockwell Energy Systems Group is the spray drying of baghouse effluents.

Radioactive-waste water treatment processes and equipment are well demonstrated. The TRU/Clear process continues to be demonstrated at Los Alamos National Laboratory (LANL) and at the West Valley Demonstration Project with good results. Although the aqueous wastes from the alpha-LLW process are different from those of nuclear power plants, the differences are not expected to impact concentration or treatment operations. Evaporators and crystallizers have been demonstrated up to $30 \mathrm{gal} / \mathrm{min}$ while the TRU/Clear process is being demonstrated on a small-scale plant basis. Depending on the process ultimately chosen, some further DT\&E may be needed to tailor these unit operations to the specific waste forms and chemistry involved.

5.2.1.12 Slag Molding, Annealing, and Packaging. Functions of this unit operation are molding, cooling, packaging, cleaning, and testing the molten slag after it is discharged from the melter. Equipment accomplishing similar functions are widely used in the metal and mining industries. However, most designs are maintenance prone and not useful for a radioactive environment. DOE's Hanford and Savannah River Sites have developed similar equipment for handling vitrified high-level waste. DT\&E is needed to combine the current DOE experience with those of the commercial industry and develop a maintenance-free slag handling system for the INEL. This effort should be performed in conjunction with the melter DT\&E.

5.2.1.13 Assay/Certification. Most functions of this unit operation are the same as the inspect/assay unit operation discussed in Section 5.2.1.2 and are subject to the same evaluations. The assay/certification has the added functions of container swiping and cleaning. These new functions can be accomplished by equipment commonly used in the nuclear industry. Therefore, DT\&E beyond that recommended for the inspect/assay system is not needed.

5.2.1.14 Interim Storage \& Shipping. This unit operation is similar to any industrial warehouse operation that is commercially available. Shipping is the external interface of the processing system with the final waste disposition. The shipping station prepares bills-of-lading for the inspicted and certified waste containers. The containers are overpacked as necessary to meet appropriate transportation limitations. These techniques are well-known, commercially available, and in current use by industry.

This shipping/storage area is located in a clean environment on a radiologically controlled area or pad. The storage area is serviceable by remote and contact handling equipment that has the capability to read container labels. No special DT\&E is anticipated for this unit operation.

\subsubsection{Program Implementation Risks}

This section identifies significant concerns associated with program implementation if the incineration/melter system is selected and qualitatively characterizes the risk of accomplishing the program objectives. The program mission and objectives are presented in Section 2, and assumptions 
used in characterizing risk are presented in Section 4. A summary of results and major areas of concern are presented in Table 5. Note that all technical issues listed in this table are engineeringsolvable issues and do not appear to present technical difficulties.

5.2.2.1 Technical Objectives. The technical objective for the alpha-LLW process can be summarized in the following two categories:

- Waste form: The waste form must meet the DOE, EPA, and DOT standards for storage, transportation, and disposal. Also, additional requirements on waste form will be derived from a performance assessment to be based on the intended disposal environments.

- Safety: Facility operation must be conducted to ensure the safety of the worker, the public, and the environment.

This system produces a high-integrity, leach-resistant waste form. Preliminary studies on the resultant waste form, ${ }^{7,8}$ iron enriched basalt, and a preliminary performance assessment ${ }^{9}$ have indicated that this waste form could successfully meet all the criteria for shallow-land long-term (permanent) burial (Note that a referenced performance assessment was conducted on process buried waste with a considerably higher TRU contamination level-greater than 20 times). Hence, it is believed that the risk associated with achieving the waste form technical objectives for ths option is very low. Areas of concern to meet safe operation objectives are as follows:

- Waste processing will be conducted in several alpha cells. These cells will contain dust (from additive soil, shredding, and other operations) and any radioactive, hazardous, toxic, and flammable gases that become airborne during the waste handling and processing operations. Protection must be provided for normal operations and contingency events, such as a fire. Alpha cells used in the nuclear environment typically have triple confinement barriers to ensure the protection of workers, the public, and the environment. The three barriers normally consist of an inner operation area (which is usually contaminated), a middle isolation vestibule, and outside corridors where workers remotely conduct the operations. Several of the waste handling operations will use existing technologies that must be adapted for use in an alpha-cell environment. Alpha-cell processing will require remote operation and ease of decontamination for maintenance, which makes this system a first-of-a-kind facility. It is uncertain if a cost-effective design can be developed that provides the following:

- Adequate confinement of radioactive, hazardous, toxic, and flammable gases during normal operating $a_{i, j}$ d contingency events.

- Effective operation of the complex mechanical equipment such as drum opening devices, sorting units, size reduction machines, manipulators, $k$ sste conveyors, and all related components that must be installed inside alpha cells. The potential for jamming and maloperation of these components is a concern. Any of these unit operations could be a potential problem because of limited characterization of waste streams. 

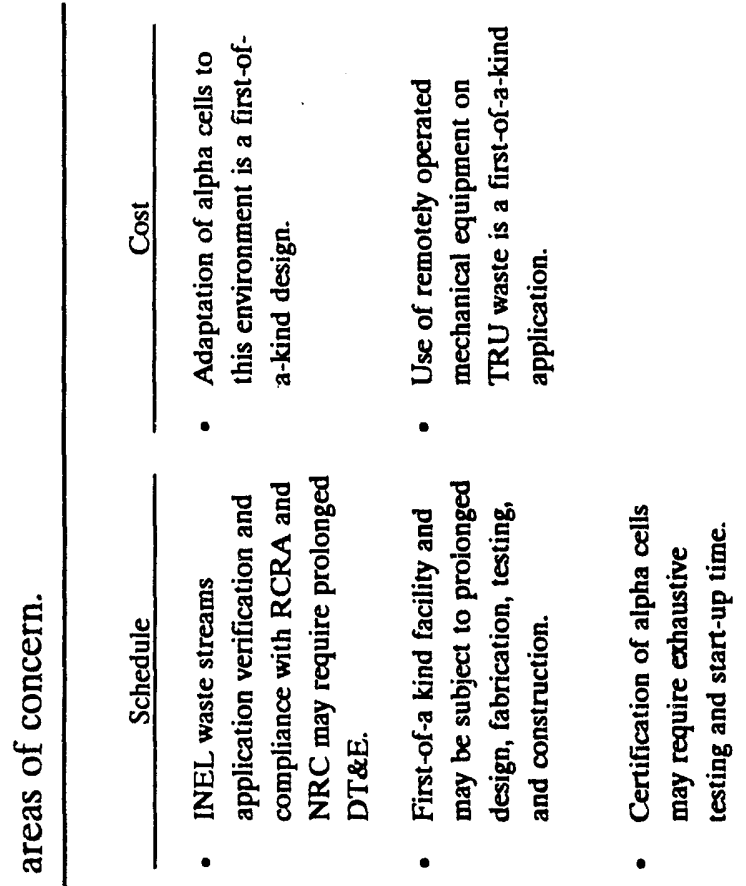

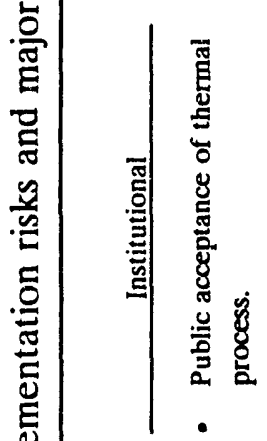

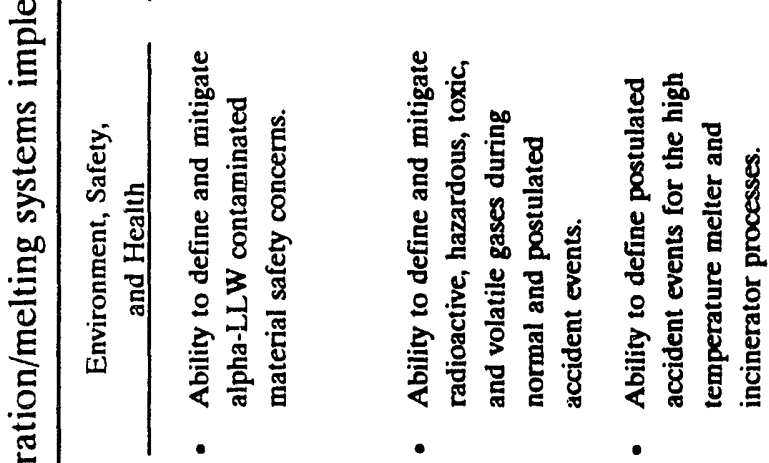
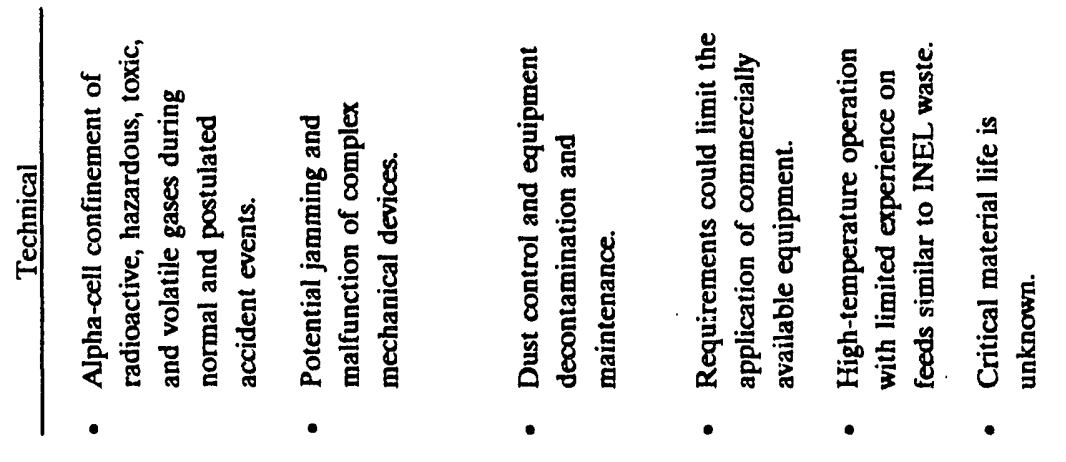

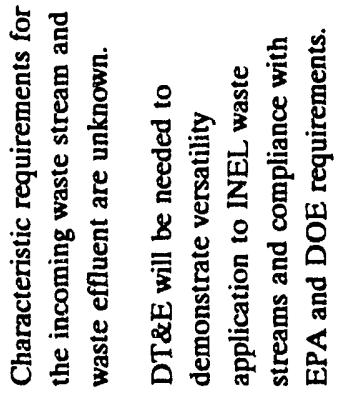

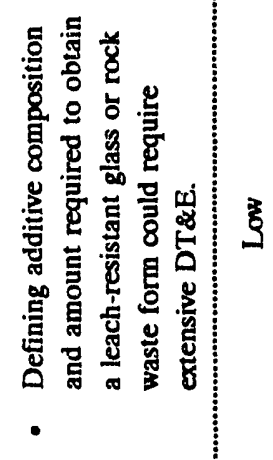


- The incineration and melter unit operations are well understood technologies and several options are available. DT\&E will be needed to demonstrate and optimize application to alpha-LLW streams and compliance with RCRA, EPA emission standards, and DOE requirements.

- DT\&E will be required to identify the compositional matrix extremes and process conditions that are needed to produce a high-integrity, leach-resistant vitrified waste form that meets the performance assessment limitations.

Based on the waste handling and processing equipment assessment, the risk of system compliance with the technical objective is moderate. However, since the system waste form has a very low implementation risk, the overall level of risk associated with achieving the technical objectives is low.

5.2.2.2 Environment, Safety, and Health Objectives. The key health and safety objectives for the alpha-LLW processing are to identify the hazards of the operation and to provide measures to eliminate, control, or mitigate identified hazards. In this system, major areas of risk are:

- The ability to design engineering controls which will contain postulated accident events (such as fire, or release of toxic or hazardous material) in the alpha cells and to provide mitigation measures which will satisfy the RCRA, EPA, and DOE requirements.

- The ability to design engineering controls which will contain postulated accident events in the melter and incinerator processes. The definition and control of the normal operations and accident events for melter and incinerator may be complex.

The risk associated with achieving health and safety objectives is largely due to the wide spectrum of incoming waste. Waste characterization DT\&E would provide a database for operational parameters. It is believed that using remote handling equipment and confining operations to the interior of the alpha cells will enhance mitigation measures for a majority of normal operation and contingency scenarios. This approach to achieve the "in-process" health and safety objectives reduces the overall level of risk to low. Long-term environment acceptability is related to the final waste form performance and is included as part of the technical objestives.

5.2.2.3 Institutional Objectives. In accordance with NEPA and DOE orders, a key institutional objective is to involve the public in the process of selecting treatment and disposal options for the stored alpha-LLW. Based on previous DOE experience, initial public and institutional support of a system, which uses a very large thermal process, will be minimal. Incineration processes are, however, BDAT for many EPA RCRA wastes similar to those in this waste stream and are in wide spread use for commercial waste reduction. Communications concerning acceptable performance experience and public education have lead to successful permitting of incineration systems. Industrial melters and smelters are in wide use and generally accepted by the public. Some public attitudes in Idaho have been expressed favoring vitrification as a method of producing a final waste form. Despite this sound technical base, the uncertanties associated with public and institutional acceptance require that the risk associated with achieving the institutional objectives be identified as moderate. 
5.2.2.4 Schedule Objectives. The objective of the IWPF project schedule is to reach Title I start by FY 1997. This is based on the assumption that a conceptual design will start by FY 1994. Following are risks associated with achieving these schedule objectives:

- The alpha enclosure is a complex, first-of-a-kind technology and could require prolonged DT\&E, design, and construction. However, detailed advanced planning could expedite and effectively manage the schedule for these activities.

- Because the use of remotely operated mechanical equipment to sort, convey, size reduce, and handle alpha LLW waste is a first-of-a-kind application, schedule delays due to prolonged DT\&E, design, and construction are anticipated. Again, detailed advanced planning could expedite and effectively manage the schedule.

- $\quad$ Prolonged DT\&E may be required to demonstrate the melter and incinerator required for INEL waste streams and to comply with RCRA, EPA, and DOE requirements.

- $\quad$ Prolonged DT\&E may be required to demonstrate melter waste vitrification and its ability to comply with EPA and DOE standards.

Based on the above scheduling considerations and the assumption that DT\&E activities will start in FY 1992, the schedule risk is believed to be moderate.

5.2.2.5 Cost Objective. Assessment of the cost objective is a qualitative characterization based on the risk associated with estimating accurate costs for the system. Significant cost estimate risks are as follows:

- Cost overruns associated with a first-of-a-kind design requiring prolonged design development. Two areas of potential cost impact are providing engineering controls for safety and for RCRA, EPA, and DOE requirements.

- Because the use of an incinerator and melter for processing and the use of remotely operated mechanical equipment for container opening, sorting, size reduction, and handling of alpha-LLW is a first-of-a-kind application, accurate cost estimates are not anticipated until design, based on DT\&E, is well into maturity.

Based on the above potential cost impacts, the cost risk is believed to be moderate.

\subsubsection{Unit Operations DT\&E Lead-Time Estimates}

The lead time, including the level of effort for each unit operation requiring DT\&E, has been estimated and is shown in Table 6. Lead-time estimates are based on the assumptions presented in Section 4.

\subsubsection{Rough-Order-of-Magnitude Cost Estimates}

ROM costs are summarized in Table 7. Assumptions, methodology and details are presented in Appendix B. 


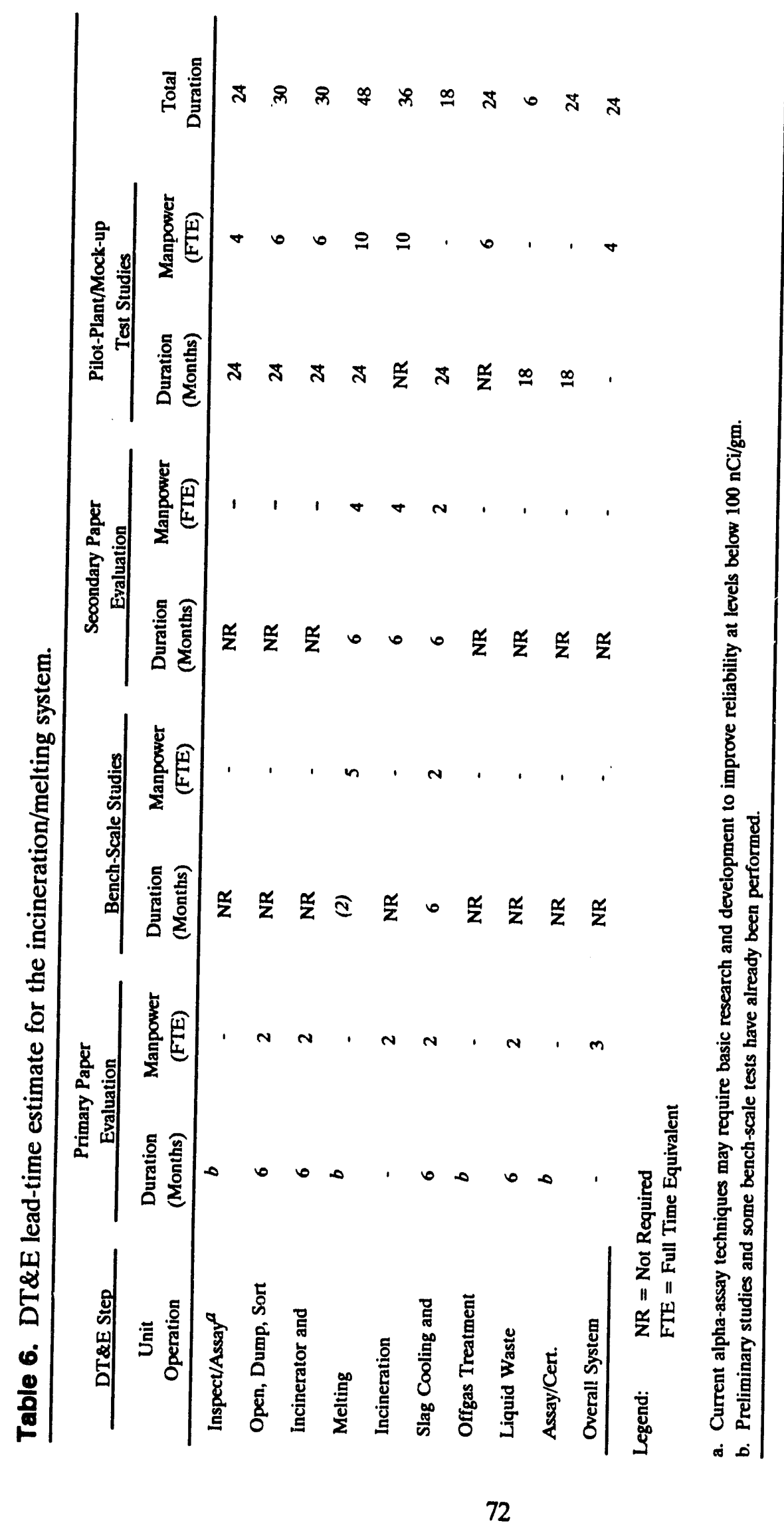


Table 7. Rough-order-of-magnitude cost estimates for incineration/melting system $(x \$ 1,000)$.

\begin{tabular}{lr}
\hline Item & $(\mathrm{x} \$ 1,000)$ \\
\hline Studies and Bench-Scale Tests & $\$ 7,938$ \\
Demonstration & $\$ 22,864$ \\
Facility Design and Construction & $\$ 158,515$ \\
Operating and Maintenance & $\$ 183,440$ \\
Disposal and Transportation & $\$ 29,500$ \\
Operating Funds Budgeted Activities & $\$ 132,200$ \\
Decontamination and Decommissioning & $\$ 30,683$ \\
Total Life-Cycle & $\$ 572,140$ \\
\hline
\end{tabular}

\subsubsection{System Evaluation Results}

This section presents an overall evaluation of the incineration/melting system and identifies the major advantages and disadvantages based on the system assessments. This includes an evaluation of integrating individual unit operations into a smooth, efficient system. Specific areas addressed include identification of system advantages and disadvantages, a qualitative ranking of performance measurables as identified in Section 3, a summary of DT\&E requirements, and an overall recommendation for the system.

5.2.5.1 Major System Advantages and Disadvantages. Currently a wide variety of melting and incineration technologies exist in various stages of development and testing. Incineration is used in fossil power plants as well as in sanitary and hazardous waste facilities; both industries have to address stringent emission requirements. In addition, melting techniques employed in the mining and meta $:$ industry are applicable to processing hazardous waste. However, melting or incineration of mixed waste has only been performed on a limited scale.

The unknown characteristics of the waste stream feed stock in the melter presents potential operation problems, such as corrosion of the refractory liner of the furnace and unexpected offgas treatment problems. Certain types of input wastes may react with the furnace refractory liner and require significant repair and downtime. This could increase maintenance personnel radiation exposures (a melter design based on cooled wall skull techniques can be used to alleviate the refractory replacement problem). In addition, the treatment of gaseous effluents from melting or incinerating unknown materials may result in a medium risk factor as the offgas unit operation must be designed for a wide range of effluents.

The major advantages of incineration and melting are significant waste volume reduction and conversion of the waste to a benign final waste form suitable for near surface land disposal. The major disadvantages of incineration and melting are related to the "in-process" potential for large volumes of offgas and the need for secondary burners to further treat offgas (the use of incinerators that minimize offgas discharge - such as pyrolysis techniques with oxygen burning and melters that use little air, such as electric arc melters - will alleviate the excessive offgas discharge problem). The system requires 3 to 4 years of lead-time for research and development, and the cost estimates for 
this system are dependent on the input waste stream composition and melting energy requirements. Following are specific advantages and disadvantages.

\subsubsection{Advantages.}

- In a separate area, metals are sorted upfront, reduced in size, and decontaminated to a LLW level, which is less costly to dispose of than alpha-LLW. Sorting the metal for decontamination in a separate facility allows cleaner and smoother operations of these processes.

- Process upsets from incompatible waste are prevented by separating the undesirable waste, such as metals and gas cylinders, prior to treatment.

- By selecting a versatile incinerator design, such as a rotary kiln, the necessity for sorting of combustibles from noncombustibles has been minimized. This should increase the process availability and minimize operating and maintenance labor.

- Melting technologies are capable of handling a wide variety of wastes, such as solids, liquids, combustibles, noncombustibles, and metals; destroying organic materials; and producing a high integrity final waste form. Heavy metals and radionuclides are dissolved in the final waste matrix.

- The volume of waste is reduced, assuming initial waste characteristics preclude the need for adding large quantities of glass additives for vitrification.

- This system produces a robust waste form that has a high probability of retaining radionuclides over geologic time frames.

\subsubsection{Disad.yantages.}

- The incinerator and melter feed preparation operations and the open, dump, and sort operations are complex and time consuming and can result in spreading contamination and increased maintenance.

- Although the melter technology is well developed, its application to alpha-LLW processing is still in the development and testing stage.

- The incinerator and melter refractory linings will require periodic maintenance.

- There is a lack of DOE incineration experience using alpha-LLW in an alpha environment.

- When compared to non-thermal processes, the offgas equipment involves high capital cost. Furthermore, it requires process DT\&E to treat anticipated exhaust gas from incineration and melting and hazardous waste destruction. The scrubber water contains volatile metals, such as mercury, which must be removed before water disposal. 
5.2.5.4 Performance Measurables Rating. Section 3 identifies performance measurables and weighting factors that are used in the evaluation of the overall system. Table 8 is a judgmentbased, qualitative assessment of the system's performance measurables. Following are the key factors considered in developing scores for the unit operation performances:

- Assay/Inspect and Assay/Certification: Even though assay systems have been developed and demonstrated at Los Alamos National Laboratory and are currently operational for drum handling, their reliability for production level application below $100 \mathrm{nCi} / \mathrm{g}$ is questionable. Therefore, risk is given a low score, and other attributes also receive a moderate score.

- Open, Dump, and Sort: The reference systems for this analysis include the manual sorting systems available for LLW at Scientific Ecology Group's facility in Oak Ridge, the glove box sorting line installed at Los Alamos National Laboratory, and the previous drum opening experience at the Rocky Flats Plant. Although the remote handling of the packages after assaying has not been demonstrated, it is assumed that this would be a direct application of available remote equipment. Therefore, the remote process system does not present increased technical risk. However, the inability of a remote device to deal with special-case situations is unknown. Therefore, these attributes receive a low score.

- Incinerator and melter feed preparation: Commercial crushers and shredders for crushing ores and soft processing solids are assumed to require modifications and enhancements to allow for remote operations and maintenance. Therefore, scores on timeliness and completeness are moderate. Slow-speed rip/tear operation shredders are commonly used, although hammer mills and high-speed chippers are also options. A slow-speed rip/tear system was selected for the PREPP system, and maintenance requirements were moderate. The assessment assumes the complete rip/tear shredder system includes a remote feed system and a capability to remove oversized and hard objects to reduce maintenance and increase reliability. The moderate scoring of the safety factor is attributed to dust created by the shredding and pulverization operations, and the moderate risk score is based on the demonstrated system at PREPP.

- Incineration and melting: Both processes address the problem well. Incineration of LLW is currently being done at the INEL using the Waste Experimental Reduction Facility controlled air incinerator and at the commercial Scientific Ecology Group facility at Oak Ridge. Incineration of radioactive wastc is also carried out at numerous facilities worldwide. Melters are used in the UI.S. and worldwide for vitrification of high-level waste. Melters are used commercially to melt ores for phosphorous gas production, steelmaking, and glass making. Thus, the challenge is to adapt the process to a nuclear waste treatment environment. Therefore, in assessing the melter, the scores are downgraded because of its extensive pilot-plant requirements. Also, the application of incineration and melter to alpha-LLW materials could impose unique requirements on the offgas system. Therefore, the risk score is also downgraded. 


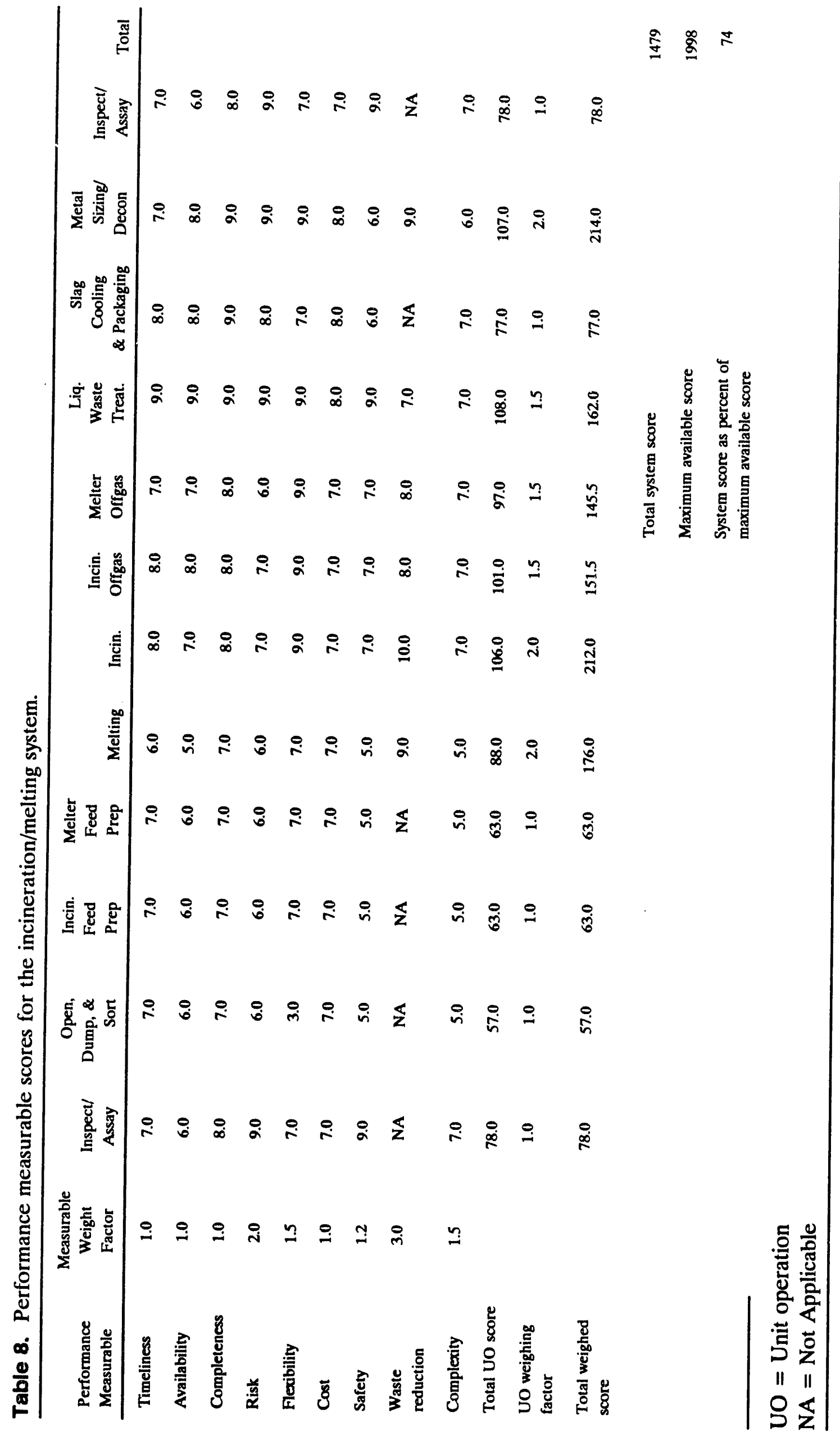


- Incinerator and melter offgas: The offgas from the incineration and melting proc $s s s e s$ must be treated to remove acid gases and particulate matter. In the melter, the offgas treatment device must also remove volatile metals. Two available options are wet and dry systems. With the expected amount of acid gases generated by the chlorinated wastes, a wet system (or semidry) is the only option that will meet regulatory requirements. Because wet systems are well developed, most attributes for the offgas receive a moderately high score. Risk for the melter offgas receives a lower score because of concern about volatile metals removal.

- Liquid waste treatment: Several liquid-waste treatment techniques are used in the nuclear industry and are readily available for application to the secondary waste streams from alpha-LLW processing operations. Therefore, most attributes for this unit operation receive a high score.

- Slag molding, cooling, and packaging: As with the melter, slag molding and cooling has been used for high-level waste (HLW) application. A moderate amourit of DT\&E may be required to transfer existing technology from the HLW and commercial applications to the alpha-LLW. No significant difficulties are foreseen in this technology transfer. Therefore, most attributes of this unit operation receive a moderate score.

\subsubsection{Summary of Demonstration, Testing, and Evaluation Needs}

The DT\&E requirements for each unit operation and for the overall system are summarized in Table 4. This table provides a ready reference to DT\&E requirements in the final system evaluation and for comparison purposes with other systems.

\subsection{Recommendation for the System}

This system utilizes incineration and melting technologies to reduce the volume of waste and thereby minimize long-term storage and disposal requirements. The sensitivity of the melting and incineration processes to the input waste streams may be minimized with further development. Some developmental work on melter systems is presently underway at bench and pilot scale, which should yield additionai information on the system capability.

Considering the hazardous and toxic nature of the hydrocarbon and heavy metal contaminants involved and the long-term hazards of the LL-TRU elements, the high-temperature melting system approach represents a viable solution to the permanent stabilization and minimization of these wastes. Further study and evaluation of specific contaminant levels, quantities, and physical condition are essential to determine which melting or incineration designs will be most appropriate for site conditions, equipment availability and costs, schedule restraints, and actual hazard levels. Several issues that will require further development include:

- Analyzing the queuing of the waste stream to determine capacities of components within unit operations

- Fine tuning of all the selected technologies to produce the desired results 
- Verifying the integration of the process streams to ensure compatibility.

Consideration should be given to on-line sensors that monitor and report status and progress of waste stream processing. With the high-temperature melting unit operation, the main effluent will be a vitreous slag phase of the constituent stable oxides. From a preliminary review of the projected feed materials, a secondary phase can be anticipated that will be composed of an accumulation of unoxidized metals in the hearth or bottom of the meltrr during slag production. These metallics must be periodically removed to maintain processing volume in the melter.

Based on the compositional breakdown, a large proportion of the secondary phase in the melter will be iron from the carbon steel. The iron accumulation may include some TRU contaminants if these elements are present as metal. However, it is expected that TRU elements which have high oxidation potential will partition to the slag as oxides and not precipitate out with the free metal (a well designed process may very well achieve a clean metals separation). Other short-lived radionuclir es may or may not follow this pattern, so the metal reduced might be beta gamma active or may be free of radionuclides. Leach rate data are needed to determine whether a cast ingot of steel would pass a performance assessment. A pilot melter program is essential to evaluate the quantity and composition of the secondary phase and appropriate disposal methods.

An alternate option exists to introduce oxygen into the furnace to convert all metals into the oxide and thus into the slag-eliminating any issue with metals accumulation. 


\section{THERMAL TREATMENT/SOLIDIFICATION SYSTEM}

This section describes a thermal treatment/solidification system devised to convert the stored alpha-LLW into a physical and chemical form that meets the Land Disposal Regulations requirements and has low hydrogen generation potential from metals. Solidification is based upon a cementitious process. The waste form produced may not be suitable for ensuring long-term TRU retention (beyond $\mathbf{3 0 0}$ years) alone and a disposal facility or added treatment will be required to ensure longer term performance.

\subsection{Functional and Operational Requirements}

\subsubsection{System Description}

The thermal treatment/solidification system, shown in Figure 13, is comprised of fourteen main process unit operations and one subsystem. The metal sizing and decontamination subsystem is described in Section 8.

The waste containers (drums, boxes, and metal bins) arrive at the thermal treatment/ solidification facility on a transport vehicle. Containers are removed from the transport vehicles and placed in a staging/storage area. The containers are visually examined, labeled, logged, recorded, and sent to an inspection and assay unit operation.

The inspection and assay results allow segregation of the containers to expedite processing. Based on the inspection and assay results, the waste containers are grouped either as bulk metals, combustibles, organic contaminated non-combustibles, semi-combustibles, inorganic sludge, or special waste. The special waste category includes any container that requires a special sorting operation.

The function of the open, dump, and sort unit operation is to receive waste containers (drums, boxes, and metal bins), remove their caps, and dump their contents either on sorting devices or on transport devices that carry the waste to the next unit operations. The unit operation's sorting functions are to remove bulk metals, combustibles, non-combustibles, and gas cylinders. The unit operation also reduces the size of empty, non-metallic containers. After the open, dump, and sort operation, the waste goes to three main processing streams: metal sizing and decontamination, thermal treatment, and organic removal. The metal sizing and decontamination subsystem, which receives bulk metals, is discussed in Section 8 of this report.

The waste is fed to the thermal treatment unit by the input preparation and feed unit operation, which crushes and shreds the incoming material. All combustible materials are thermally destroyed while inert materials pass through with the ash. The solids discharged from the thermal treatment unit are cooled, sampled, and then transported to a solidification unit operation.

Noncombustible wastes contaminated with organic compounds are fed to the organic removal unit. An input preparation and feed unit operation crushes and shreds the incoming waste, as needed, before it is fed to the organic removal unit. After organic removal, the waste is transported to the solidification unit operation. 


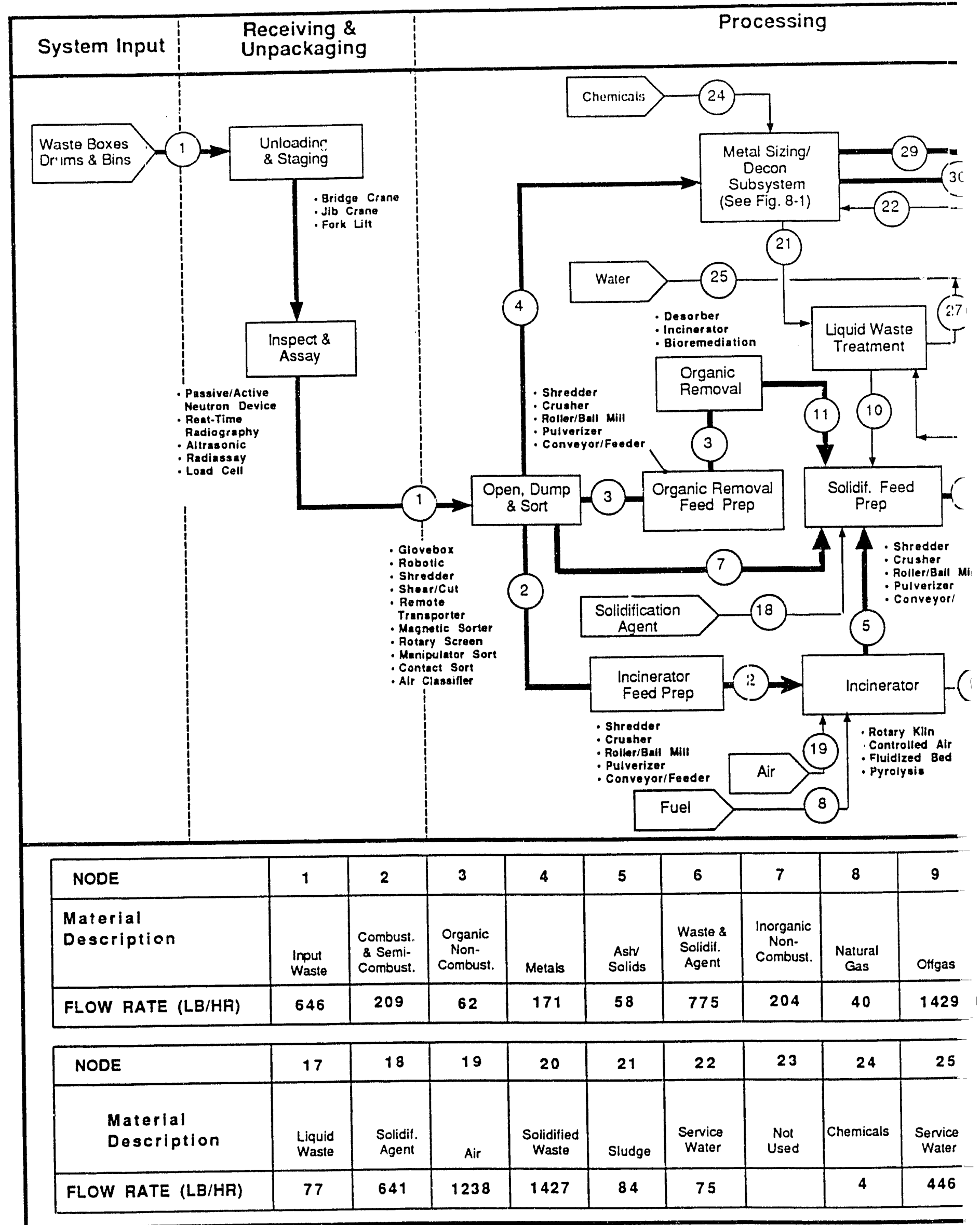

Figure 13. Process functional diagram for thermal treatment/solidification system. 


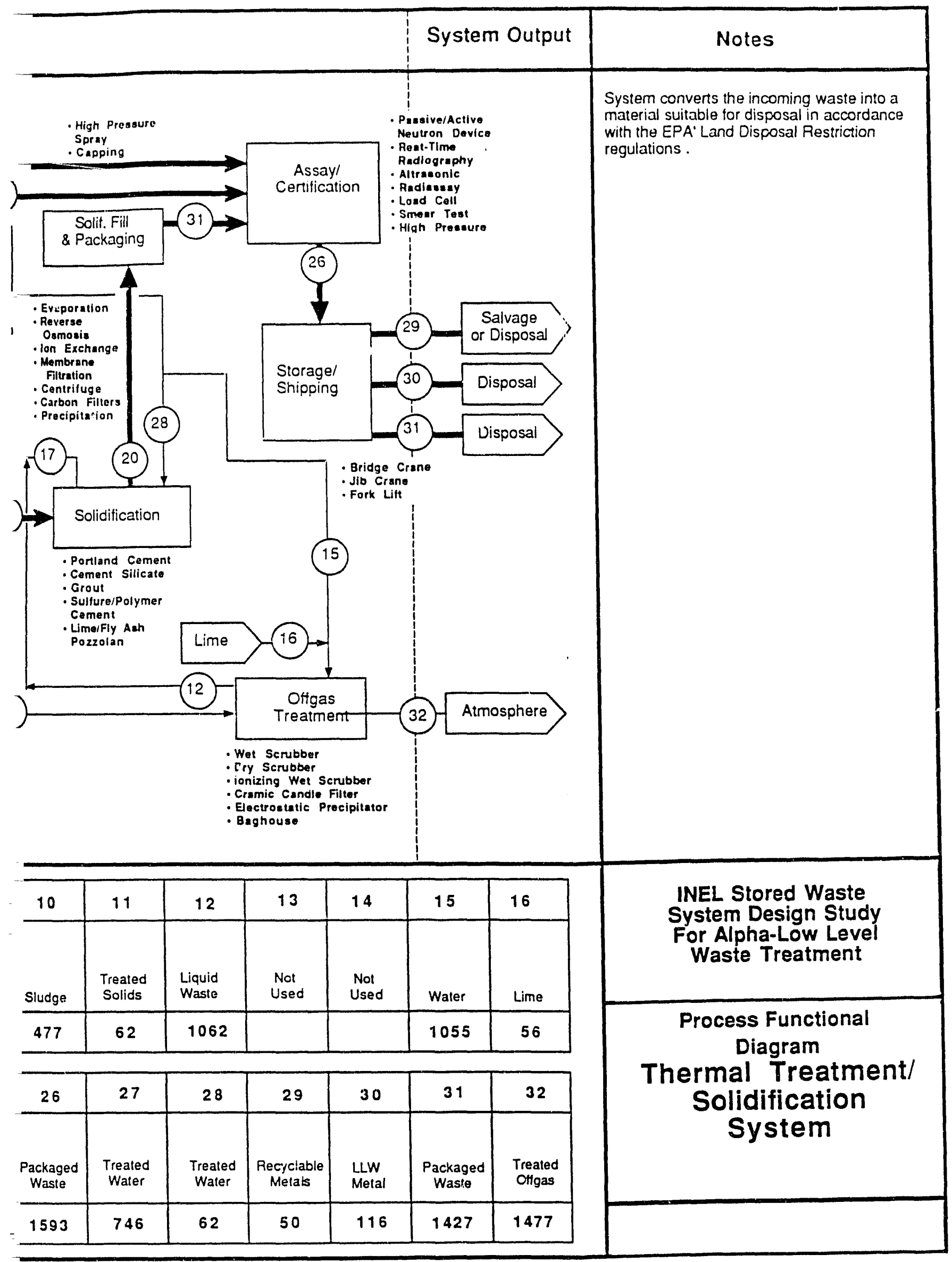


The solidification unit operation receives treated waste from both the thermas treatment and organic removal processes. Additionally, waste not requiring thermal treatment is transported directly from the open, dump, and sort operation to the solidification unit. The waste is first processed by a feed preparation unit, then mixed with a solidification additive, and finally poured into disposal containers. The mixing and curing formulations will produce the most stabilized waste form.

The system's major product is the solidified waste. Other system products include decontaminated metals (suitable for shallow-land disposal or recycle and reuse as permitted by regulations) discharged from the metal sizing and decontamination subsystem. All system products are containerized and processed through a radio-assay and a final certification process. Certified containers are kept in the facility for an interim period before offsite shipping.

The system has two secondary waste streams, liquid and offgas. Both the thermal treatment and organic removal unit operations are equipped with a secondary combustion unit that completes the volatile gas destruction process. The secondary combustion effluent is fed to air pollution control devices designed to remove particulates, $\mathrm{SO}_{2}, \mathrm{HCl}$, and $\mathrm{NOx}$. A surge tank allows retention for reprocessing in the event of a process upset.

Secondary liquid waste is processed by a liquid waste-treatment unit operation. This unit operation removes dissolved and suspended solids (organic and inorganic) from the liquid waste. Treated waste water is recycled for reuse. Sludge and other wet solids are fed to the solidification unit for processing.

\subsubsection{System Requirements}

The system requirements are the same as those described in Section 5.1.2 for the incineration melter system with the exception that the final waste is solidified, meets the LDR requirements, and low hydrogen generation properties are achieved by eliminating metals to the lowest possible level.

\subsubsection{Unit Operations Functional Requirements}

Each unit operation has facilities, equipment, devices, and accessories required to perform the functional and subfunctional operations discussed below. Detailed performance requirements for the unit operations will be developed in future studies. A preliminary unit operation subfunctional flow diagram for the system is shown in Figure 14.

Because many of the unit operations in the thermal treatment/ solidification system and the incineration/melting system are similar, the corresponding sections of the incineration/melter system are referenced when the unit operation descriptions are the same for both systems.

6.1.3.1 Unloading and Staging. See Section 5.1.3.1 for unit operation functional and subfunctional descriptions.

6.1.3.2 Inspect/Assay. See Section 5.1.3.2 for unit operation functional and subfunctional descriptions. 


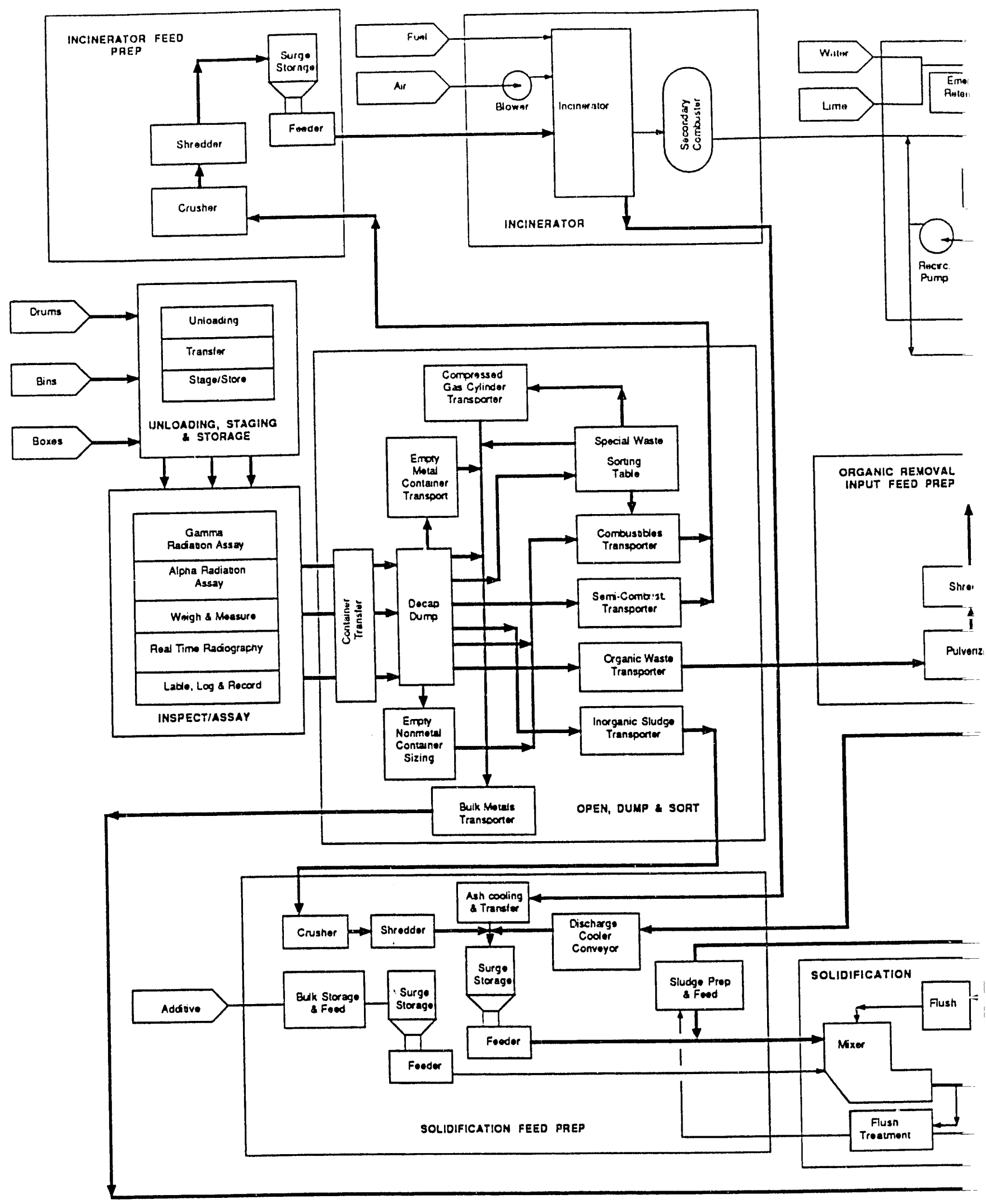

Figure 14. Unit operations subfunctional llow diagram for thermal treatment/solidification system. 
6.1.3.3 Open, Dump, and Sort. See Section 5.1.3.3 for unit operation functional and subfunctional descriptions. The open, dump, and sort unit in the thermal treatment/solidification system has an additional function of separating the organic-contaminated, non-combustible waste. This waste stream is sent to an organic removal feed preparation unit operation. Reliable techniques for this process must be developed and demonstrated.

6.1.3.4 Thermal Treatment Feed Preparation. The system employs incineration technologies for the thermal treatment unit operation. The functional and subfunctional descriptions are the same as those detailed in Section 5.1.3.4.

6.1.3.5 Incineration. The functional and subfunctional descriptions are the same as that given in Section 5.1.3.5 with the exception that the incinerator ash and solids are transferred to the solidification feed preparation unit operation.

6.1.3.6 Incinerator Offgas. The functional and subfunctional descriptions are the same as those detailed in Section 5.1.3.6.

\subsubsection{Organic-Removal Feed Preparation.}

- Unit operation functions summary: The organic-removal feed preparation unit operation receives, stores, and prepares the incoming waste streams into a proper size and mixture, and feeds at a rate that is required for the organic removal unit operation.

- Allocated functions: Unit operation functions are allocated to the following subfunctions:

- Controlled environment: Operation and maintenance are conducted remotely in a controlled environment as discussed in Section 5.1.3.3.

- Crusher: The incoming waste is crushed so that the larger pieces (e.g., cemented sludge, concrete, and brick) are reduced in size.

- Shredder: After crushing, the waste shredder further reduces the waste to expedite complete organic removal.

- Waste surge storage: Size reduced waste is stored in a container with sufficient capacity to provide the required feed surge. The solids in the surge storage container can be sampled.

- Waste feeder: A waste feeder conveys the material to the organic removal unit at the desired feed rate.

\subsubsection{Organic Removal.}

- Unit operation function summary: The organic-removal unit operation treats organic solids, gases, and liquids, volatile organic compounds (VOC) that contaminate the waste. The output from this system meets the LDR treatment standards. 
- Allocated functions: Unit operation functions are allocated to the following subfunctions:

- Controlled environment: Operations and maintenance are conducted remotely in a controlled environment as described in Section 5.1.3.3.

- Organic removal: Organic removal uses a low-temperature thermal desorber process to heat the waste and vaporize organic compounds. The thermal-desorber secondary waste is a vapor which requires further treatment at high temperatures with sufficient residence time for complete destruction. The treated solids are transferred to the solidification unit for stabilization and packaging.

- Vapor removal: A blower removes vapor from the desorber and transfers it to the next unit operation.

- Particulate removal: A filtration device removes suspended particulates in the vapor.

- Thermal oxidizer: A high temperature $\left(2000-2500^{\circ} \mathrm{F}\right)$ combusting unit treats vapor from the desorber. The gases remain at the high temperature for a minimum of 2 seconds. Oxidized vapor is fed to the thermal treatment offgas unit for treatment, monitoring, and discharge.

- Rejected product: After processing, any rejected waste is brought back to the head of the organic removal process and reprocessed to meet the acceptance criteria.

\subsubsection{Solidification Feed Prep.}

- Unit operation functions summary: The solidification feed preparation unit operation receives, stores, and prepares the incoming waste streams into a proper size and mixture, and feeds at a rate that is required by the solidification unit operation.

- Allocated functions: Unit operation functions are allocated to the following subfunctions:

- Controlled environment: Operations and maintenance are conducted remotely in a controlled environment as discussed in Section 5.1.3.3.

- Crusher: The larger waste pieces (e.g., cemented sludge, concrete, and brick) are reduced in size by a crusher.

- Shredder: After crushing, the waste is further reduced to facilitate complete solidification.

- Cooling and transportation of ash and solids: Ash and solids are collected from the thermal treatment discharge, cooled, and transported to the surge storage container.

- Organic removal solids cooling and conveying: Solids from the desorber unit are collected, cooled, and transported to the surge storage container. 
- Waste surge storage: Waste, desorber solids, and thermal treatment unit ash and solids are stored in a container sized to provide the required solidification feed surge capacity. The surge storage container is equipped for sampling the solids.

- Waste feeder: The feeder conveys the waste to the solidification unit at the desired feed rate.

- Solidification agent bulk storage and transfer: Solidification agent is stored in bulk containers and transferred to the agent surge storage unit as needed. Bulk storage capacity and transfer rate is sufficient to support the system availability requirements.

- Liquid residue feed: Liquid residue from the liquid waste- treatment unit operation is fed to the solidification unit.

- Solidification agent surge storage: Solidification agent transferred from the bulk storage area is stored in a container sized to meet the solidification feed surge capacity needs.

- Solidification agent feeder: The feeder conveys the material to the solidification unit at the desired feed rate.

\subsubsection{Solidification.}

- Unit operation function summary: The solidification unit operation mixes solid and liquid waste with a solidification agent to produce a stabilized waste form meeting the technical objectives of the system presented in Section 3.

- Allocated functions: Unit operation functions are allocated to the following subfunctions:

- Controlled environment: Operation and maintenance are accomplished remotely in a controlled environment as described in Section 5.1.3.3.

- Mixer: The mixer blends the liquid, sludge, or solid waste with the solidification agents, and the product is then discharged into shipping containers. With curing, the product becomes a stabilized waste form suitable for long-term storage or disposal. Various mixers, such as pug mill, ribbon blenders, or inline mixers, may be used.

- Flush: The mixer is rinsed with water after each mixing cycle and during upset conditions.

- Flush treatment: The mixer-flushing waste is treated to remove suspended solids. Treated waste is sent to the water treatment unit operation, and the sludge is fed back to the mixer for solidification.

- Solidification processes: Solidification processes are conducted with solidification agents that are compatible with the waste, creating a waste/solidification agent mixture. Typically, these are cementitious agents, e.g., Portland cement. 
6.1.3.11 Liquid Waste Treatment. The functional and subfunctional description of this unit operation is the same as that described in Section 5.1.3.10 for the incinerator/melter system.

\subsubsection{Fill and Package.}

- Unit operation functions summary: The fill and package unit operation pours into containers, cures, and packages for shipment the waste/solidification agent mixture discharged from the solidification unit operation. After packaging, the waste container is cleaned (to remove any exterior contamination) and sent to an assay/certification unit operation.

- Allocated functions: Unit operation functions are allocated to the following subfunctions:

- Controlled environment: Operation and maintenance are accomplished remotely in a controlled environment as discussed in Section 5.1.3.3.

- Fill container: Shipping containers are filled with the waste/solidification mixture in a manner to maximize density and control contamination spread (by splashing or spillage). Filled containers are set aside to allow the mixture to cure.

- Rejected waste: After solidification, if waste quality is found unacceptable, the solidified waste is brought back to the head of the organic removal unit operation and is reprocessed.

- Cap: Filled containers are capped and sealed.

- Cleaning: The packaged waste is smear tested and, if needed, is surface cleaned to remove any loose contamination. The liquid waste from the container washdown operation is sent to the liquid waste treatment unit operation.

- Transfer: Filled containers are moved from one place to another to accomplished the various functions and subfunctions described above.

6.1.3.13 Assay/Certification. Refer to Section 5.1.3.12 for functional and subfunctional descriptions of this unit operation.

6.1.3.14 Interim Storage \& Shipping. Refer to Section 5.1.3.13 for functional and subfunctional descriptions of this unit operation.

\subsubsection{System Boundaries}

Refer to Section 5.1.4 for a description of the system boundaries.

\subsubsection{System-Specific Assumptions}

Following are the system-specific assumptions: 
- Solidification: The cement solidification process will produce a waste/cement mixture with a density of $112 \mathrm{lbs} / \mathrm{ft}^{3}$.

- Waste characterization: The mass and composition of the input waste stream was based on the characterization of the waste at the TSA (see Appendix A).

- Thermal treatment equipment: The process will use a rotary kiln incinerator similar to that of the incineration/melting system.

- Organic removal equipment: A low-temperature thermal desorber will remove organics.

- Mass flow rates: Estimated mass flow rates for the system are summarized in Figure 13.

- Offgas treatment: The offgas from the thermal treatment unit is cooled, filtered, and processed through an offgas treatment system. The offgas system can handle radionuclides, particulates, and other air pollutants.

- Unit operation capacities: The unit operation capacities are at a minimum $125 \%$ of design flow rate, based on the mass of waste that must be processed over a 10-year period. Because of the low input feed rate, the unit operation estimated capacities are sometimes larger than the required size. This is especially true for the incineration unit.

- Basis for alpha cell design: The pre-conceptual design for the process cells handling opened containers is based on a conservative assumption that errors in alpha radiation measurement will result in the processing waste with higher than $100 \mathrm{nCi} / \mathrm{gm}$ TRU content.

\subsubsection{Facility Description}

A scoping study layout for the system is shown in Figure 15. A single building houses the system, and incoming waste is unloaded at the truck bay in front of the building. A large open area adjacent to the truck bay is used for container staging, storage, and inspection and assay operations. From the open area, the containers are moved to the processing cells located in the center of the building.

Three parallel process cells are located perpendicular to an open, dump, and sort cell with pipelines and conveyors passing over and under the operations and maintenance aisles. Each process cell is arranged with glass windows at the front so an operator is able to view the operations. The rear of each process cell adjoins a maintenance and decontamination cell. Equipment requiring repair or upkeep is pulled from the process cell and repaired in the maintenance cell.

The maintenance and decontamination cells are accessible through airlocks and have a confinement barrier level commensurate with the hazards level established by the design criteria. 


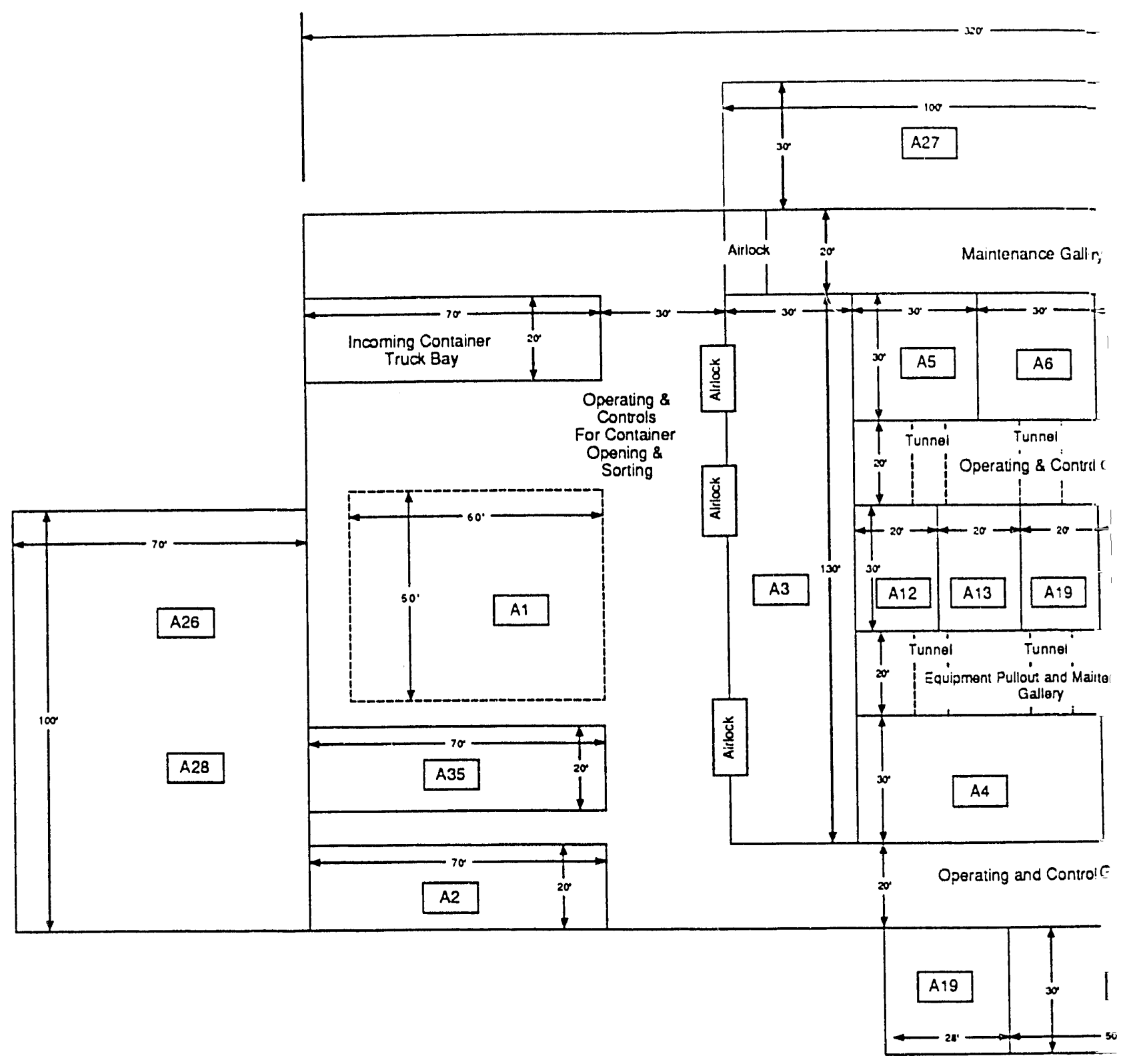

Figure 15. General arrangements for the thermal treatment/solidification system. 


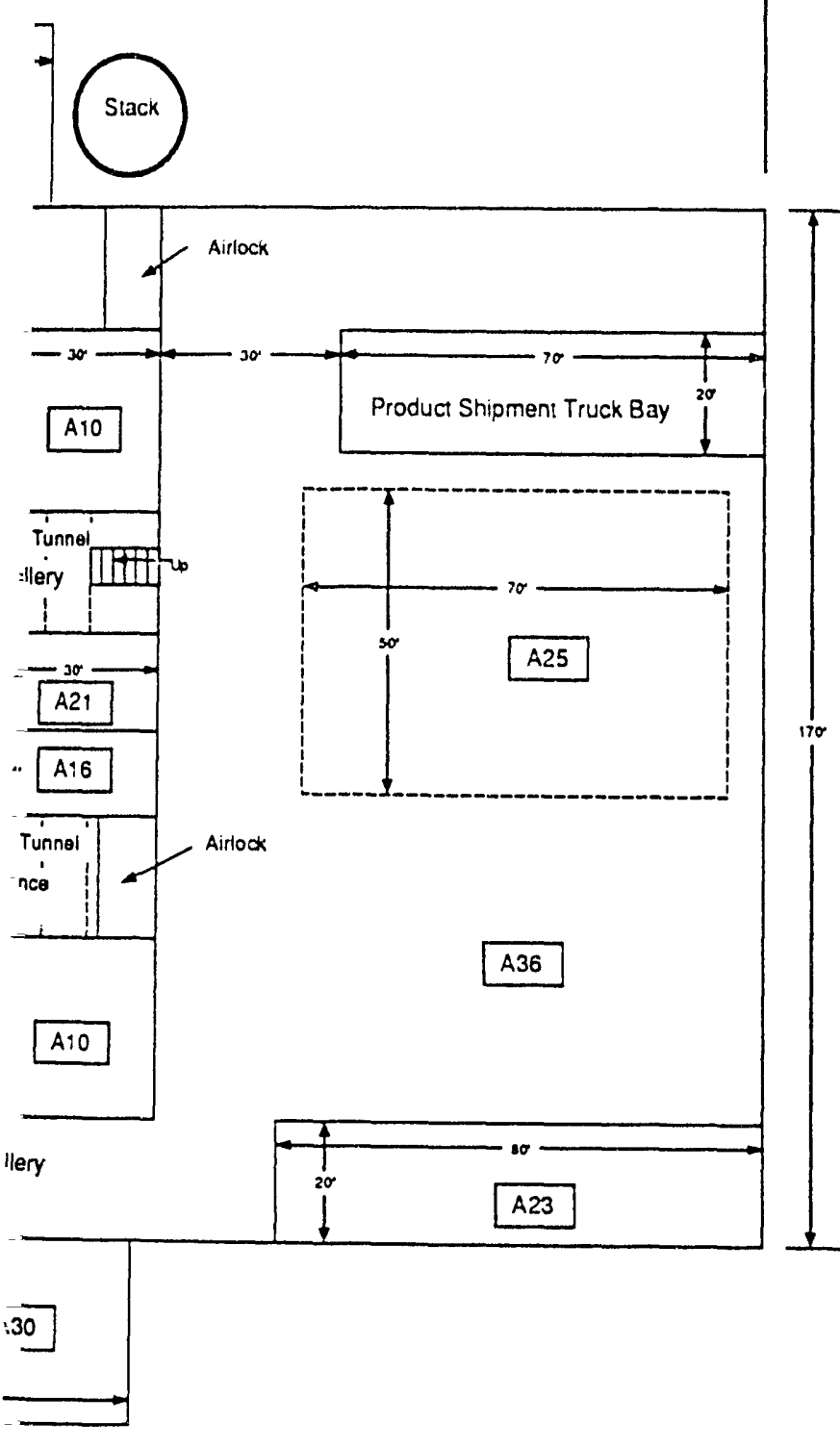

\begin{tabular}{ll} 
NO & DESCAIPTION \\
\hline A1 & Unload, Stage \& Store \\
A2 & Inspect /Assay \\
A3 & Open, Dump \& Sort \\
A4 & Metal Sizing/Decon Subsystem \\
A5 & Incinerator Feed Prep \\
A6 & Incinerator \\
A10 & Incinerator OHgas Treatment \\
A12 & Organic Removal Feed Prep \\
A13 & Organic Removal \\
A16 & Solidification Fill \& Package \\
A19 & Solidification Feed Prep -TTSS \\
A21 & Solidification - TTSS \\
A23 & Assay/Certification \\
A24 & Liquid Waste Treatment \\
A25 & Storage \& Shipping \\
A26 & Administration Support \\
A27 & Heating, Ventilation \& Exhaust \\
A28 & Analytical Laboratory \\
A30 & Utilities/Mech. Equipment - TTSS \\
M35 & Chem Storage Area \\
A36 & Maintenance Shop
\end{tabular}

INEL Stored Waste System Design Study For Alpha-Low-Level Waste Treatment

\section{Scoping Study Layout Thermal Treatment/ Solidification System}




\subsubsection{Interface Requirements}

Following are the interface requirements for the overall system (see Section 8 for the metal sizing and decontamination subsystems). The flow rates for the input, output, and intermediate points are given in the process functional diagram, Figure 13.

6.1.7.1 System Output. The system interface outputs include:

- LLW and alpha-LLW packages from solidification and metal decontamination operations to a long-term storage or disposal facility

- Exhaust gases from the stack discharged to atmosphere

- Sanitary waste discharged to drainage fields.

6.1.7.2 Input from Other Systems. System interface inputs include:

- Alpha-LLW packages from SWEPP and Storage Modules

- Utilities including service water, normal and emergency power, natural gas, and communications

- Consumables including personnel protective equipment, laboratory material, solidification materials, packaging materials, and disposable and reusable shipping containers.

6.1.7.3 Miscellaneous Systems. The system interfaces with the site communication and alarm systems including telephone, evacuation, fire, security alarm, and public address systems. The process automatically shuts down if the fire system or the evacuation alarm are activated.

\subsection{System Assessment}

This section presents preliminary scoping assessments based on the subjective judgment and existing knowledge of the preparers. Additional technology evaluations are needed prior to the selection of component technologies and to identify detail development and demonstration needs for selected technologies. Specifically, this section discusses the development level of some of the key unit operations and typical technologies available for performing the required functions. A qualitative assessment of the risks associated with the ability to achieve the required functions is given based on current knowledge and limitations of the available technologies. The strengths and weaknesses of the unit operations are also noted.

Many of the unit operations in the thermal treatment/solidification system and the incineration/ melting system are similar; the corresponding sections of the incineration/melter system are referenced when the assessments are the same. 


\subsubsection{Evaluation of Unit Operation Technologies}

To accomplish the functions specified for the unit operations, several unique devices, components, and processes are needed. These devices, components, and processes are identified and assessed in this section. Each unit operation is evaluated individually to assess the overall feasibility of the system and to identify areas requiring focused attention. The details of the evaluation are presented below while the assessment is summarized in Table 9.

6.2.1.1 Unloading and Staging. This unit operation is evaluated in Section 5.2.1.1.

6.2.1.2 Inspect/Assay. This unit operation is evaluated in Section 5.2.1.2.

6.2.1.3 Open, Dump, and Sort. This unit operation is evaluated in Section 5.2.1.3.

6.2.1.4 Thermal Treatment, Organic Removal, and Solidification Feed Preparations. Feed preparation unit operations for thermal treatment, organic removal, and solidification use similar technologies. Therefore, evaluation of these feed preparation unit operations are similar to the incinerator feed preparation as discussed in Section 5.2.1.4.

6.2.1.5 Thermal Treatment. This unit operation is evaluated in Section 5.2.1.6.

6.2.1.6 Organic Removal. This equipment removes organic contamination from solids such as soil, concrete, debris, and other inert material. It also thermally destroys any combustible or organic vapor removed from the waste. Technologies include biological treatment and thermal treatment. Biological treatment for radioactive waste is still in the R\&D stage. A potentially feasible thermal treatment technique for alpha-LLW is thermal desorption. This technique heats the waste in an oxygen deficient environment. The organics are either directly volatilized or decomposed into light organics and then volatilized. Both indirectly heated systems and microwave systems have been tested on a pilot scale. Microwave and indirect heating devices are commercially available and operational. Microwave heating of sludges is being evaluated at the Rocky Flats Plant and at the Oak Ridge National Laboratory (ORNL). Decontamination of various soils containing PCBs, furans, and dioxin has been reported, and this process could be applied to sludges.

Incineration can also be used to eliminate volatile organics from sludges but the operating cost may be more expensive than low-temperature thermal desportion treatment followed by thermal oxidization. The latter option was used in this study. This approach has become a common practice for treatment of petroleum and other hydrocarbon-contaminated soil. The Clean Soil Machine by Penn Thermal Process, Sewickley, PA, was used as reference equipment in this study. In general, commercial equipment is available for this unit operation, but DT\&E to ensure the applicability of the commercially available products to the INEL radioactive waste streams is needed before final selection of an approach.

6.2.1.7 Solidification Feed Preparation. The solidification feed preparation uses equipment that is similar to the incinerator feed preparation unit operation discussed in Section 5.2.1.4.

6.2.1.8 Solidification. Solidification stabilizes the incoming waste (i.e., ash, inorganic sludge, and treated combustibles) into a material that meets LDR, EPA, and DOE requirements. The 

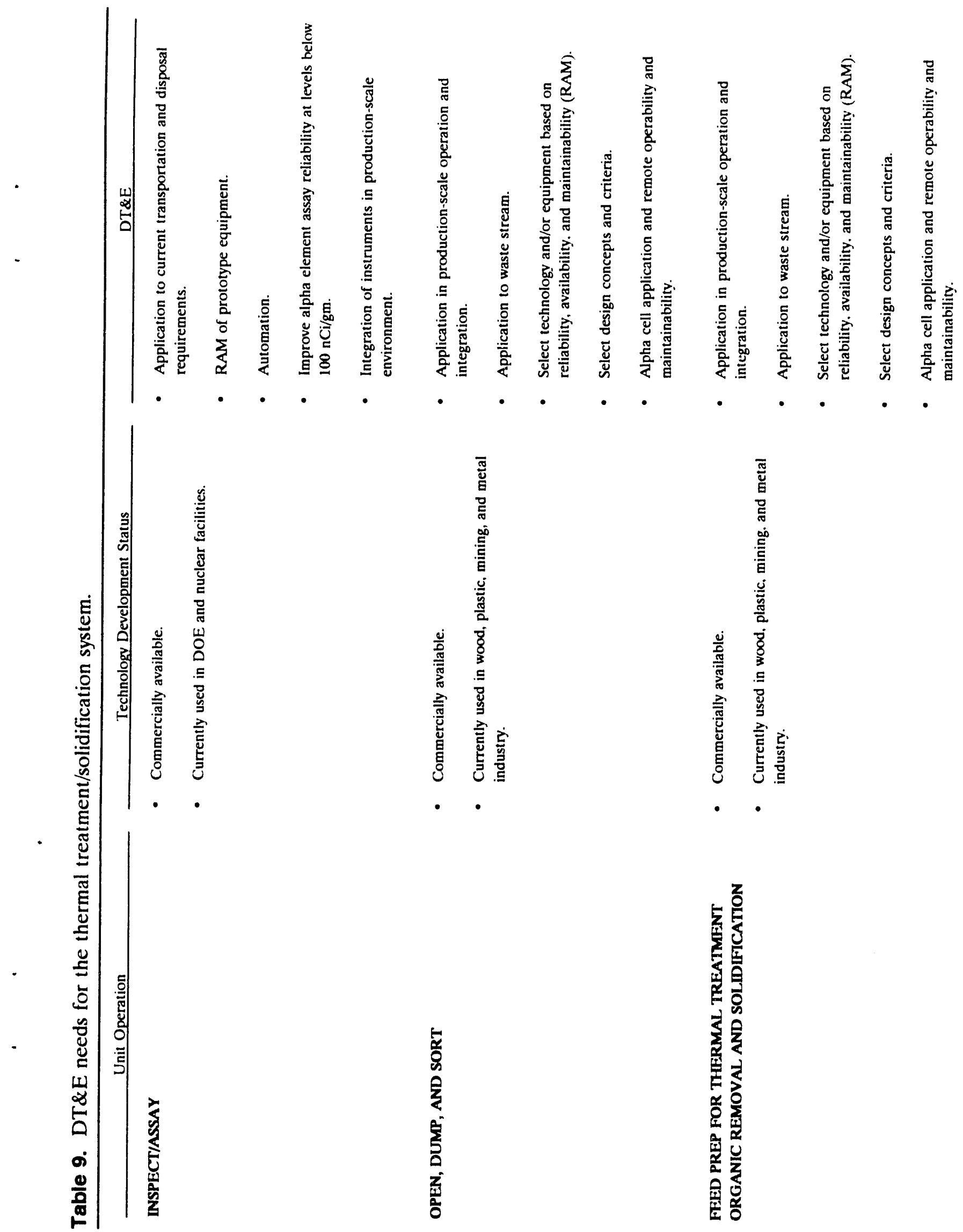


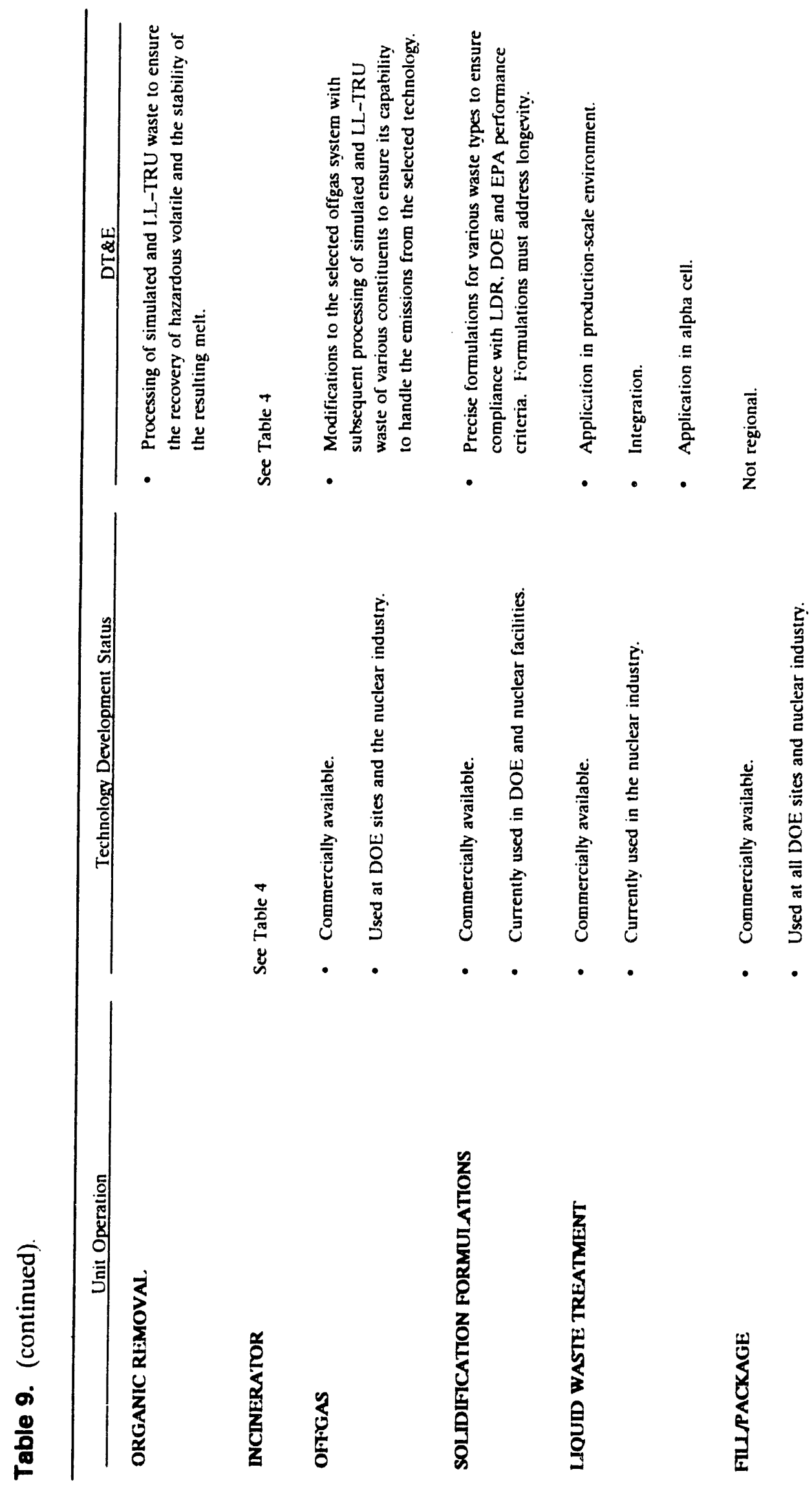




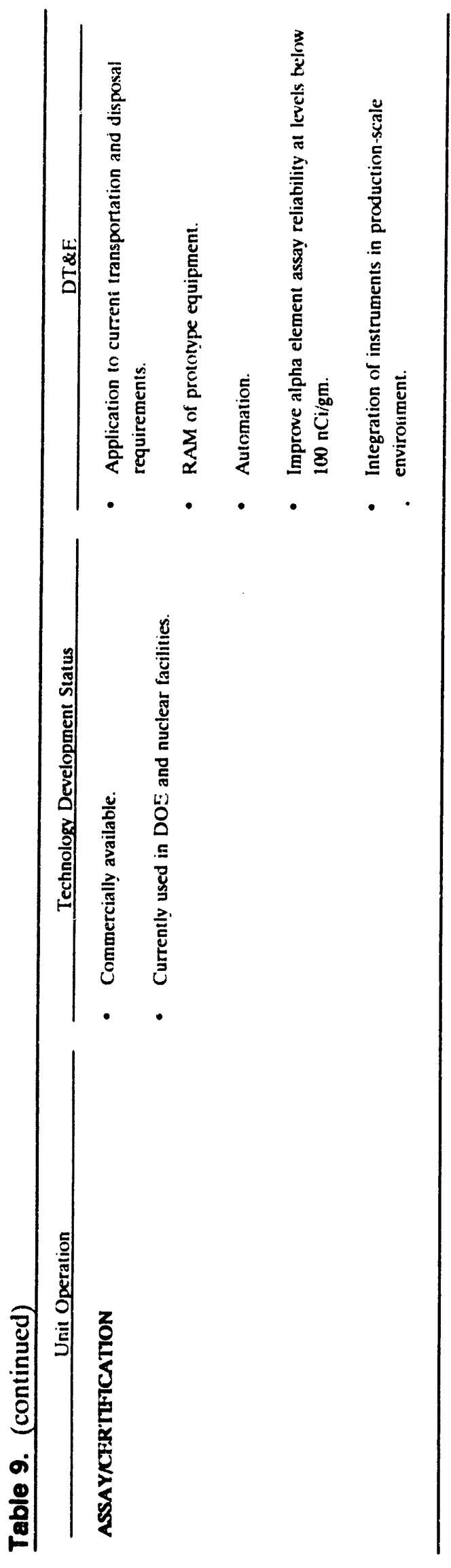


solidification process using bitumen or cement for LLW is currently operational. At commercial utilities, evaporator concentrates are solidified in drums or large containers. These technologies have been demonstrated in the United States and abroad, particularly for nuclear power station wastes. The degree to which these technologies have been proven is a function of required leach resistance duration of material integrity (durability) and waste composition of application.

Available alternative solidification agents include organic and inorganic materials. ${ }^{10,11}$ Organic agents are less desirable because gas generation from the biological degradation of organics is a concern. In this study, Portland cement is selected for solidifying alpha-LLW.

Hardware required for solidification is well developed and commercially available. Solidification systems exist in both stationary and mobile configurations for a variety of wastes. The candidate processes are cement solidification, bitumen, Dow process (solidification of waste in a plastic medium supplied by Dow Chemical), and other polymer processing (solidification of waste in a polymer medium). Sulfur polymer cement systems are under development and also are potentially useable for solidification of the waste. The equipment typically used in these processes includes automated conveyor equipment, container handling equipment, tanks, drums/containers, pumps, slurry equipment, chemical process control equipment, and dewatering equipment. The processes and equipment are all commercially available and in use.

Cementation is the predominant solidification technique currently in use. Bitumen solidification is being used to process boric acid concentrates, sodium sulfate concentrates, and spent ion exchange resins from commercial nuclear power plants. Incinerator ash from the INEL Waste Experimental Reduction Laboratory (WERF) incinerator is also cemented.

The Transportable Volume Reduction and Solidification System (TVR-III) offered by U.S. Ecology is a mobile unit that uses bitumen as the solidifying agent. SEG uses the DOW process for stabilizing incinerator ash. The DOE Savannah River site uses a combination of cement and ash process, referred to as Saltstone, to stabilize supernate waste-containing nitrates. The WERF facility at the INEL uses portland cement for ash stabilization. The DOE Haniord, WA, site is using Transportable Grout Equipment to solidify a variety of radioactive liquid waste and sludges.

Most solidification processes are highly sensitive to waste characteristics. For example, highliquid acidic or organic contents can prevent cement from curing. Different waste types require different formulations to produce a waste form that meets the required performance criteria of leachability, strength, and longevity. Therefore, an essential part of the process is waste characterization before the process is designed and/or some type of process measurement to determine composition of the feed to the solidification unit.

In conclusion, although solidification processes have long been operational, DT\&E is needed to verify that the required performance can be achieved, given the wide range of waste types expected from the INEL. Formulas are needed for a broad range of ash, sludge, soil, and other waste compositions to ensure they can meet the LDR requirements. Because alpha-LLW remains hazardous longer than typical LLW, formulations must specifically address waste characteristic sensitivities to longevity. In summary, solidification requires DT\&E to determine precise formulations for the treated INEL waste streams. 
6.2.1.9 Liquid Waste Treatment. An evaluation of this unit operation is presented in Section 5.2.1.11.

6.2.1.10 Fill and Package. Functions of this unit operation are filling, capping, packaging, cleaning, and testing the solidified waste mixture after it is discharged from the solidification mixer. Equipment accomplishing similar functions are widely used in the nuclear industry and no specific DT\&E is anticipated.

6.2.1.11 Assay/Certification. An evaluation of this unit operation is presented is Section 5.2.1.13.

6.2.1.12 Interim Storage \& Shipping. An evaluation of this unit operation is presented is Section 5.2.1.14.

\subsubsection{Program Implementation Risks}

This section identifies significant concerns associated with program implementation if the thermal treatment/solidification system is selected and qualitatively characterizes the risk of accomplishing the program objectives. The program mission and objectives are presented in Section 2, and assumptions used in characterizing risks are presented in Section 4. A summary of results and major areas of concern are presented in Table 10. Note that all technical issues listed in this table are engineering-solveable issues and do not appear to present any technical difficulties.

In the following discussion, the thermal treatment/solidification system risks are compared with the incineration/melting system. Reference is made to the analysis provided for the incineration/melting process, when applicable.

6.2.2.1 Technical Objectives. Technical objectives for the alpha-LLW process can be summarized in the following two categories:

- Waste form: The waste form must meet the DOE, EPA, and DOT standards for storage, transportation, and disposal. Also, additional requirements on waste form will be derived from a performance assessment to be based on the intended disposal environments.

- Safety: Facility operation must be conducted to ensure the safety of the worker, the public, and the environment.

Because this system produces a solidified waste form, the risk associated with achieving the waste form technical objectives is greater than risks for the incineration/melting system. A key concern is the ability to prove that solidified waste forms will retain the hazardous components for the required long-term ( $>500$ years) period. Longevity criteria will probably be required by the performance assessment results if shallow-land burial is considered.

In assessing the safety of waste handling and process equipment operations, the risk of system compliance with the technical objective is characterized as moderate, similar to the incineration/melting system (see Section 5.2.2.1). However, when this rating is combined with the concerns for meeting the waste form criteria (which was not the case for the incineration/melting 


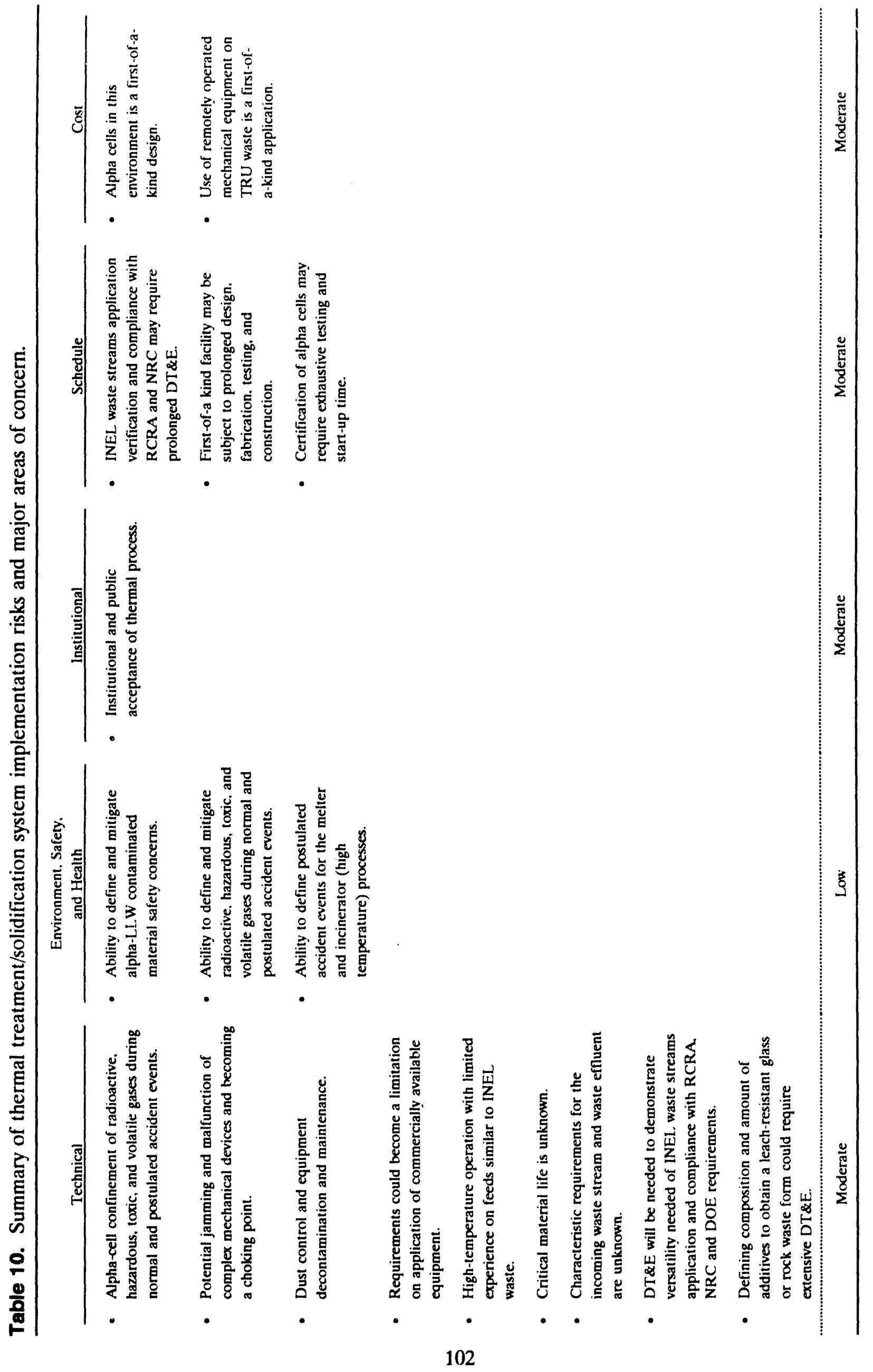


system), the resultant overall risk characterized for this system is higher than the incineration/melting system, and a moderate rating is assigned.

6.2.2.2 Health and Safety Objectives. Program implementation risks to meet health and safety objectives are similar to the discussion presented in Section 5.2.2.2, and the overall risk is low.

6.2.2.3 Institutional Objectives. Program implementation risks to meet institutional objectives are similar to the discussion presented in Section 5.2.2.3, and the overall risk is high.

6.2.2.4 Schedule Objectives. Program implementation risks to meet schedule objectives are similar to the discussions presented in Section 5.2.2.4, with the exception that the prolonged melter DT\&E, which is required for the incineration/melting systems, is not needed for the thermal treatment/solidification system. However, because of the anticipated delays during the incinerator startup tests, the schedule objectives risk for this system receives a moderate rating.

6.2.2.5 Cost Objective. As with the incineration/melting system (see Section 5.2.2.5), accurate cost estimates are not anticipated until design, based on DT\&E, is well into maturity. Therefore, the cost objective risk for this system is moderate.

\subsubsection{Unit Operations DT\&E Lead-Time Estimates}

The DT\&E lead time and manpower for each unit operation requiring DT\&E have been estimated and are shown in Table 11. Lead-time estimates are based on the assumption: presented in Section 4.

\subsubsection{Rough-Order-of-Magnitude Cost Estimates}

ROM costs are summarized in Table 12. Assumptions, methodology and details are presented in Appendix B.

\subsubsection{System Evaluation Results}

This section presents an overall evaluation of the system and identifies the major advantages and disadvantages based on the system assessments. This includes an evaluation integrating individual unit operations into a smooth, efficient system. Specific areas addressed include identification of system advantages and disadvantages, a qualitative ranking of performance measurables as identified in Section 3, a summary of DT\&E requirements, and an overall recommendation for the system.

6.2.5.1 Major System Advantages and Disadvantages. Currently a wide variety of incineration, organic removal, and solidification technologies exist in various stages of development, testing, and application. Incineration is used in fossil power plants as well as in sanitary waste facilities; both industries have to address stringent emission requirements. In addition, thermal desorbers and solidification techniques employed in the hazardous waste industry, are applicable to processing alpha-LLW. However, application of these technologies to mixed radioactive and hazardous waste has only been performed on a limited scale. 


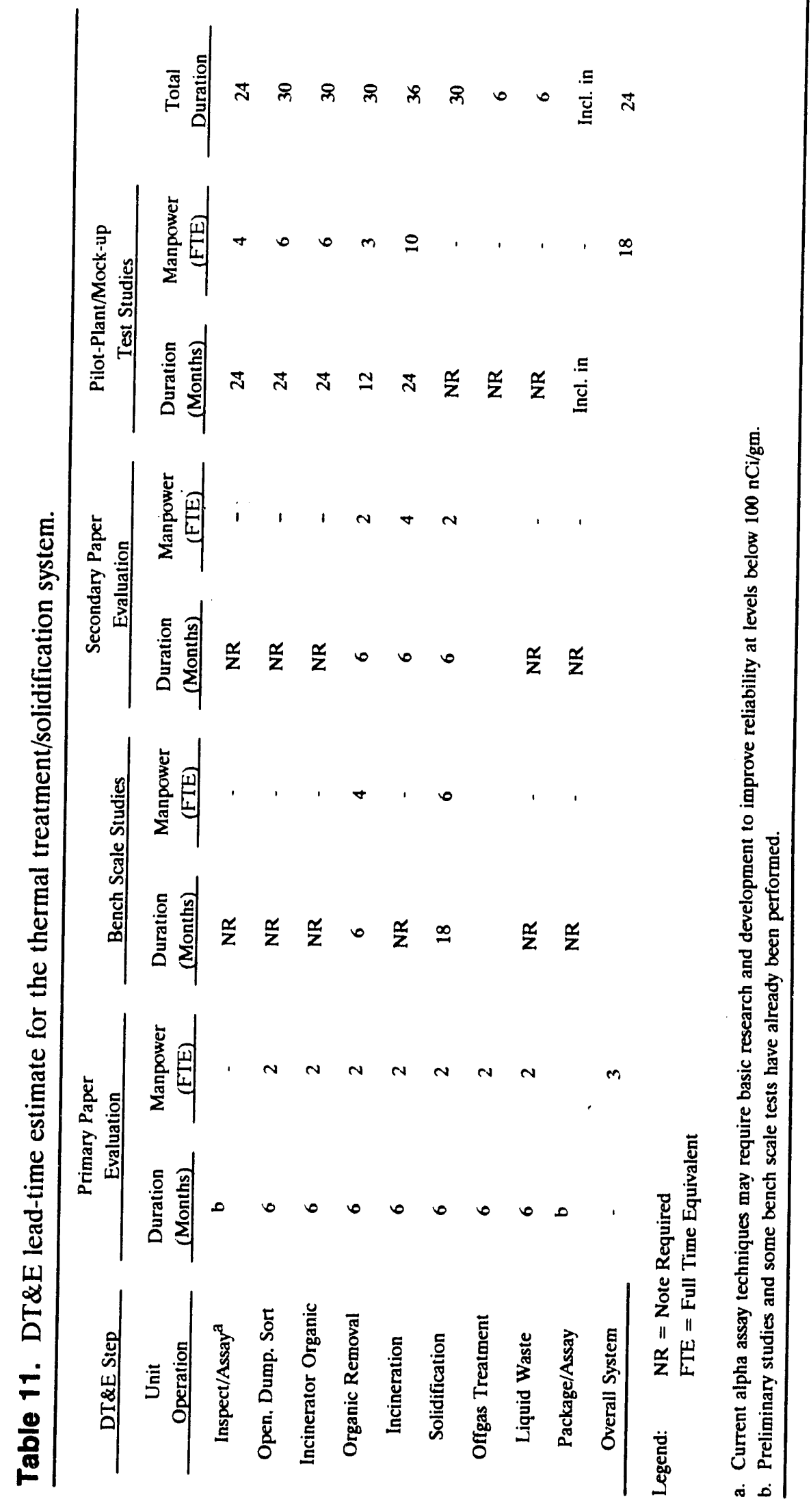


Table 12. Rough-order-of-magnitude cost estimates for thermal treatment/solidification system $(\mathrm{x} \$ 1,000)$.

\begin{tabular}{lr}
\hline Item & $(x \$ 1,000)$ \\
\hline Studies \& Bench Scale Tests & $\$ 8,600$ \\
Demonstration & $\$ 17,479$ \\
Production Construction & $\$ 131,049$ \\
Operating and Maintenance & $\$ 170,600$ \\
Disposal and Transportation & $\$ 108,740$ \\
Operating Funds Budgeted Activities & $\$ 139,200$ \\
Decontamination \& Decommissioning & $\$ 29,663$ \\
Total Life-Cycle & $\$ 605,271$ \\
\hline
\end{tabular}

The unknown characteristics of the waste stream feed stock in the incinerator and organic removal units present potential operation problems such as deterioration of the refractory liner of the furnace (a refractory design based on common skull technique can be used to reduce the refractory replacement problems). Certain types of input wastes may react with the furnace refractory liner requiring repair and significant downtime, and may expose maintenance personnel to radiation hazards. In addition, the treatment of gaseous effluent resulting from processing unknown materials may result in a moderate risk factor as the offgas unit operation must be designed for a wide range of effluent.

The significant advantage of the thermal treatment/solidification system is combustible waste volume reduction and destruction of hazardous organics. The significant disadvantages are the potential for large volumes of offgas (the use of incinerators that minimize offgas discharges - such as pyrolysis technique with oxygen burning - will reduce the high offgas generation problem), the need for secondary burners to further treat offgas, and the potential for poor-quality waste forms. Solidification agents are generally cementitious in nature and, although very near-term stable if properly formed, they do not provide for assurrance for long-term ( $>300$ years) retention of TRU elements, as does the vifrification system option. The thermal treatment and solidification system requires a relatively short lead-time for DT\&E. Following are specific system advantages and disadvantages.

\subsubsection{Advantages.}

- Metals are sorted upfront, size reduced, and decontaminated to a LLW level which is less costly to dispose of than alpha-LLW (note that a majority of the metals are believed to be already LLW). Sorting the metal for decontamination in a separate facility allows cleaner and smoother operations of these processes.

- Process upsets from incompatible waste are prevented by separating the undesirable waste prior to treatment. 
- Due to a versatile incinerator design, the sorting of combustibles from noncombustibles has been minimized. This should increase the process availability and minimize operating and maintenance labor.

- Solidification technologies are simple. With proper characterization of the incoming waste and correct formulations, they are capable of handling a wide variety of wastes.

\subsubsection{Disadvantages.}

- The incinerator, organic removal, and solidification feed preparation operations and the open, dump, and sort operations are complex and time consuming and can result in contamination spread and increased maintenance.

- Even though the volume of waste is reduced by the incinerator, the full benefit is not realized because a significant amount of solidification agent must be added to stabilize the waste. This increases the volume of the final product, usually by a factor of 2 .

- Solidification agents are generally cementitious in nature and, although very near-term stable if properly formed, they do not provide for assurrance for long-term ( $>300$ years) retention of TRU elements, as does the vifrification system option.

- The incinerator refractory linings have annual maintenance and a deactivation schedule.

- There is a lack of incineration and organic removal experience with alpha-LLW and in an alpha environment.

- When compared to non-thermal processes, the offgas equipment requires high capital costs. Also, it requires process development work on anticipated exhaust gas from hazardous waste destruction.

6.2.5.4 Performance Measurable Rating. Section 3 identifies performance measurables that are used in the evaluation of the overall system. Table 13 is a judgment-based qualitative assessment of the system's performance measurables. Following are the key factors considered while developing scores for the unit operation performance:

- Assay/Inspect and Assay/Certification: The performance rating is presented in Section 5.2.5.4.

- Open, Dump, and Sort: The performance rating is presented in Section 5.2.5.4.

- Incinerator, organic removal, and solidification feed preparation: The performance rating is similar to the feed preparation unit for incinerator/melter pres ented in Section 5.2.5.4.

- Incineration: LLW is currently being incinerated at the INEL in the WERF controlled-air incinerator and at the commercial SEG facility at Oak Ridge. Radioactive waste is also incinerated at numerous facilities abroad. The application of incineration to alpha-LLW materials could impose unique requirements on the offgas system. Therefore, the risk score is downgraded. 


$$
\begin{aligned}
& \text { สำ }
\end{aligned}
$$

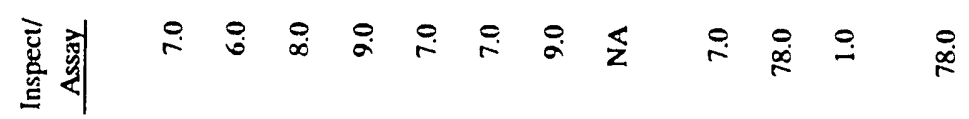

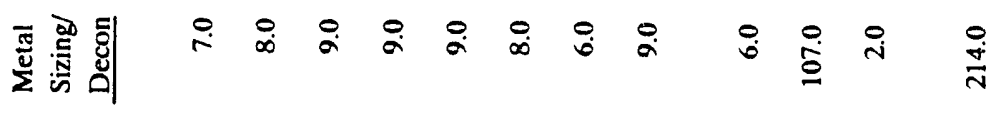

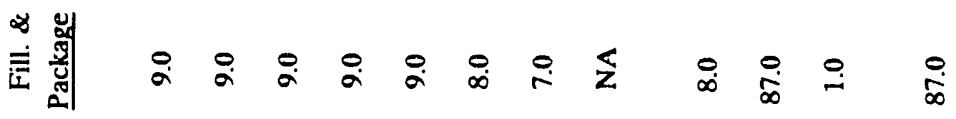

$$
\begin{aligned}
& \text { 旁离 }
\end{aligned}
$$

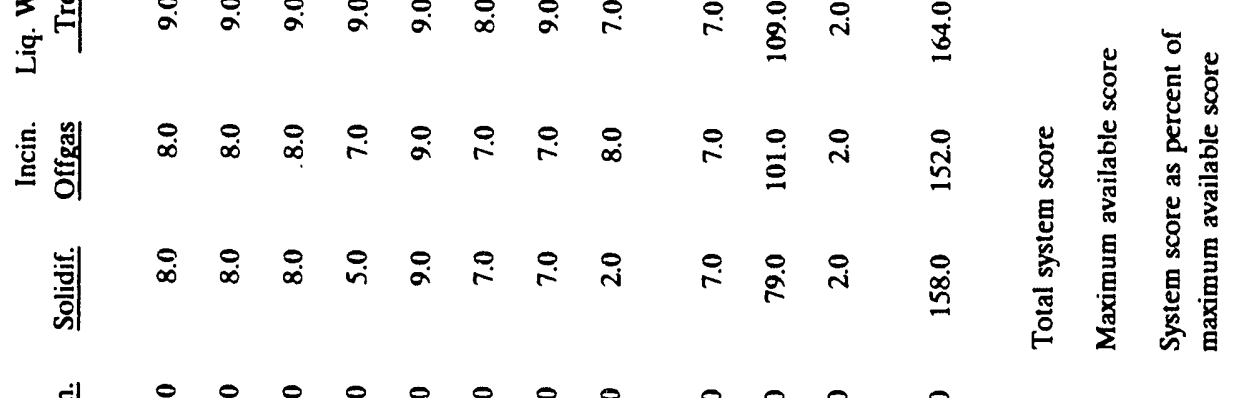

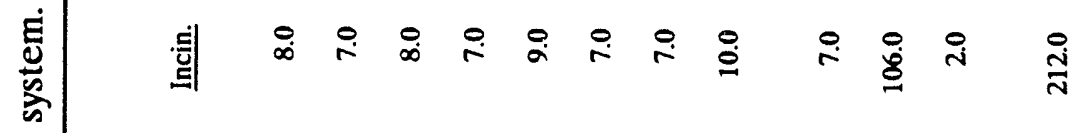

$$
\begin{aligned}
& \text { 氖总 }
\end{aligned}
$$

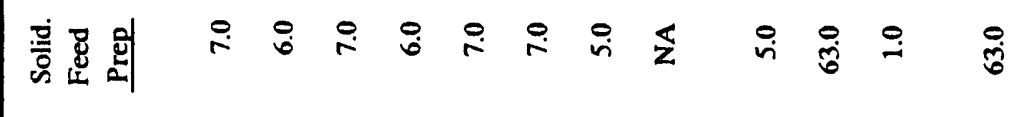

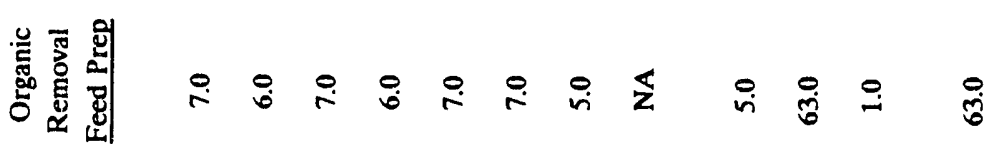

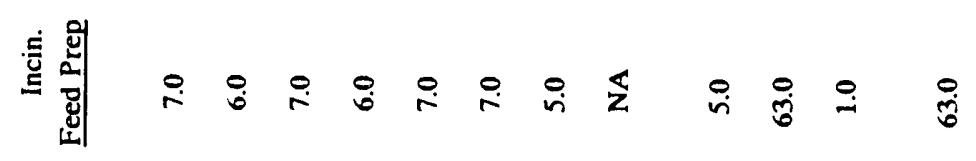

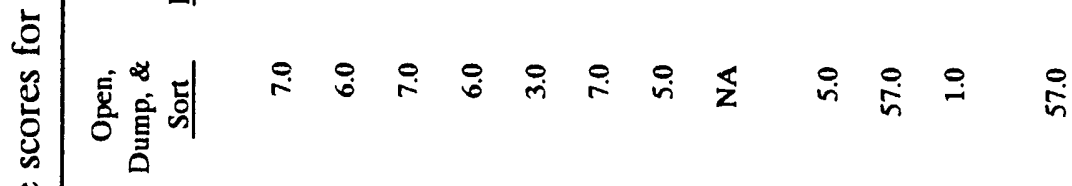

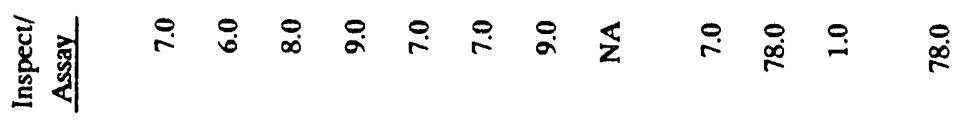

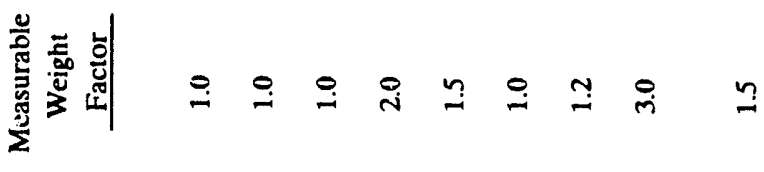

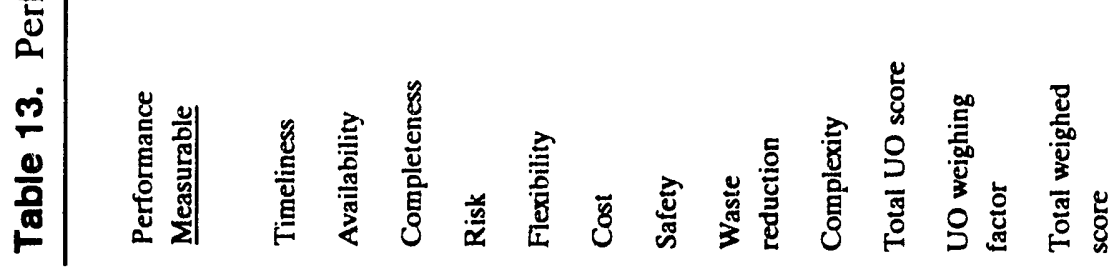

$$
\begin{aligned}
& \text { 莺 } \\
& \text { 导 }
\end{aligned}
$$


- Organic removal: Organic removal by thermal desorbers is a commercially accepted practice for hazardous waste. However, the application of this technology to alpha-LLW materials could impose unique requirements on the material handling equipment, the offgas system, and the overall design of the unit for remote operation and maintenance. Therefore, the scores are downgraded.

- Incinerator and organic removal offgas: The offgas from the incineration and organic removal processes must be treated to remove acid gases and particulate matter. Two available options are wet and dry systems. With the expected amount of acid gases generated by the chlorinated wastes, a wet system (or semi-dry) is the only option that will meet regulatory requirements. Because wet systems are well developed, most attributes for the offgas receive a moderately high score.

- Liquid waste treatment: The performance rating is presented in Section 5.2.5.4.

- Fill and package: Most of the system components have been used in the nuclear industry and can be acquired from specialized firms. Therefore, most attributes of this unit operation receive a high grade.

\subsubsection{Summary of Demonstration, Testing, and Evaluation Needs}

The DT\&E requirements for each unit operation and for the overall system are summarized in Tables 9 and 11. These tables provide a ready reference to DT\&E requirement in the final system evaluation and for comparison purposes with other systems.

\subsection{Recommendation for the System}

This system utilizes thermal treatment and solidification technologies to treat the waste. Thermal treatment reduces the volume of the waste requiring long-term storage and disposal. However, some of the volume reduction effects are negated by the solidification process, which almost doubles the final volume of the processed waste. The thermal treatment and solidification processes are sensitive to the input waste streams and precise process control is required.

A thermal desorber is used for treating noncombustible wastes contaminated with organic compounds. As an alternative, this category of waste can be processed in the " inerator unit operation, which would reduce the number of unit operations. However, for this aliernative to be practical, the incinerator design must tolerate a large amount of noncombustibles without causing unacceptable refractory wear.

A major concern of solidification is its waste form acceptability. Even though solidification processes are the most widely used techniques for waste stabilization, their ability to stabilize TRU element migration in a shallow-land burial environment or in an engineered facility has not been examined, to the authors' knowledge, in a performance assessment. Test data along with performance assessments are needed to ensure that the level of long-term protection this waste form provides is adequate per DOE Order 5820.2A. 
Several issues that will require further development include:

- Analyzing the queuing of the waste stream to determine capacities of components within unit operations

- Fine tuning of all the selected technologies to produce the desired results

- Verifying the integration of the process streams to ensure compatibility.

There are several technology advantages that recommend this system for consideration: thermal treatment destroys most combustibles and organics and significantly reduces the waste volume and hazards, the treated waste requiring stabilization is contaminated with only radionuclides and heavy metals, and the proposed stabilization technique is a simple solidification process. Furthermore, the implementation of the system involves less DT\&E than the incineration/melting system. The integration of the unit operations into a functioning facility should not present any extraordinary challenges. 


\section{SORT, TREAT, AND REPACKAGE SYSTEM}

This section describes a sort, treat, repackage system devised to convert the stored alpha-LLW into a physical and chemical form that meets the requirements of a deep geologic repository such as the Waste Isolation Pilot Plant (WIPP). (This waste stream is specifically excluded from WIPP since it is $<100 \mathrm{nCi} / \mathrm{gm}$.) Accordingly, the waste acceptance criteria for WIPP is used to model the waste form requirements of this system.

\subsection{Functional and Operational Requirements}

\subsubsection{System Description}

The sort, treat, and repackage system, shown in Figure 16, is comprised of twelve main process unit operations and a metal sizing and decontamination subsystem. The metal sizing and decontamination subsystem and its related unit operations are described in Section 8.

Procedures and operations to transport the waste containers to the facility, inspect and assay the containers, and transfer them to the open, dump, and sort unit operation are the same for this system as the incineration/melting and thermal treatment/solidification systems (see description in Section 5.1.1).

The open, dump, and sort unit operation receives the waste containers, de-caps them, and dumps their contents either on a sorting device or on transport devices that carry them directly to the next unit operation, the metal sizing/decontamination subsystem or the liquids/fines sort. When dumped on the sorting device, special wastes (i.e., compressed gas cylinders, bulk metals, and remote handled) are separated first and then placed on the transport devices. The open, dump, and sort unit operation can also size-reduce empty non-metal containers. The empty metal containers are transported to the metal sizing and decontamination subsystem for processing.

After the open, dump, and sort operations, the waste is transferred to a second sorting device where liquids and fines are removed and fed to a solidification feed preparation unit. The remaining dry solid waste is size reduced, placed in shipping containers, compacted, and repackaged without any further treatment.

After processing by a feed preparation unit, the liquids/fines waste stream is mixed with a solidification additive and poured into disposal containers. The mixing and curing formulations will achieve the most stabilized waste form.

The system's two major products are the repackaged waste and the solidified waste. Other system products include decontaminated metals (suitable for shallow-land disposal or potential recycling, if allowed by regulation) discharged from the metal sizing and decontamination subsystem. All system products are containerized and processed through a radio-assay and a final certification process. Certified containers are kept in the facility for an interim period before offsite shipping to long-term storage and disposal facilities. 


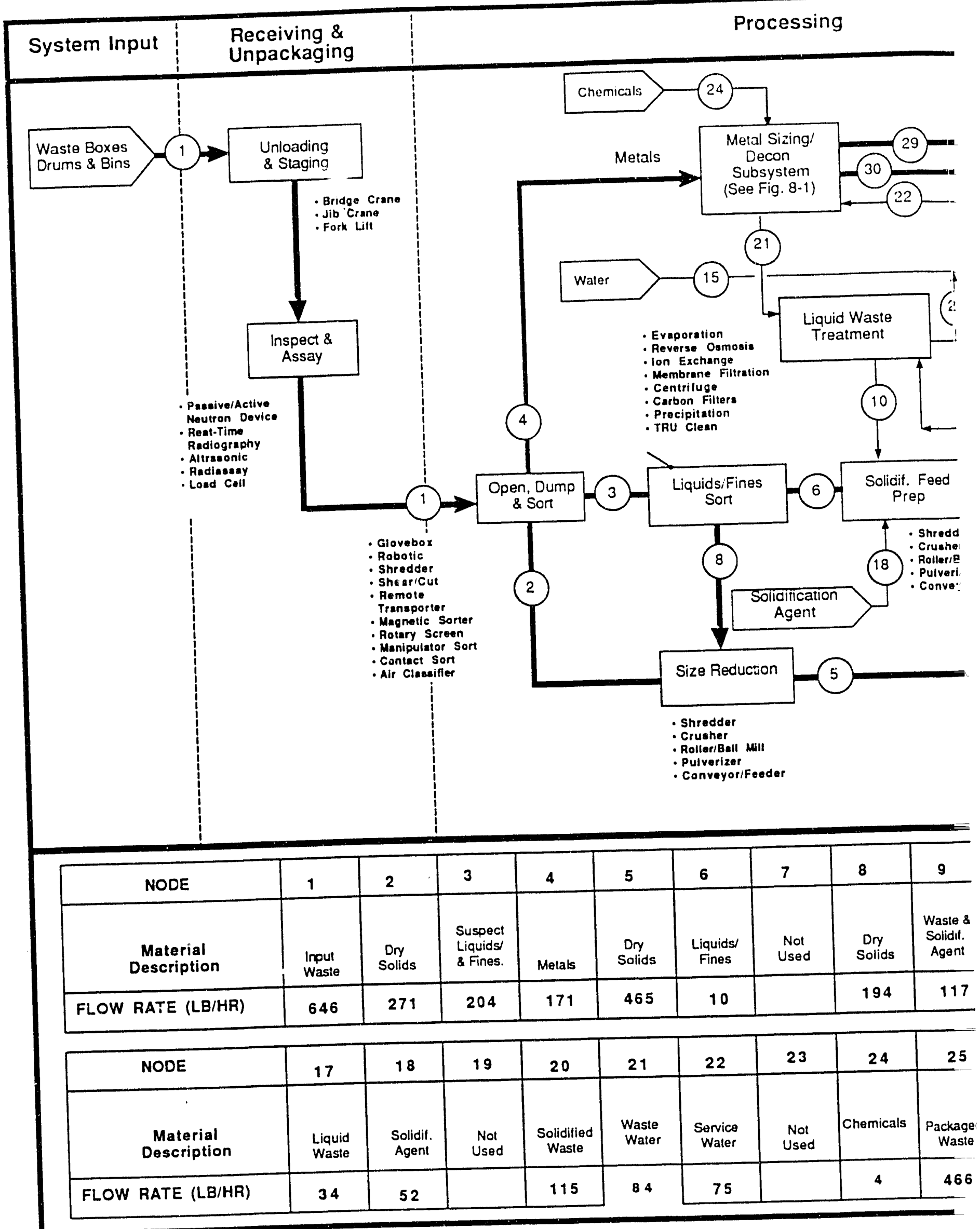

Figure 16. Process functional diagram for sort, treat, and repackage system. 


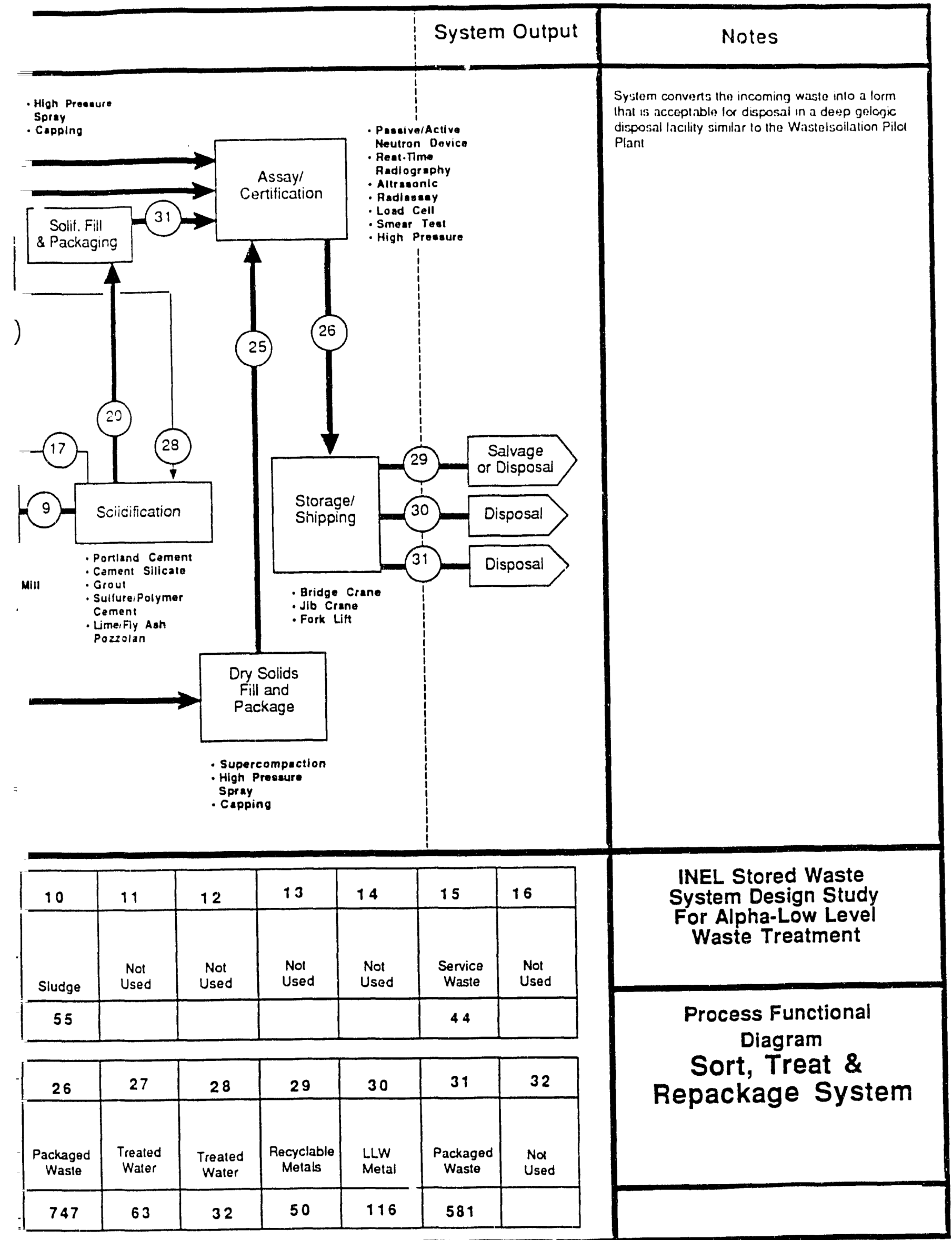


The system has two secondary waste streams: processing cell ventilation offgas and liquids. Offgas is processed by HEPA and carbon filters, monitored, and then discharged.

Secondary liquid waste is processed by a liquid waste-treatment unit operation. This unit operation removes dissolved and suspended solids (organic and inorganic) from the liquid waste. The treated waste water is recycled and reused. Sludge and other wet solids are fed to the solidification unit for processing.

\subsubsection{System Requirements}

The system functions are the same as those described in Section 5.1.2 with the following exceptions:

- The waste form is suitable for a geologic disposal and is assumed to be exempt from the LDR requirements.

- Only liquids and fines are stabilized as required by WIPP waste acceptance criteria. Other wastes are simply repackaged and certified in compliance with WIPP waste acceptance criteria and TRAMPAC.

\subsubsection{Unit Operations Functional Requirements}

Each unit operation has facilities, equipment, devices, and accessories required to perform the functional and subfunctional operation discussed below. Detailed performance requirements for the unit operations will be developed in future studies. A preliminary unit operations subfunctional flow diagram for the system is shown in Figure 17.

Because many of the unit operations in this system and the incineration/melting and thermal treatment/solidification system are similar, the corresponding sections of the incineration/melting and thermal treatment/solidification systems are referenced when the unit operation descriptions are the same.

7.1.3.1 Unloading and Staging. See Section 5.1.3.1 for unit operation functional and subfunctional descriptions.

7.1.3.2 Inspect/Assay. See Section 5.1.3.2 for unit operation functional and subfunctional descriptions.

7.1.3.3 Open, Dump, and Sort. See Section 5.1.3.3 for unit operation functional and subfunctional descriptions.

\subsubsection{Liquids and Fines Sort.}

- Unit operation functions summary: This unit operation receives waste from the open, dump, and sort unit operation and separates liquids and fines from the incoming waste. Liquids and fines are sent to a solidification unit while the remaining waste is transferred to a size reduction unit operation. 


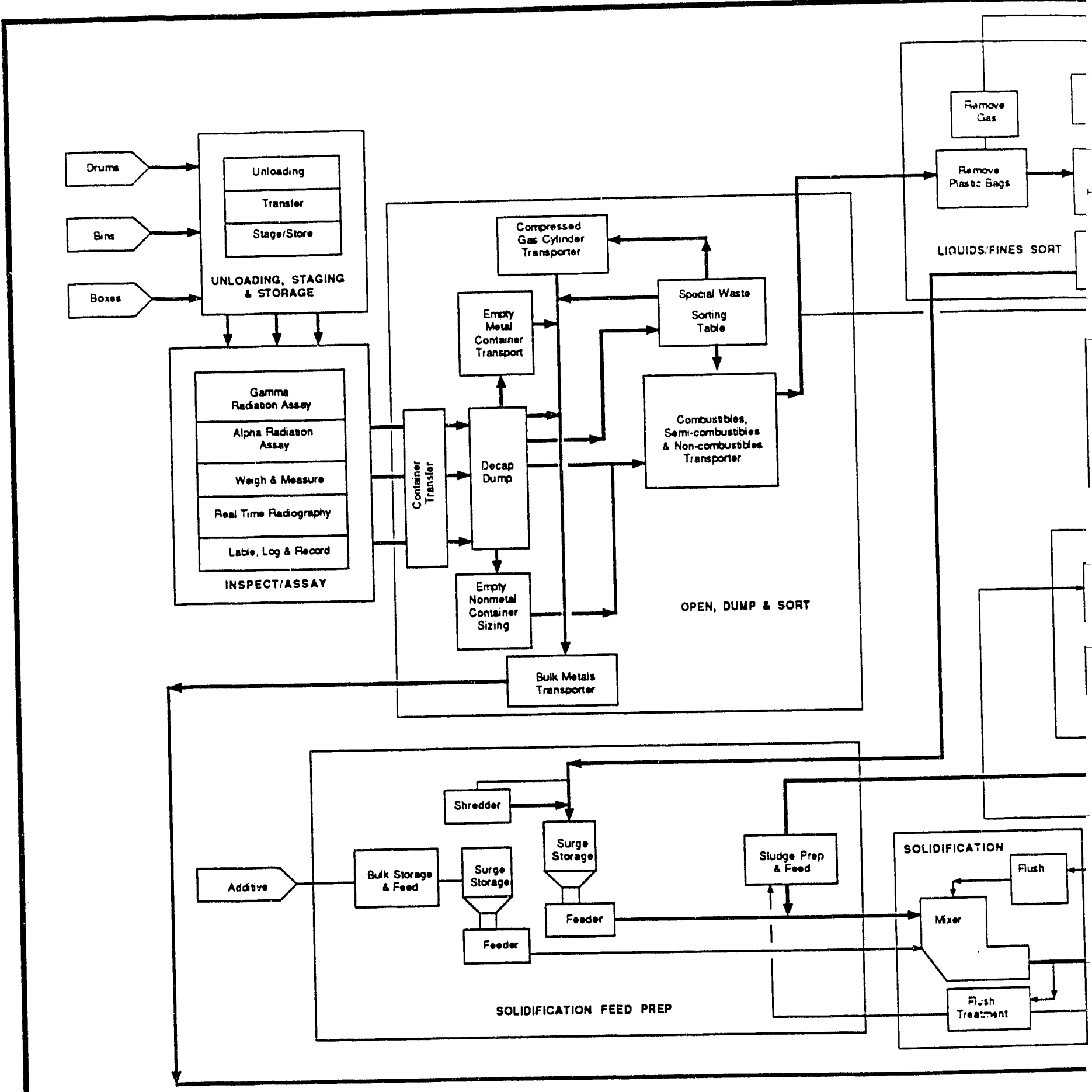

Figure 17. Unit operations subfunctional tlow diagram for sort, treat, and repackage system (4-BE-1). 


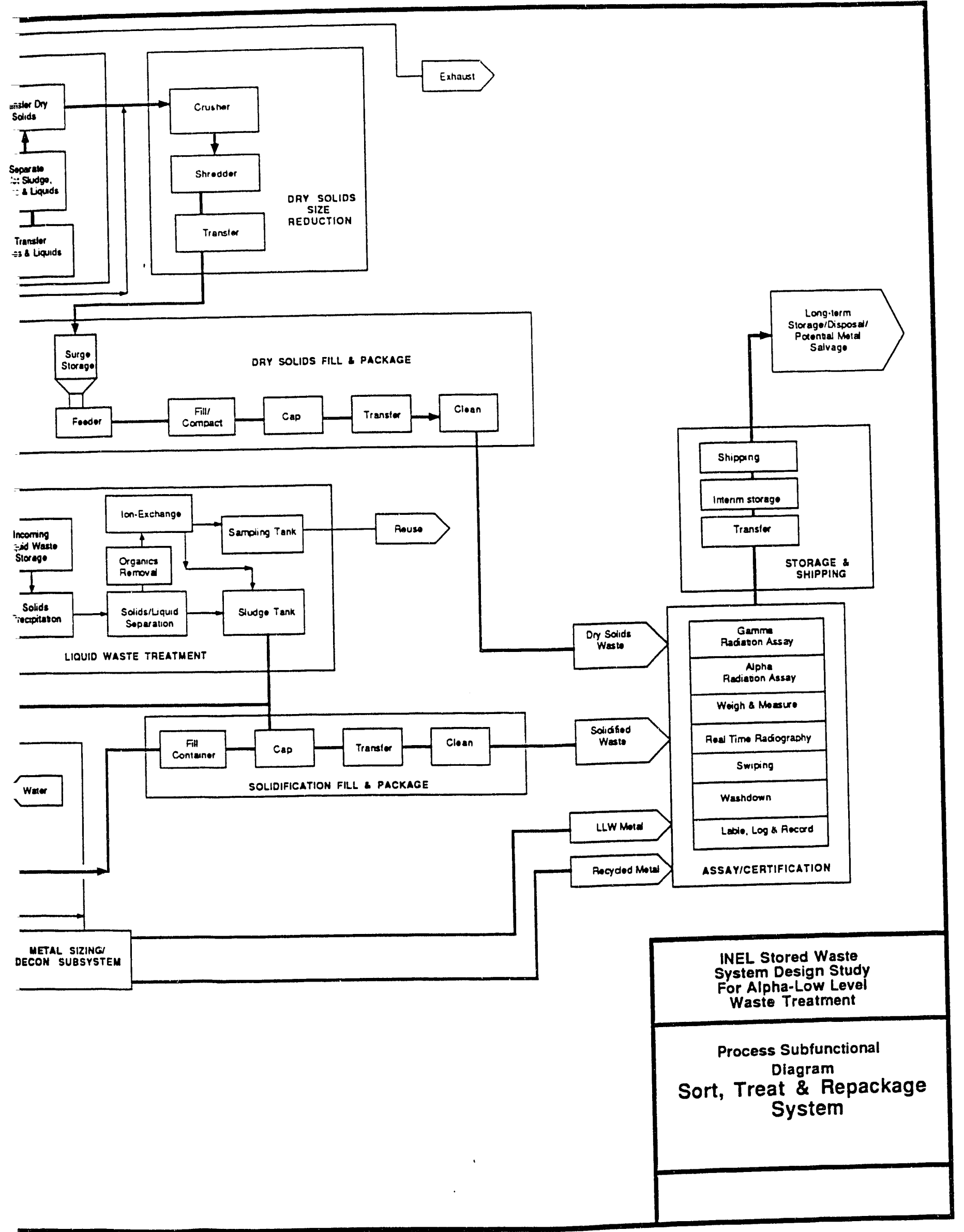


- Allocated functions: Unit operation functions are allocated to the following subfunctions:

- Controlled environment: Operation and maintenance are accomplished remotely in a controlled environment as discussed in Section 5.1.3.3.

- Remove plastic bags: Any waste wrapped in plastic bags is unpackaged and the packaging material (i.e., plastic bags and tapes) is sent to the size reduction unit operation. The waste is sent to the fines and liquids separation device.

- Separate liquids and fines: Waste is examined to detect any material containing liquids and fines (as defined by WIPP waste acceptance criteria). Liquids, fines, and dry solids are placed on separate transfer devices.

- Transfer liquids and fines: Liquids and fines are transferred to the solidification feed and preparation unit.

- Transfer dry solids: Dry solids are transferred to a size reduction unit.

- Vent bags: Vapors and gases from punctured plastic bags are collected, removed, and treated.

\subsubsection{Size reduction.}

- Unit operation functions summary. The function of this unit operation is to reduce the size of dry solids. After size reduction, the waste is sent to a fill and package unit.

- Allocated functions: Unit operation functions are allocated to the following subfunctions:

- Controlled environment: Operation and maintenance are accomplished remotely in a controlled environment as discussed in Section 5.1.3.3.

- Crusher: The incoming waste is crushed to reduce the size of the larger pieces.

- Shredder: After crushing, the waste is further reduced to efficiently fill the containers.

- Transfer dry solids: Size-reduced waste is transferred to a dry solids fill and package station.

\subsubsection{Dry Solids Fill and Package.}

- Unit operation functions summary. The unit operation stores the incoming dry solids, dumps them into shipping or disposal containers, compacts the waste inside containers, caps the containers, and swipe tests and cleans each container surface to remove exterior contamination. The packaged waste is sent from this operation to an assay/certification and storage area. 
- Allocated functions: Unit operation functions are allocated to the following subfunctions:

- Controlled environment: Operation and maintenance are accomplished remotely in a controlled environment as discussed in Section 5.1.3.3.

- Waste surge storage: Size-reduced waste is stored in a storage container with sufficient capacity to provide the required feed surge. The solids in the surge storage container can be sampled.

- Waste feeder: The feeder conveys the size-reduced waste to the shipping/disposal containers located at a compaction device.

- Container fill and compaction: The containers are filled with dry solids and compacted to maximize volume reduction and minimize contamination spread by spillage or airborne release.

- Cap: Filled containers are capped and sealed.

- Cleaning: The filled containers are smear tested; any loose surface contamination is removed with a water wash. The liquid waste from the container washdown operation is sent to the liquid waste-treatment unit operation.

- Transfer: Containers are moved by transfer devices to accomplish the various functions and subfunctions of the unit operation.

\subsubsection{Solidification Feed Preparation.}

- Unit operation functions summary. The solidification feed preparation unit receives, stores, handles, processes the incoming waste streams into a proper size and mixture, and feeds at a rate required by the solidification unit operation.

- Allocated functions: Unit operation functions are allocated to the following subfunctions:

Controlled environment: Operations and maintenance are conducted remotely in a controlled environment as discussed in Section 5.1.3.3.

- Crusher: The incoming waste is crushed to size reduce the larger pieces such as bottles, bags, and cans containing liquids and fines.

- Shredder: After crushing, the waste shredder further size reduces the waste to facilitate complete solidification.

- Waste surge storage: Size-reduced waste is stored in a storage container with sufficient capacity to provide the required solidification feed surge. The waste in the surge storage container can be sampled. 
- Waste feeder: A feeder conveys the material to the solidification unit at a desired feed rate.

- Solidification agent bulk storage and transfer: Solidification agent is stored in bulk containers and transferred to the agent surge storage unit as needed. Bulk storage capacity and transfer rate is sufficient to support the system availability requirements.

- Liquid residue feed: Liquid residue is received from the liquid waste treatment unit operation and is fed to the solidification unit.

- Solidification agent surge storage: Solidification agent transferred from the bulk storage area is stored in a container sized to provide the solidification feed surge capacity needs.

- Solidification agent feeder: The solidification agent feeder conveys the material to the solidification unit at the desired feed rate.

7.1.3.8 Solidification. The functional and subfunctional descriptions of this unit operation are the same as those described in Section 6.1.3.10.

7.1.3.9 Liquid Waste Treatment. The functional and subfunctional descriptions of this unit operation are the same as those described in Section 5.1.3.10.

7.1.3.10 Solidification Fill and Package. The functional and subfunctional descriptions of this unit operation are the same as those described in Section 6.1.3.12.

7.1.3.11 Assay/Certification. The functional and subfunctional descriptions of this unit operation are the same as those described in Section 5.1.3.12.

7.1.3.12 Interim Storage and Shipping. The functional and subfunctional descriptions of this unit operation are the same as those described in Section 5.1.3.13.

\subsubsection{System Boundaries}

Refer to Section 5.1.4 for a description of the system boundaries.

\subsubsection{System-Specific Assumptions}

Following are the system-specific assumptions:

- Solidification: The cement solidification process will produce a waste/cement mixture with a density of $112 \mathrm{lbs} / \mathrm{ft}^{3}$.

- Waste characterization: The mass and composition of the input waste stream was based on the characterization of the waste at the TSA (see Appendix A). 
- Mass flow rates: A summary of the estimated mass flow rates for the system is shown in Figure 16. The following assumptions have been used in developing these flow rates:

- Liquids/fines quantity: The quantity of this waste is $5 \%$ by weight of the total incoming waste.

- Fill/compaction efficiency: Reduced in size solids compaction produces containers with an average density of $40 \mathrm{lbs} / \mathrm{ft}^{3}$.

- Unit operation capacities: The unit operation capacities are at a minimum $125 \%$ of the design flow rates, based on the mass of waste that must be processed over a 10 -year period. Because of the low input feed rate, the unit operation estimated capacities are sometimes larger than the required size.

- The preconceptual design for the process cells handling opened containers is based on a conservative assumption that errors in alpha radiation measurement will result in the processing of waste with higher than $100 \mathrm{nCi} / \mathrm{gm}$ TRU content.

\subsubsection{Facility Description}

A scoping study layout for the system is shown in Figure 18. A single building houses the system, and incoming waste is unloaded at the truck bay in front of the building. A large open area adjacent to the truck bay is used for container staging, storage, and inspection and assay operations. From the open area, the containers are moved to the processing cells located in the center of the building.

Three parallel process cells are located perpendicular to an open, dump, and sort cell, with pipelines and conveyors passing over and under the operations and maintenance aisles. Each process cell is arranged with glass windows at the front so an operator is able to view the operations. The rear of each process cell adjoins a maintenance and decontamination cell. Equipment requiring repair or upkeep is pulled from the process cell and repaired in the maintenance cell. The maintenance and decontamination cells are accessible through airlocks and have a confinement-barrier level commensurate with the hazards level established by the design criteria.

\subsubsection{Interface Requirements}

Following are the interface requirements for the overall system (see Section 8 for the metal sizing and decontamination subsystems). The flow rates for the input, output, and intermediate points are given in the process functional diagram, Figure 16.

7.1.7.1 System Output. The system interface outputs include:

- $\quad$ Alpha-LLW, LLW metal, and potentially recyclable metal packages from the dry solids packaging, solidification, and metal decontamination operations to a long-term storage or disposal facility

- Ventilation exhaust gases from the stack discharged to atmosphere 


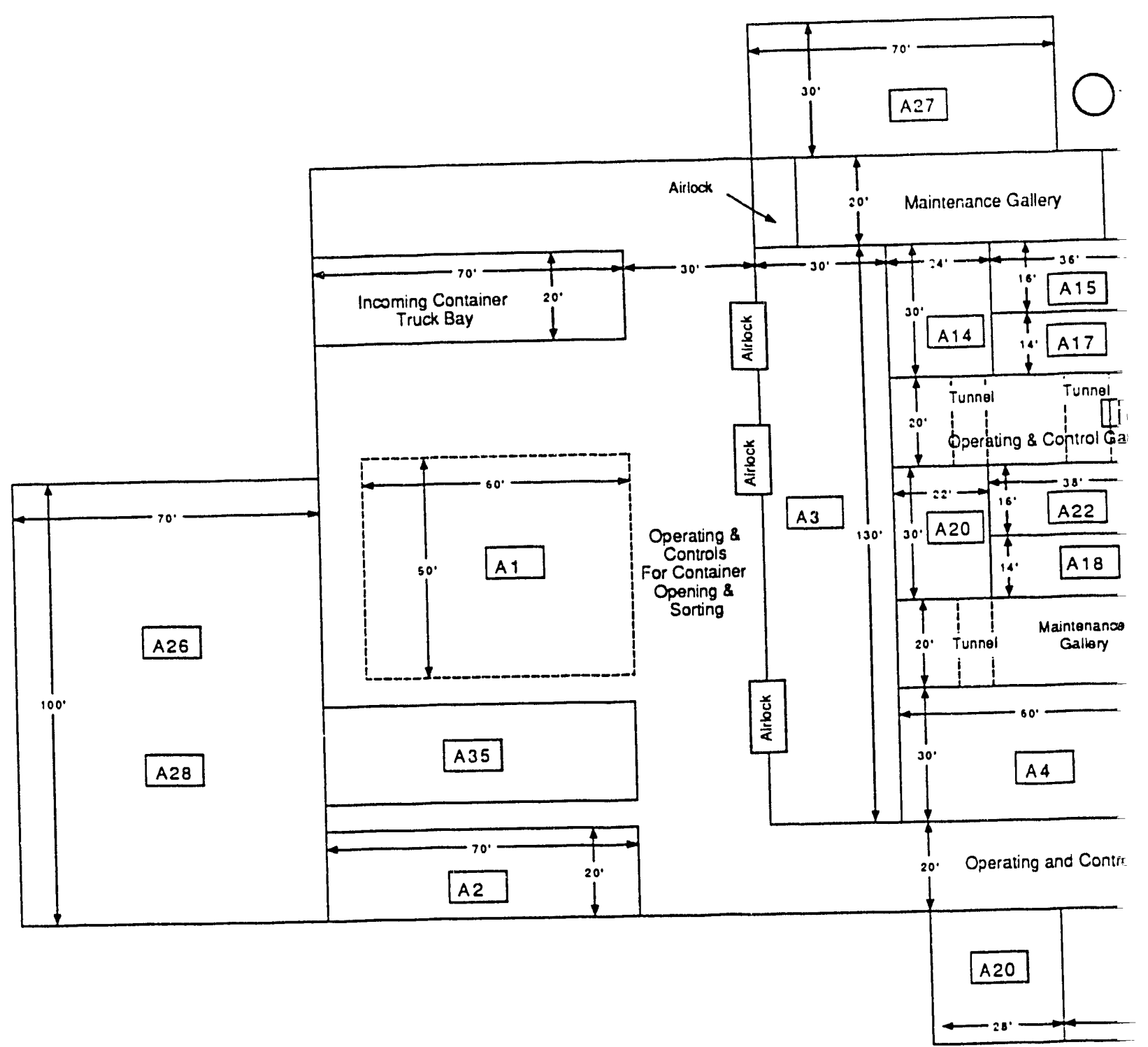

Figure 18. General arrangements for the sort, treat, and repackage system. 
NO DESCRIPTION

A1 Unload, Stage \& Store

A2 Inspect/Assay

A3 Open, Dump \& Sort

A4 Metal Sizing/Decon Subsystem

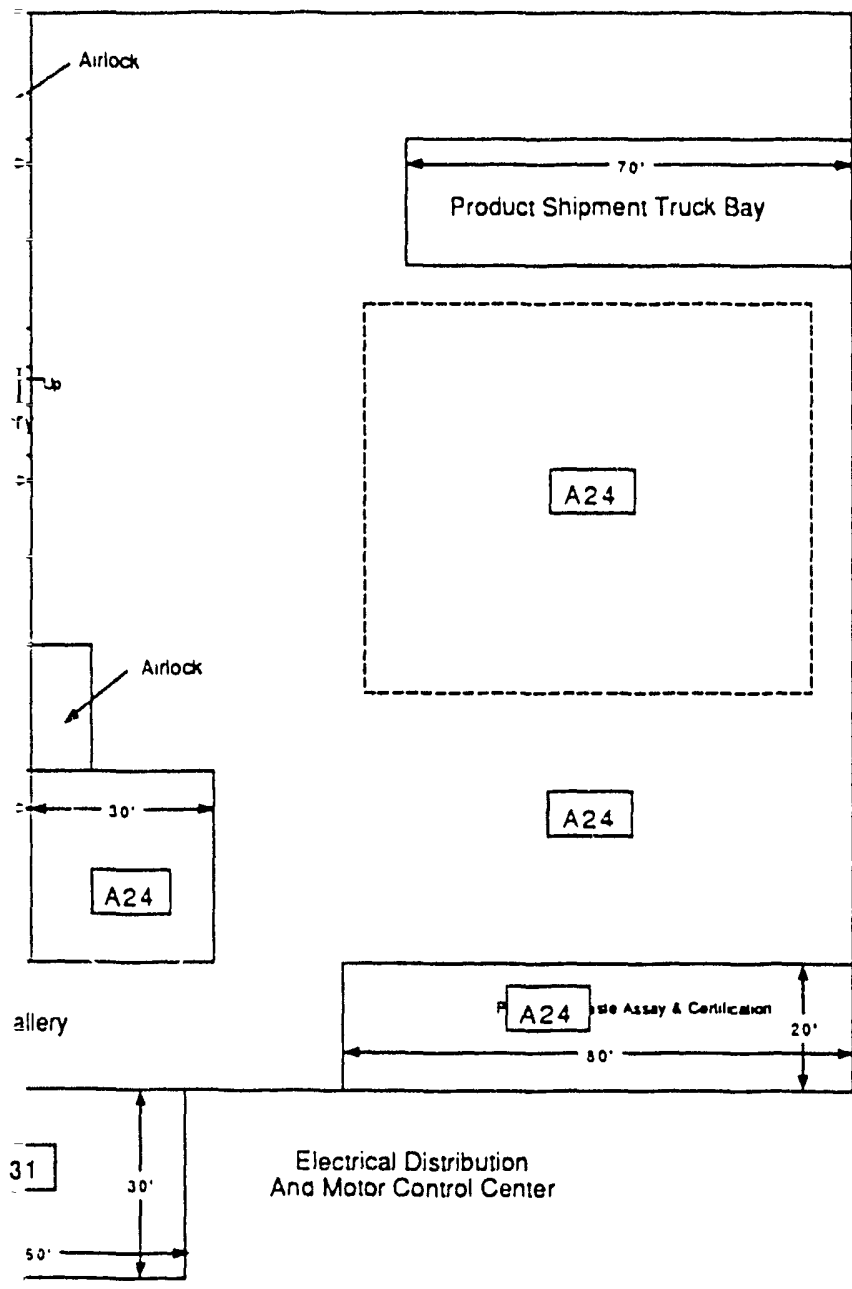

A14 Liquids/Fines Sort

A15 Size Reduction

A17 Dry Solids Fill \& Package

A18 Solidification Fill \& Package

A20 Solidification Feed Prep - STR

A22 Solidification - STR

A23 Assay/Certification

A24 Liquid Waste Treatment

A25 Storage \& Shipping

A25 Administration Support

A27 Heating, Ventilation \& Exhaust

A28 Analytical Laboratory

A31 Utilities/Mech. Equipment - STR

A35 Chem Storage Area

A36 Maintenance Shop

INEL Stored Waste System Design Study For Alpha-Low Level Waste Treatment

Electrical Station A31 
- Sanitary waste discharged to drainage field.

7.1.7.2 Input from Other Systems. System interface inputs include:

- Alpha-LLW from SWEPP and Storage Modules

- Utilities including service water, normal and emergency power, natural gas, and communications

- Consumables including personnel protective equipment, laboratory material, solidification materials, packaging materials, and disposable and reusable shipping containers.

7.1.7.3 Miscellaneous Systems. The system interfaces with the site communication and alarm systems including telephone, evacuation, fire, security alarm, and public address systems. The process automatically shuts down if the fire system or the evacuation alarm are activated.

\subsection{System Assessment}

This section presents preliminary scoping assessments of systems component technologies based on the subjective judgment and existing knowledge of the preparers. Additional technology evaluations are needed prior to the selection of component technologies and to identify detail development and demonstration needs for selected technologies. Specifically, this section discusses the development level of some of the key unit operations and typical technologies available for performing the required functions. A qualitative assessment of the risks associated with the ability to achieve the required functions is given based on current knowledge and limitations of the available technologies. The strengths and weaknesses of the unit operations are also noted.

Many of the unit operations in the sort, treat, and repackage system are the same as either the incineration/melting or thermal treatment/solidification systems. Discussions from Sections 5 and 6 are referenced as appropriate.

\subsubsection{Evaluation of Unit Operations Technologies}

To accomplish the functions specified for the unit operations, several unique devices, components, and processes are needed. These devices, components, and processes are identified and assessed in this section. Each unit operation is evaluated individually to assess the overall feasibility of the system and to identify areas requiring focused attention. The details of the evaluation are presented below while the assessment is summarized in Table 14.

7.2.1.1 Unioading and Staging. This unit operation is evaluated in Section 5.2.1.1.

7.2.1.2 Inspect/Assay. This unit operation is evaluated in Section 5.2.1.2.

7.2.1.3 Open, Dump, and Sort. This unit operation is evaluated in Section 5.2.1.3. 


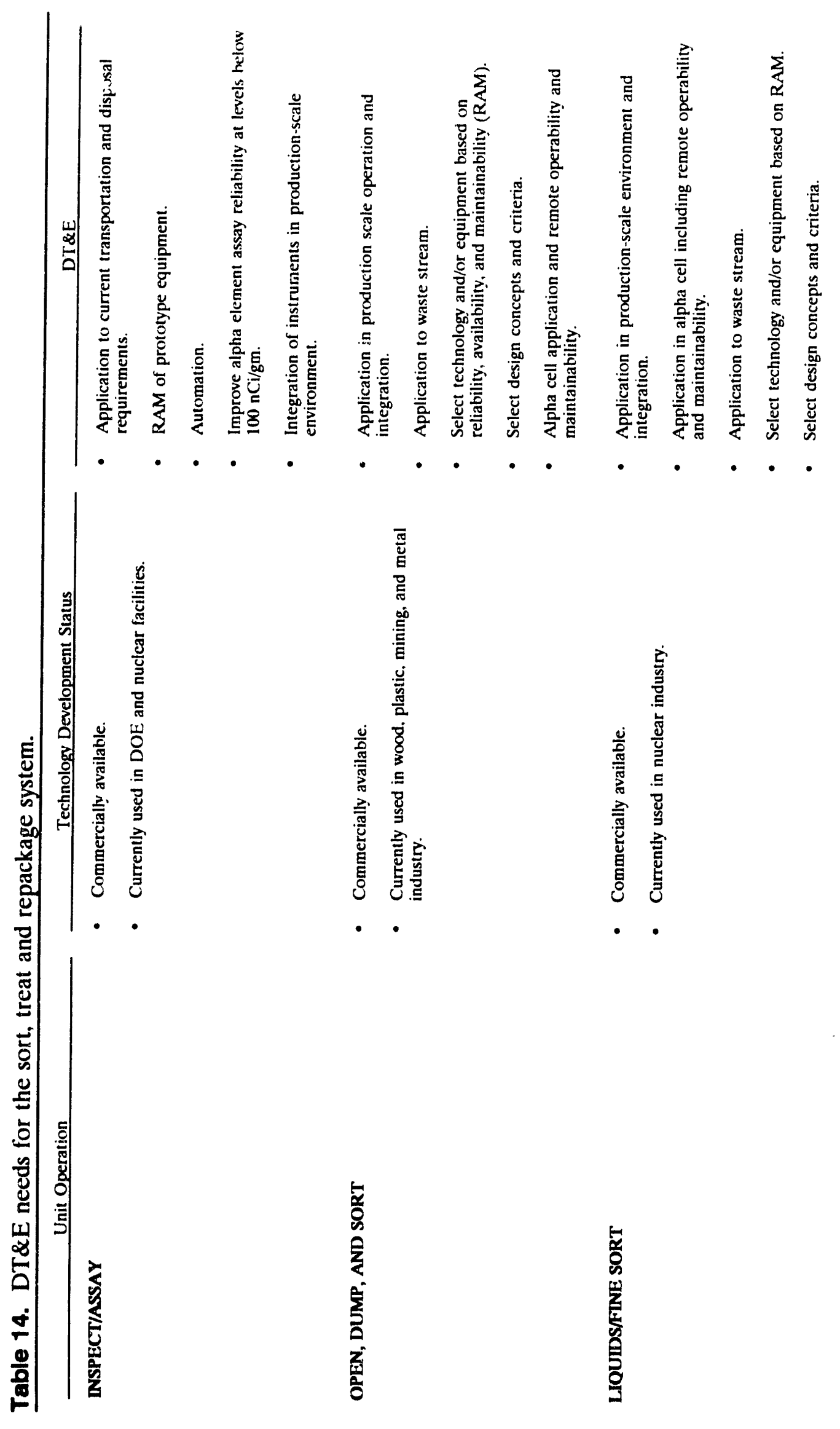




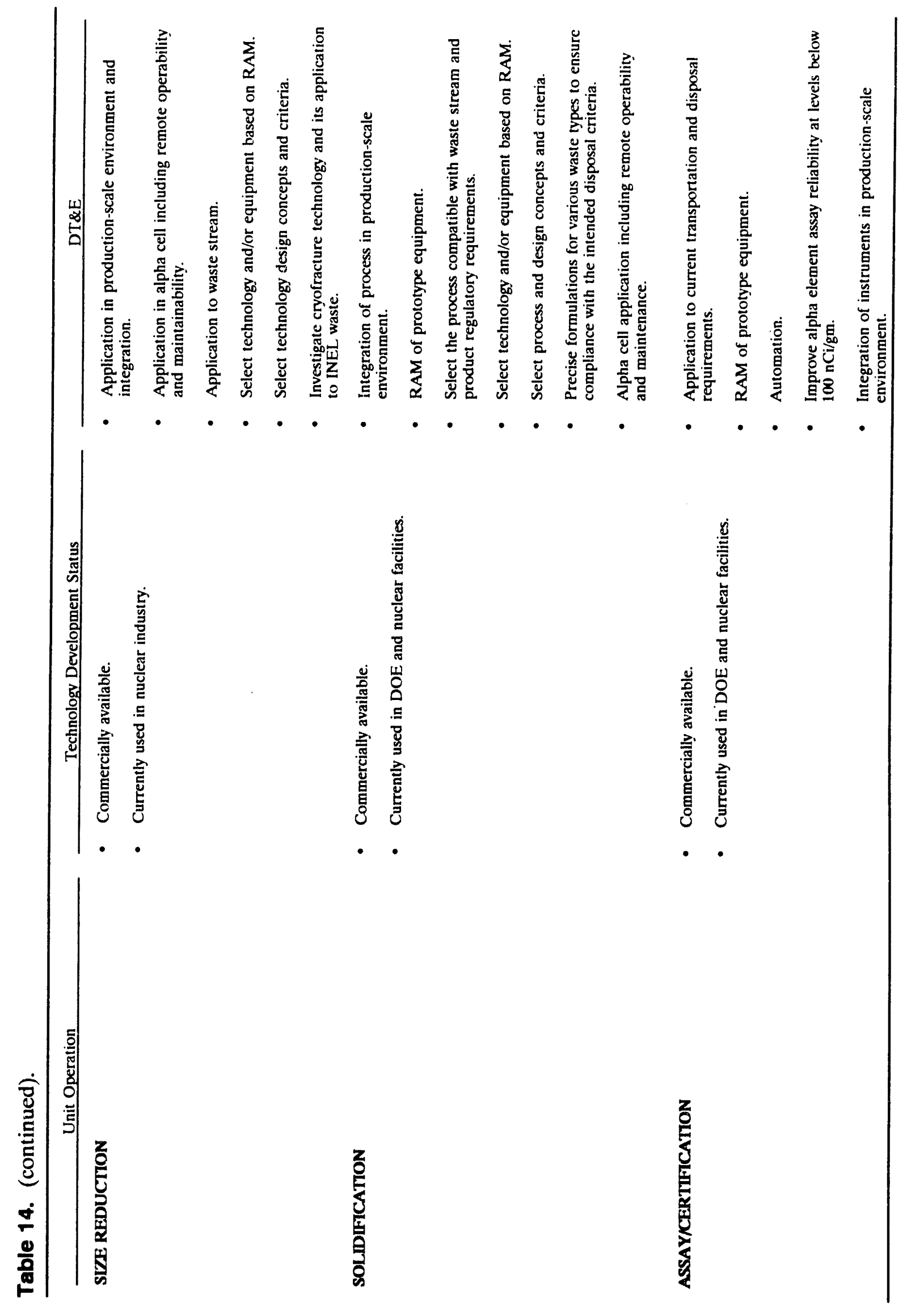


7.2.1.4 Liquids and Fines Sort. The sorting unit operation segregates liquids and fines from the waste and, where applicable, further sorts the metal waste. This operation can be performed manually using glove boxes or remotely using through-the-wall and crane-mounted manipulators and robots. Given the system throughput of $10-20 \mathrm{ft}^{3} / \mathrm{hr}$, manual operation is at the limit of its capacity. Remote techniques using master/slave manipulators are versatile and can best perform these tasks. Commercially available power manipulators (e.g., electromechanical manipulators) have high lifting capabilities (10-400 lbs for standard units) and could be used in this application.

Commercial equipment that sorts waste is not currently available. The Scientific Ecology Group (SEG) at Oak Ridge, Tennessee, developed a revolving sorting table and a shaker table to hand sort combustibles and noncombustibles as a part of a feed preparation train in a $725 \mathrm{~kg} / \mathrm{hr}-\mathrm{LLW}$ incineration facility. The Solid Waste Certification Facility at Los Alamos National Laboratory will be used for packaging, sorting, and certifying WIPP-bound TRU waste. This facility consists of nine interconnected gloveboxes used for various operations. The SEG sorting system is an operating, fullscale facility; the LANL facility will be operational in 1992. Waste characteristics such as size, weight, and physical form are all important to the design of a sorting system. The SEG LLW sorting system is used for combustible waste and does not handle large objects. The LANL system sorts dry waste and can accept some large solid objects. It should be noted that real-time radiography (RTR) is being routinely used as a presort waste characterization tool and could be applied to sorting waste packages at INEL.

Remote operations using through-the-wall and crane-mounted manipulators are commonly used in the nuclear industry. Remote tooling to handle and open waste containers requires engineering to apply these tools to a specific task. These are engineering challenges requiring DT\&E to ensure reliability, ease of operation, and maintainability.

7.2.1.5 Size Reduction. To maximize container fill efficiency, the size reduction unit operation coarse size reduces the incoming waste stream to a coarse size by crushing and shredding. Shredders are available commercially and have been proven in a wide variety of applications. Cryofracture is a relatively new process that has been used in processing defense waste. Cryofracture would require development and demonstration on sample waste streams. A brief demonstration of this process was conducted in FY-91 by NRT Corporation for EG\&G Idaho. The results were generally successful. ${ }^{12}$

Many varieties of crushers are available and have been used commercially for many years. Various industries, including mineral ore sizing and particulate sizing, have used such equipment for all types of minerals. Available crusher-type equipment includes jaws, gyrators, cones, pans, rolls, rotaries, and hammer types. Pulverizers such as balls, ring rollers, hammers, disks, and fluid energy mills are readily available. Selection is a function of the desired feed size, hardness, and reduction ratio. Modification for radioactive or alpha confinement will require engineering and DT\&E.

Shredders of the counter-rotation type are installed at the Savannah River site and were previously installed in the INEL Process Experimental Pilot Plant (PREPP) facility. The INEL tested a shredder for feed preparation for incineration/solidification using simulated TRU wastes. A shredder/compactor also operates at the Tennessee Valley Authority-Watts Bar Nuclear Plant. Other technologies also exist, such as the screw-type auger shredder (manufactured by KOMAR) which was 
tested at PREPP. In general, large shredders have been demonstrated commercially and at municipal waste treatment plants.

Hardened steels and large pieces of material are difficult to shred. To eliminate this problem, larger metals will be separated from the waste and will be size reduced. Thin, flat material has also been a challenge at times. It is anticipated that shredder maintenance in alpha-LLW processing may present some difficulties, but removal of metals from the waste should minimize maintenance. These are primarily engineering challenges, and DT\&E is required to place shredders into alpha-LLW processing.

In conclusion, most of the equipment is a-first-of-a-kind application in an alpha-cell environment. Therefore, special machine and tool design combined with DT\&E efforts are needed. Areas requiring focused attention are remote operability, ease of decontamination, and alpha-cell maintainability (i.e., by personnel suited in personnel protective equipment).

7.2.1.6 Dry Solids Fill and Package. Functions of this unit operation are filling, compaction, capping, packaging, cleaning, and testing of dry solids after they are discharged from the size reduction unit. Equipment performing similar functions, including all types of compactors and supercompactors, are widely used throughout the nuclear industry and no specific DT\&E is required.

7.2.1.7 Solidification Feed Preparation. The solidification feed preparation unit uses equipment similar to that used in the incinerator feed preparation unit operation discussed in Section 5.2.1.4.

7.2.1.8 Solidification. An evaluation of this unit operation is presented in Section 6.2.1.8.

7.2.1.9 Liquid Waste Treatment. An evaluation of this unit operation is presented in Section 5.2.1.10.

7.2.1.10 Solidification Fill and Package. Functions of this unit operation are filling, capping, packaging, cleaning, and testing solidification mixtures after they are discharged from the solidification unit. Equipment accomplishing similar functions are widely used in the nuclear industry and no specific DT\&E is required.

7.2.1.11 Assay/Certification. An evaluation of this unit operation is presented is Section 5.2.1.12.

7.2.1.12 Interim Storage and Shipping. An evaluation of this unit operation is presented is Section 5.2.1.13. 


\subsubsection{Program Implementation Risks}

This section identifies significant concerns associated with program implementation if the sort, treat, and repackage system is selected and qualitatively characterizes the risk of accomplishing the program objectives. The program mission and objectives are presented in Section 2. Assumptions used in characterizing risks are presented in Section 4. A summary of results and major areas of concern are shown in Table 15. Note that all technical issues listed in this table are engineering solvable issues and do not appear to present any technical difficulties.

The following discussion of the sort, treat, and repackage system risks are compared with the incineration/melting and thermal treatment/solidification systems. When applicable, reference is made to the analysis provided for these systems.

7.2.2.1 Technical Objectives. Technical objectives for the alpha-LLW process can be summarized in the following two categories:

- Waste form: The waste form must meet the DOE, EPA, and DOT standards for storage, transportation, and disposal. Also, additional requirements on waste form will be derived from a performance assessment to be based on the intended disposal environments.

- Safety: Facility operation must be conducted to ensure the safety of the worker, the public, and the environment.

This system produces a waste form that only meets the requirements of an engineered deep geologic repository such as WIPP and assuming that a no migration variance is granted by the EPA for LDR wastes. Since the probability of such a disposal option for these wastes is very low, the risk associated with achieving the waste form technical objectives is given a high rating.

In assessing the safety of waste-handling and process equipment operations, the risk of system compliance with the technical objective is characterized as moderate, similar to the incineration/melting system (see Section 5.2.2.1). However, when this rating is combined with the concerns for meeting waste form criteria, the resultant overall risk characterized for this system is higher than both the incineration/melting and thermal treatment/solidification systems. Therefore, a high risk rating is assigned.

7.2.2.2 Health and Safety Objectives. Program implementation risks to meet health and safety objectives are similar to the discussion presented in Section 5.2.2.2, and the overall risk is low.

7.2.2.3 Institutional Objectives. This system does not have technology features that typically create institutional concern. Therefore, the risk associated with achieving the institutional objectives is low.

7.2.2.4 Schedule Objectives. Program implementation risks for schedule objectives are similar to the discussion presented in Section 5.2.2.4, with the exception that a prolonged melter and incinerator DT\&E, which is required for the other systems, will not be needed for the sort, treat, and repackage system. Therefore, the schedule objectives risk for this system receives a low rating. 


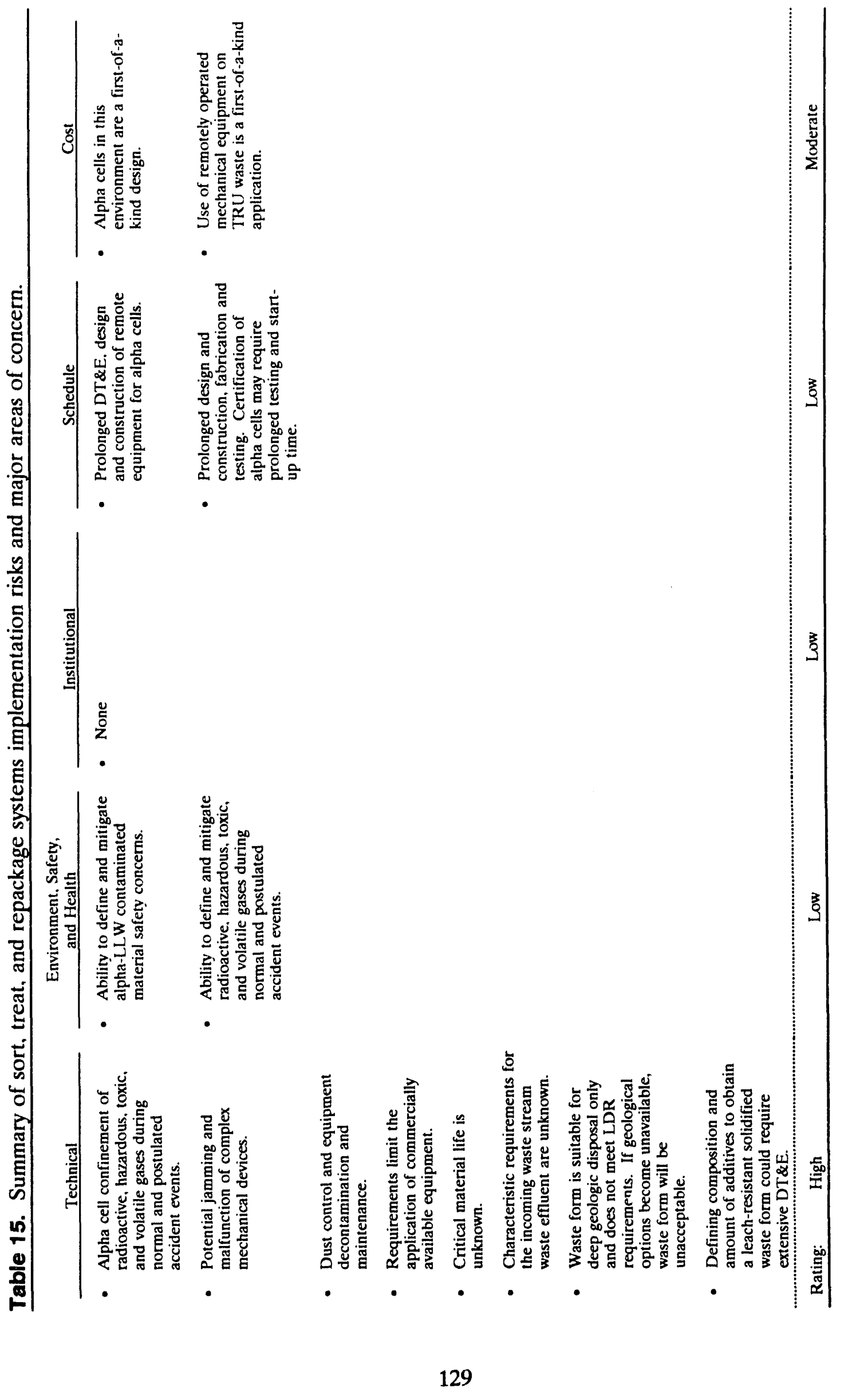


7.2.2.5 Cost Objective. As with the incineration/melting system (see Section 5.2.2.5), accurate cost estimates are not anticipated until design, based on DT\&E, is well into maturity. Therefore, the cost objective risk for this system is moderate.

\subsubsection{Unit Operations DT\&E Lead-Time Estimates}

Estimates of the DT\&E lead time and manpower for each unit operation requiring DT\&E are shown in Table 16. Lead-time estimates are based on the assumptions presented in Section 4.

\subsubsection{Rough-Order-of-Magnitude Cost Estimates}

ROM costs are summarized in Table 17. Assumption, methodology and details are presented in Appendix B.

\subsubsection{System Evaluation Results}

This section presents an overall evaluation of the system and identifies the major advantages and disadvantages based on the system assessments. This includes an evaluation integrating individual unit operations into a smooth, efficient system. Specific areas addressed include identification of system advantages and disadvantages, a qualitative ranking of performance measurables as identified in Section 3, a summary of DT\&E requirements, and an overall recommendation for the system.

7.2.5.1 Major System Advantages and Disadvantages. The significant advantages of this system are that waste processing and handling are minimized; most of the processing techniques are well-developed, commercially available, and currently in use; and the system requires a relatively short lead-time for DT\&E. The significant disadvantages are the lack of volume reduction and the potential for its waste forms becoming unacceptable should the engineered deep geologic disposal option not become available. Following are specific system advantages and disadvantages.

\subsubsection{Advantages.}

- Metals are sorted upfront, reduced in size, and decontaminated in a separate area which will reduce the cost of metals disposal. Sorting the metal for decontamination in a separate facility may or may not offset the savings realized from reducing the amount of alpha-LLW metal being processed by the main process units, but it will facilitate cleaner and smoother operation of these units.

- Process upsets from incompatible waste are prevented by separating the undesirable waste prior to treatment.

- Compaction and repackaging techniques are simple and available.

- Solidification technologies are simple. With proper characterization of the incoming waste and effective formulations, they are capable of handling a wide variety of wastes such as liquids and fines. 


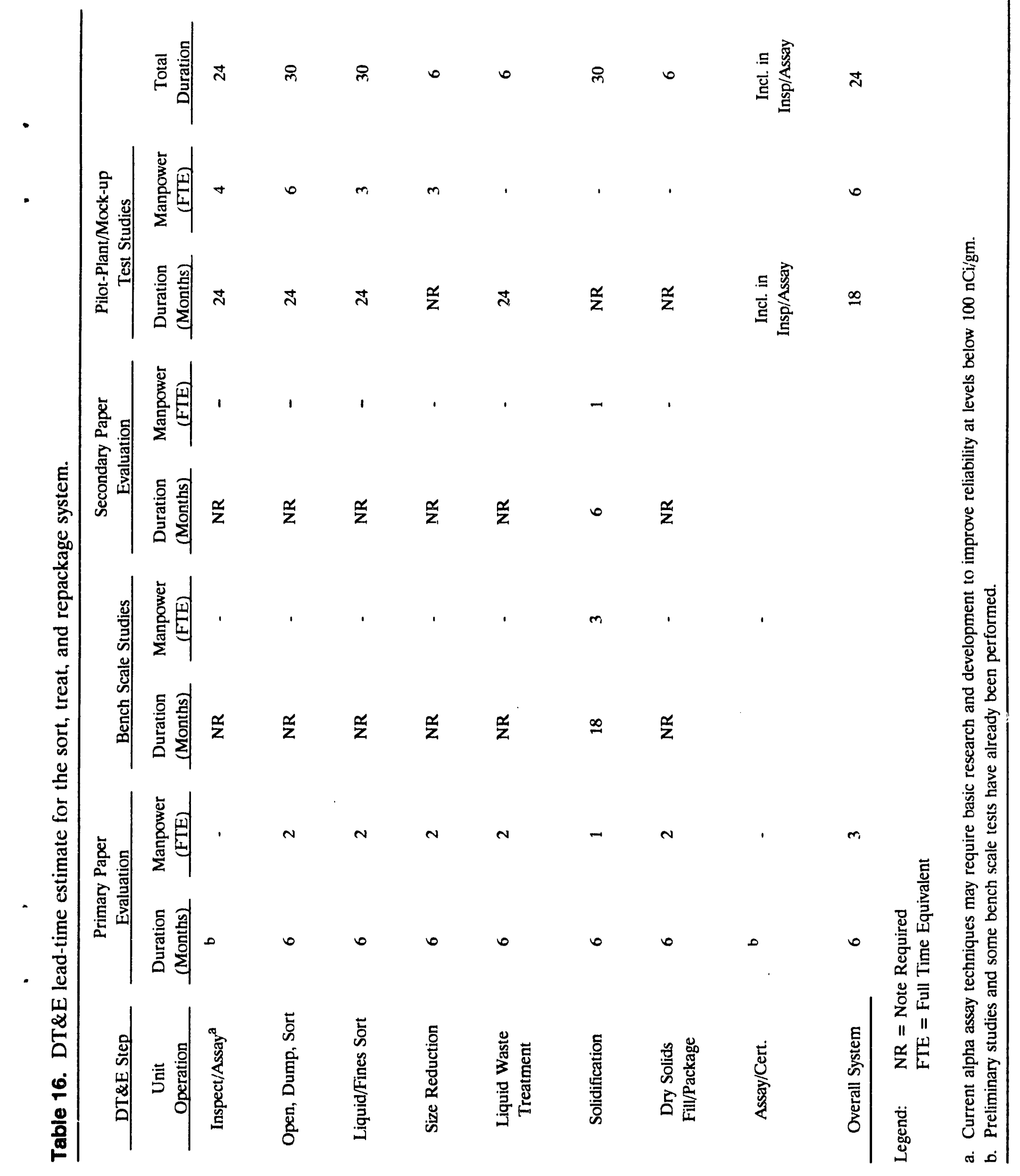


Table 17. Rough-order-of-magnitude cost estimates for the sort, treat and repackage system $(x \$ 1,000)$.

\begin{tabular}{lr}
\hline Item & $(x \$ 1,000)$ \\
\hline Studies and Bench-Scale Tests & $\$ 6,088$ \\
Demonstration & $\$ 11,868$ \\
Production Construction & $\$ 103,816$ \\
Operating and Maintenance & $\$ 151,000$ \\
Disposal and Transportation & $\$ 103,540$ \\
Operating Funds Budgeted Activities & $\$ 139,200$ \\
Decontamination and & $\$ 28,235$ \\
Decommissioning & \\
Total Life-Cycle & $\$ 543,747$ \\
\hline
\end{tabular}

\subsubsection{Disadvantages.}

- The open, dump, sort, and size reduction operations are complex and time consuming and can result in contamination spread and increased maintenance.

- Even though the volume of waste is reduced by the size reduction and compaction steps, the full benefit of highly efficient volume-reduction techniques (such as incineration and melting) is not realized.

- The final waste forms do not meet LDR or DOE requirements for shallow land burial and will require the disposal facility to meet these requirements for mixed wastes.

7.2.5.4 Performance Measurable Rating. Section 3 identifies performance measurables that are used in the evaluation of the overall system. Table 18 is a judgment-based qualitative assessment of the system performance measurables. Following are the key factors considered in developing scores for the unit operation performance:

- Assay/Inspect and Assay/Certification: The performance rating is presented in Section 5.2.5.4.

- Open, Dump, and Sort: The performance rating is presented in Section 5.2.5.4.

- Feed preparation unit operations for the incinerator, organic removal, and solidification: The performance rating is similar to the feed preparation units for incinerator/melter system presented in Section 5.2.5.4

- Liquids and fines sort: Existing material handling equipment can be used for this unit operation but requires modifications to include remote control and maintenance features. This is not considered to be a significant challenge. This unit operation could pose safety problems because it opens bags containing hazardous material that could easily spill and 
핍 $\stackrel{0}{\cong} \underset{\infty}{\infty} \infty$

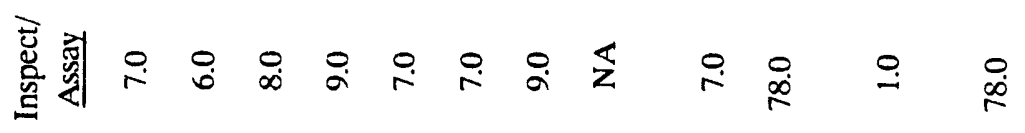

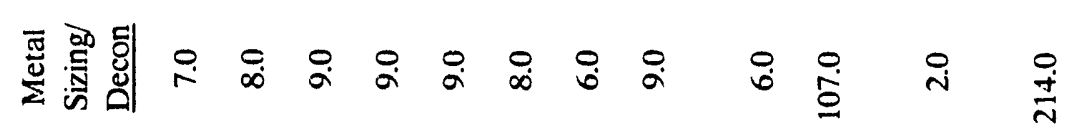

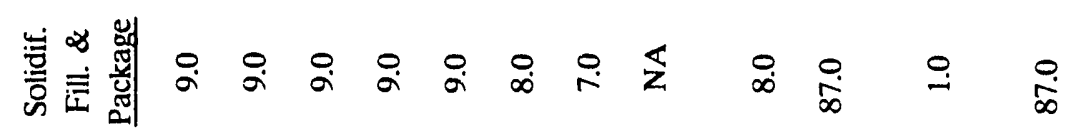

虽

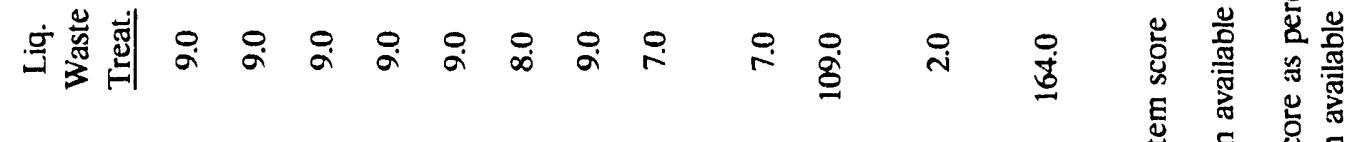

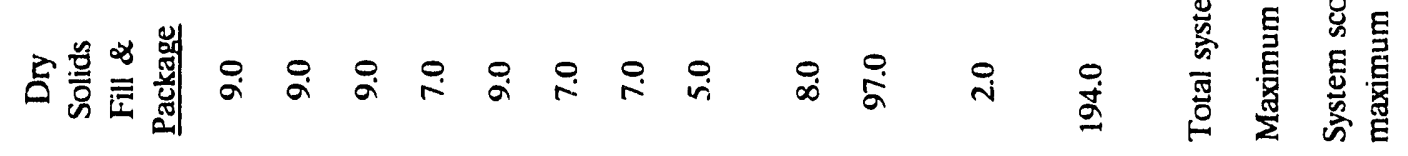

敬

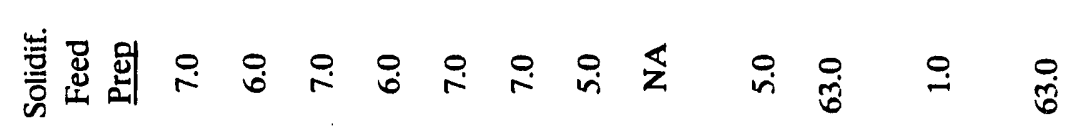

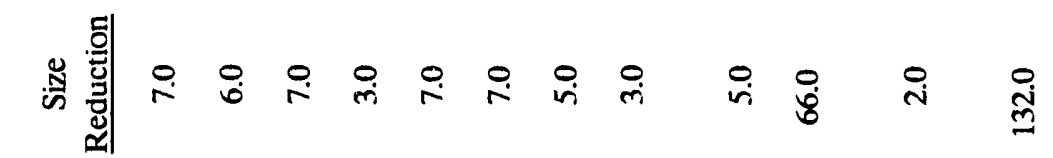

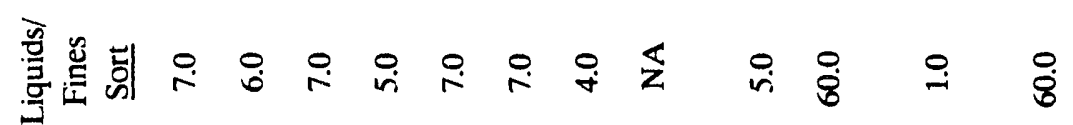

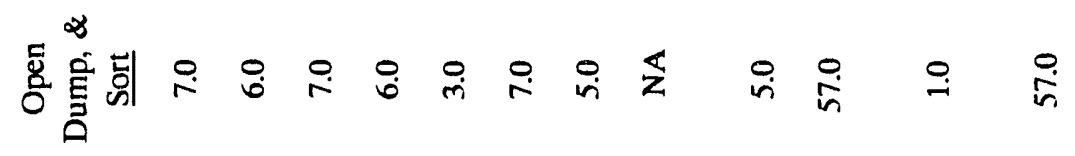

噌阅

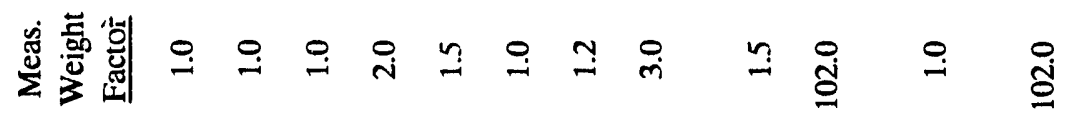

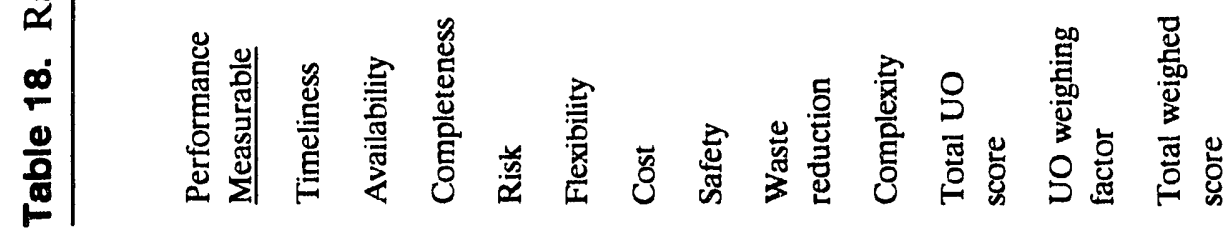


spread contamination. Therefore, all performance attributes, except for safety, receive high ratings.

- Size reduction: Existing material handling equipment can also be used for this unit operation, but requires modifications for remote operations and maintenance. Again, there are significant safety concerns with this unit operation because it processes open bags containing unknown hazardous and radioactive material. Therefore, because of the safety issue, the rating is downgraded.

- Solidification feed prep: The solidification feed preparation unit has size reduction functions similar to the size reduction unit operations, and similar attributes receive the same rating.

- Solidification: Most components of the solidification unit operation have been used in nuclear industry and can be acquired from specialized firms. Therefore, most attributes of this unit operation receive a high grade. There is a risk with the acceptability of the solidified waste form, and the unit increases the waste volume; therefore, the risk and volume reduction attributes for solidification receive a low rating.

- Liquid waste treatment: See Section 5.2.5.4 for discussions of performance ratings for this unit operation.

- Solidification and dry solids fill and package: Most components of this system have been used in nuclear industry and can be acquired from specialized firms. Therefore, most attributes of this unit operation receive a high rating.

\subsubsection{Summary of Demonstration, Testing, and Evaluation Needs}

The DT\&E needs for each unit operation and for the overall system are summarized in Tables 14 and 16. These tables provide a ready reference to DT\&E requirements in the final system evaluation and for comparison purposes with other systems.

\subsection{Recommendation for the System}

The sort, treat, and repackaging system essentially uses existing technology to collect, sort, size reduce, solidify, and package the stored waste to meet engineered deep-geologic disposal facility criteria similar to WIPP waste acceptance criteria standards. The final waste forms will not, in general, meet LDR standards for hazardous wastes nor DOE requirements for shallow land burial of radioactive wastes, particularly long-term retention of TRU compounds. The disposal facility must provide this protection. There is no physical or chemical conversion of the input material streams except for the physical size reduction and liquids/fines solidification processes. The technologies employed are all currently available, thereby permitting an early start on design, fabrication, and installation. It appears that much of the alpha-LLW could be processed now using these technologies. However, the system does not use volume reduction concepts and is based on a minimal processing philosophy. 
Several issues that will require further DT\&E include further testing of dry solids packaging and solidification processes basc $d$ on detailed waste characterization (for example, different organic contamination in liquids will require different solidification processes); fine tuning of all the selected technologies to produce the desired results; analyzing the queuing of the waste stream to determine capacities of unit operations components; reviewing the integration of the process streams to ensure compatibility; and considering the addition of on-line sensors to monitor and to report the status and progress of waste stream processing.

A significant concern about this system is its final waste form acceptability. It only solidifies fines and liquids, while other material is simply repackaged. Because it assumes disposal in an engineered deep geological repository (such as WIPP), LDR is assumed to be exempted (treatment to LDR standards is exempted for test waste received at WIPP, but continuation of the no migration variance at the end of the 5-year test period is uncertain). Consequently, the waste form will not be suitable for other disposal methods, such as shallow-land disposal which requires LDR compliance. The sort, treat, and repackage system is a risky approach because there is a very low probability that a deep geologic repository such as WIPP will become available for alpha-LLW disposal (this waste is now specifically excluded from WIPP). 


\section{METAL SIZING/DECONTAMINATION SUBSYSTEM}

This section describes a metal sizing/decontamination subsystem which cleans alpha-LLW contaminated metals for direct shallow land disposal or potential recycling and reuse, as allowed by regulations.

\subsection{Functional and Operational Requirements}

\subsubsection{Subsystem Description}

The metal sizing/decontamination subsystem, shown in Figure 19, is comprised of several unit operations including pretreatment, decompression, size reduction, metal decontamination, liquid waste treatment, and assay.

The subsystem is located within the facility that contains the parent system, and receives waste from the open, dump, and sort unit operation of the parent system. The open, dump and sort unit operation of any of the three proposed parent systems is equipped to transport the metals to the subsystem. The three major output streams from this subsystem include LLW metals, recyclable/reusable metals, and liquid and sludge residues. The subsystem output is transferred to the parent system unit operations for further processing.

The subsystem includes equipment to pretreat and reduce the size of the incoming contaminated bulk metals, loose metals, gas cylinders, and empty metal containers. Compressed gas cylinders are first punctured in a controlled environment. Their contents are removed and treated and the cylinder shell is sent to the size reduction unit. The surface of size-reduced metals and remaining loose metals is decontaminated to remove or reciuce the LDR controlled materials and alpha-LLW contamination. The decontaminated metal is assayed to segregate the recyclable metals from the LLW metal. Lead is also segregated. The LLW and recyclable metals are packaged and transferred to other unit operations of the parent system for assay and certification. Lead is processed through a macroencapsulation process to meet the LDR requirements.

The liquid waste stream produced from the metal decontamination and pretreatment is treated in a liquid waste-treatment unit operation to remove sludges and chemical decontamination agents that may require special treatment. The treated liquid and sludge are sent to the liquid wastetreatment unit operation within the parent system for final treatment and disposal.

The subsystem includes an alpha cell enclosure with the appropriate ventilation equipment to control and prevent release of alpha-LLW and other hazardous waste.

8.1.1.1 Pretreatment. The pretreatment unit operation performs the following functions:

- $\quad$ Receives bulk metals; punctured gas cylinders; empty metal containers (drums); and loose metal from the open, dump, and sort unit operation within the parent facility and from a decompression unit operation within the subsystem 


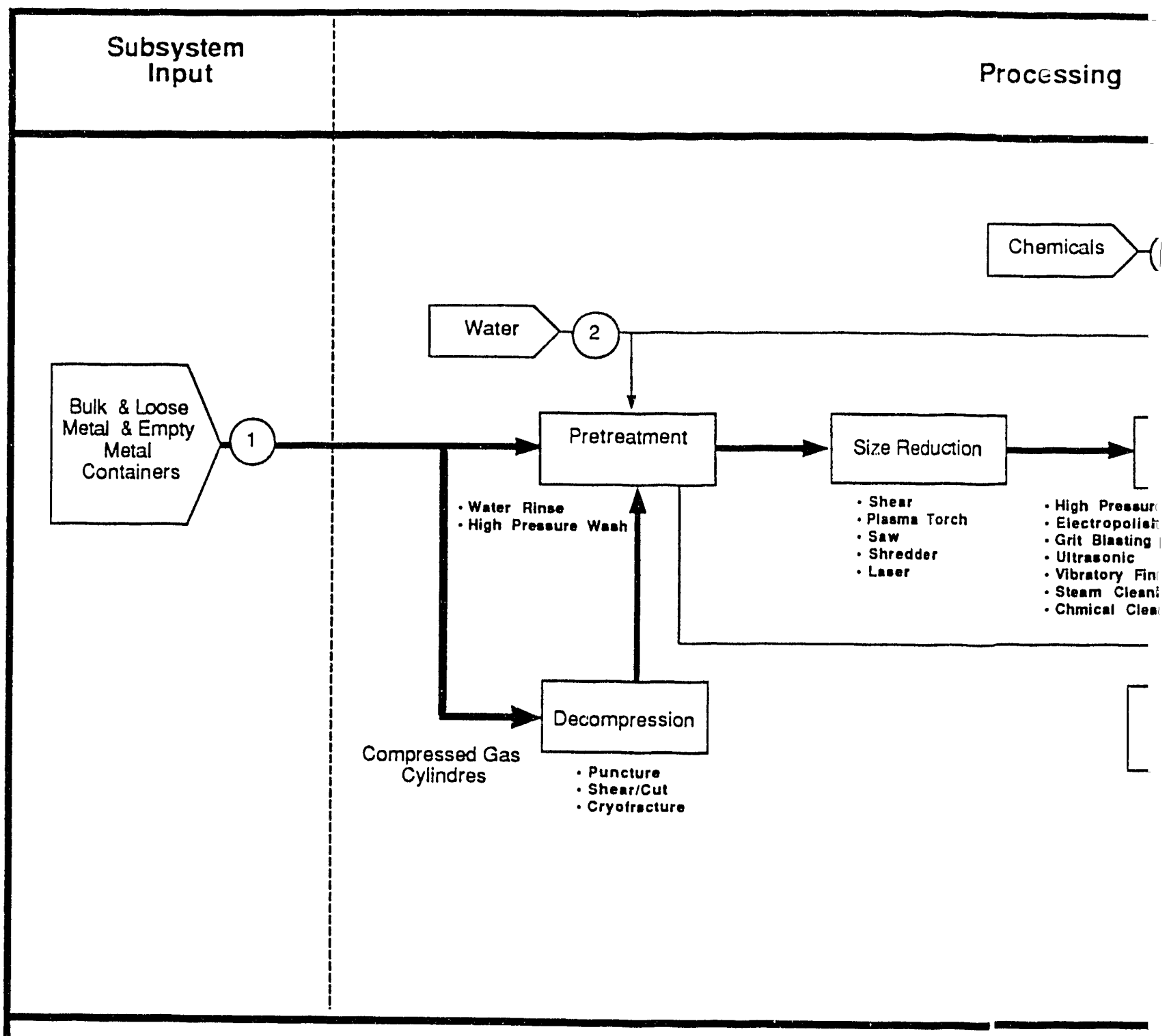

Note:

\begin{tabular}{|c|c|c|c|c|c|c|}
\hline NODE & 1 & 2 & 3 & 4 & 5 & 6 \\
\hline $\begin{array}{c}\text { Material } \\
\text { Description }\end{array}$ & $\begin{array}{c}\text { Input } \\
\text { Waste }\end{array}$ & Water & Chemicals & $\begin{array}{c}\text { Metals } \\
\text { Metal }\end{array}$ & $\begin{array}{c}\text { Recyclable } \\
\text { Metal }\end{array}$ & $\begin{array}{c}\text { Liquids/ } \\
\text { Sludge }\end{array}$ \\
\hline FLOW RATE (LB/HR) & 171 & 75 & 4 & 116 & 50 & 04 \\
\hline
\end{tabular}

The subsyst: into a form ti, regulations : disposal facil

Figure 19. Functional flow diagram for metal sizing/decontamination subsystems. 
- Cleans and washes the surface of the metal with a high-pressure rinse to remove debris and soil contamination

- Transfers bulk metals requiring size reduction to the size reduction unit operation

- Transfers metals not requiring size reduction to the metal decontamination unit operation.

8.1.1.2 Decompression. The decompression unit operation performs the following functions:

- Punctures cylinders and empties the gas from the cylinder

- Collects and treats the gases released during the cylinder decompression operation

- Transfers decompressed gas (at atmospheric pressure) to the pretreatment unit operation.

8.1.1.3 Size Reduction. The size reduction unit operation reduces the size of the pretreated bulk metal and loose metal to expedite the metal decontamination unit operation.

- Size reduction device: Bulk metals requiring size reduction can be processed by a variety of size reduction technologies such as shearing, sawing, shredding, laser sectioning, and plasma torch. The size-reduced metal is transferred to the metal decontamination unit operation.

- Transfer device: The transfer device conveys the size-reduced metal to the decontamination unit operation.

8.1.1.4 Decontamination. The decontamination unit operation performs the following functions:

- Using metal transfer devices, transfers the incoming metal waste from the size reduction and the metal pretreatment unit operations to the metal decontamination staging area.

- Decontaminates the metallic waste from the size reduction unit operation and metal pretreatment. Various technologies such as electropolishing, grit blasting, ultrasonic cleaning, vibratory finishing, steam cleaning, and chemical cleaning may be used to decontaminate the sectioned and loose metal waste. Any liquid produced from the decontamination unit operation is collected and pumped to the liquid waste treatment unit operation within the subsystem. After drying, the decontaminated metal is transferred to the container filling unit operation. If additional decontamination of the metal is required, the metal is diverted from the waste stream and reprocessed.

- Collects and transfers liquid waste to the liquid waste-treatment unit operation within the subsystem.

- Transfers the decontaminated metal to the container assay unit operation. 
8.1.1.5 Liquid Waste Treatment. The liquid waste-treatment unit operation performs the following functions:

- Receives and stores liquid waste and sludge from the metal decontamination and metal pretreatment unit operations.

- Treats the liquid waste to reduce the volume and detoxify and remove contaminants to meet input criteria for the liquid waste- treatment unit operation within the parent system. A combination of evaporation, precipitation, filtration, TRU/Clear, and centrifuge treatment methods are available. The treated clean liquid and residue (sludge) meeting the discharge criteria are released to the parent system liquid waste-treatment unit.

- Samples the treated clean liquid and residue for radioactivity and chemical constituents before sending them to the parent system.

8.1.1.6 Package/Assay. The package/assay unit operation functions include the following:

- Assays decontaminated metals to ensure all LDR-controlled components are removed. The adequacy of radiation contamination removal is decided based on the disposal and recycling cost effectiveness. Metals requiring additional decontamination are returned to the decontamination unit.

- Packages decontaminated metal in containers for maximum volume reduction.

8.1.1.7 Lead Macroencapsulation. The function of this unit operation is to encapsulate lead according to the LDR specified technology.

\subsubsection{Subsystem Boundaries}

The subsystem consists of the unit operations shown in Figure 19. It is contained in an alpha cell within the parent system facility.

8.1.2.1 Physical Boundaries. The open, dump, and sort unit operations within the parent facility are the physical boundaries of the input stream; the assay/certification and liquid waste treatment unit operations are the physical boundaries for the output streams.

8.1.2.2 Utilities. The subsystem requires services from the water system, plant steam system, and electrical power supply. The boundaries for the utilities include service water shut-off valves located at the parent system facility service water header, the steam shut-off valves located at the parent system facility steam header, and the power supply at the parent system facility power main.

8.1.2.3 Environment. The subsystem interfaces with the building ventilation system discharge.

\subsubsection{Subsystem Specific Assumptions}

The following specific assumptions apply to the subsystem: 
- $68 \mathrm{lbs}$ of LLW metal are obtained per $100 \mathrm{lbs}$ of metal feed.

- $29 \mathrm{lbs}$ of recyclable metal are obtained per $100 \mathrm{lbs}$ of metal feed.

- $\quad 2 \mathrm{lbs}$ of chemicals are used per $100 \mathrm{lbs}$ of metal feed.

- $45 \mathrm{lbs}$ of water per $100 \mathrm{lbs}$ of metal feed is introduced for the washing and decontamination operations.

- $3 \mathrm{lbs}$ of solids (debris, powdered metals, and rust) is generated per $100 \mathrm{lbs}$ of metal feed. The solids are part of the sludge in the washing and decontamination solutions discharged to water treatment.

\subsubsection{Facility Description}

8.1.4.1 General Arrangement. A scoping study layout for the subsystem is shown in the layout for the parent system.

\subsubsection{Subsystem Design Requirements}

8.1.5.1 Functional Requirements. Following are the functional requirements for the subsystem:

- Receive bulk and loose metal from the parent system.

- Decompress gas cylinders.

- Decontaminate metallic waste to levels allowing either disposal as LLW or recycling and reuse as permitted by regulations.

- Process, assay, and transfer all metallic waste streams to the assay/certification unit operation in the parent system.

- Process all secondary waste, such as gases and liquid waste from the decontamination process, to a level acceptable to the treatment unit operations provided in the parent system.

- Transfer secondary wash to the treatment unit operations in the parent system.

\subsubsection{Penformance Requirements.}

- $\quad$ Process and package alpha-LLW from TSA over a 10-year period.

- Meet the INEL onsite transportation requirements for hazardous waste transfer.

- Sort and segregate LLW and recyclable metal. 
- Have minimal impact on the health and safety of the worker, the public, and the environment.

- Have high reliability, operability, and maintainability factors.

- Ability to reduce the incoming metal waste to a size required for efficient processing and packaging.

- Ability to decontaminate the metal waste for LDR treatment.

- Ability to process secondary wastes to a level acceptable the treatment unit operations in the parent system.

\subsubsection{Interface Requirements}

8.1.6.1 Output to Other Systems. The subsystem outputs to the main system facility include:

- $68 \mathrm{lbs}$ of LLW per $100 \mathrm{lbs}$ of feed metal.

- $29 \mathrm{lbs}$ of recyclable metal per $100 \mathrm{lbs}$ of feed metal.

- $50 \mathrm{lbs}$ of liquid waste per $100 \mathrm{lbs}$ of feed metal.

8.1.6.2 Input from Other Systems. The subsystem receives bulk and loose metals, compressed gas cylinders, and empty metal containers from the parent system facility. The subsystem receives service water, power, ventilation input, and steam from the parent facility utilities. Input consumables include reusable containers, solidification materials, and decontamination fluids.

\subsection{System Assessment}

The current status, program implementation risks, and analusis of the unit operations associated with the subsystem are discussed below. Integration of unit ope $\ldots$.tions to form a complete subsystem that satisfies the functional, performance, and interface requirements is complex. DT\&E of individual unit operations is necessary to integrate the subsystem.

\subsubsection{Current Status of Unit Operations}

The status of the unit operations is discussed below.

8.2.1.1 Pretreatment. The metal pretreatment unit operation cleans and initially sorts the bulk metal stream. The sorting operation classifies the incoming material to allow proper decontamination. Pretreatment of the bulk metal removes soil, soluble salts, and other nonmetal materiais on the metal surface. The technologies employed include vibratory screen, material handling, manipulator, and high-pressure pulsating jet wash equipment. The components associated with the metal pretreatment unit operation are commercially available and used by industry; 
therefore, no DT\&E of the technology will be required except for minor efforts to determine pretreatment requirements for various metal types.

8.2.1.2 Decompression. The decompression unit operation depressurizes the compressed gas cylinders. A wide range of technologies may be employed to process the gas cylinders including cryogenic fracturing, a crusher/shearer, a slow speed shredder, plasma torch cutting, electrical discharge cutting, mechanical cutoff saws, and manual or automated venting devices.

The most significant aspect of this unit operation is the control, venting containment, and processing of hazardous pressurized gases. Identifying cylinder contents is a paramount safety concern. If possible, this identification should be conducted before processing. The decompression station should be housed either in a pressure vessel or a vented chamber.

A commercially available depressurization chamber has been designed and is offered by Integrated Environmental Services, Atlanta, GA, for use with deteriorated or unusable containers and cylinders of known or unknown contents. This device, referred to as Cylinder Management Device, consists of a pressure vessel equipped with an automatic puncturing tool fitted inside the chamber. The entire processing operation occurs inside a self-contained, self-decontaminating, closed system. Once released, the gas is sampled and analyzed using a Fourier Transform-Infrared (FT-IR) analyzer in conjunction with a Mass Spectrometer. In-line detectors are provided for radioactive gases. Once identified, the gases can be pumped out of the vessel using diaphragm compressors or other commercially available pumps to properly preconditioned receptacles or other systems.

To summarize, decompression equipment used in this unit operation is standard and commercially available, and DT\&E is not required.

8.2.1.3 Size Reduction. The technology employed for size reduction may include shearing, sawing, shredding, laser sectioning, and plasma torch. The components associated with the metal pretreatment unit operation, except for laser sectioning, are all commercially available and in use by industry. Plasma torch is currently used in an alpha-cell environment at the Rocky Flats Plant and the Los Alamos National Laboratory. Because these components, with the exception of laser sectioning, are commercially available, no DT\&E of the technology will be required. Laser sectioning requires DT\&E to develop applications and to integrate the equipment within an alpha cell enclosure.

8.2.1.4 Decontamination. The metal decontamination unit operation uses decontamination techniques to remove surface contamination to the greatest extent possible. Technologies under consideration for the decontamination unit operation include electropolishing, grit blasting, $\mathrm{CO}_{2}$ pellets, blasting, ultrasonic cleaning, vibratory finishing, steam cleaning, and chemical cleaning.

These technologies are currently employed in the nuclear industry and are commercially available. Research of additional technologies is not required. However, DT\&E of the application of these techniques to a wide range of expected metal objects would be required to ensure that the objectives of the metal decontamination unit operation are achieved. The development of these technologies should also focus on waste minimization and integration within an alpha-cell enclosure. 
8.2.1.5 Liquid Waste Treatment. The liquid waste-treatment unit operation collects and drains any contaminated waste liquids and sludges from the other metal decontamination unit operations. The objective is to remove any special impurities that cannot be treated by the liquid waste-treatment unit in the parent system. The collected waste may be treated to remove dissolved and suspended organic and inorganic solids and to minimize the liquid waste volume using a combination of technologies including demineralization, centrifuge, evaporation, filtration, and TRU/Clear.

These technologies, except for TRU/Clear, are currently in use in the nuclear industry, and the components associated with these technologies are all commercially available. Only minimal DT\&E is required to integrate and improve the efficiencies of the technologies within the metal decontamination unit operation and to ensure that the output streams are compatible with the parent system liquid waste-treatment input requirements.

8.2.1.6 Package/Assay. The package/assay unit operation characterizes the metal waste streams in accordance with the EPA, DOE and NRC transportation and disposal requirements and packages the decontaminated metal. The technologies employed in this unit operation include PAN, SGS/multichannel analysis, gross gamma detectors, gross alpha detectors, gross beta detectors, and smear tests. The packaging functions can be accomplished by a high-or low-pressure compactors. These technologies are currently in use in the nuclear industry.

The components of this unit operation are all commercially available and are currently in use in the nuclear industry. There should be no DT\&E required of these technologies or new technologies except PAN. PAN techniques commercially available today are not likely to satisfy the detection requirements of TRU at $100 \mathrm{nCi} / \mathrm{gm}$ levels and below. Therefore, DT\&E in this area will be needed. Demonstrating component integration to meet the objectives of the assay unit operation may also be required.

8.2.1.7 Macroencapsulation. Macroencapsulation is an LDR mandated technology which is based on best demonstrated available technology (BDAT). Therefore, no DT\&E is needed.

\subsubsection{Program Implementation Risks}

Following is a qualitative assessment of risk associated with each unit operation of the subsystem. The purpose of this risk assessment is to determine if this subsystem will have a significant impact on the technical performance, environment, health and safety, schedule, and cost risks of the parent system. Based on the discussions presented below, the program implementation risk from this subsystem is low in all areas.

8.2.2.1 Pretreatment. The metal pretreatment unit operation cleans and initially sorts the incoming bulk metal stream. The pretreatment of the bulk metal removes soil, soluble salts, and other nonmetal materials on the metal surface. The metal pretreatment segregates, washes. and prepares the waste for processing. It is unlikely that these technologies will fail. All technologies identified are currently performing the same tasks at various industrial facilities, and the safety procedures isolate the hazardous waste from human contact. The risk is low because there is little likelihood of failure, providing reasonable precautions are taken to ensure proper operation within 
an alpha-cell environment. The cost is not a significant risk because known technologies are used. Also, there is no unusual schedule risk.

8.2.2.2 Decompression. This unit operation depressurizes deteriorated gas cylinders and containers. It collects, samples, and treats the released gas. Commercially available equipment can accomplish these functions; therefore, the unit operation represents no risk to meet the parent system objectives.

8.2.2.3 Size Reduction. This unit operation size reduces the larger bulk metal objects to expedite decontamination of the metal, to permit a more efficient container filling operation, and to reduce the size of bulk metal for subsequent operations. All of the identified technologies under consideration have historically performed well at this task. There is little technical risk that these methods will not perform their function within the given environment. Large machine-tool equipment will be difficult to size reduce and may take specialized procedures and additional time. There is little risk associated with these technologies as long as the appropriate industrial safety and operations procedures are observed. The cost is not at significant risk because known technologies are used. There is no unusual schedule risk.

8.2.2.4 Decontamination. The metal decontamination unit operation uses available decontamination techniques to remove surface radioactive contamination to the greatest extent possible. Most of the identified technologies have historically performed well at this task. There is little technical risk that these methods will not perform their function within the given environment, and the safety risk associated with these technologies is small as long as the appropriate industrial safety and operations procedures are observed. The cost is not at significant risk because known technologies are used. There is no unusual schedule risk.

8.2.2.5 Liquid Waste Treatment. The liquid waste-treatment unit operation collects and treats any contaminated waste liquids and sludges from the other metal decontamination unit operations. The function of the liquid waste treatment is to remove suspended and dissolved solid impurities and to minimize the volume of output waste. All of the identified technologies have historically performed well at this task. There is little technical risk that these methods will not perform their function within the given environment. There is little safety risk associated with these technologies as long as the appropriate industrial safety and operations procedures are observed. The cost is not at significant risk since known technologies are used. There is no unusual schedule risk.

8.2.2.6 Package/Assay. This assay unit operation packages the metals into shippirg/disposal containers and provides a characterization of the metal waste streams in accordance with EPA, DOE, and DOT transportation and disposal requirements. The function of the assay unit operation is to sense, quantify, record, and report levels of radioactive contamination of metals. All of the identified technologies have historically performed well at this task. There is some technical risk that these methods will not perform their function within the given environment. The assay process must be improved to match the anticipated system material process rate. The safety risk associated with these technologies is low as long as the appropriate industrial safety and operations procedures are observed. The cost is not at significant risk because known technologies are used. There is no unusual schedule risk. 
8.2.2.7 Macroencapsulation. Macroencapsulation is a proven process which has been adopted by EPA as a BDAT. Therefore, there is no unusual risk.

\subsubsection{Unit Operations DT\&E Lead-Time Estimates}

DT\&E lead time required for each unit operation that may require research and development before installation in the field is estimated and presented in Table 19. The development of the lead time required for DT\&E is based on a qualitative judgment and should be further refined.

\subsubsection{Rough-Order-of-Magnitude Cost Estimates}

ROM cost estimates for the subsystem is included in the parent system costs provided in Sections 5,6 , and 7 .

\subsubsection{Subsystem Evaluation Results}

The purpose of this section is to provide an overall evaluation of the subsystem and to identify the major advantages and disadvantages. This includes an evaluation of the ability of the subsystem to integrate the various unit operations into a smooth, efficient subsystem.

Specific areas addressed include identification of the major advantages and cisadvantages of the subsystem, a qualitative judgment rating of performance measurables, a summary of research and development needs, and an overall recommend.:ion for the subsystem.

8.2.5.1 Identification of Major Subsystem Advantages and Disadvantages. The technologies employed in this subsystem are well-known, commercially available, and in current use by the industry. There is a risk associated with the alpha-cell enclosure and accessibility to repair or maintain the equipment. There is operational risk associated with processing the size and volume of the anticipated waste stream. This risk may require added redundancy or larger capacity or both to avoid processing delays.

The significant advantages of this subsystem are that most of the technologies employed by the subsystem are currently in use and well developed. These technologies do not require significant DT\&E. The significant disadvantage of this subsystem is the generation additional liquid waste without the benefit of free release of metal. Other disadvantages of the subsystem are that many metallic materials absorb radioactive contamination within the grain boundaries of the metal, and decontamination of the metal to free release is extremely difficult.

The DT\&E needs for each unit operation and for the overall subsystem have been summarized in Table 20. These tables provide a ready reference to $R \& D$ needs in the final subsystem evaluation and for comparison purposes with other subsystems.

\subsection{Recommendation for the System}

All of the three parent systems evaluated in this report require separation of the bulk, and to a lesser degree, loose metal in the incoming feed. The metal sizing/decontamination subsystem 


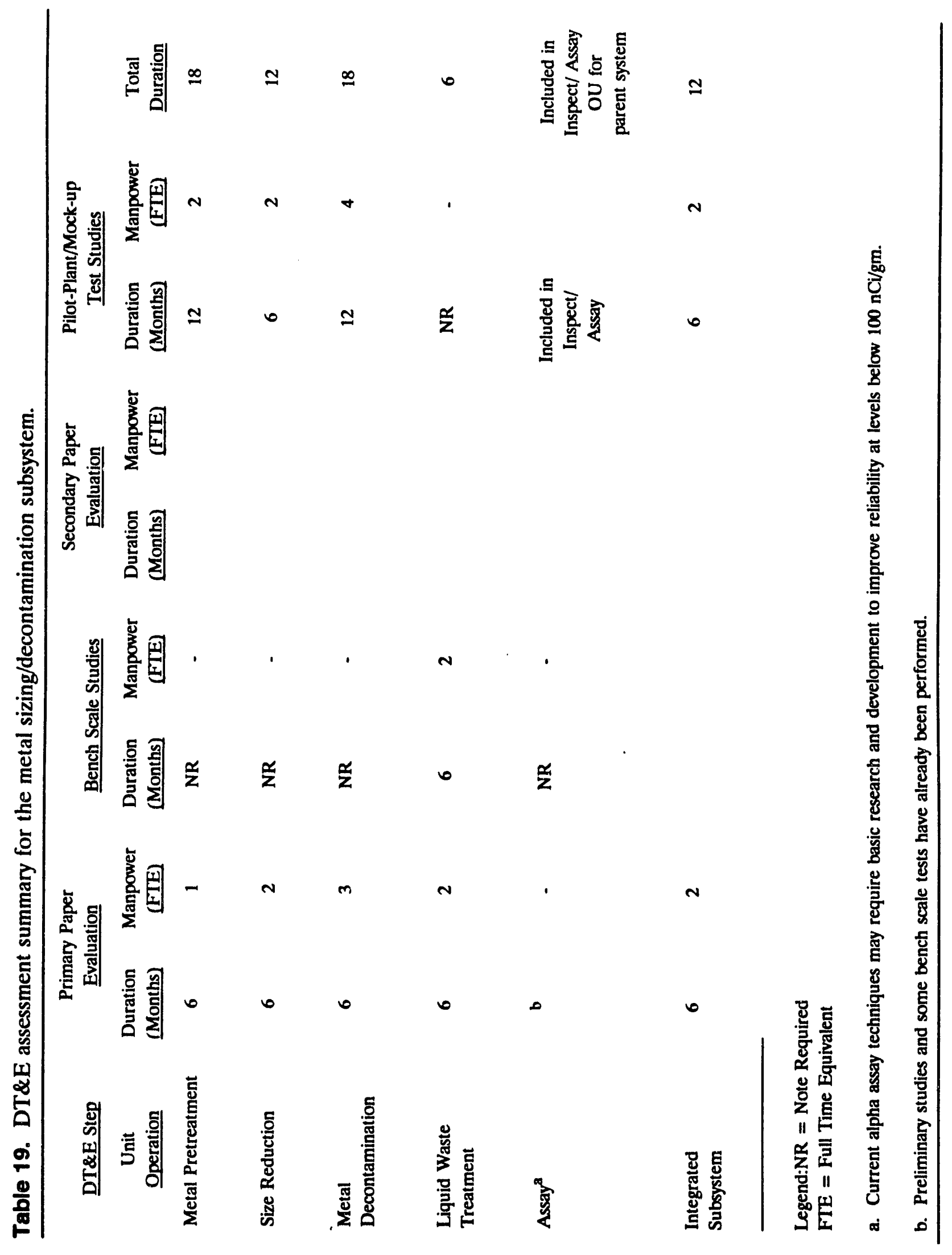




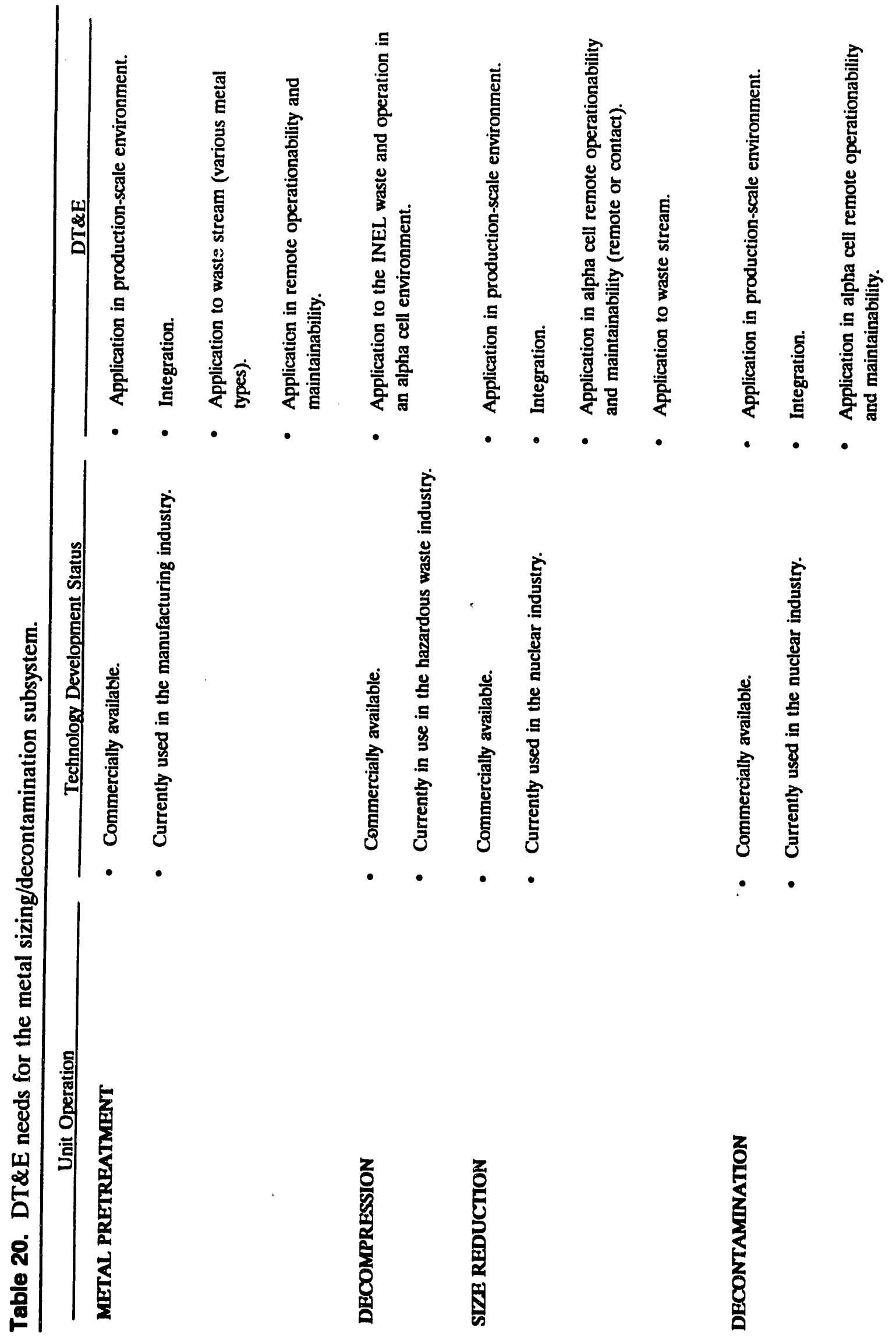




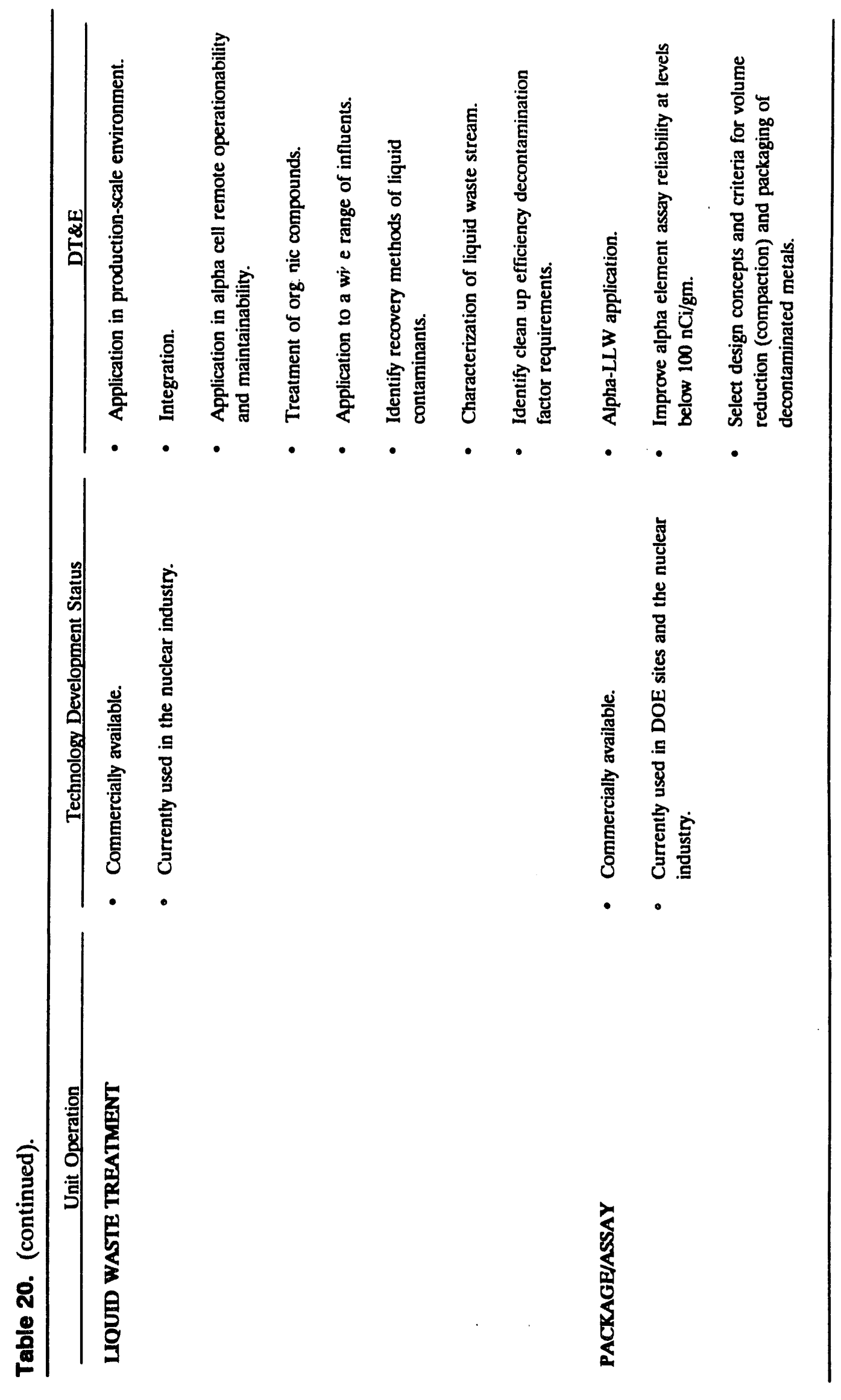


essentially uses existing technology to pretreat, size-reduce, decontaminate, package, and assay retrieved metallic waste to minimize the quantity of metal waste requiring disposal. The technologies employed are all currently available, permitting an early start on design, fabrication, and installation.

Recommended DT\&E for this subsystem includes the following:

- An analysis of the queuing of the metal waste stream to determine the capacities of components for unit operations

- Fine tuning of all the selected technologies to produce the desired results

- The integration of the process streams to ensure compatibility

- Installation of on-line sensors to monitor and report the status and progress of waste stream processing

- A prototype of this subsystem to evaluate its benefits.

In summary, the key benefit of the subsystem is that it offers a treatment process for metals that minimizes the degree of contamination and quantity of the metals requiring disposal. 


\section{SUMMARY AND CONCLUSIONS}

\subsection{Waste Form}

Since a required waste form has yet to be defined for the stored alpha-L.LW treatment project, the SWSDS used the three generic waste forms identified in the BWSDS (see Reference 1): Waste Form 2, which is a leach-resistant, high-integrity structure glass- or rock-like material which meets the LDR requirements; Waste Form 3, which is a solidified waste which meets LDR requirements; and Waste Form 4, which is based on the current WIPP and TRAMPAC transportation package acceptance criteria and the assumption that the LDR requirements are exempted. System concepts examined by the SWSDS are based on producing an output that meets the criteria of one or more of the established waste forms.

\subsection{System Concepts Summary}

The SWSDS examined three systems concepts which are summarized below.

\subsubsection{Incineration/Melting System}

The incineration/melting system concept produces a leach-resistant final waste form. In this system the intact containers (drums, boxes, and bins) are transported to a processing facility where the container contents are dumped out and sorted into metals, combustibles, semi-combustibles and noncombustibles. Metals are processed in a metal sizing and decontamination subsystem, which converts them into either low-level (less than $10 \mathrm{nCi} / \mathrm{g}$ ) waste or potentially recyclable material. The combustibles and semi-combustibles are processed in an incinerator. Ash and solids from the incinerator discharge are combined with the noncombustibles and an additive soil and fed to a melting furnace. System secondary waste, such as sludge from water treatment, is also fed to the melter. The melter output is a molten slag which is cooled and annealed into a leach-resistant glass- or rock-like product.

The principal advantages of the incineration/melting system concept are waste volume reduction, destruction of hazardous organics, and conversion of the noncombustible TRU-bearing wastes to a benign final waste form. The principal disadvantages are the potential for large volumes of offgas ${ }^{i}$ and the associated need for secondary burners and air pollution control devices to treat the offgas.

\subsubsection{Thermal Treatment/Solidification}

The thermal treatment/solidification system will produce a waste form in compliance with the LDR regulations. It also reduces potential for hydrogen generation from the waste form by removing as much metallic material as possible. The initial handling of containers and processing of bulk metals are the same as the incineration/melting system; the containers are dumped and the contents are sorted, and bulk metals are fed to the metal sizing/decontamination subsystem while combustibles and

i. The use of incinerators that minimize offgas (such as pyrolysis technique with oxygen burning) and melters that use little air (such as arc melters with a little oxygen for redox control and/or metal decontamination) will alleviate the high offgas discharge concerns. 
semi-combustibles are processed in an incinerator. Noncombustibles are sorted to remove organiccontaminated solids such as soil, concrete, and brick. The organic-contaminated solids are treated by an organic removal process to vaporize and burn the volatile organic compounds. Ash and solids discharged from the incinerator and treated solids from the organic removal processes are stabilized with one of several solidification agents. Inorganic noncombustibles are stabilized in the same manner.

Characterization of organic-contaminated noncombustible waste will be a critical factor in this system because it will form the basis for selecting the organic removal process to meet the LDR requirements. The thermal treatment/solidification system has the same advantage as the thermal vitrification system in that the thermal process effectively burns h?zardous organic compounds. However, its cementitious solidified waste form is less leach resistant and less durable than the incineration/melting system. Compliance with the performance assessment goals of DOE Order 5820.2A is unknown at this time. Another disadvantage of the thermal treatment/solidification system is that the addition of solidifying agent increases the waste volume and thus disposal cost. As with the incineration/melting system, the principal disadvantages are the potential for large volumes of offgas and the need for secondary burners and air pollution control devices to treat the offgas.

\subsubsection{Sort, Treat, and Repackage System}

The sort, treat, and repackage system concept produces a final waste form that only meets WIPP and TRAMPAC requirements. The initial container handling and dumping operations in this system are the same as the two earlier systems. Because of WIPP limitations on compressed gas cylinders this system ensures that all cylinders are separated and sent to the metal sizing and decontamination subsystem where they are punctured, shredded, and their contents treated.

Nonmetal waste is segregated in two categories, dry solids and liquids/fines. Dry solidis are reduced in size for volume reduction and repackaged directly into shipping/disposal containers; liquids/fines are first solidified and then placed in shipping/disposal containers.

A principal advantage of this system is that the processes are all in use and technically well-developed. The major disadvantage is that the final waste forms produced do not meet the LDR requirements for shallow-land disposal nor provide for TRU retention. The system can be used only if a deep geological disposal facility receives exemptions from the LDR requirements and becomes available for disposal of the final waste forms from this system.

\subsection{System Implementation Risk Assessment Summary}

Progrcmmatic risks associated with implementing each concept are assessed to identify major system uncertainties and areas requiring focused work and attention. An implementation risk assessment also establishes whether or not the program can meet the required technical, environmental, safety and health, institutional, schedule, and cost objectives.

Because the stored alpha-LLW project is still in the initial phase of the data acquisition process, a full implementation risk analysis will be performed when detailed information becomes availabie. Therefore, qualitative judgements were made based on several assumptions. Experienced personnel ranked the ability of each system to meet each of the program objectives as low, moderate, or high. A summary of the implementation risk for the three system concepts is presented in Table 21. A low 
Table 21. Program implementation risk summary.

\begin{tabular}{|c|c|c|c|c|c|c|}
\hline \multirow[b]{2}{*}{ System Concept } & \multicolumn{2}{|c|}{ Technical } & \multirow[b]{2}{*}{$\begin{array}{c}\text { Health and } \\
\text { Safety }\end{array}$} & \multirow[b]{2}{*}{ Institutional } & \multirow[b]{2}{*}{ Schedule } & \multirow[b]{2}{*}{ Cost } \\
\hline & $\begin{array}{l}\text { Waste } \\
\text { Form }\end{array}$ & $\begin{array}{l}\text { Process } \\
\text { Technology }\end{array}$ & & & & \\
\hline $\begin{array}{l}\text { Incineration/ } \\
\text { Melting }\end{array}$ & Low & Moderate & Low & Moderate & Moderate & Moderate \\
\hline $\begin{array}{l}\text { Thermal Treatment/ } \\
\text { Solidification }\end{array}$ & Moderate & Low & Low & Moderate & Moderate & Moderate \\
\hline $\begin{array}{l}\text { Sort, Treat, and } \\
\text { Repackage system }\end{array}$ & High & Low & Low & Low & Low & Moderate \\
\hline
\end{tabular}

risk ranking indicates that the system could be implemented with virtually no risk. A moderate risk ranking indicates that although the implementation of the system concept is feasible, certain aspects of the implementation still need to be resolved. A high risk ranking indicates a considerable amount of uncertainty of the system's ability to achieve its objective.

The technical risk has been subdivided into waste form and process technology. The incineration/melting system receives a low risk ranking for the waste form but a moderate risk for the process technology. The low ranking for the waste form is because this system produces a waste form that has a high probability of retaining radionuclides over geologic time frame. The moderate ranking of the technology is because of the current maturity of melter process application to alpha-LLW.

The thermal ireatment/solidification system receives a moderate ranking in the waste area but a low ranking for the process technology. The moderate ranking is the result of uncertainties regarding long-term ( $>300$ years) integrity of the stabilized waste. A preliminary performance assessment is needed to determine if waste-form longevity could become an issue if shallow-land disposal of alpha-LLW is considered.

The high waste form risk ranking of the sort, treat, and repackage system is also the result of a low quality waste form produced by this system. Most of the waste (dry solids) is simply repackaged, has no stability, and is suitable only for disposal in a deep geological repository.

Because they employ thermal processes, the incineration/melting and thermal treatment/solidification systems compliance with the institutional objectives are given a moderate ranking. DOE has had limited success in the past in obtaining institutional support to install incinerators at its sites; however, thus far this has not been a problem at the INEL.

Thermal processes are prone to schedule delays due to extensive permitting and approval requirements; therefore, systems using thermal processes receive a moderate risk ranking on their schedule compliance objectives.

Risk associated with the ability to define the cost is believed to be moderate for all systems because cost uncertainties are anticipated until design, based on DT\&E, is well into maturity. 


\subsection{Summary of ROM Life-Cycle Cost Estimates}

ROM life-cycle cost estimates are developed to compare the relative cost effectiveness of the three options. These costs are summarized in Table 22. The ROM cost estimates include DT\&E, facility construction costs, and annual operational costs. Although decommissioning and disposal facility concept explorations are nct a part of the SWSDS scope, costs for these aspects of waste management have been added to the overall life cycle cost. Decommissioning and disposal costs used in this report are based on unit rates estimated in previous EG\&G tasks (see Reference 2).

Building costs are derived by first estimating the squarc footage needed to house each unit operation and then multiplying the square footage by the building unit rate costs. Four different categories of building unit rates are considered: low-hazard buildings at $\$ 150 / \mathrm{ft}^{2}$, moderate-hazard buildings at $\$ 350 / \mathrm{ft}^{2}$, double-barrier confinement alpha cells at $\$ 1000 / \mathrm{ft}^{2}$, and triple-barrier confinement alpha cells at $\$ 1200 / \mathrm{ft}^{2}$. The building costs are based on the assumptions that waste handling, processing, and equipment maintenance functions are accomplished in alpha cells, operating rooms are in moderate-hazard areas, and support function are in low-hazard areas of the facility. The offsite utility cost of power, water, and sewer facilities was not included in the estimate.

The initial DT\&E costs and the annual operating and maintenance costs are derived by developing the size of the operating and maintenance staff, utility costs, and material costs for each unit operation.

Costs for design, construction, construction management, and testing are estimated by multiplying the equipment and building costs by a given set of factors which are uniformly applied to each of the three options. These factors are based on EG\&G Idaho's experience on similar projects. All costs are in 1992 dollars.

In accordance with DOE orders, there are a number of activities which cannot be charged to the Line Item Construction Project (LICP) funds. These include conceptual design, program management and administration planning prior to conceptual design, environmental and permitting, safety documentation, and preparation for operation. Budgeted cost for these activities are obtained from the current IWPF estimates and are added to the system ROMLC cost estimates. Furthermore, it is assumed that these costs are the same for all system options.

As shown in Table 22, the ROM life-cycle cost estimate for the three systems are between 605 and 543 million dollars. The variation between the most and the least expensive system is approximately 10 percent. At this point of the system analysis, this variation is not considered significant enough to affect system selection.

Cost sensitivity analyses are performed to determine the impact of the equipment, building and disposal costs, and the alpha-cell area vanations on the overall system costs. A key conclusion of the cost assessment effort is that the overall system concept cost is significantly impacted by the size of the alpha cells required for waste processing. Therefore, a detailed design study is required to optimize the facility layout and to adequately def a the alpha-cell space requirements and evaluate options such as glovebox versus remote alpha-cell waste handling. 


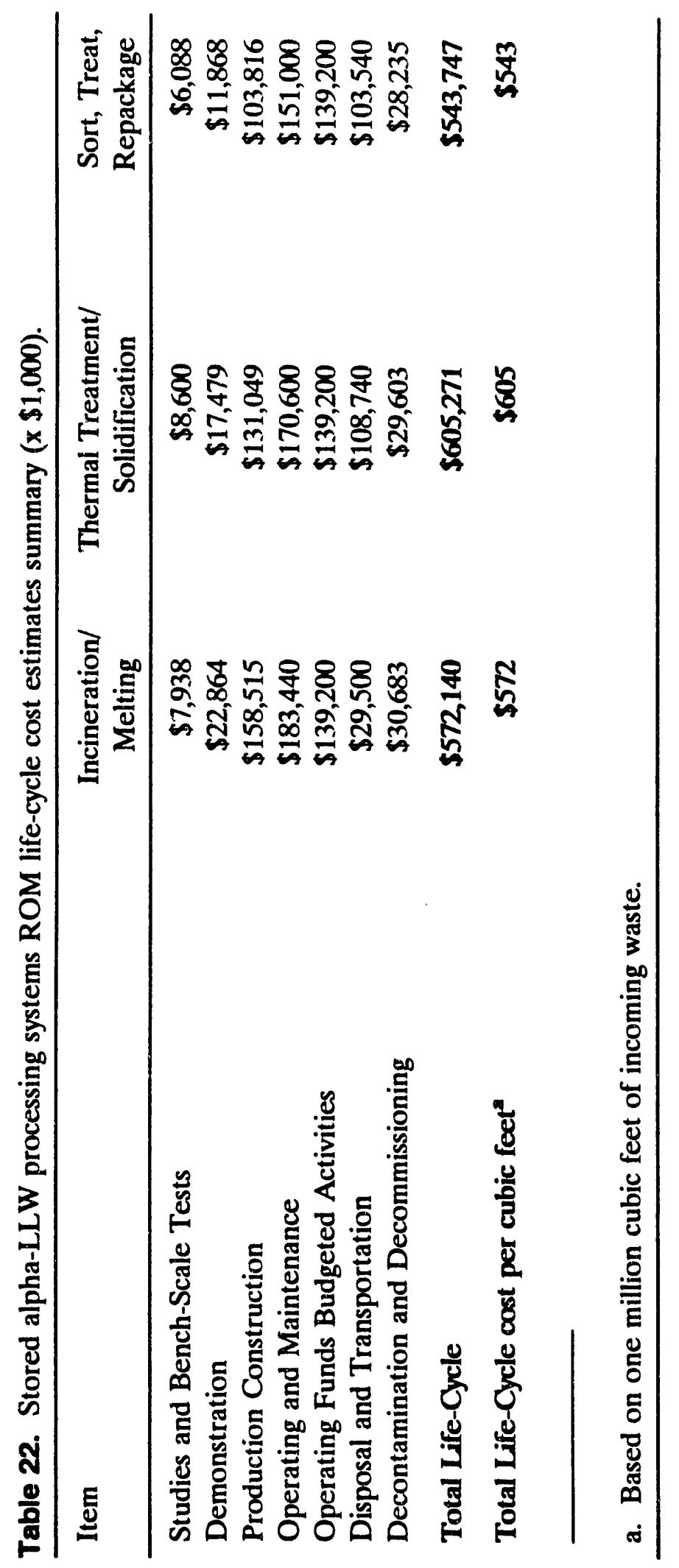




\subsection{Volume Reduction Effects}

The three systems are sized to process approximately one million cubic feet of alpha-LLW weighing about 13,120 tons. The volume of the packaged waste produced by each system and the resultant volume reduction factors are as follows:

Incineration/melting

Thermal treatment/solidification

Sort, treat, and repackage

\begin{tabular}{cc}
$\begin{array}{c}\text { Packaged Waste } \\
\text { Volume }\end{array}$ & $\begin{array}{c}\text { Volume Reduction } \\
\text { Factor }\end{array}$ \\
\cline { 2 - 2 } $155,800 \mathrm{ft}^{3}$ & 6.4 \\
$573,400 \mathrm{ft}^{3}$ & 1.7 \\
$546,000 \mathrm{ft}^{3}$ & 1.8
\end{tabular}

\subsection{DT\&E Leadtime Estimates}

A summary of the areas requiring DT\&E is presented in Table 23. DT\&E lead time for the incineration/melting system is four years. Initial paper studies and bench-scale tests on scveral incineration and melting techniques are either complete or in progress. However, a rotary kiln incinerator has been extensively tested at the Process xperimental Pilot Plant (PREPP) at the INEL. In addition to these efforts, it is assumed that a demonstration model of the melter, slag molding, cooling and packaging, and the offgas train is needed to prove process feasibility in an alpha cell environment. It is also assumed that the current research in slag formulations and chemical and assessment of physical properties will continue.

DT\&E lead time for the thermal treatment/solidification system is three years. The organic removal and solidification unit operations within the thermal treatment/solidification system will require DT\&E. Additionally, it is assumed that DT\&E of the selected incineration design will be performed at an offsite location by the vendors.

DT\&E lead time for the sort, treat, and repackage system is 2.5 years. This system and the above two systems conduct waste handling inside the alpha cell. This includes equipment such as drum opening, dumping, and transfer devices; crushers; shredders; and sorting devices. Although most of these devices have been used extensively in wood, plastic, metal, and mining industries, their use in an alpha cell environment is a first-of-a-kind application and DT\&E will be required. DT\&E, combined with machine tool design and application engineering, must focus on optimizing the remote operation, dei:ontamination, and maintenance aspects of the waste handling components.

A critical device used in all three systems is the TRU-element assay instrument. This instrument is used to classify a waste as LLW, alpha-LLW, or TRU. Currently, this classification is made using an passive/active neutron (PAN) detection instrument developed by the Los Alamos National Laboratory. A DOE conference on this issue, held in Pocatello, Idaho, in 1991, ir.jicated that there may be insufficient data to establish a reliability factor for this instrument. Therefore, DT\&E efforts in this area are also required. 
Table 23. DT\&E summary.

\section{System/Subsystem Concept}

Incineration/Melting
Thermal Treatment/Solidification
DT\&E Areas

- Equipment selection for melting process. Investigate plasma pyrolysis, plasma arc furnace, plasma centrifugal reactor Joule melter, gas cyclonic, and slagging pyrolysis melter techniques.

- Equipment selection for incineration process. Investigate applicability of rotary kiln, controlled air, fluidized bed, infrared, and pyrolysis techniques.

- Selection of thermal-train process flow sheet (see the four options given in Section 5).

- Alpha cell designs including material handling equipment such as drum and box transfer, opening, dumping, crushing, and shredding.

- Slag additive and process condition requirements to optimize physical, chemical, and leachability properties and identify process tolerance.

- Reliability of TRU element assay instruments.

- Equipment selection for the incineration and melter offgas process. Optimize equipment selection and design for alpha cell application and volatile metal removal.

- Equipment selection for incineration process. Investigate applicability of rotary kiln, controlled air, fluidized bed, infrared, and pyrolysis techniques.

- Equipment selection for organic removal. Applicability of biological treatment, supercritical fluid, thermal desorption, or carbon adsorption processes .

- Alpha cell designs including material handling equipment such as drum and box transfer, opening, dumping, crushing, and shredding.

- Reliability of TRU element assay instruments.

- Equipment selection for the incineration offgas process. Optimize equipment selection and design for alpha cell application and volatile metal removal.

- Characterization techniques for the incoming waste in order to allow for determination of the applicable LDR treatment requirements.

- S. 'idification and treatment techniques for alpha-LLW sludges, ash, and other waste material in the system including formulations to achieve a LDR acceptable waste form.

- Solidified final waste form performance acceptance criteria and associated disposal facility requirements, particularly for TRU elements (performance assessment related). 
Table 23. (continued).

System/Subsystem Concept

Sort, Treat, and Repackage

Metal Sizing

\section{DT\&E Areas}

- Equipment selection for incineration process. Investigate applicability of rotary kiln, controlled air, fluidized bed, infrared, and pyrolysis techniques.

- Equipment selection for size reduction. Investigate techniques suitable for shredding plastic, wood, paper, brick, and concrete.

- Alpha cell designs including material handling equipment such as drum and box transfer, opening, dumping, crushing, and shredding.

- Reliability of TRU element assay instruments.

- Solidification and treatment techniques for liquids and fines including formulations to achieve an acceptable waste form.

- Equipment selection for decontamination unit operation. Investigate abrasive blasting, $\mathrm{CO} 2$ grit blasting, electro-polishing, ultrasonic, and other state-of-the art techniques.

- Selection of size reduction devices for ferrous and non-ferrous bulk metals. Investigate plasma torch, remote shear/saw cutting tools, and shredders.

- Effectiveness of decontamination methods in alpha cell environment

- Treatment (detoxification) of liquid/sludge waste from decontamination operations. 


\subsection{Performance Measurable Summary}

The unit operations of each system are individually ranked against the nine performance measurables given in Section 3. The ranking for each of the three systems is obtained by first multiplying the total score of each unit operation score by an established weighing factor, given in Section 3, to obtain a weighed score for each unit operation. The weighted scores of all unit operations in the system are then added to obtain a total score for the system. The system score is divided by the maximum available score for that system, and this value, expressed in percentage of the total available maximum score, is used for system comparison. Accordingly, the incineration/melting and thermal treatment/solidification each received a ranking of 74 percent, and the sort, treat, and repackage system received a ranking of 67 percent. This is a further indication that both the incineration/melting and thermal treatment/solidification systems are more viable than the sort, treat, and repackage system. 


\section{RECOMMENDATIONS}

Based on the evaluation of three alpha-LLW treatment systems, the following are preliminary recommendations.

\subsection{Viable Systems}

At this stage of the project, both the incineration/melting and thermal treatment/solidification systems can be considered viable. The final selection depends on a key factor, waste form acceptability, which can be determined only after further DT\&E on melter slag and solidified waste forms. Waste form acceptability also depends on the chosen disposal method. Until the disposal method is identified and preliminary performance assessments are conducted, DT\&E and other concept exploration efforts on both options should be pursued.

The sort, treat, repackage system assumes that a deep geologic repository, exempted from the LDR requirements, will be the final disposal place for alpha-LLW. Since it is unlikely that a deep geologic repository will become avialable for this waste, significant DT\&E on the sort, treat, repackage system is not justified.

\subsection{Trade-off Studies}

The following future activities are recommended.

\subsubsection{Incineration/Melting Flow Sheet}

Studies in conjunction with the incineration/melting system DT\&E should focus on developing an optimized flow sheet for the arrangement of the thermal train (i.e., incinerator, melter, offgas train, slag molding, cooling and packaging). A preliminary investigation of four different options indicates that selection of an optimized flow sheet depends on equipment design and, if properly selected, could increase process reliability, improve space utilization, and save cost. For example, if one thermal vessel is used both for the incineration and melting functions, the required alpha cell space will be reduced by almost half.

\subsubsection{System Capacity Optimization}

The design flow rate for the incinerator/melter units, which is approximately $700-1000 \mathrm{lbs} / \mathrm{hr}$, is relatively low for most of the melters used in the metal and mining industry. Therefore, studies are recommended to define optimum process flow rates to maximize operating efficiency and resource utilization. Processing of waste from other DOE sources should be on: of the options considered in the studies.

\subsubsection{Remotely Operated Alpha-Cell Versus Glovebox}

The SWSDS systems are based on remotely operated alpha cells. Tr:de-off studies should be conducted to see if this approach or glove box handling is the most feasible approach. 


\subsection{DT\&E Activities}

Alpha-LLW processing DT\&E should be organized into the following major tasks.

\subsubsection{Melter DT\&E}

Since the melter is a first-of-a-kind facility, a full-scale testing is justified. Testing can be conducted in an existing INEL building using simulated nonradioactive waste.

\subsubsection{Incinerator DT\&E}

Incinerator DT\&E can be performed offsite by vendors. If a rotary kiln design is selected, test data from the Process Experimental Pilot Plant at the INEL, combined with industry experience in burning hazardous waste, may be sufficient for the alpha-LLW process design.

\subsubsection{Waste Handling Devices DT\&E}

All systems conduct waste handling inside the alpha cell. Although most of these devices have been used extensively in wood, plastic, metal, and mining industries, their use in an alpha cell environment is a first-of-a-kind application and DT\&E will be required. This activity can also be performed in an existing INEL building using simulated non-radioactive waste.

\subsubsection{Waste Formulations DT\&E}

Waste formulations for both the vitrification and solidification processes are important factors in system selection and ensuring compliance with the LDR requirements. Waste formulation tests, largely bench-scale, can be done at laboratories with expertise in these fields.

\subsubsection{TRU Assay Device DT\&E}

The importance of the TRU assay device to ensure overall process safety and compliance with the waste classification requirements was noted in Section 5 of this report. EG\&G Idaho is currently pursuing DT\&E in this field. This program should be expanded to consider application in a production-scale environment. The most important aspect of the DT\&E effort should be improving the reliability and speed of the assay process.

\subsubsection{Metal Decontamination DT\&E}

Metal decontamination DT\&E tasks are recommended to optimize the metal sizing/decontamination unit operation. The DT\&E program can be performed offsite by specialized firms or by INEL personnel and vendors working onsite. DT\&E tasks should address secondary waste treatment and optimize, methods that produce reduced secondary waste. 


\subsection{Systems Design Studies}

System design studies on two of the waste sources (buried TRU/alpha-LLW and stored TRU) are now complete. Studies on the remaining two sources (stored TRU and newly generated) are needed to evaluate the available options and to complete feasibility studies on all of the waste sources to be handled by the IWPF. The results of the studies on the four waste forms will be helpful in analyzing the various waste processing options for the two phases of the IWPF.

\subsection{Systems Engineering Activities}

The systems engineering tasks should continue developing the systems requirements document. This document should be based on the results of this study and should contain input/output, performance, unit operations technology, utilization of resource, tradeoff, and system test requirements. Some of the activities needed to accomplish the above tasks include development of incoming waste characteristics, and exploration of concepts at the system and unit operations level. These activities should develop cost estimates, resource requirements, system integration requirements, and figure-of-merit analysis criteria. 


\section{REFERENCES}

1. J. L. Mayberry et al., Preliminary Systems Design Study Report, EGG-WTD-9594, Volumes I through VIII, July 1991.

2. R. Schlueter et al., Low Level and Transuranic Waste Transportation, Disposal and Facility Decommissioning Cost Sensitivity Analysis, EGG-WTD-10092, March 1992.

3. EPA, Office of Solid Waste and Emergency Response, Joint EPA/NRC Guidance on the Definitions and Identification of Commercial Mixed Low-Level Radioactive and 'iazardous Waste, Directive No. 9432-00-2, October 4, 1989.

4. U.S. Nuclear Regulatory Commission, Clarification of RCRA Hazardous Waste Testing Requirements for Mixed Waste, U.S. NRC, Draft Guidance, March 1992.

5. R. Geimer et al., Assessment of Incineration and Melting Treatment Technologies for RWMC, EGG-WTD-10035, February 1992.

6. A. D. Donaldson et al., Melter Development Needs Assessment for RWMC Buried Wastes, EGG-WTD-9911, February 1992.

7. G. A. Reimann et al., Summary of INEL Research on Iron-Enriched Basalt Waste Form, EGG-WTD-10056, January 1992.

8. P. C. Kong, "Recommended Final Waste Form Requirements for TRU Waste," SPECTRUM '92, Boise, Idaho, August 1992.

9. A. S. Rood, "Performance Assessment of Radioactive Waste Encapsulated in Iron-Enriched Basalt and Disposed at the Idaho National Engineering Laboratory's Radioactive Waste Management Complex," SPECTRUM '92, Boise, Idaho, August 1992.

10. E. Barth et al., Stabilization and Solidification of Hazardous Waste, Noyes Data Corporation, Park Ridge, N.J., 1990.

11. J. R. Connor, Fixation and Solidification of Wastes, Van Nostrand Reinhold, New York, N.Y., 1990.

12. G. G. Loomis et al., Executive Summary of the Cryofracture Demonstration Program, EGG-WTD-9916, September 1991. 
Appendix A

Waste to be Treated in the IWPF Engineering Design File IWPF-0009-Rev. 0 
A-2 
EG\&G Idaho, lnc

FORM EG\&G-2631 (Rev. 12-88)
Project File Number

EDF Serial Number IWPF-0009 Rev. 0

Functional File Number

\section{ENGINEERING DESIGN FILE}

Project/Task Idaho Waste Processing Facility

Subtask IWPF Process Definition

EDF Page 1 if 16

\section{Subject : Wastes to be Treated in the IWPF}

\section{Abstract:}

The purpose of this EDF is to document the wastes that will be processed by the Idaho Waste Processing Facility (IWPF). Physical characteristics of the waste which determine IWPF processes are included. Reterences are provided for the waste content codes and hazardous material characterization of the content codes.

The wastes consist of TRU wastes (those with $>100 \mathrm{nCi} / \mathrm{g}$ of transuranic radionuclides) and Low-Level Waste which is contaminated with transuranic radionuclides (LL-TRU) (those with contamination between 12 and $100 \mathrm{nCi} / \mathrm{g}$ ). About 28.5 million kilograms of the waste are to be processed through IWPF. Both Contact Handled waste (less than $200 \mathrm{mR} / \mathrm{hr}$. at the surface of the package) and Remote Handled waste (greater than $200 \mathrm{mR} / \mathrm{hr}$.) are to be processed by IWPF.

Distribution (complete package):

J. E. Langford, L. G. Gale, G. L. Anderson, W. S. Roesener, A. L. Ayers, Jr. L. W. Ball

Distribution (cover sheet only):

L. J. Bal1, H. Henze, M. R. Martin

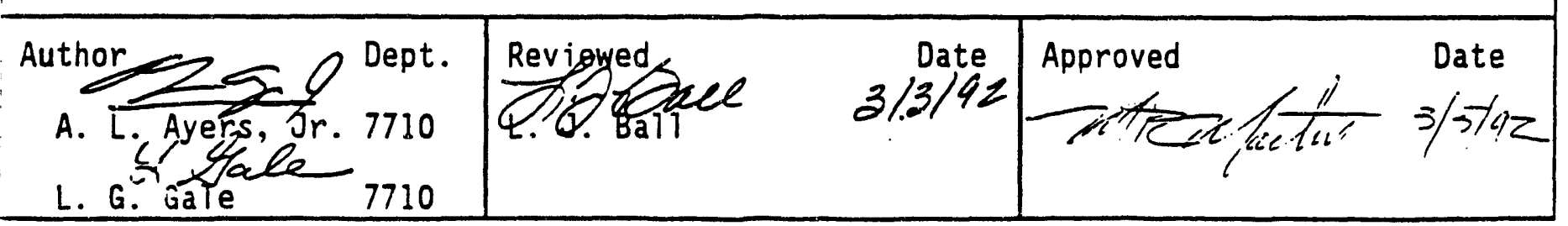


EDF-IWPF-0009, Rev. 0

गage 2 of 16

\section{INTRODUCTION:}

The Idaho Waste Processing Facility (IWPF) project will provide facilities for handling and jrocessing wastes which are contaminated with transuranic radionuclides. Those wastes at the idaho National Engineering Laboratory (INEL) are from sources at INEL and other DOE acilities, primarily from Rocky Flats Production Facilities. Prior to the early 1970's, all vastes received at INEL were disposed in subsurface pits and trenches with minimal iegregation of waste types. In the early 1970's, wistes contaminated with transuranic adionuclides at levels greater than $10 \mathrm{nCi} / \mathrm{g}$ began to be separated from other wastes and -etrievably stored at the Radioactive Waste Management Complex (RWMC). The Waste Isolation 'ilot Plant (WIPP) project was astablished in the early 1980's to dispose of Transuranic laste (TRU)--wastes with transuranic contamination levels above $100 \mathrm{nCi} / \mathrm{g}$. Wastes with :ransuranic concentrations lower than $100 \mathrm{nCi} / \mathrm{g}$ were reclassified as low-level wastes (LLW). :urrent criteria for LLH at DOE disposal facilities limit transuranic concentrations to less :han $10 \mathrm{nC}: \mathrm{g}$. Thus, a defacto class of wastes exists with transuranic contaminations letween 10 and $100 \mathrm{nCi} / \mathrm{s}$. This defacto waste is variously referred to as "reclassified TRU" ir low-level TRU (LL--RU). In addition to the radioactive contamination, much of the waste las hazardous constituents which require treatment prior to disposal. Within this report TRU -efers to Transuranic Waste and LL-TRU is low-level waste contaminated with Transuranic adionuclides. The wastes to be treated by the IWPF are divided into chree categories: LLitored TRU, stored TRU, and retrieved transuranic contaminated buried waste.

he LL-TRU wastes are to be treated to allow disposal in a future LLW disposal faci?ity. lany of these wastes will require treatment to the Land Disposal Restriction (LDR) equirements of the Environmental Protection Agency (EPA). IWPF will treat all LL-TRU lastes.

he TRU wastes (as opposed to LL-TRU wastes) are to be disposed at WIPP. TRU wastes are to e processed per the requirements of the WIPP-Waste Acceptance Criteria (WAC). ${ }^{1}$ The WIPP rogram has proposed that the WIPP facility will contain the hazardous component of the waste ithout additional treatment. This "No Migration" petition has not been ruled upon by EPA. he IWPF project currently assumes that TRU will not require treatment as hazardous waste and he waste will not need to meet LDR requirements. The wastes must meet TRUPACT-II Authorized lethods for Payload Control (TRAMPAC) requirements for transportation to WIPP. ${ }^{2.3}$ TRAMPAC ill necessitate treatment of much of the waste prior to shipment to WIPP. That treatment $s$ expected to be less extensive than that of LL-TRU. Therefore, it is assumed that 25 to 00 per cent of the TRU wastes will be processed by IWPF.

$f$ all the wastes to be processed by IWPF, buried waste has the most uncertainty in both aste material and quantities to be processed. The existing disposal areas are under the omprehensive Environmental Response, Compensation, and Liability Act (CERCLA) process of emediation evaluation. The options for treatment of buried waste include: (a) leaving all aste in place; (b) treating part of the waste; or (c) removing and processing all buried aste. In addition, the sites have not been characterized in sufficient detail to determine he current form of the waste and how much processing capability will be required. Wastes rom this source are expected to be similar to LL-TRU and TRU wastes with the addition of a onsiderable amount of soil. During remediation, the wastes will be split into TRU and LLRU streams. IWPF will process both the TRU and the LL-TRU wastes from buried waste. owever, the operating time and capacity of IWPF will be reviewed as additional data become vailable on the buried waste. 
EDF-IWPF-0009, Rev. 0

Page 3 of 16

WASTE CHARACTERISTICS:

All wastes processed by the IWPF facility shall be either TRU or LL-TRU, as described above. DOE Order 5820.2A defines transuranic waste as waste that is contaminated with alphaemitting radionuclides at concentrations of greater than $100 \mathrm{nCi} / \mathrm{g}$ at time of assay. The radionuclides also have atoliic numbers greater than 92 and half-lives greater than 20 years. Within the IWPF project, the determination of TRU shall also add Pu-241 ( 14.35 year halflife) desay products to assayed radioactivicy quantities. LL-TRU shall be wastes contaminated between 10 and $100 \mathrm{nCi} / \mathrm{g}$. No other wastes will be a basis for desigri of the facility. Beta and gamma-emitting radionuclides shall be used to determine shielding requirements for $\mathrm{CH}$ and $\mathrm{RH}$ waste.

Information on transuranic contaminated waste has been accumulated by RWMC personnel upon receipt of the waste. The information was entered into a data base called the Transuranic Waste Data Base (TWDB). ${ }^{4}$ Although not complete, the TWDB has the most comprehensive view of waste characteristics. The data base was established after many of the waste containers were received at INEL and data currentiy required was not provided. In addition, the data requirements have change in time and data on older containers is not available. The data base includes container identification, gross package weight, content code, radionuclide quantities, gross/container/waste weights, hazardous material numbers and quantities, surface dose rates, and radioactive curie estimates. Other information is also available. Content codes are used to characterize waste physical form. Reference 5 is a description of the codes. A number of the containers are identified as containing polychlorinated biphenyls $(P C B)$.

Studies of the hazardous chemical conditions of the stored waste were performed using the container content codes as a basis. A review was made in 1990 of the content codes to determine chemical compatibility of the wastes. "In 1991, further characterization of the chemical constituents of each content code was reported. ${ }^{7}$

In order to reduce the number of waste streams considered, content codes were grouped into 19 categories. Appendix A provides more information on the categorization of the waste. Table 1 is a compilation of the categories and the content codes within each category. The weights are given for each code and summarized as TRU and LL-TRU wastes. Totals of waste container types are included for each waste type. Much of the waste is not defined with sufficient accuracy to allow placement into discrete categories. These wastes are 1 isted as 'Unclassified".

The stored wastes listed in Appendix $A$ are divided into contact-handled (CH) and remoterandled (RH) wastes. IWPF will process both types. The $\mathrm{CH}$ waste will be processed in -isolated but non-shielded systems. A separate shielded process system shall be used to jrocess RH wastes. 


\section{ECEIPT OF WASTE AT RWMC:}

he wastes are packaged in a variety of containers. Table 2 lists the types used for the ajority of wastes. Thirty additional non-standard containers are also included in the data ase. All containers are lined with plastic to provide double containment of the waste. In ddition, many of the wastes inside the container are wrapped in plastic film or bags.

he waste received at the RWMC was in accordance with approved waste acceptance criteria. urrent criteria can be found in Reference 8. Corresponding General Waste Acceptance iriteria from Revision I (August 1981) are included in Appendix B. ${ }^{9}$ Similar criteria existed :or waste received prior to 1981. In all cases, exceptions could be approved for nonitandard shipments.

ach container was received at INEL as waste. Therefore neither special nuclear materials iccountability nor Fissile Materials Control Area controls are expected for processing the laste.

\section{DDITIONAL INFORMATION AVAILABLE AT PROCESS TIME:}

iditional information will be available as waste is delivered to IWPF for processing. iesults of testing the gas in the headspace of the container will be available for each :ontainer. Each container will be inspected by the Stored Waste Examination Pilot Plant SWEPP). Information provided by SWEPP will include radiological surveys, transuranic ontent surveys, and Real Time Radiography results. About five to ten percent of the ontainers will also have been examined in the Waste Characterization Facility (WCF). The ICF is currently being designed and will be in operation before the IWPF construction project legins. The results of all the above examinations will be available at the time of irocessing.

\section{IASTE INPUT RATE:}

WPF will be sized to process all stored LL-TRU and between 25 and 100 percent of stored TRU lastes over a 10-year period. The plant will be assumed to be operational an average of 1 months per year with 3 three months allotted for maintenance activities. Based upon Table wastes, the plant will process about 40 to 65 drum equivalents per day. 
EDF-IWPF-0009, Rev. 0

Page 5 of 16

Table 1. Stored Waste Category Description

$\checkmark$

COMBUSTIBLE

$10 \quad 82000 \quad$ COMBUSTIBLES (RAGS, GLOVES, POLY)

$116710300 \quad$ CERTIFIED TRU COMBUSTIBLE WASTE

$202 \quad 3680$ COMBUSTIBLE SOLIDS-PAPER-CLOTH

$328 \quad 620 \quad$ FULFLO INCINERATOR FILTERS

$330 \quad 2430000$ DRY PAPER ANO RAGS

$336 \quad 830000 \quad$ MOIST PAPER AND RAGS

$337 \quad 189800$

$80 \mathrm{~L}-2100$

$804 \quad 11000$

$847 \quad 87000$

$900 \quad 37200$

$970 \quad 62000$

PLASTICS, TEFLON, WASH, PVC

RAGS, PAPER, WOOD, ETC

PLASTIC, TYGON. MANIPULATOR-BOOTS, ETC.

LSA < $100 \mathrm{NCI/G} \mathrm{COMEUSTIBLE}$

LSA PAPER, PLASTICS. ETC.

WOOD

Quantity of TRU Waste

\# of Drums $=3901$

\# of Boxes $=2133$

$\#$ of Bins $=1$

Total TRU Waste Weight $=2.370,541 \mathrm{Kg}$

COMMENTS

Quantity of LL-TRU

\# of Drums $=13246$

\# of Boxes $=713$

\# of Bins = 4

Total LL-TRU Waste Weight $=2.075,159 \mathrm{Kg}$

\section{METAL - STEEL AND OTHER STRUCTURAL METALS}

\begin{tabular}{lr} 
CODE & \multicolumn{1}{c}{ KG } \\
480 & 4580000 \\
481 & 290000 \\
803 & 13000
\end{tabular}

Quantity of ifiU Waste

* Si Jrums $=1838$

- of Boxes $=1319$

\# of Bins = 0

Tota 1 TRU Waste Weight $=2,175,566 \mathrm{Kg}$
COMHENTS

NON SS SCRAP METAL

LEACHED NON SS METAL

METAL EQUIPMENT, PIPES, VALVES, ETC.

Quantity of LL-TRU

* of Drums $=1697$

* of Boxes = 2052

\# of Bins =

Total LL-TRU Waste We ight $=3,107,434 \mathrm{Kg}$

\section{METAL - SPECIAL}

\begin{tabular}{rrl} 
CODE & \multicolumn{1}{c}{ KG } & DESCRIPTION \\
117 & 684000 & CERTIFIED TRU METAL WASTE \\
-320 & 47100 & TANTALUM \\
416 & 220 & ZINC-MAGNESIUM ALLOY METAL
\end{tabular}

Quantity of TRU Waste

$*$ of Drums $=422$
of Boxes $=515$
of Bins $=0$

Quantity of LL-TRU

- of Drums = 121

\# of Boxes = 0

\# of Bins = 0

Total TRU Waste Weignt $=717,401 \mathrm{Kg}$

Tota i LL-TRU Waste Weight $=13,919 \mathrm{Kg}$ 
:DF-IWPF-0009, Rev. 0

'age 6 of 16

able 1. Stored Waste Category Description (continued)

\section{GLASS}

\begin{tabular}{|c|c|c|}
\hline DOE & KG & \\
\hline $\begin{array}{l}18 \\
10 \\
41 \\
42 \\
10\end{array}$ & $\begin{array}{r}68300 \\
152000 \\
140000 \\
145000 \\
970\end{array}$ & \\
\hline & $\begin{array}{l}\text { TRU Wast } \\
\text { of Drums } \\
\text { of Boxes } \\
\text { of Bins }\end{array}$ & $\begin{array}{r}2252 \\
54 \\
0\end{array}$ \\
\hline
\end{tabular}

DESCRIPTION

COMMENTS

CERTIFIED TRU GLASS WASTE

GLASS

UNLEACHED RASCHIG RINGS

LEACHED RASCHIG RINGS

GLASS, FLASKS, SAMPLE VIALS, ETC.

otal TRU Waste Weight $=310.131 \mathrm{Kg}$

Quantity of LL-TRU

* of Drums = 1829

" of Boxes $=0$

" of Bins = 0

Tota) LL-TRU Waste Weight $=196.139 \mathrm{Kg}$

\section{GRAPHITE MOLDS AND CRUCIBLES}

\begin{tabular}{lr} 
OOE & \multicolumn{1}{c}{ KG } \\
15 & 34000 \\
00 & 210000 \\
01 & 4200 \\
03 & 6600 \\
10 & 1800 \\
11 & 1790 \\
12 & 690
\end{tabular}

DESCRIPTION

COMMENTS

CERTIFIED TRU GRAPHITE WASTE

GRAPHITE

GRAPHITE CORES

SCARFED GRAPHITE CHUNKS

GRAPHITE SCARFINGS

GRAPHITE HEELS

COARSE GRAPHITE

uantity of TRU Waste

- of Drums $=1940$

- of Boxes = 1

of Bins $=0$

stal TRU Waste Weight $=247,694 \mathrm{Kg}$

Quantity of LL-TRU

of Drums $=87$

* of Boxes = 0

H of Bins = 0

Tota I LL-TRU Waste Weight $=11,386 \mathrm{~kg}$

\section{MOLDS AND CRUCIBLES - OTHER NONMETALLIC}

$\begin{array}{ccc}\text { JOE } & \text { KG } & \\ 0 & 5600 & \\ 11 & 3300 & C \\ 2 & 1300 & S \\ 13 & 4400 & \text { S } \\ & & \\ \text { lantity of TRU Waste } & \\ & \text { H of Drums }= & 62 \\ & \text { of Boxes }= & 0 \\ & \text { of Bins }= & 0\end{array}$

ttal TRU Waste Weight =
OESCRIPTION

LECO CRUCIBLES

CRUCIBLES AND SAND

SAND. SLAG AND CRUCIBLES

SAND. SLAG, AND CRUCIBLE HEELS
COMMENTS

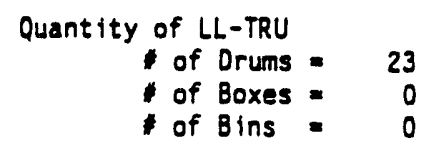

Total LL-TRU Waste Weight $=3,465 \mathrm{Kg}$ 
EDF-IWPF-0009, Rev. 0

Page 7 of 16

Table 1. Stored Waste Category Description (continued)

\section{UNCEMENTED INORGANIC SLUDGES}

CODE KG DESCRIPTION COMMENTS

$\begin{array}{lrl}-1 & 2712000 & \text { FIRST STAGE SLUDGE } \\ 2 & 1900000 & \text { SECOND STAGE SLUDGE } \\ 7 & 960000 & \text { BLDG 374 ORY SLUDGE } \\ 30 & 5460 & \text { SOLIUIFIED GRINDING SLUDGE, ETC. } \\ 95 & 4000 & \text { SLUDGE } \\ 290 & 66 & \text { FILTER SLUDGE } \\ 292 & 69000 & \text { CEMENTED SLUDGE } \\ 811 & 300 & \text { EVAPORATOR AND OISSOLVER SLUDGE } \\ 980 & 81 & \text { EQUIPI ENT (s ing le drum with sludge ??) } \\ 995 & 30000 & \text { SLUDGE }\end{array}$

Quantity of TRU Waste

\# of Drums $=17,184$

\# of Boxes $=0$

Quantity of LL-TRU

* of Drums $=4907$

* of Bins $=0$

\# of Boxes $=8$

\# of Bins = 0

Total TRU Waste Weight $=4,538,023 \mathrm{Kg}$

Tota) LL-TRU Waste Weight= $1,192,844 \mathrm{Kg}$

\section{UNCEMENTED ORGANIC SLUDGES}

CODE

KG

DESCRIPTION

3

1617000

Quantity of TRU Waste

of Drums $=1914$

- of Boxes = 0

Oof Bins $=0$

Total TRU Waste Weight $=493,497 \mathrm{Kg}$
COMMENTS

ORGANIC SET UPS, OIL SOLIDS

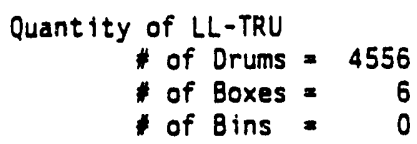

Total LL-TRU Waste We ight= $1,123,503 \mathrm{Kg}$ 
DF-IWPF-0009, Rev. 0

age 8 of 16

able 1. Stored Waste Category Description (continued)

\section{CEMENTED SLUDGES ANC ABSORBED LIQUIDS}

$\begin{array}{lrr}30 E & K G & \\ & & \\ 3 & 411700 & \\ 32 & 99 & \\ 34 & 28000 & \\ 34 & 1700 & \\ 35 & 170000 & \\ 36 & 290000 & \\ 76 & 1200000 & \\ 78 & 42400 & \\ & 21000 & \\ \text { Jantity of TRU Waste } & \\ & \text { \# of Drums }= & 2360 \\ & \text { of Boxes }= & 4 \\ & \text { Oof Bins }= & 83\end{array}$

Jtal TRU Waste Weight $=619.482 \mathrm{Kg}$
COMMENTS

SPECIAL SET UPS (CEMENT)

SOLIDIFIED SOLUTIONS

ABSORBED LIQUIDS

SOLIDIFIED SOLUTIONS

HIGH LEVEL ACID

HIGH LEVEL CAUSTIC

HIGH LEVEL SLUDGE/CEMENT

BLDG 776 PROCESS SLUDGE

LAUNDRY SLUDGE

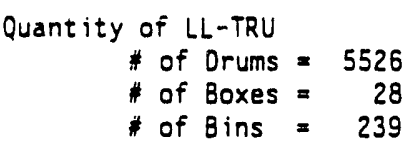

Total LL-TRU Waste Weight $=1,838,517 \mathrm{Kg}$ 
EDF-IWPF-0009, Rev. 0

Page 9 of 16

Table I. Stored Waste Category Description (continued)

\section{CONCRETE AND BRICK}

$\begin{array}{rr}\text { CODE } & \text { KG } \\ .371 & 185000 \\ 377 & 54 \\ 360 & 460000\end{array}$

DESCRIPTION

COMMENTS

FIREBRICK

COARSE FIREBRICK

CONCRETE, ASPHALT, ETC

Quantity of TRU Waste

$\begin{array}{rr}\text { \# of Drums }= & 332 \\ \text { \# of Boxes }= & 12 \\ \text { \# of Bins }= & 0\end{array}$

Quantity of LL-TRU

* of Drums $=1349$

* of Boxes = 183

\# of Bins = 0

Total TRU Waste Weight $=71,374 \mathrm{Kg}$

Total LL-TRU Waste Weight $=573,680 \mathrm{Kg}$

\section{SALTS}

\begin{tabular}{|c|c|c|}
\hline SODE & KG & OESCRIPTION \\
\hline $\begin{array}{l}\vdots \\
\vdots 24 \\
\$ 09 \\
110 \\
111 \\
\vdots 12 \\
114\end{array}$ & $\begin{array}{r}11400 \\
1100 \\
3200 \\
3200 \\
530 \\
110 \\
430\end{array}$ & $\begin{array}{l}\text { EVAPORATED SALTS-RETRIEVED RF TRU } \\
\text { CERTIFIED TRU PYROCHEMICAL SALT WASTE } \\
\text { MOLTEN SALTS-30\% UNPULVERIZED } \\
\text { MOLTEN SALTS-30\% PULVERIZED } \\
\text { ELECTROREFINING SALT } \\
\text { GIBSON SALTS } \\
\text { DIRECT OXIDE REDUCTION SALT }\end{array}$ \\
\hline
\end{tabular}

Juantity of TRU Waste

* of Drums $=82$

- of Boxes = 0

\# of Bins $=0$

DIRECT OXIDE REDUCTION SALT

Total TRU Waste Weight $=9.125 \mathrm{Kg}$

Quantity of LL-TRU

* of Drums = 49

\# of Boxes = 1

* of Bins = 0

\section{LEADED RUBBER}

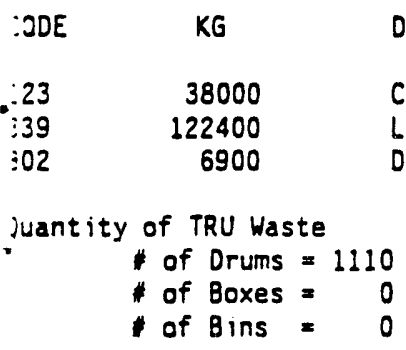

otal TRU Waste Weight $=163,647 \mathrm{Kg}$
DESCRIPTION

CERTIFIED TRU LEADED RUBBER

LEADED RUBBER GLOVES \& APRONS

DRY BOX GLOVES AND O-RINGS

COMMENTS

$\begin{aligned} \text { Quantity of LL-TRU } & \\ & \text { of Drums }= \\ & 21 \\ & \text { of Boxes }= \\ \text { of Bins }= & 0\end{aligned}$

Total LL-TRU Waste Weight $=3.653 \mathrm{Kg}$ 
:DF-IWPF-0009, Rev. 0

'age 10 of 16

able 1. Stored Waste Category Description (continued)

\section{BENELEX AND PLEXIGLASS}

$\begin{array}{lll}\text { COE } & \text { KG } & \text { DESCRIPTION } \\ 02 & 50200 & \text { BENELEX ANO PLEXIGLASS } \\ 64 & & \text { PLEXIGLASS AND BENELEX }\end{array}$

uantity of TRU Waste

* of Drums $=8$

\# Of Boxes $=4$

* of Bins $=0$

otal TRU Waste Weight $=13.055 \mathrm{Kg}$

COMMENTS

Lead shielding $\left(1 / 8^{\prime \prime}\right.$ to $\left.1 / 4^{\prime \prime}\right)$ laminated to some of the
Benelex

Quantity of LL-TRU

\# of Drums = 7

* of Boxes = 13

\# of Bins = 0

Total LL-TRU Waste Weight $=37.145 \mathrm{Kg}$

\section{RESINS}

$\begin{array}{lll}\text { SOE } & K G & \text { DESCRIPTION } \\ 30 & 5200 & \text { ION COLUMN UNLEACHED RESIN } \\ 31 & 1100 & \text { LEACHED RESIN } \\ 32 & 35000 & \text { LEACHED AND CEMENTED RESIN }\end{array}$

COMMENTS

Jantity of TRU Waste

* of Drums $=245$

* of Boxes $=0$

\# of Bins = 0

otal TRU Waste Weight $=36.779 \mathrm{Kg}$

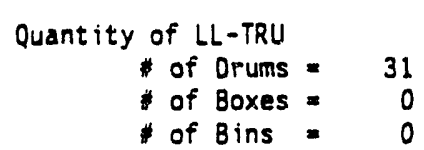

Total LL-TRU Waste Weight $=4.521 \mathrm{Kg}$ 
EDF-IWPF-0009, Rev. 0

Page 11 of 16

Table 1. Stored Waste Category Description (continued)

\begin{tabular}{lr} 
CODE & \multicolumn{1}{c}{ KG } \\
20 & \\
100 & 85000 \\
101 & 321100 \\
105 & 81800 \\
113 & 320 \\
122 & 23000 \\
155 & 21000 \\
156 & $7068(?)$ \\
161 & 11000 \\
& 140 \\
163 & \\
& 490 \\
201 & \\
203 & 51000 \\
241 & 6900 \\
824 & 20000 \\
825 & 400000 \\
826 & 30000 \\
& 28610
\end{tabular}

827

838

848

950
710
$0.15(?)$
13000
413000

Quantity of TRU Waste

- of Drums $=989$

\# of Boxes = 315

\# of Bins $=136$

Total TRU Waste Weight $=704,604 \mathrm{Kg}$

TRU SCRAP

\section{MIXED WASTE-PAPER, METAL, GLASS}

DESCRIPTION COMMENTS

NON-COMPRESSIBLE, NON-COMBUSTIBLE

GENERAL PLANT WASTE

CUT UP GLOVEBOXES

EMPTY BOTTLES

CERTIFIED SOLIO LAB WASTE

CERTIFIED TRU INORGANIC SOLID WASTE

CHEM CELL RIP-OUT

ANL-W ALC GLASSWARE, PAPER, POLY, $\quad{ }^{235} \mathrm{U}$

AND HISCELLANEOUS HAROWARE

ANL-W ACL COLD-LINE ABSORBED LIQUID,

MISC. . HARDWARE ANO POLYETHYLENE

NON-COMBUSTIBLE SOLIDS

PAPER, METALS, GLASS

AMERICIUM FROCESS RESIDUE

NONCOMBUSTIBLE EQUIPMENT BOXES

NONCOMBUSTIBLE EQUIPMENT DRUMS

COMBUSTIBLE EQUIPMENT BOXES Or

FLOOR SWEEPINGS \& RUST

COMBUSTIBLE EQUIPMENT DRUMS

<10 NCI/G NONCOMBUSTIBLE

LSA <100 NCI/G NONCOMBUSTIBLE

LSA METAL GLASS, ETC.

${ }^{235} \mathrm{U}$ is 1 isted along with $\mathrm{Pu}$.

${ }^{235} \mathrm{U}$ is listed a long with $\mathrm{Pu}$.

${ }^{232} \mathrm{Th},{ }^{233} \mathrm{U},{ }^{235} \mathrm{U}$ are listed a long with Pu.

${ }^{235} \mathrm{U}$

Need additional information

Need add tional information

Need additional information

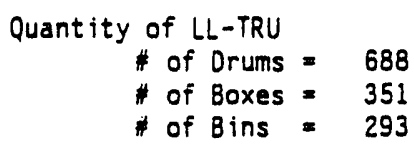

Tota I LL-TRU Waste Weight $=809,535 \mathrm{Kg}$ 
DF-IWPF-0009, Rev. 0

age 12 of 16

able 1. Stored Waste Category Description (continued)

\section{INSULATION AND FILTERS}

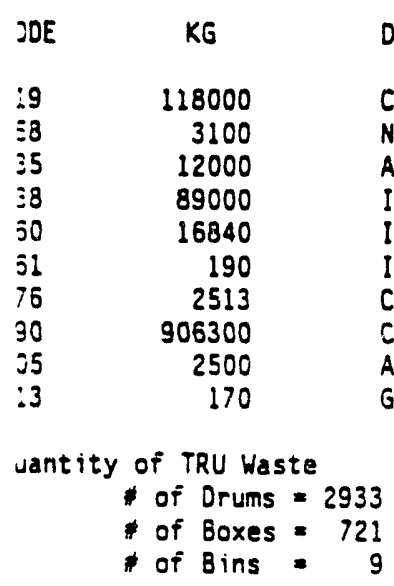

DESCRIPTION

COMMENTS

CERTIFIED TRU HEPA FILTER WASTE

NWCF FILTERS

ABSOLUTE $8 \times 8$ FILTERS

INSULATION \& CWS FILTER MEDIA

INSULATION

INSULATION HEEL

CEMENTED INSULATION \& FILTER MEDIA

CWS FILTERS

ASBESTOS FILTERS

GLASS FILTERS AND FIBERGLASS

ota) TRU Waste Weight $=937,660 \mathrm{Kg}$

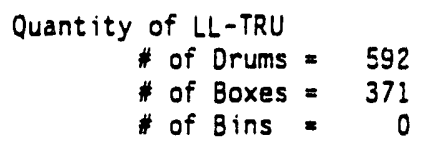

Tota 1 LL-TRU Waste Weight $=418,040 \mathrm{Kg}$ 
EDF-IWPF-0009, Rev. 0

Page 13 of 16

Table 1. Stored Waste Category Description (continued)

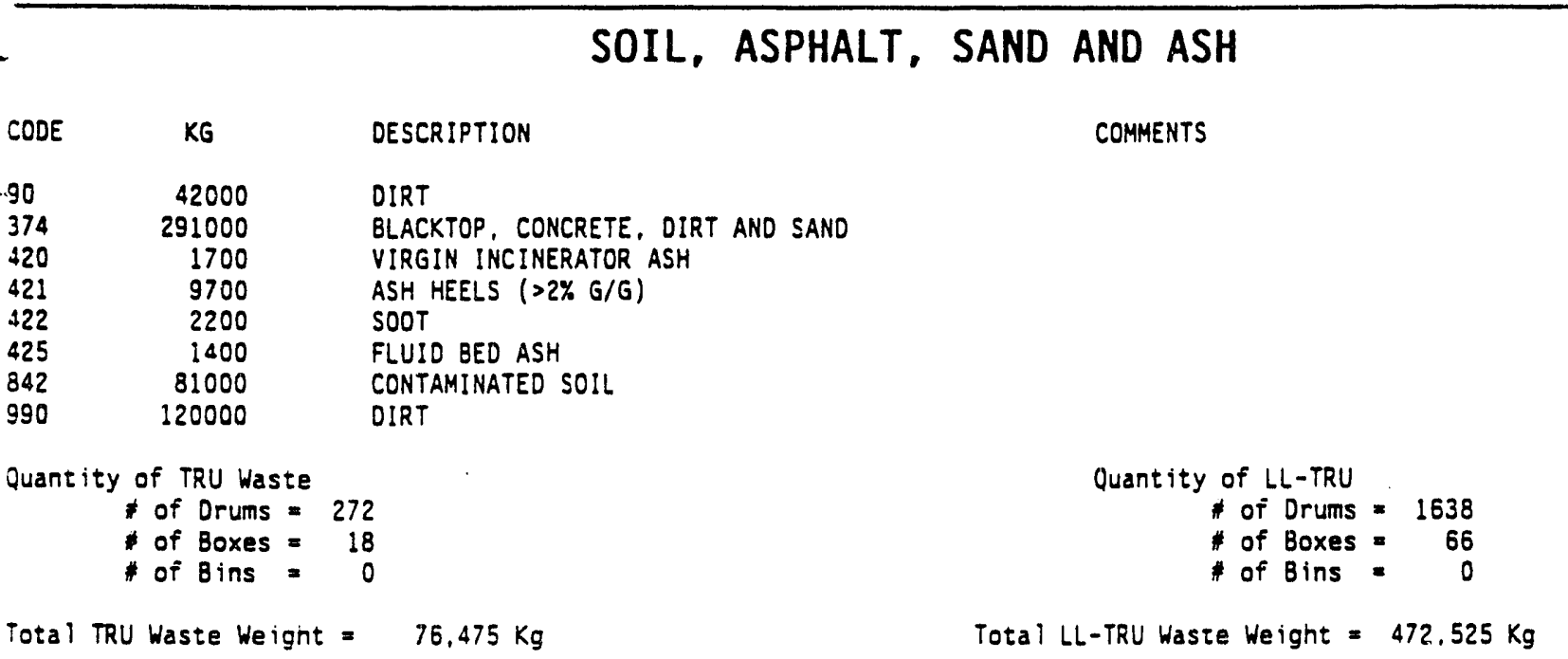

\section{REMOTE HANDLED}

\begin{tabular}{lrl} 
:ODE & \multicolumn{1}{c}{ KG } & DESCRIPTION \\
$: 2$ & 160 & MISC. SOURCES \\
$: 5$ & 3.6 & NEUTRON SOURCES \\
40 & 38000 & SOLID BINARY SCRAP POWOER, ETC. \\
91 & 1400 & METAL - MET SAMPLES FISSILE \\
104 & 25870 & ALPHA HOT CELL WASTE \\
106 & 75 & SPECIAL SOURCE MATERIAL \\
107 & 1600 & UNCERTIFIED TRU-RH WASTE \\
151 & 320 & SOLIDIFIED FUEL SLUDGE \\
152 & 2470 & PU NEUTRON SOURCES \\
153 & 3100 & COMBUSTIBLE LAB WASTE \\
$: 54$ & $? ?$ & SAMPLE FUEL \\
$: 57$ & 150 & MISCELLANEOUS SOURCES
\end{tabular}

COMMENTS

${ }^{228} \mathrm{Ra} \mathrm{Pu}$ in 3 drums.

Contains large quantities of ${ }^{233} \mathrm{U}$ and ${ }^{232} \mathrm{Th}$. Contains large quantities of ${ }^{233} \mathrm{U}$ and ${ }^{232} \mathrm{Th}$. LL-TRU

LL-TRU 
DF-IWPF-0009, Rev. 0

age 14 of 16

able 1. Stored Waste Category Description (continued)

UNCLASSIFIED

\begin{tabular}{|c|c|c|}
\hline SDE & $K G$ & DESCRIPTION \\
\hline & 1867000 & NOT RECORDED-UNKNOWN \\
\hline 10 & 1330 & $\begin{array}{l}\text { WIPP PRECERTIFIED RGW COMPACTIBLE \& } \\
\text { COMBUSTIBLE SOLIDS }\end{array}$ \\
\hline$: 1$ & 831600 & $\begin{array}{l}\text { WIPP PRECERTIFIED RGW NONCOMPACTIBLE } \\
\text { SOLIDS OO CERTIFIED SOLIDS WET SLUDGE }\end{array}$ \\
\hline $\begin{array}{l}\vdots 2 \\
\vdots 4 \\
\vdots 0\end{array}$ & $\begin{array}{r}200000 \\
62000 \\
150\end{array}$ & $\begin{array}{l}\text { CERTIFIED SOLID ORGANICS } \\
\text { CERTIFIED SOLID PROCESS SOLUTION } \\
\text { WIPP PRECERTIFIED DOW COMPACTIBLE } \\
\text { SOLIDS OR CERTIFIED TRU INSULATION } \\
\text { \& FILTER MEDIA }\end{array}$ \\
\hline 21 & 11044 & $\begin{array}{l}\text { WIPP PRECERTIFIED DOW NONCOMPACTIBLE } \\
\text { SOLIDS OR CERTIFIED TRU ORGANIC } \\
\text { SOLIO WASTE }\end{array}$ \\
\hline 50 & 230 & $\begin{array}{l}\text { ANL }-W \text { HFEF ANALYTICAL CHEMISTRY AND } \\
\text { METALLOGRAPHIC COMBUSTIBLES }\end{array}$ \\
\hline 52 & 2200 & $\begin{array}{l}\text { ANL-W FMF EFL ZR-U-PU FUEL CASTING } \\
\text { ALLOYS RESIDUES }\end{array}$ \\
\hline 72 & 2300 & GRIT \\
\hline $\begin{array}{l}75 \\
50 \\
20 \\
14\end{array}$ & $\begin{array}{r}2700 \\
1300 \\
2400 \\
120\end{array}$ & $\begin{array}{l}\text { OIL-JRI RESIDUE FROM INCINERATOR } \\
\text { WASHABLES. RUBBER, PLASTICS } \\
\text { OASIS WASTE } \\
\text { CONTAMINATED MERCURY Or GRAPHITE } \\
\text { CRUCIBLES ?? } \\
\text { CLASSIFIED PARTS }\end{array}$ \\
\hline
\end{tabular}

\author{
COMMENTS \\ Waste retrieved from Subsurface Disposal Area at INEL. \\ $1,847,371 \mathrm{Kg}$ TRU: $19.629 \mathrm{Kg} \mathrm{LL}$-TRU \\ Need additional information \\ Need additional information \\ Need additional information \\ Need additional information \\ $\mathrm{U}_{3} \mathrm{O}_{8}$ pellets, dissolved fuel \& lab waste. $79.201 \mathrm{Kg}$ TRU: \\ $599 \mathrm{Kg} \mathrm{LL}-T R U$ \\ ${ }^{235} \mathrm{U}$ is listed a long with \\ ${ }^{239} \mathrm{Pu}$. \\ ${ }^{235} \mathrm{U}$ is listed a long with ${ }^{230} \mathrm{Pu}$ \\ and ${ }^{240} \mathrm{pu}$. \\ $\mathrm{Al}_{2} \mathrm{O}_{3}$ - Fe blasting grit and silica gel desiceant. $1.797 \mathrm{Kg}$ \\ TRU; $503 \mathrm{Kg} \mathrm{LL-TRU}$ \\ $763 \mathrm{Kg}$ TRU: $1937 \mathrm{Kg} \mathrm{LL-TRU}$ \\ Unknown waste. \\ Need additional information \\ Need additional information \\ Unknown waste.
}


EDF-IWPF-0009, Rev. 0

Page 15 of 16

Table 2. Waste Container Description

DRUM:

$\begin{array}{ll}\text { Metal } & 30 \text {-gallon } \\ \text { Metal } & 55-\text { gallon }\end{array}$

Metal 83-gallon

$4.1 \mathrm{ft}^{3} \quad 42$ lbs.

$7.5 \quad 50$

$11.2 \quad 101$

BOX:

FRP*

FRP

Metal

Metal

Metal

Metal

Metal

Metal

$4 \mathrm{ft} . \times 2 \mathrm{ft} . \times 7 \mathrm{ft}$.

$4 \mathrm{ft} . \times 4 \mathrm{ft} . \times 7 \mathrm{ft}$.

84 in. $x 48$ in. $\times 48$ in.

74.4 in. $x 50.5$ in. $\times 38.5$ in.

68 in. $x 54$ in. $x 38.5$ in.

88 in. $x 54$ in. $x 54$ in.

50.4 in. $x 58.4$ in. $x 72.4$ in.

112 in. $x 68$ in. $x 77$ in.

56.0

112.0

112.0

83.3

82.1

147.8

123.5

339.3

BIN :

Metal

50.4 in. $\times 58.4$ in. $\times 72.4$ in.

123.5

676

RH CANISTERS:

Metal

Metal

No. H-2-91273-1

No. H-2-91284-1

37.3

37.3

* FRP is Fiberglass Reinforced Plywood 
DF-IWPF-0009, Rev. 0

age 16 of 16

\section{REFERENCES}

Westinghouse/WIPP, TRU Waste Acceptance Criteria for the Waste Isolation Pilot Plant, Rev. 3, WIPP-DOE-069, January 1989.

U.S. Department of Energy, "Transuranic Package Transporter (TRUPACT-II) Authorized Methods for Payload Control (TRAMPAC)" Appendix 1.3.7 of Safety Analys is Report for the TRUPACT-II Shipping Package, Rev. 4, Docket No. 71-9218, August 1989.

D. E. Kudera and C. D. Rauen, RWMC Compliance Plan for TRUPACT-II Authorized Methods for Payload Control, WM-PD-88-012, October 1991.

U.S. Department of Energy, Idaho National Engineering Laboratory Transuranic Waste Management Information System Transuranic Waste Database Users Manual, DOE/ID-10272, March 1990.

T. L. Clements, Jr., Content Code Assessments for INEL Contact-Handled Stored Transuranic Wastes, WM-Fl-82-021, October 1982.

Chemical Compatibility of Stored TRU Mixed Waste, From R. S. Hefta of EG\&G Idaho RWMC/SWEPP Technical Programs, EDF No. RWMC-413, June 21, 1990.

EPA Hazardous Waste Codes Found in INEL Stored TRU Waste Content Codes, From T. L. Clements, Jr. and K. P. Guay of EG\&G Idaho TRU Waste Technology, EDF No. RWMC-421, February 23, 1991.

J. D. Wells, INEL Transuranic Waste Acceptance Criteria, Revision of Reference 7 , IDO-10074, Rev. 4, July 1987.

B. C. Anderson, Criteria for Packaging Transuranic Waste for Receipt at the Idaho National Engineering Laboratory Radioactive Waste Management Complex-Offsite Generated Waste, ID0-10074, Rev. 1, August 1981. 
APPENDIX A

\section{WASTE PROCESS GROUP DETERMINATION}

To Be Determined 
APPENDIX B

GENERAL WASTE ACCEPTANCE CRITERIA

(ca 1981) 


\section{GENERAL CRITERIA}

Shipment of radioactive waste generated offsite musi contain transuranic material as defined in Section 2. Beta-gamma waste and nontransuranic radioactive waste, as defined in Section 9 , will not be accepted at the INEL RWMC per these criteria. All news releases pertaining to shipment or receipt of offsite waste must have the prior approval of DOE-ID.

To allow appropriate planning for future waste shipments, each generator shall prepare a waste forecast, including curies, volume, number and type of waste package by classification, and frequency of shipment. This forecast shall be submitted to DOE-ID by December first of each year. Forecasts are to be prepared for a 10-year period, with the first year divided into 3 -month increments and updated annualiy.

The waste generator shall have budgetary responsibility for all costs necessary to deliver waste shipments to the INEL RWMC. Normal waste handling and storage activities at INEL are not charged to the waste generator.

The following criteria apply to all transuranic waste shipped to INEL:

1. Materials prohibited from receipt for storage at the RWMC are:

a. Vessels pressurized greater than 7 psig

b. Radioactive gaseous waste. Exceptions to th is are defined in items 4,5 , and 12 , be low

c. Pyrophoric naterials which could ignite spontaneously as defined in 49 CFR, parts 100-199, subparts $D$ and $E$, are prohibited. An exception may be approved for a material that has been rendered safe by mixing it with chemically stable materials (e.g., concrete, glass, etc.). or processed to eliminate its hazardous properties. 
d. Liquid metals

e. If the acidic waste material is ionized and immobilized liquid, the acidic level of the resulting waste form shall be greater than $4 \mathrm{pH}$

f. Elemental alkaline metals

g. Explosives

n. High level fuel assemblies and first stage raffinates from fuel processing facilities

i. Toxic or poisonous materials defined as poison $A$ or poison $B$ by 49 CFR, parts $100-199$

j. Flammable liquids, solids, and/or gases

k. Materials, which spontaneously emit ionizing radiation but have an estimated specific activity less than $2 \mathrm{nCi} / \mathrm{g}$ of material and their radioactivity is essentially uniformly distributed, are not considered radioactive, as defined in 49 CFR 173.389 (e); consequently, they are prohibited from disposal at the RWMC. In addition, materials with removable surface contamination less than $200 \mathrm{dpm} / 100 \mathrm{~cm}^{2}$ beta-gamma and less than $20 \mathrm{dpm} / 100 \mathrm{~cm}^{2}$ alpha and less than $0.1 \mathrm{mrem} / \mathrm{h}$ are also not to be considered radioactive material

1. Other reactive materials that could cause a fire, explosion, or pressure buildup in the waste packages.

m. Liquid organic waste is prohibited in liquid or immobilized form. The material represents a toxic chemical hazard which is unacceptable at the RWMC. 
2. Free liquids, meaning any liquids which are not immobilized or absorbed, are prohibited from recsipt at the RWMC in any transuranic waste as defined by ERDAM, 0511. 
3. The waste generator must load the containers to ensure that the interior volume is efficiently and compactly loaded with radioactive material. Such high density loading will reduce the number of radioactive shipments by the waste generators and enhance space utilization at the RWMC.

4. Radioactive waste containing biological, pathogenic, or infectious material shall be treated with sufficient preservatives and desiccants to prevent bacterial action, significant gas buildup ( 7 psi, maximum), or the formation of free liquids. Chelating or organic material shall be treated to eliminate the potential for interaction with radionuclides forming stable complexes which may increase the mobility of the radionuclides.

5. Radioactive gases must be processed to convert them to a solid form of such a nature that decomposition or environmental heat will not result in release of the original or other radioactive gases. The collection of radioactive gases into a pressure vessel or container is not an acceptable method of solidification for disposal at the RWMC.

6. Materials that could lead to spontaneous combustion (strong oxidants in combination with solidified oil, greases, solvents, or other materials) shall not be combined in a waste package.

7. Waste shipments shall be accompanied by the documents identified in Section 6.

8. Waste generators with accountable nuclear materials for shipment to the RWMC shall contact EG\&G Safeguards and Security Branch at 526-2372 (FTS 583-2372) to ensure that the proper documents are completed prior to shipment. 
9. Radiation levels defined in this criteria shall be verified with an ion chamber radiation survey instrument calibrated semiannually. Upon receipt, EGaG will perform radiation surveys using an instrument (Eberline Model RO-3A calibrated to $\pm 10 \%$ ) with a $2-1 / 2$ in. diameter cylindrical probe. If the waste generator readings and the $\Xi G \& G$ readings are significantly different, the waste generator will be requested to show that they are in compliance.

10. Combustible and noncombustible waste shall be segregated and packaged separately. Waste packages loaded with combustible waste shall be marked with a brignt green, 4-in., equilateral triangle painted on or adhered to the package. Each drum shall be labeled at three places, $120^{\circ}$ apart, around the sides; boxes shall be labeled on each of the four sides to be plainly visible to the forklift operators handing the waste package.

11. The exterior of all packages must be reasonably free of dirt, moisture, rust, and removable surface contamination. Surface contamination on each package shall be less than $2200 \mathrm{dpm} /$ $100 \mathrm{~cm}^{2}$ beta-gamma and less than $220 \mathrm{dpm} / 100 \mathrm{~cm}^{2}$ alpha. The costs associated with the correction of rust problems, decontamination, or cleaning of waste packages prior to storage may be billed to the waste generator.

12. The waste generator shall package all waste to minimize gas buildup. Total gas buildup shall not exceed 7 psig. The amount of activity on hydrogenous materials must be restricted to less than $4 \times 10^{5} \mathrm{nCi}$ of alpha activity per gram of waste, provided the total activity in a 55-gal waste package does not exceed $14.6 \mathrm{Ci}$. This quantity corresponds to about $200 \mathrm{~g}$ of weapons grade Pu, or $1 \mathrm{~g}$ of heat source grade ${ }^{238} \mathrm{Pu}$ in a 55-gal waste package (200 g fissionable material limit). The maximum curie limit for containers of different sizes is considered to be directly proportional to the fissionable material limit. The 
total activity permitted in a 30 -gal waste package (100 g fissionable material limit) would be $7.3 \mathrm{Ci}$.

13. Waste package specifications and other waste handling changes that may affect 20 -vear storage integrity must have approval of DOE-ID prior to implementation.

14. Each waste package shipped to the RWMC shall be marked and labeled as follows: Packages for retrievably stored waste shall have an identification number affixed in such a manner as to be intact and legible after a 20-year storage period. The identification number is to be placed near the top of the package and be clearly visible. The identification number must correspond to that listed on Form ID-137, defined in Section 6 and Exhibit 3. The security seal number and identification number may be the same, provided the criteria of each are met. In addition, the waste generator shall stencil or affix labels containing the gross weight, major nuclide, compactible or noncompactible, and the radioactive waste symbol. This information is to be placed on the head and side of each drum or on the top and on the two long sides of each fiberglassed box. The only other markings permitted on the waste package are those required by the Department of Transportation (DOT) for the shipment of the waste package (i.e., waste package description, package type, radioactive material label, name of radioactive material, etc., which is to be prefixed as designated by DOT).

15. Transuranic waste shall be segregated from nontransuranic waste and packaged for retrievable storage in 20-year-integrity containers in accordance with ERDAM, 0571.

16. Thermal power

a. Individual waste packages in which the average thermal power density exceeds $0.1 \mathrm{~W} / \mathrm{ft}^{3}$ shall be marked with an orange 4-in.-square symbol painted or adhered to the 
container. Each drum shall be labeled at three places, $120^{\circ}$ apart, around the sides. Boxes shall be labeled on each of the four sides so as to be plainly visibie to the forklift operators handling the waste package.

b. Individual waste packages must comply with the requirements of 49 CFR 173.393 for heat generation and temperature.

c. The radioactive thermal decay energy must not exceed $10 \mathrm{~W}$ per waste package.

17. Fissionable material gram limits stated in Tables 1 and 2 (Section 5) are based on criticality limits at the RIMAC. These gram limits do not pertain to packages containing only unirradiated natural or depleted uranium waste which are criticality safe in any configuration. Fissionable material is defined in ERDAM, 0530.

18. Dry powders, ashes, and similar particulate waste materials will not be accepted at the RIMMC unless they have been immobilized. Imobilized material shall not contain more than $1 \%$ by weight of dry particles below 10 microns in diameter.

19. Waste generation and shipping sites must provide the RWMC with a Certification Statement (Section 6) to certify that the package meets the requirements of these criteria. Waste generators packaging and shipping solid radioactive waste to the RWMC shall submit to the Manager, RWMC Operations, in writing, a quality assurance program utilized to provide assurance that waste material shipped to the RIIMC meets current packaging requirements. EG\&G approval of the program will be required prior to initiating shipment. The following requirements shall be addressed in the submittal:

a. The quality assurance program shall document procedures and describe the methods and activities utilized by the waste 
generator to assure compliance with the applicable RVIIC packaging and waste acceptance criteria. The quality assurance program shall be documented and conducted in accordance with DOE Order NE5840, Quality Assurance Policy for Nuclear Energy.

b. The quality assurance program shall, as a minimum, define those procedures, methods, and activities utilized to assure that the following packaging and requirements are addressed by the waste generator:

i. Determination of the fissile material content of each waste package and methods used to assure that fissile material limits are not exceeded;

ii. Controls utilized to assure that prohibited materials are not packaged with the waste;

iii. Methods utilized to calculate thermal energy of the waste package and to assure thermal energy limits are not exceeded;

iv. Methods utilized to assure that the waste container meets the specifications of the packaging criteria;

v. Determination of isotopic content, curie content, and radiation levels of the waste form;

vi. Controls utilized to verify segregation of waste forms into transuranic and nontransuranic, compactible and noncompactible, combustible and noncombustible;

vii. Controls utilized to assure proper marking/labeling/ waste records preparation and shipping of the waste material; 
viii. Determination of the waste package weight and total package weight for lifting (i.e., casks with removable insert).

c. The quality assurance program shall indicate the organizational structure responsible for waste packaging, shipping, certification and for processing any requests for exception to current criteria.

d. The quality assurance program submittal shall include (as exhibits) the various documents (logs, checklists, procedures, forms), utilized to provide documented evidence of compliance with the packaging criteria. Revisions to the program shall be controlled and submitted as they are promulgated.

e. The quality assurance program, including all records of shipments, must be auditable by the Department of Energy or their designated al ternate.'

20. All waste packages shall be provided with permanently attached skids, cleats, offsets, rings, handles, or other auxiliary lifting devices to allow handling by means of fork trucks, cranes, or similar handling equipment. Lifting rings and other auxiliary lifting devices on the package are permissible, provided they are recessed, offset, or hinged in a manner that does not inhibit stacking the packages.

The lifting devices must be designed to a $5: 1$ safety factor based on the ultimate strength of the material. All rigging devices that are not permanently attached to the waste package must have a current load test based on $125 \%$ of the safe work load. 
21. Bulky or heavy waste itens shall be blocked inside the wastc package such that they will not present a hazard during handling due to veight shifting.

22. Haste packages containing materials that present hazards in addition to radioactivity are considered dual hazardous materials and must display labeling applicable to each of the hazards. The nonradiological hazardous material description must be included in the documentation submitted with the vaste package.

23. All exterior surfaces of wooden containers must be painted with white, fire-retardant paint to achieve a flame spread rating of 25 to 75 per ASTM E-84.

24. Tritium waste nust be solidified and placed in containers coated with asphalt to minimize migration of this type waste.

25. Vermiculite shall be used to fill any voids in vaste packages in all waste classifications. This material will reduce possible gas generation. 


\section{INE \\ Idaho National Engineering Laboratory}

March 10, 1992

Mr. Fred Feizollahi

M-K Environmental Services, Inc.

180 Howard Street

San Francisco, CA 94105

TRANSMITTAL OF INFORMATION ON TRANSURANIC STORAGE UNIT - RAH-21-92

Dear Mr. Feizollahi:

Per your request, I have obtained the types and quantities of drums, boxes, and bins at the Transuranic Storage Area at the Radioactive Waste Management Complex at the Idaho National Engineering Laboratory. These are presented below.
55-gal steel drums:
30-gal steel drums:
103,421
83-gal steel drums:
122
1,840
$4 \times 4 \times 7$ wood boxes:
$4 \times 4 \times 7$ wood/fiberglass boxes:
SAND boxes $\left(4 \times 4 \times 88^{\prime \prime}\right)$ :
897
TX- 4 boxes $(4 \times 4 \times 8)$ :
23,164
827
38
$4 \times 5 \times 6$ metal bins:
$2.81 \mathrm{~m}^{3}$ bins:
533
284
Oddsize metal containers: 28
Oddsize wood/fiberglass boxes: 255
Oddsize $\left(1.51 \mathrm{~m}^{3}\right)$ fiberglass boxes: 8
Oddsize:
20
$20 \mathrm{ft}$ Cargo Containers:
Oversize fiberglass-reinforced
209
Misc. $\left(3.2 \mathrm{~m}^{3}\right)$ :
29
92

These numbers were obtained from:

1) K. P. Guay, Inventory Analysis of Stored Transuranic (TRU) Waste at the Radioactive Waste Management Complex (RWMC), WM-PD-90-003, April 30, 1990.

2) EG\&G Drawing Nos. 155663, Revision C; 418322, Revision B; and 418323, Revision $C$. 
Mr. Fred Feizollahi

March 10, 1992

RAH-21-92

Page 2

If you have any questions or require further assistance, please call me at (208) 526-0741.

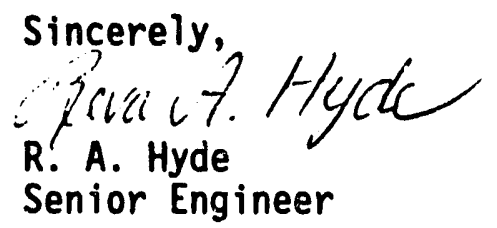

amp 
Appendix B

Cost Estimating Model 


$$
\text { B-2 }
$$




\section{Appendix B}

\section{Cost Estimating Model}

\section{B-1. INTRODUCTION}

This appendix contains assumptions and methodology used in developing rough-order-ofmagnitude (ROM) cost estimates for the three alternative stored alpha low-level waste (alpha-LLW) processing systems presented in Sections 5, 6, 7 and 8 of the main report. A cost estimating model based on an inter-linked spreadsheet in Lotus 1-2-3 computer software is used in developing these costs.

\section{B-2. COST ESTIMATING METHODOLOGY}

Because the three systems have several waste handling/processing unit operations and support facilities that are common in two or three of the system concepts, a modular cost estimating approach is used as follows:

- Each of the three system concepts are divided into several cost modules consisting of either a unit operation or a support facility (examples of support facilities are maintenance shop, HVAC, laboratory, and the office areas). The modules and the systems in which they are used are shown in Table B-1.

- Cost for each module is divided into five cost components: studies and bench-scale tests, demonstration, production facility design and construction, operating and maintenance, and decontamination and decommissioning. After estimating the five cost components of the modules, the system subtotal cost is developed by adding the costs of the modules used in the given system.

- The total ROM life-cycle estimate for the given system is developed by adding a sixth cost component, transportation and disposal, which is developed by multiplying the volume of the output waste by the transportation and disposal cost unit rates.

Methodology and assumptions used in developing ROM cost estimates for the various cost components are given below.

\section{B-3. STUDIES AND BENCH-SCALE TESTS}

Estimated ROM costs for the studies and bench-scale test cost component are shown in Table B-2. As shown, cost for each module consists of three subcomponents: manpower during research, equipment, and installation. Manpower includes the effort needed for the initial paper studies, bench-scale tests, and the secondary paper studies. Study durations and manpower estimates for these efforts are obtained from Tables 6,11,16, and 19. Equipment budgetary costs which include lab equipment, such as mixers and prototype ovens, are estimated whenever a bench-scale test is specified in the aforementioned tables. Similarly, budgetary costs are estimated for bench-scale 
test installation which include labor and material required to mount the equipment, consumables, and laboratory sampling used during bench-scale tests.

This cost component is estimated based on the assumption that engineering and scientists inspection manpower cost is $\$ 140,000$ per full-time equivalent (FTE).

\section{B-4. DEMONSTRATION}

The demonstration cost component consists of nine subcomponents. Only three of the subcomponents (manpower during demonstration, building structure, and equipment costs) are estimated by SWSDS. The remaining six subcomponents (design, inspection, project administration, indirect, construction management, and contingency) are obtained using percentage factors provided by EG\&G Idaho.

The demonstration manpower estimates and activity durations are obtained from Tables 6,11 , 16 , and 19 in the main report. Based on this table, budgetary costs are estimated for demonstration equipment and installation and are listed in Table B-2.

Percentage rates and other major assumptions used in developing the budgetary cost estimates for demonstration cost components are given below.

- Design, inspection, project administration, indirect, construction management, and contingency costs: These cost subcomponents are developed using the same percentages used for the production facility (see Section B-5).

- The equipment cost estimates are budgetary and are based on industrial equipment having lower cost than the final equipment that will be provided for the production facility. The material used in test assemblies is fabricated from commonly available industrial equipment.

- In the incineration/melting system, it is assumed that:

- The melter train (i.e., meter, offgas treatment, and slag cooling/packaging) will be tested in an existing building as a single assembly. The cost for the assembly is distributed to the modules involved.

- Remotely-operated devices needed for container opening, dumping, sorting, crushing, and shredding are demonstrated in a simulated cell environment as an integrated single assembly. The integrated test assembly equipment cost is distributed according to the modules requiring demonstration.

- Incineration demonstration, including its offgas, is carried out in a contract pilot-plant that is assembled in an existing building.

- The thermal treatment/solidification system demonstration assumptions are the same as the incineration/melting system with the exception that a melter train demonstration is not applicable. The thermal treatment/solidification system has an organic removal unit which 
requires demonstration. This test assembly is assumed to be demonstrated by vendors in an existing facility.

- The sort, treat, and repackage system demonstration efforts include a single waste handling assembly similar to the unit needed for demonstrating the material handling equipment in the incineration/melting system.

- All other demonstrations, such as liquid waste treatment, alpha assay instruments, and decontamination, are performed by vendors.

\section{B-5. PRODUCTION FACILITY CONSTRUCTION}

The production facility cost consists of nine subcomponents. Two of the subcomponents, equipment and installation, are estimated in the SWSDS and are shown in Table B-3. These costs are obtained by first developing an equipment list based on the information provided in the functional and operational requirements and flow diagrams given in Sections 5.1, 6.1, 7.1 and 8.1 of the main report. Then, equipment budgetary purchase costs are estimated based on either vendor budgetary quotations, historical cost information, or engineering judgements. Installation costs were estimated for each piece of equipment and include labor, construction equipment, small tools and supplies, and appropriate overhead and profit.

The third subcomponent, building cost, is developed by estimating the building space required for each module and multiplying the space by a set of unit rates provided by EG\&G Idaho. The allocated building space estimates are obtained from the scoping study layout sketches (see Figures 12,13 , and 18 ) presented in the main report. The estimates include allocated space in each of the four space categories: low hazard, moderate hazard, double barrier alpha cell, and tipple barrier alpha cell. The estimated square footage and the calculated building cost estimates for each module are shown in Table B-4.

The remaining six cost subcomponents (design, inspection, project administration, indirect, construction management, and contingency) are obtained using percentage factors provided by EG\&G Idaho. These percentages, building unit rates, and other major assumptions used in developing the production facility construction costs are given below.

- Design, inspection, project administration, indirect, construction management, and contingency costs: These cost subcomponents are developed using percentage guidelines provided by EG\&G Idaho. This approach is used to facilitate development of ROM cost estimates suitable for relative comparison of the three system concepts. These percentages are historical averages experienced by EG\&G Idaho for the types of activities covered by SWSDS concepts.

- Contingency on all costs is $25 \%$

- Design costs, applied to construction costs total, is $30 \%$

- Inspection costs, applied to construction costs total, is $7 \%$ 
- Project administration costs, applied to construction costs total, is $10 \%$

- Indirect, applied to total building plus equipment and installation costs, is $20.9 \%$

- Construction management (CM) and $\mathrm{CM}$ reserve (combined percent), applied only to production construction costs total, are $28.7 \%$.

- Building space unit rates: The building unit rate costs (supplied by EG\&G Idaho) listed below are based on similar facilities at the INEL. The costs are representative of the building and its support systems, including utilities, fire protection, and site development costs. The alpha cell space building costs include the high-efficiency particulate air (HEPA) filter systems. Special equipment and any additional mechanical or electrical systems needed for the operation of the equipment have not been included in these building unit rate costs. The unit rates include the construction contractor direct and indirect costs and the appropriate overheads and profit.

- Areas for support and non-process functions including office, and incoming and outgoing packaged waste storage and handling spaces are $\$ 150 / \mathrm{ft}^{2}$.

- Moderate hazard building space is $\$ 350 / \mathrm{ft}^{2}$.

- Alpha cell space with double confinement barrier is $\$ 1,000 / \mathrm{ft}^{2}$.

- $\quad$ Alpha cell space with triple confinement barriers is $\$ 1,200 / \mathrm{ft}^{2}$.

- Stainless steel equipment is selected to allow for easy decontamination and maintenance, even when materials considerations indicated cheaper construction would be appropriate. Therefore, the estimate assumes the most expensive equipment or factors.

- The process areas are located in an alpha cell with triple confinement barriers.

- Maintenance areas are located in an alpha cell with double confinement barriers.

- This estimate does not include the infrastructure (utilities or site development).

\section{B-6. OPERATING AND MAINTENANCE}

Operating and maintenance (O\&M) cost is comprised of four subcomponents: operating manpower, utility, materials, and maintenance. Operating manpower is estimated for each module by assuming an appropriate operating crew for that module. The estimated operating FTE for each module is presented in Table B-5. ROM cost estimates for the utility cost subcomponents, summarized in Table B-5, include electric power, natural gas and No. 2 fuel oil, as appropriate. These costs are estimated by developing the equipment horsepower and energy consumption rates for each module and multiplying them by the given energy cost unit rates (see below).

The material cost subcomponents include consumables such as shipping/disposal containers, additives, chemicals, and personnel protective equipment. Again, these are estimated for each 
module based on the process flow rates given in Figures 12, 15, and 18 of the main report and are presented in B-5.

The maintenance cost subcomponent is divided into maintenance labor and maintenance replacement equipment cost. These costs, presented in Table B-5, are obtained by assuming that the annual maintenance equipment cost is $7 \%$ of the original equipment cost and that the maintenance labor cost is $25 \%$ of the maintenance equipment cost.

General assumptions used in developing the operating and maintenance costs are given below:

- The utility rates and operating rates listed below are established by EG\&G Idaho for use in the development of life cycle costs.

- Electricity is $\$ 0.035 / \mathrm{kWh}$.

- Propane is $\$ 0.60 /$ gal.

- No. 2 fuel oil is $\$ 0.80$ per gallon.

- Present day costs are used for preparation of the O\&M estimates.

- A contingency factor of $25 \%$ is applied to the project subtotal O\&M costs.

- $\quad$ Operating staff is $\$ 110,000 /$ full time equivalent.

- $\quad$ Additive soil cost is negligible.

- The O\&M costs are based on a facility operating schedule of three 8-hour shifts, 5 days/week, and 240 days/year.

- $\quad$ Additive solidification agent (Portland cement) is $\$ 0.05 / \mathrm{b}$.

- $\quad$ Shipping/disposal container is $\$ 25 /$ each.

\section{B-7 OPERATING FUNDS BUDGETED ACTIVITIES}

In accordance with DOE orders, there are a number of activities that cannot be charged to the Line Item Construction Projects (LICP) funds. A breakdown of these activities and preliminary cost estimates (planning level) for the IWPF, as estimated by EG\&G Idaho, are given below. In the SWSDS, it is assumed that the level of effort required for these activities is the same for all alternatives. Project activities to be funded by operating budgets are:

- Conceptual Design $\$ 6,800,000$.

- Program management and administration planning prior to conceptual design $\$ 14,200,000$. 
- Environmental and permitting (NEPA documentation including environmental impact statements, federal, state, and local permits) $\$ 6,800,000$.

- Safety documentation (safety analysis, reliability, availability and maintainability analysis, probabilistic risk assessment, hazards analysis, criticality reviews, and radiation analysis) $\$ 4,400,000$.

- Preparation for operation (operatio : procedure, operating personnel staffing, training and testing, spare parts, and material) $\$ 107,000,000$.

The total estimated cost for the activities covered under operating funds is $\$ 139,200,000$.

\section{B-8. DECONTAMINATION AND DECOMMISSIONING}

Decontamination and decommissioning costs are based on a recent cost study conducted by EG\&G Idaho for the buried TRU waste (see Reference 2 in main report). Based on this study, a cost of $\$ 450 / \mathrm{ft}^{3}$ average unit rate is used. The calculated cost is shown in Table B-6.

\section{B-9. TRANSPORTATION AND DISPOSAL}

Transportation and disposal costs are based on a recent cost study conducted by EG\&G Idaho for the buried TRU waste (see Reference 2 in main report). Based on this study the following rates are used:

- Transportation: $\$ 1.71$ per $\mathrm{ft}^{3}$

- Disposal: $\$ 150$ per $\mathrm{ft}^{3}$ which is based in an engineered shallow land buried site.

Transportation and disposal costs are calculated based on the system output waste volumes given in Section 9 in the main report. The results are shown in Table B-7.

\section{B-10. ROM COST ESTIMATED SUMMARY}

The ROM cost estimates for the three systems are summarized in Table B-7. 
Table B-1. List of LL-TRU processing system cost modules.

\begin{tabular}{|c|c|c|c|c|}
\hline Number & Module Description & $\begin{array}{l}\text { Used in } \\
\text { IMS }\end{array}$ & $\begin{array}{c}\text { Used in } \\
\text { TTSS }\end{array}$ & $\begin{array}{l}\text { Jsed in } \\
\text { STR }\end{array}$ \\
\hline 1 & Unloading, staging and storage & $\mathbf{x}$ & $\mathbf{x}$ & $\mathbf{x}$ \\
\hline 2 & Inspect/assay & $\mathbf{x}$ & $\mathbf{x}$ & $\mathbf{x}$ \\
\hline 3 & Open, dump and sort & $\mathbf{x}$ & $\mathbf{x}$ & $\mathbf{x}$ \\
\hline 4 & Metal sizing and decon subsystem & $\mathbf{x}$ & $\mathbf{x}$ & $\mathbf{x}$ \\
\hline 5 & Incinerator feed prep. & $\mathbf{x}$ & $\mathbf{x}$ & \\
\hline 6 & Incineration & $\mathbf{x}$ & $\mathbf{x}$ & \\
\hline 7 & Melter feed prep & $\mathbf{x}$ & & \\
\hline 8 & Melting & $\mathbf{x}$ & & \\
\hline 9 & Slag cooling \& packaging & $\mathbf{x}$ & & \\
\hline 10 & Incinerator offgas treatment & $\mathbf{x}$ & $\mathbf{x}$ & \\
\hline 11 & Melter offgas treatment & $\mathbf{x}$ & & \\
\hline 12 & Organics removal feed prep & & $\mathbf{x}$ & \\
\hline 13 & Organics removal & & $\mathbf{x}$ & \\
\hline 14 & Liquids/fines sort & & & $\mathbf{x}$ \\
\hline 15 & Size reduction & & & $\mathbf{x}$ \\
\hline 16 & Fill and package - TTSS & - & $\mathbf{x}$ & \\
\hline 17 & Dry solids fill and package & & & $\mathbf{x}$ \\
\hline 18 & Solidification fill and package & & & $\mathbf{x}$ \\
\hline 19 & Solidification feed prep - TTSS & & $\mathbf{x}$ & \\
\hline 20 & Solidification feed prep - STR & & & $\mathbf{x}$ \\
\hline 21 & Solidification TTSS & & $\mathbf{x}$ & \\
\hline 22 & Solidification STR & & & $\mathbf{x}$ \\
\hline 23 & Assay/certification & $\mathbf{x}$ & $\mathbf{x}$ & $\mathbf{x}$ \\
\hline 24 & Liquid waste treatment & $\mathbf{x}$ & $\mathrm{x}$ & $\mathrm{x}$ \\
\hline 25 & Storage and shipping & $\mathbf{x}$ & $\mathbf{x}$ & $\mathbf{x}$ \\
\hline 26 & Administration support & $\mathbf{x}$ & $\mathbf{x}$ & $\mathbf{x}$ \\
\hline 27 & Heating ventilation and exhaust & $\mathbf{x}$ & $\mathbf{x}$ & $\mathbf{x}$ \\
\hline 28 & Analytical laboratory & $\mathbf{x}$ & $\mathbf{x}$ & $\mathbf{x}$ \\
\hline
\end{tabular}


Table B-1. (continued).

\begin{tabular}{llccc}
\hline Number & Module Description & $\begin{array}{c}\text { Used in } \\
\text { IMS }\end{array}$ & $\begin{array}{c}\text { Used in } \\
\text { TTSS }\end{array}$ & $\begin{array}{c}\text { Used in } \\
\text { STR }\end{array}$ \\
\hline 29 & Utilities/mech. equipment - IMS & $\mathbf{x}$ & & \\
30 & Utilities/mech equipment - TTSS & & & $\mathbf{x}$ \\
31 & Utilities/mech equipment - STR & & & \\
32 & Others -IMS & & & $\mathbf{x}$ \\
33 & Others - TTSS & & $\mathbf{x}$ & $\mathbf{x}$ \\
34 & Others - STR & $\mathbf{x}$ & $\mathbf{x}$ \\
35 & Chemical storage area & & & \\
36 & Maintenance shop & & & \\
Legend: & & & & \\
IMS $=$ Incineration/melting system & & \\
TTSS $=$ Thermal treatment/solidification system \\
STR = Sort, treat, and repackage system
\end{tabular}




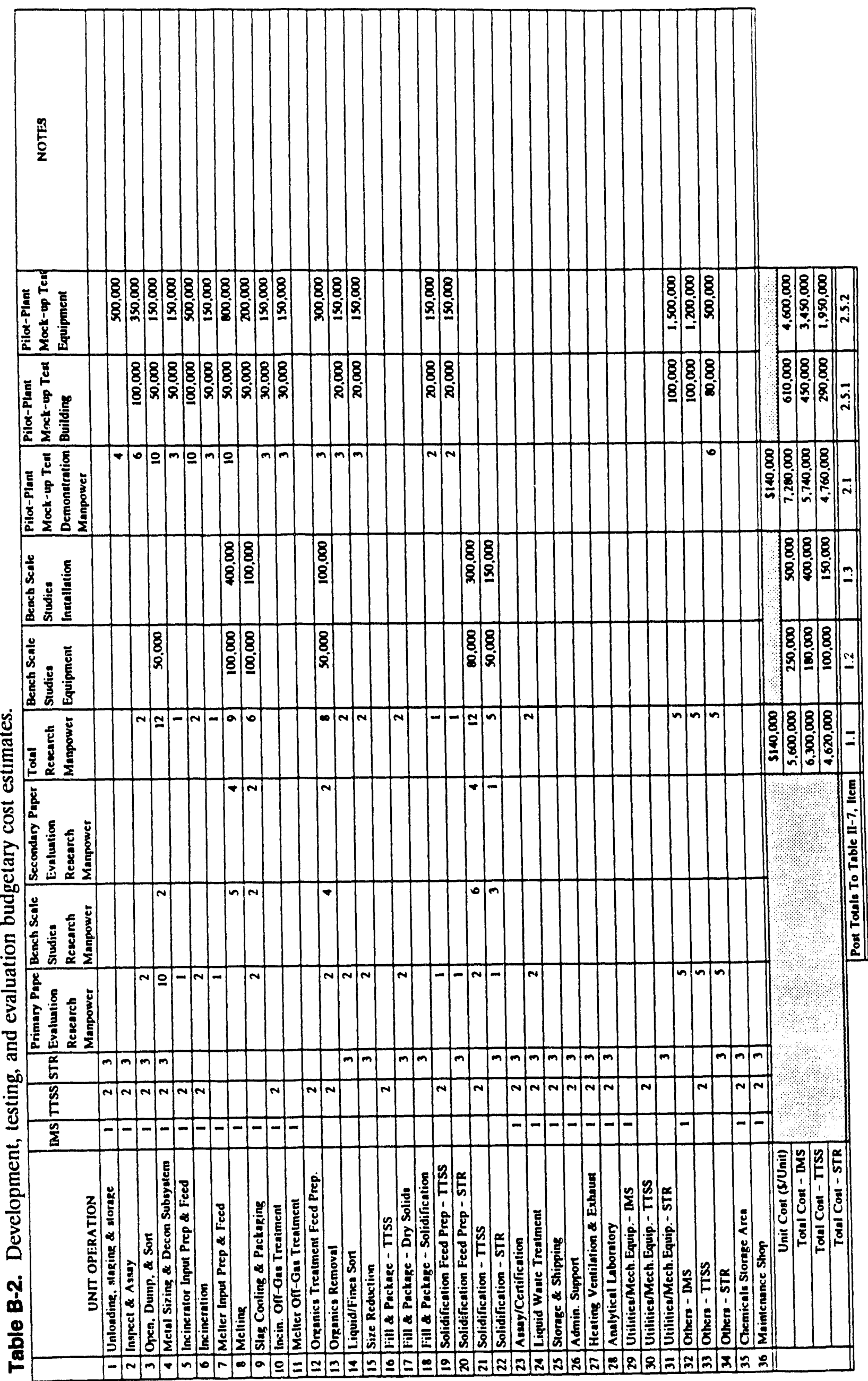

B-11 


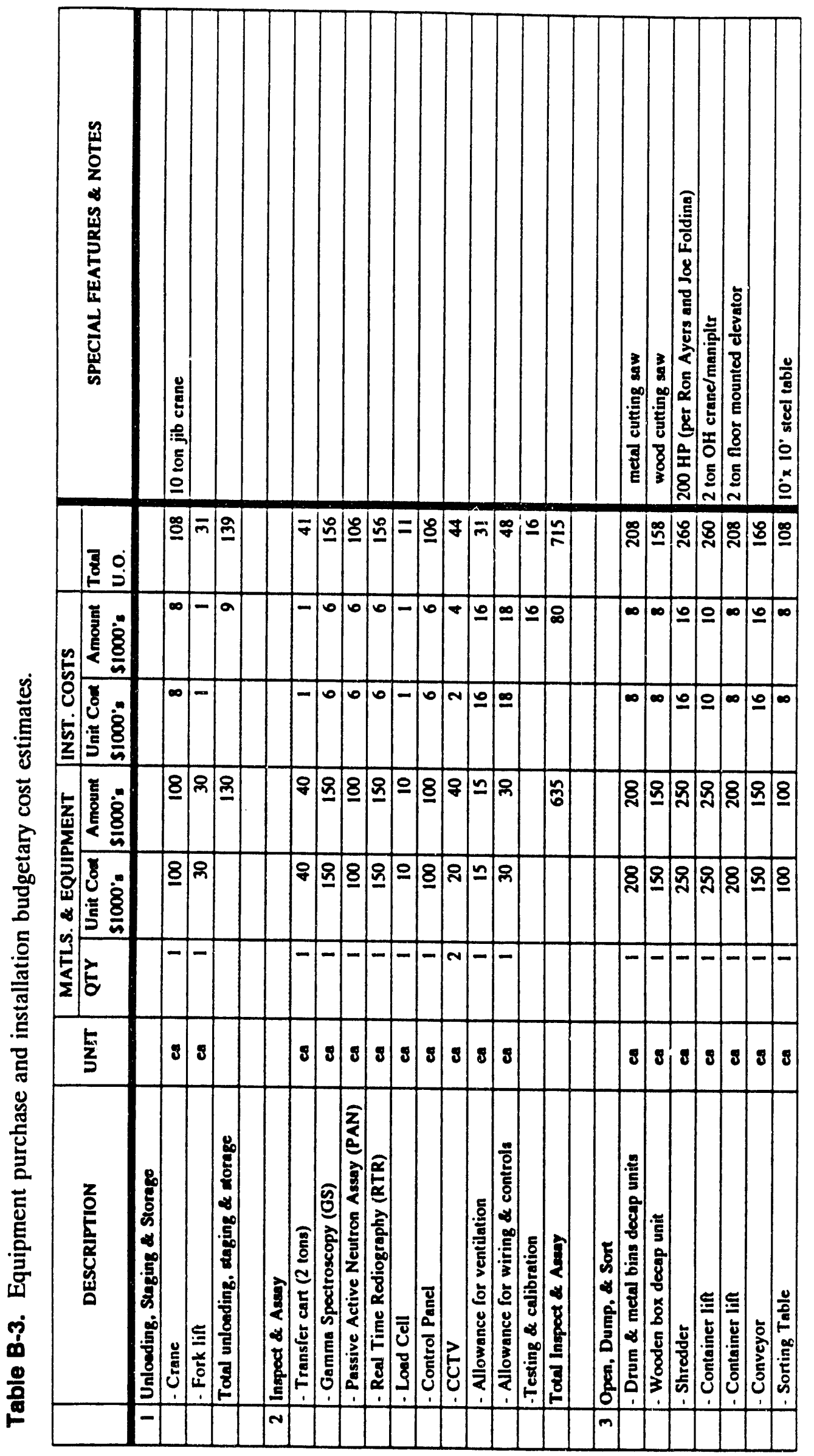

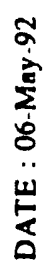

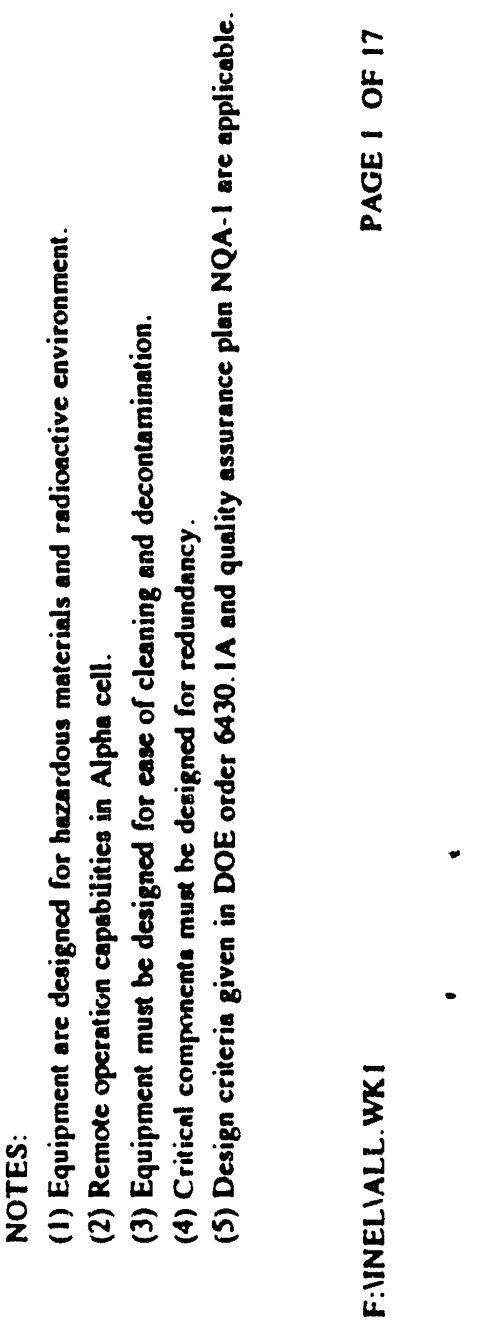




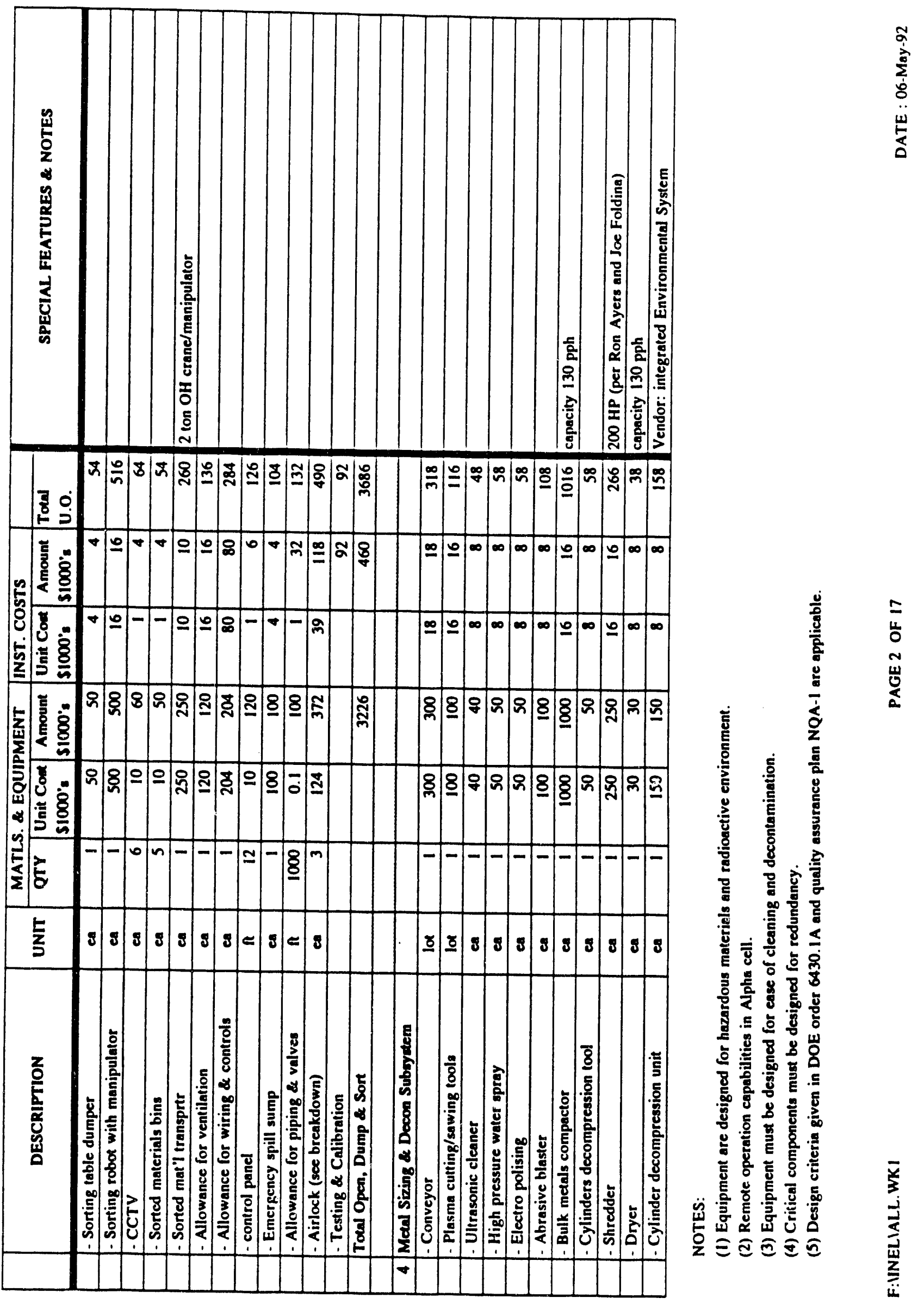




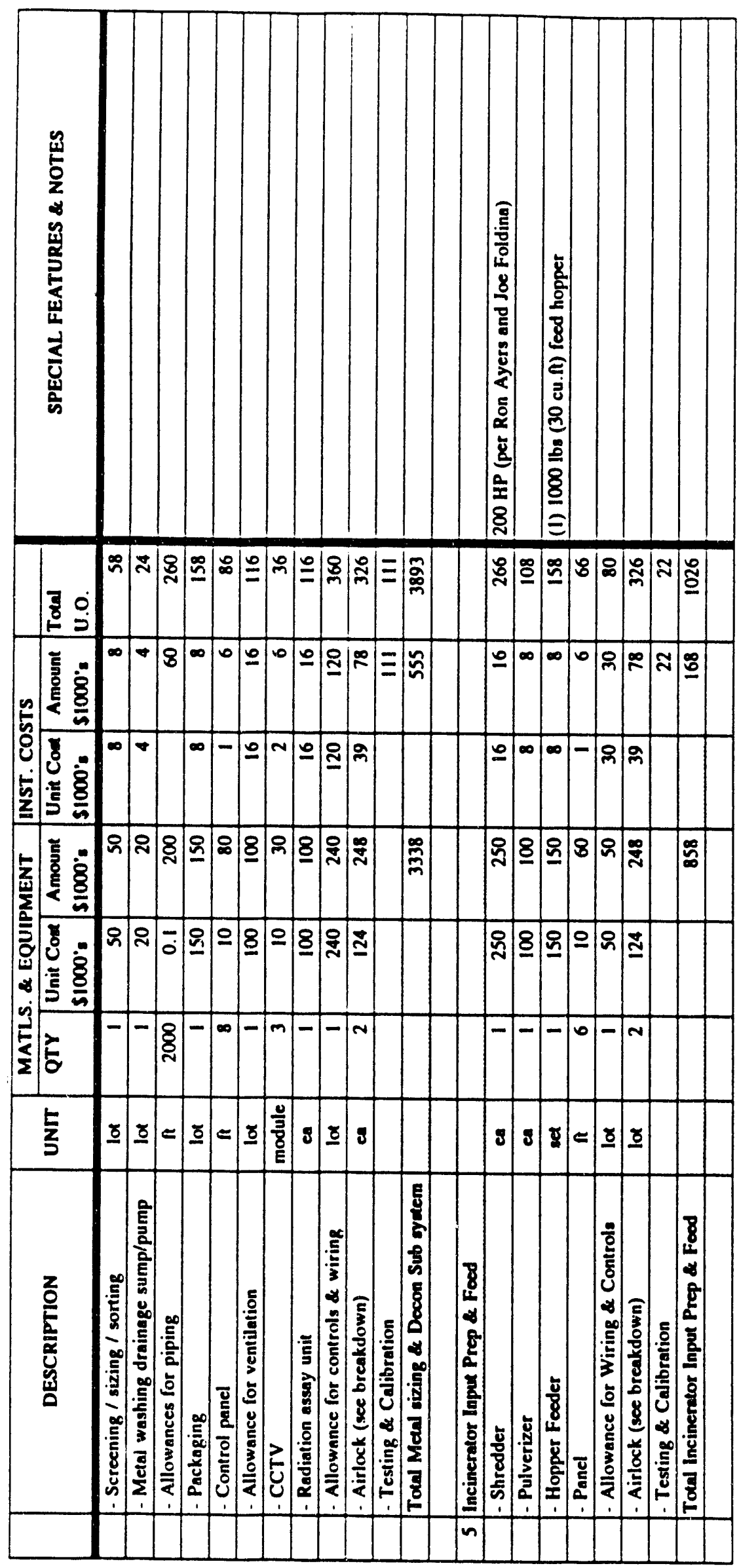




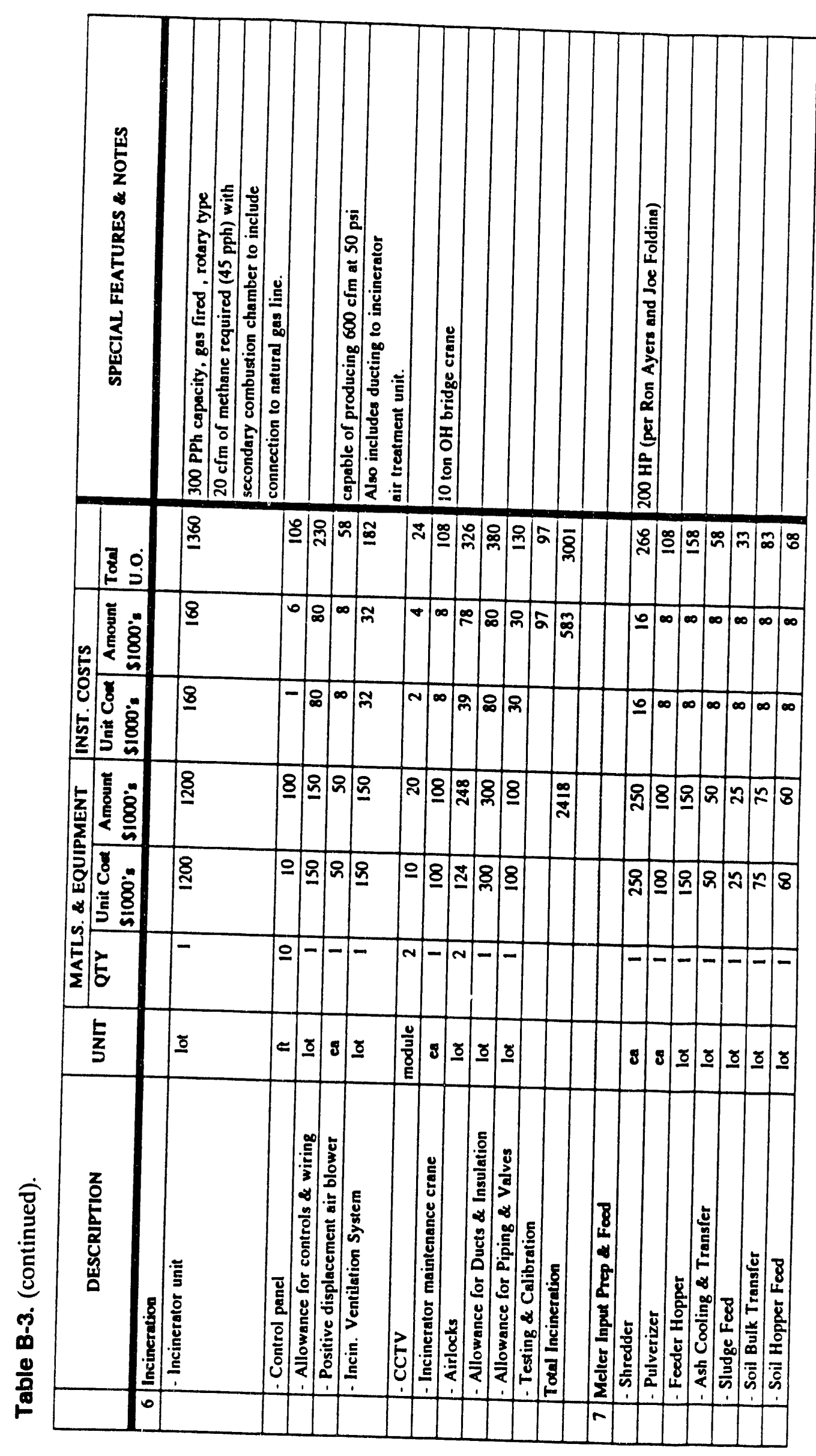

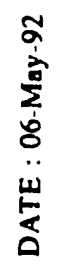

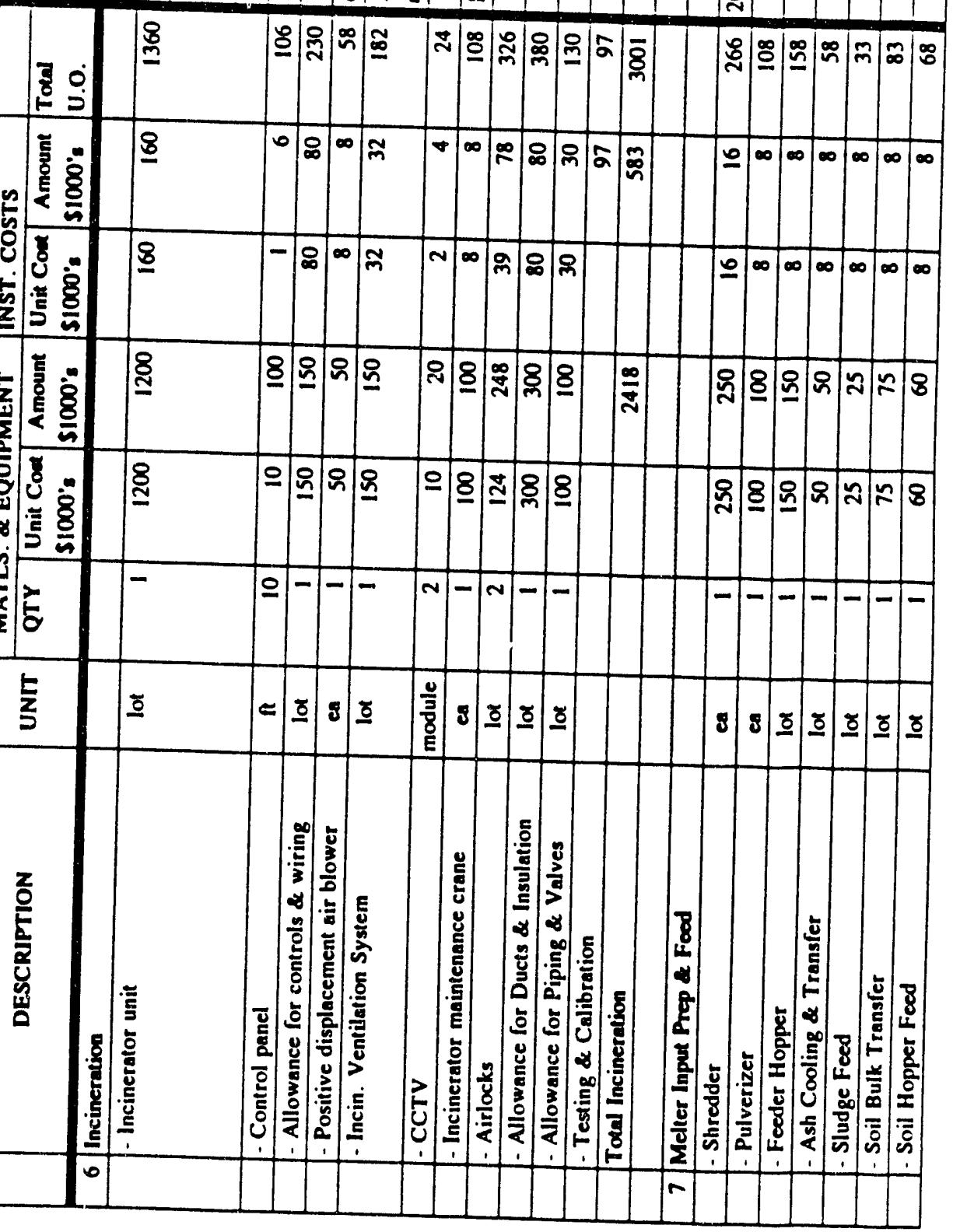




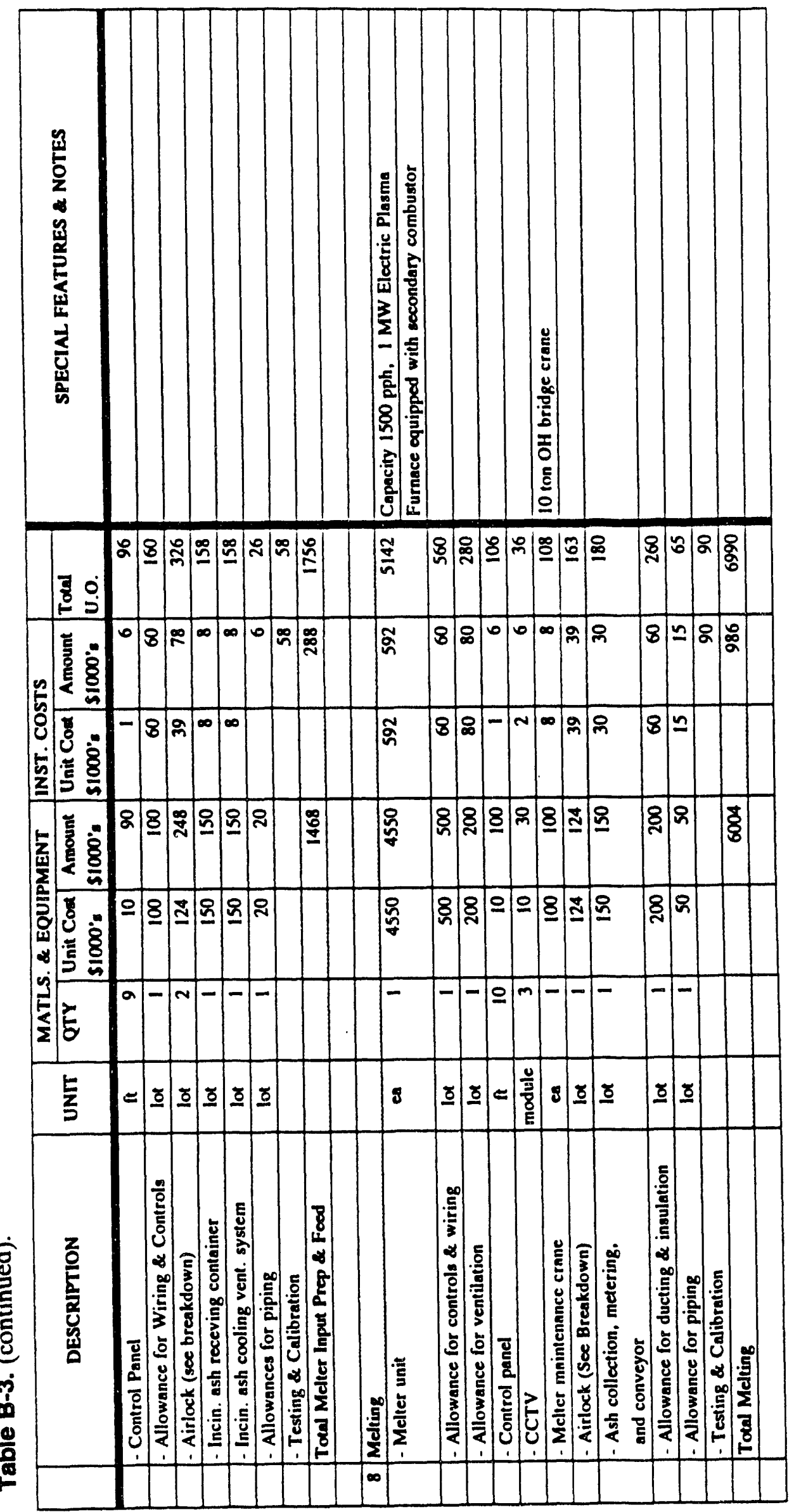

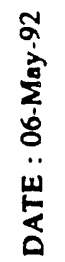

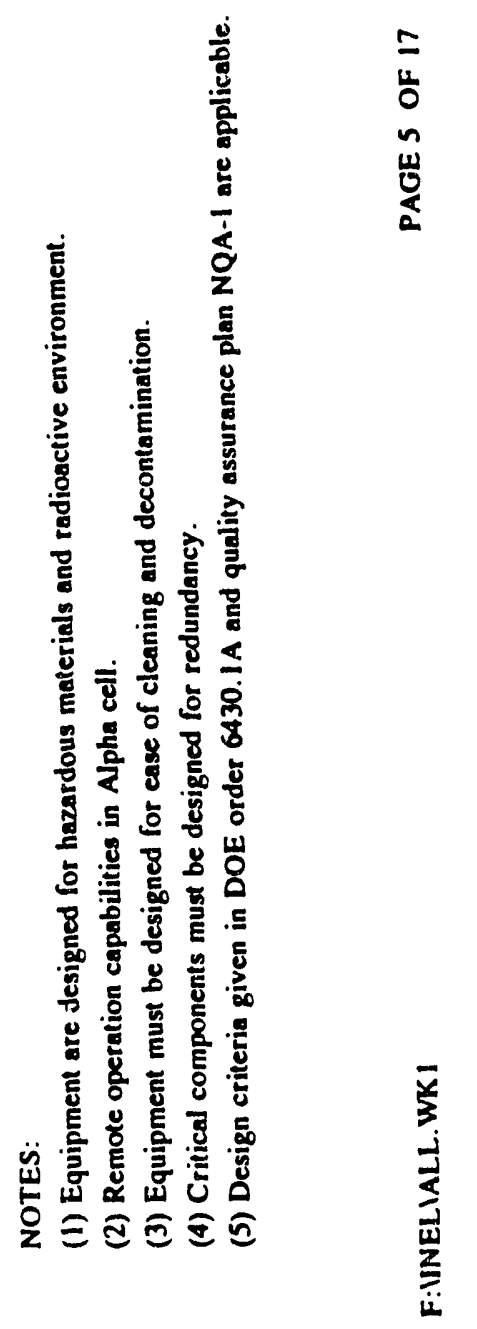




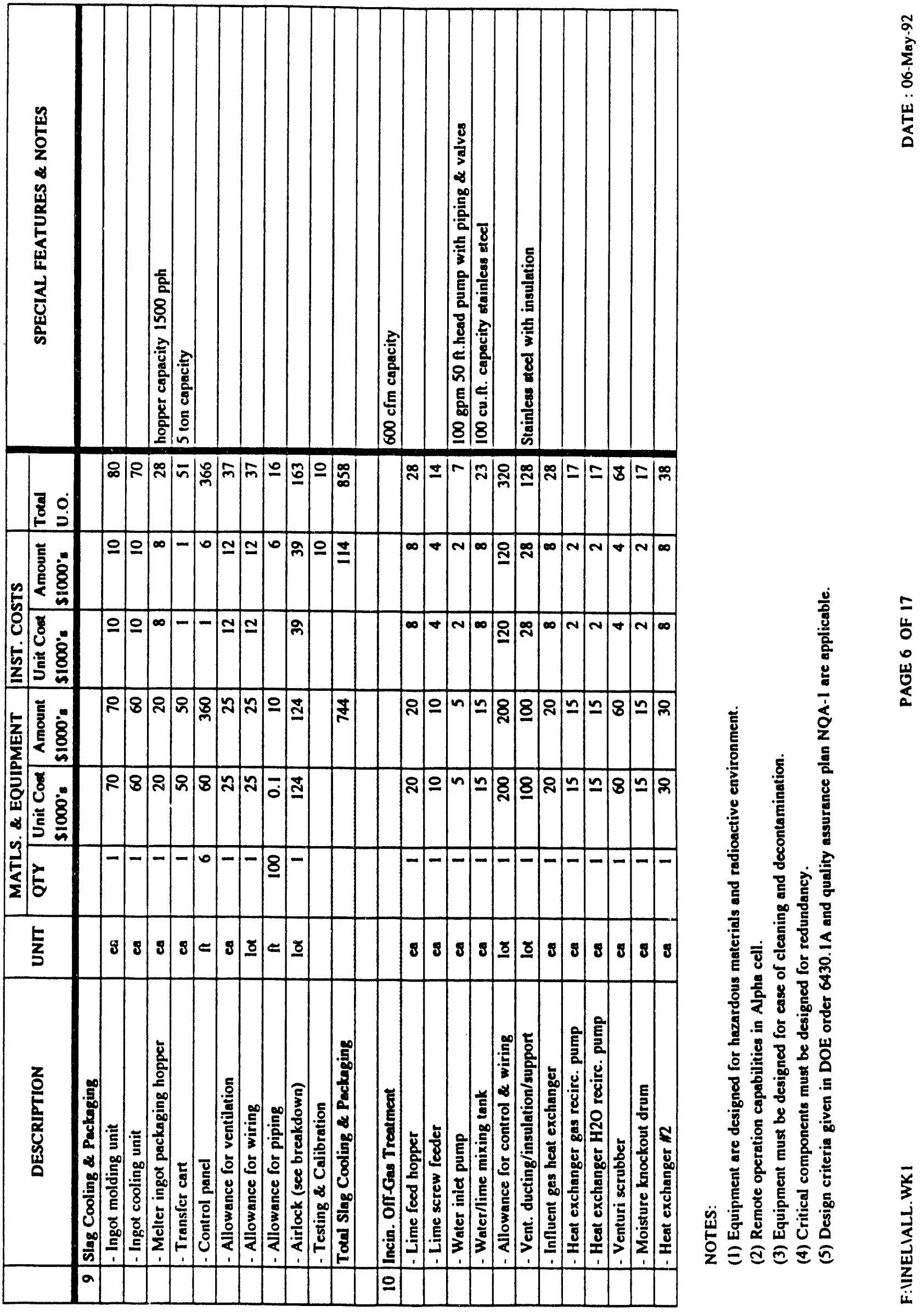




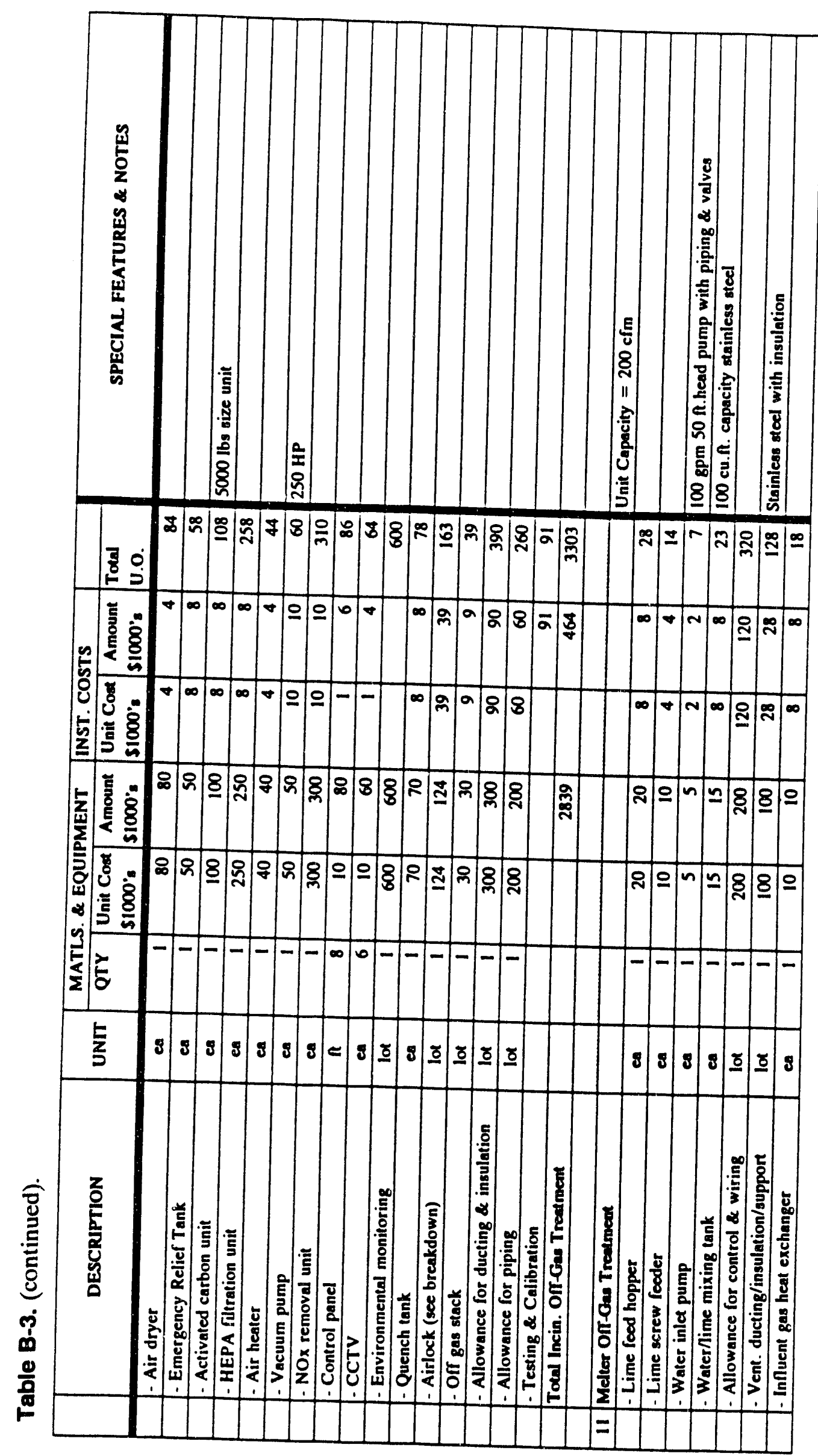

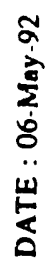

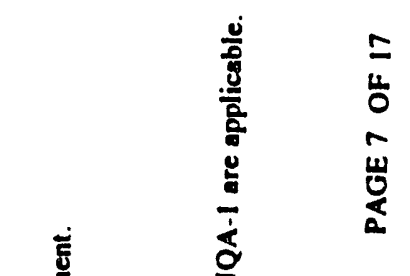

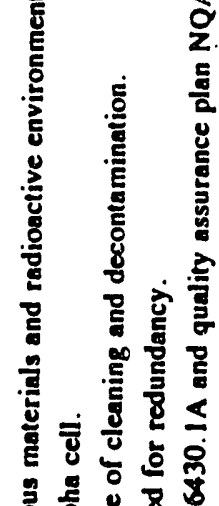

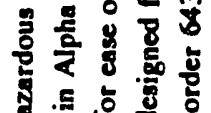
을

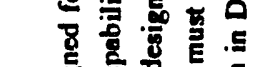

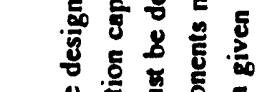

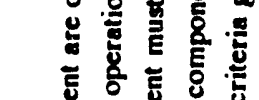
..

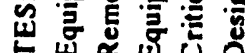

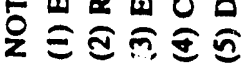

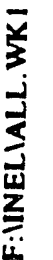




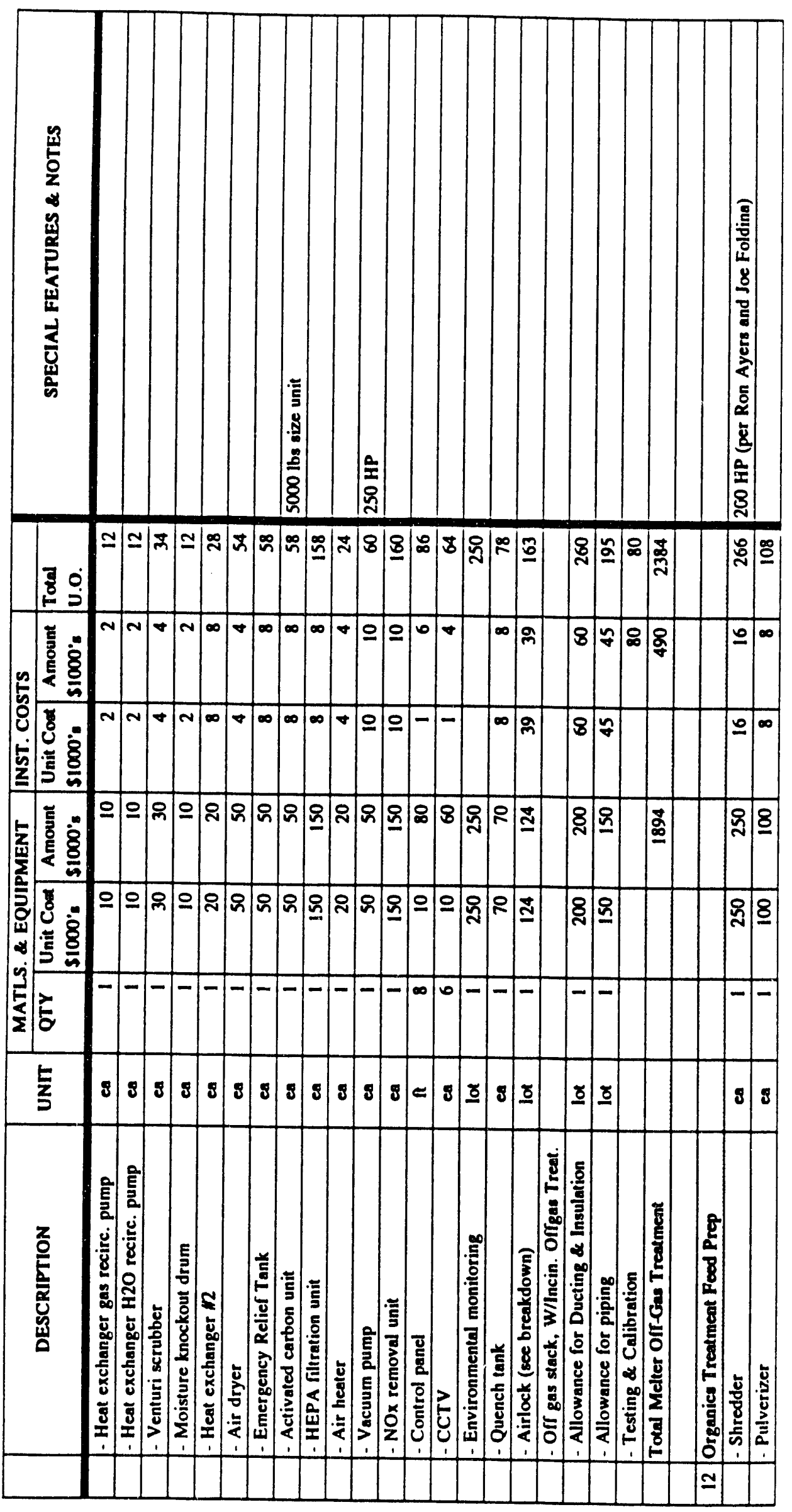

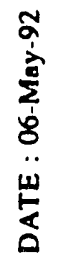

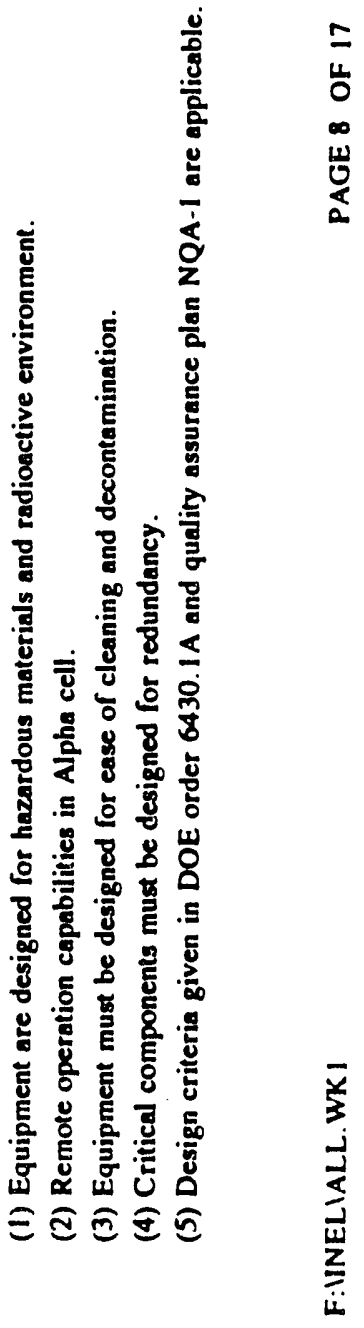




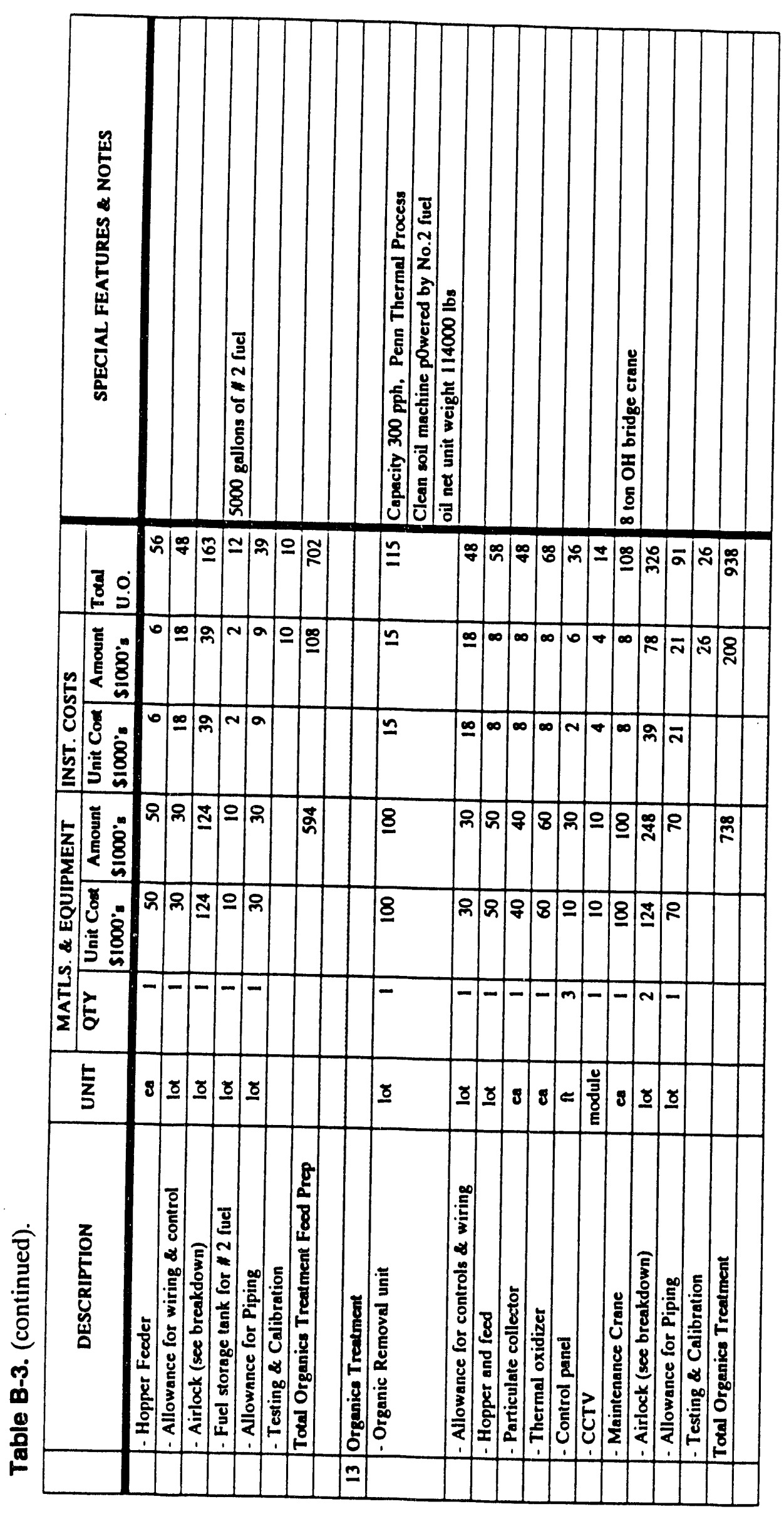

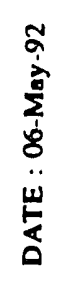

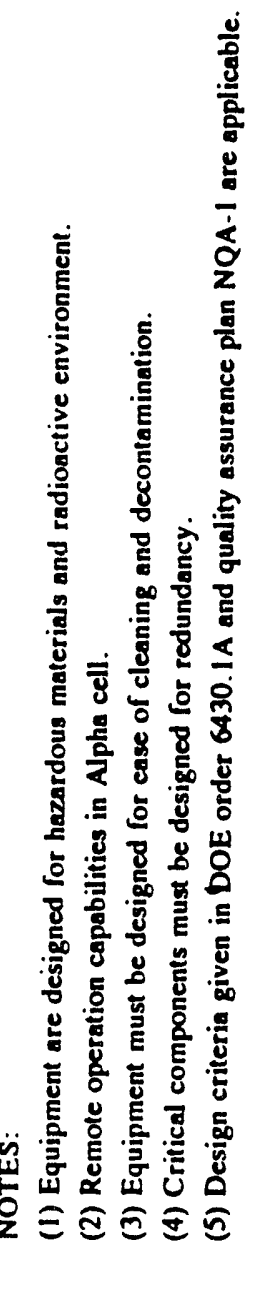

$=$
4
0
$a$
$w$
0
0
0

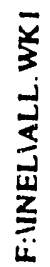




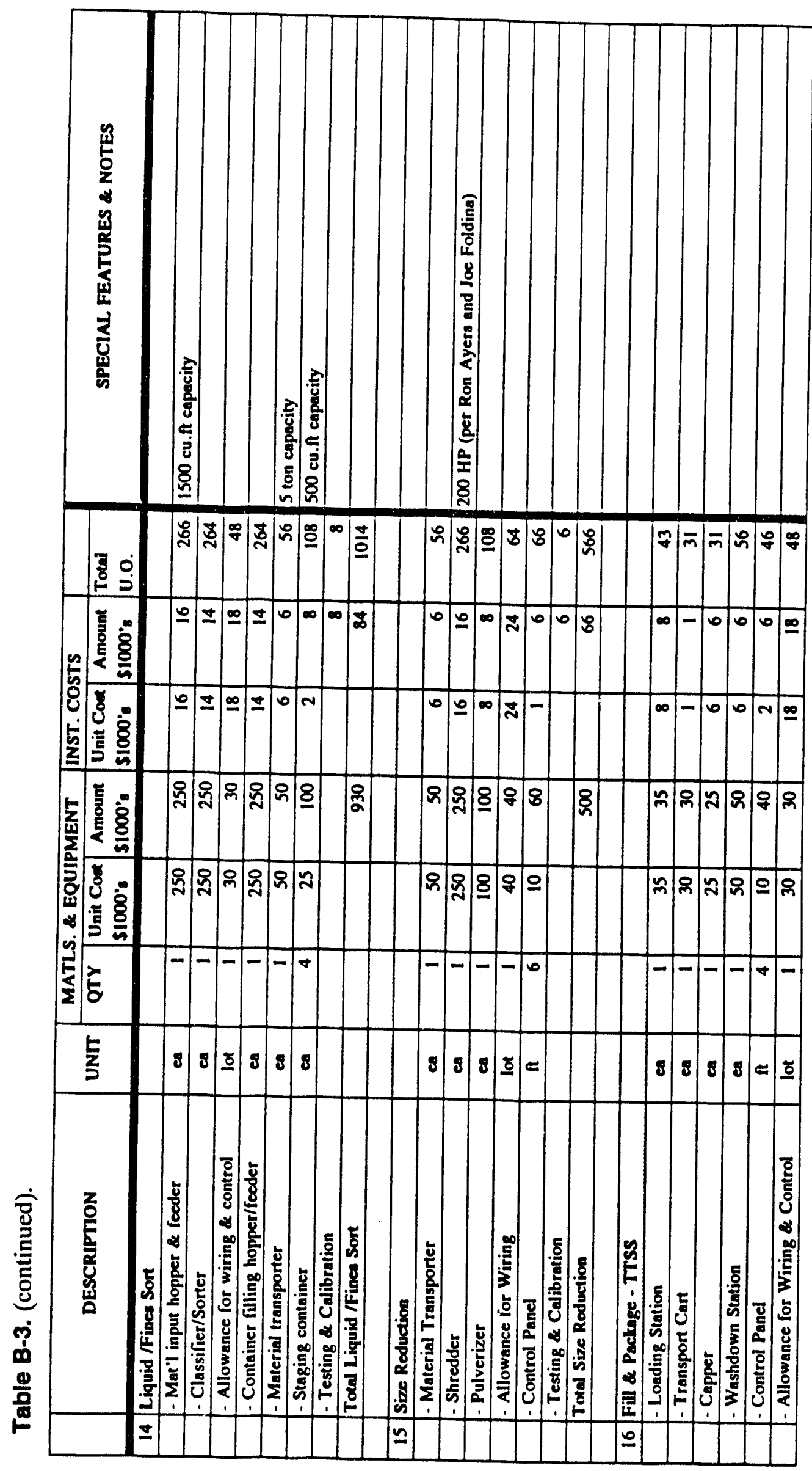

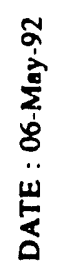

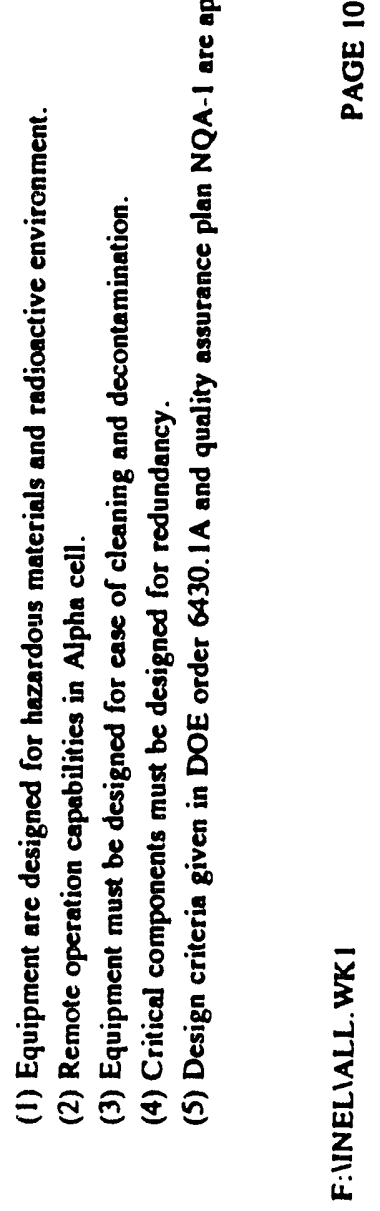




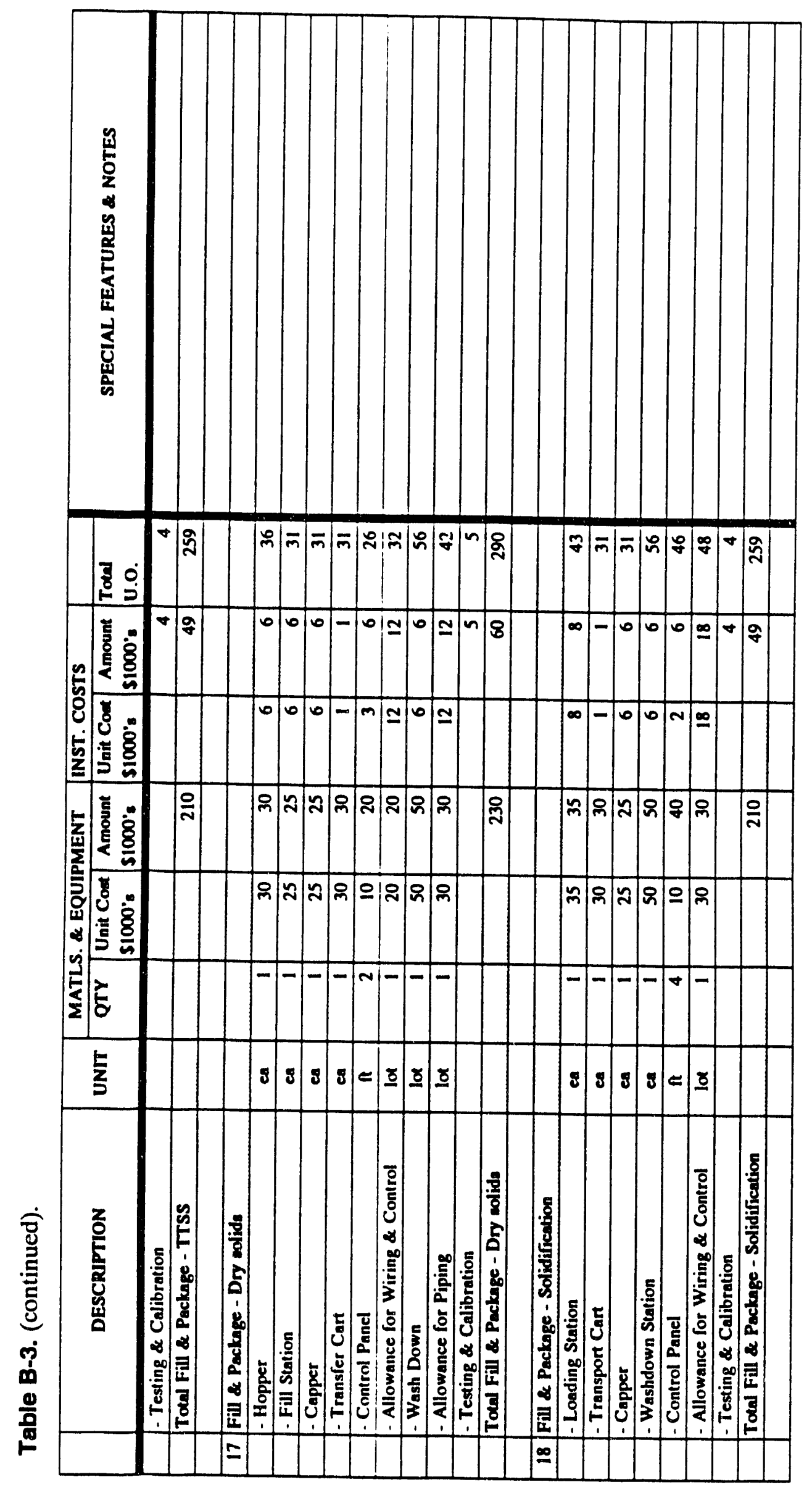

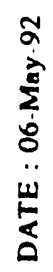

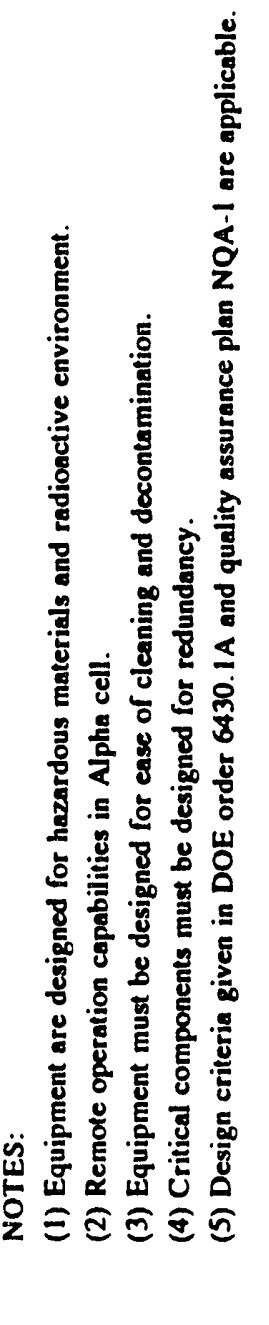

$=$
0
$=$
$u$
0
0
0

نَ 


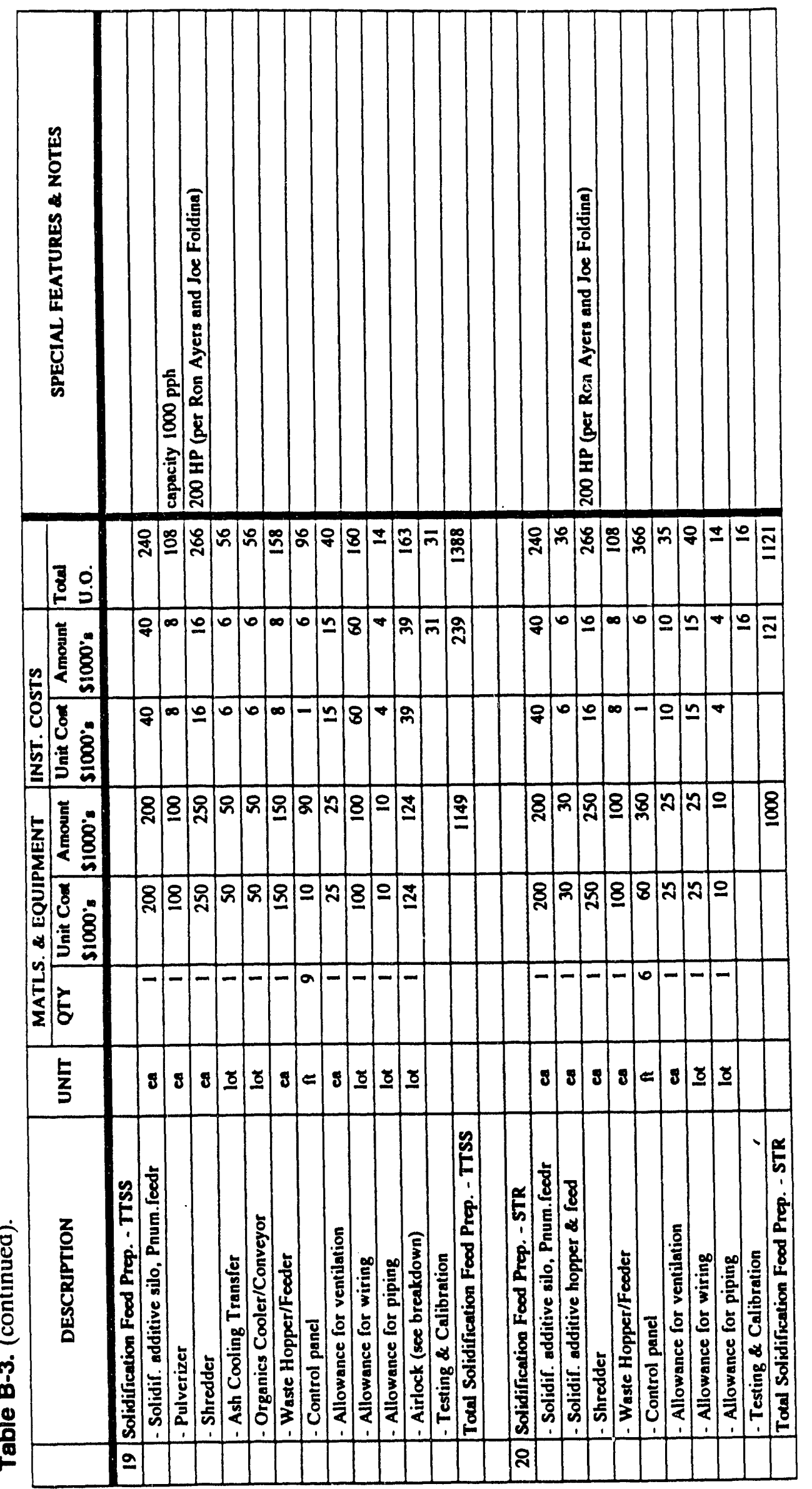

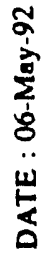

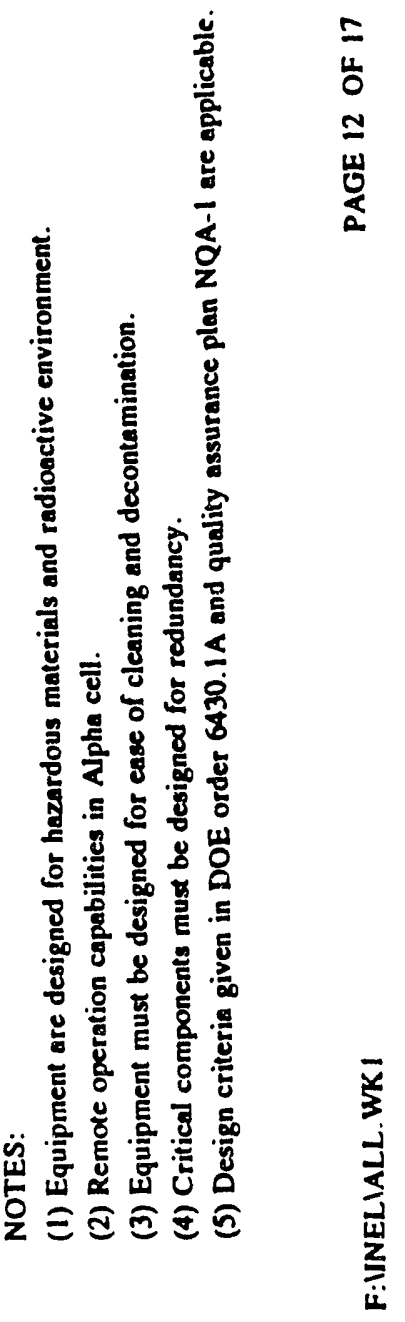




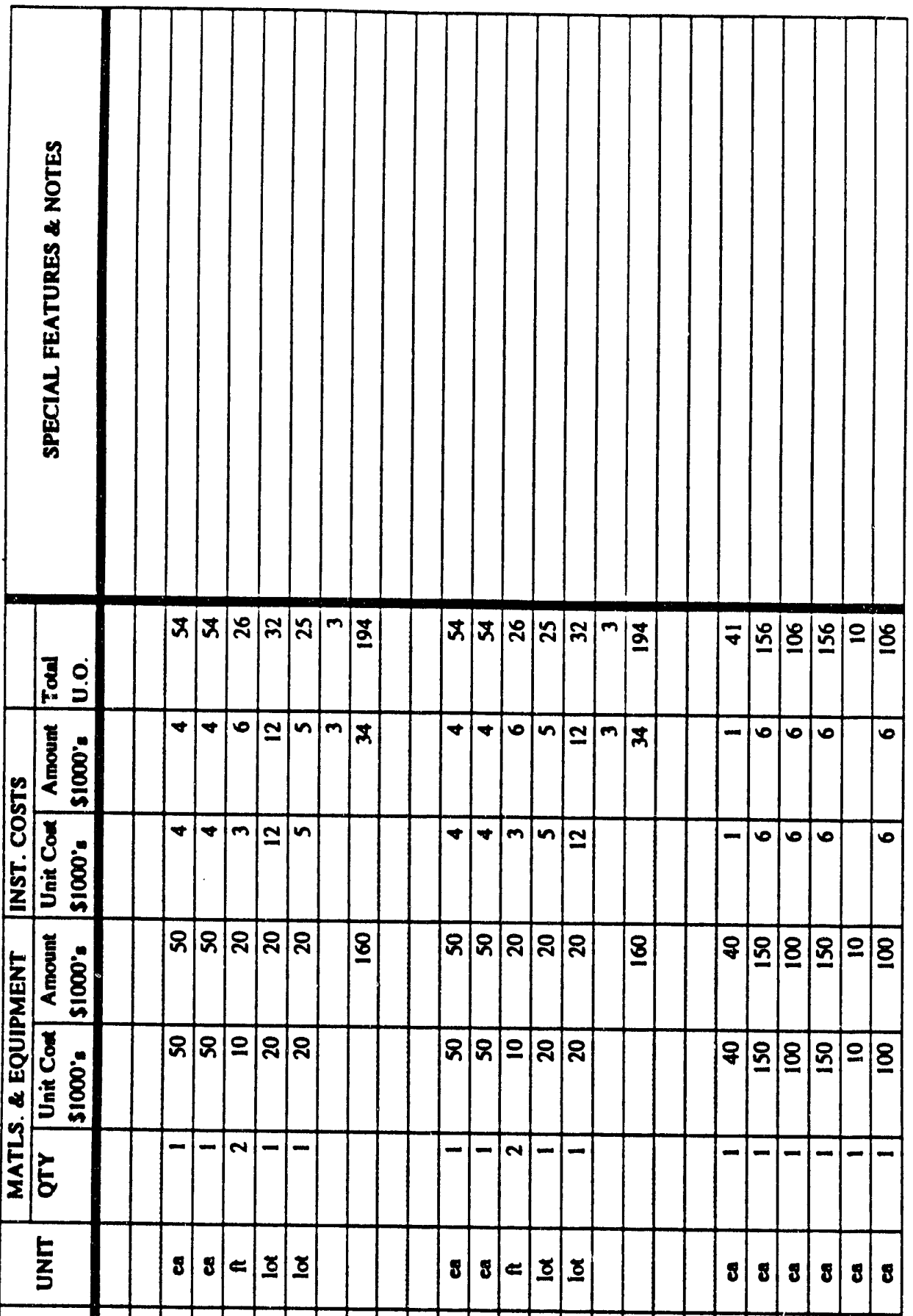

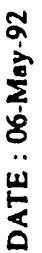

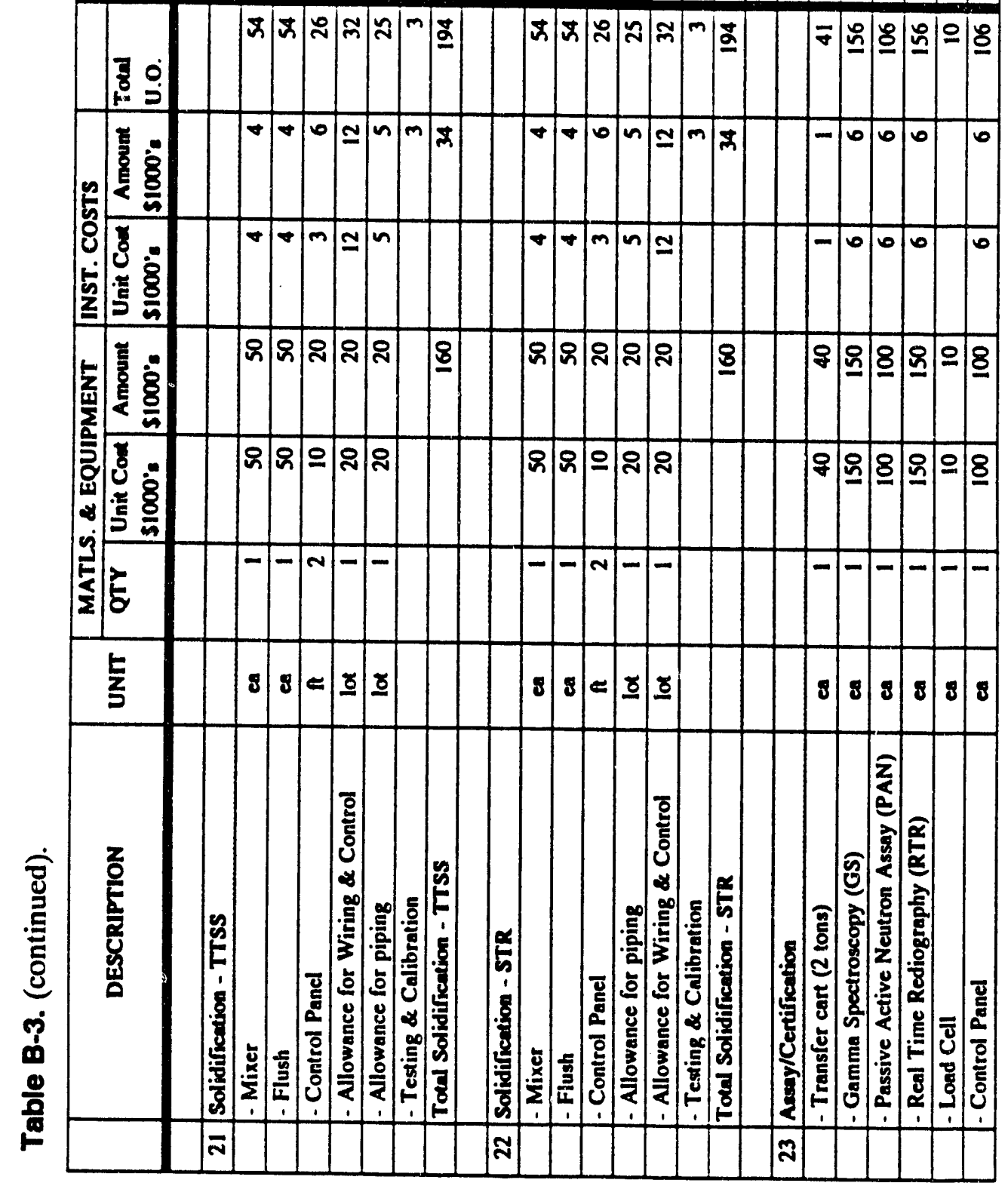

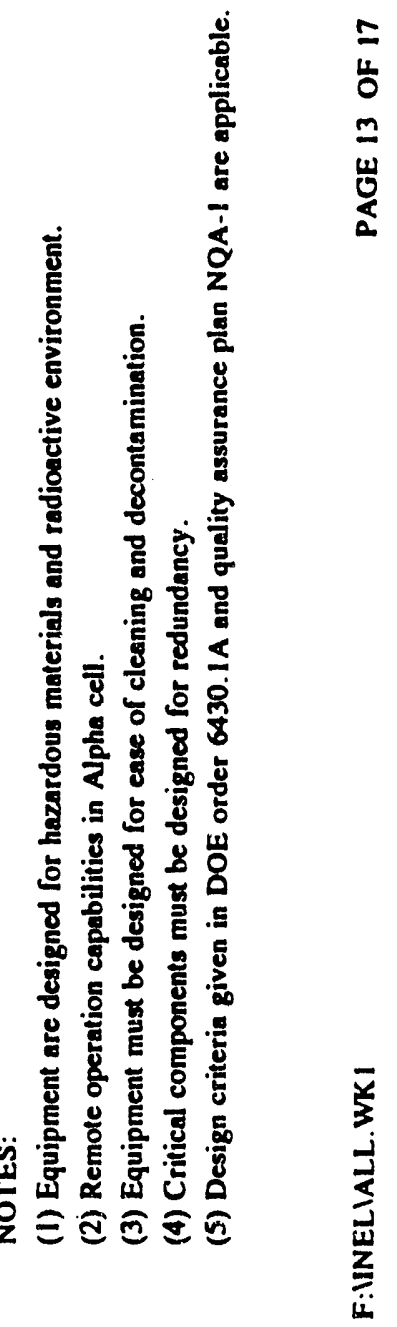




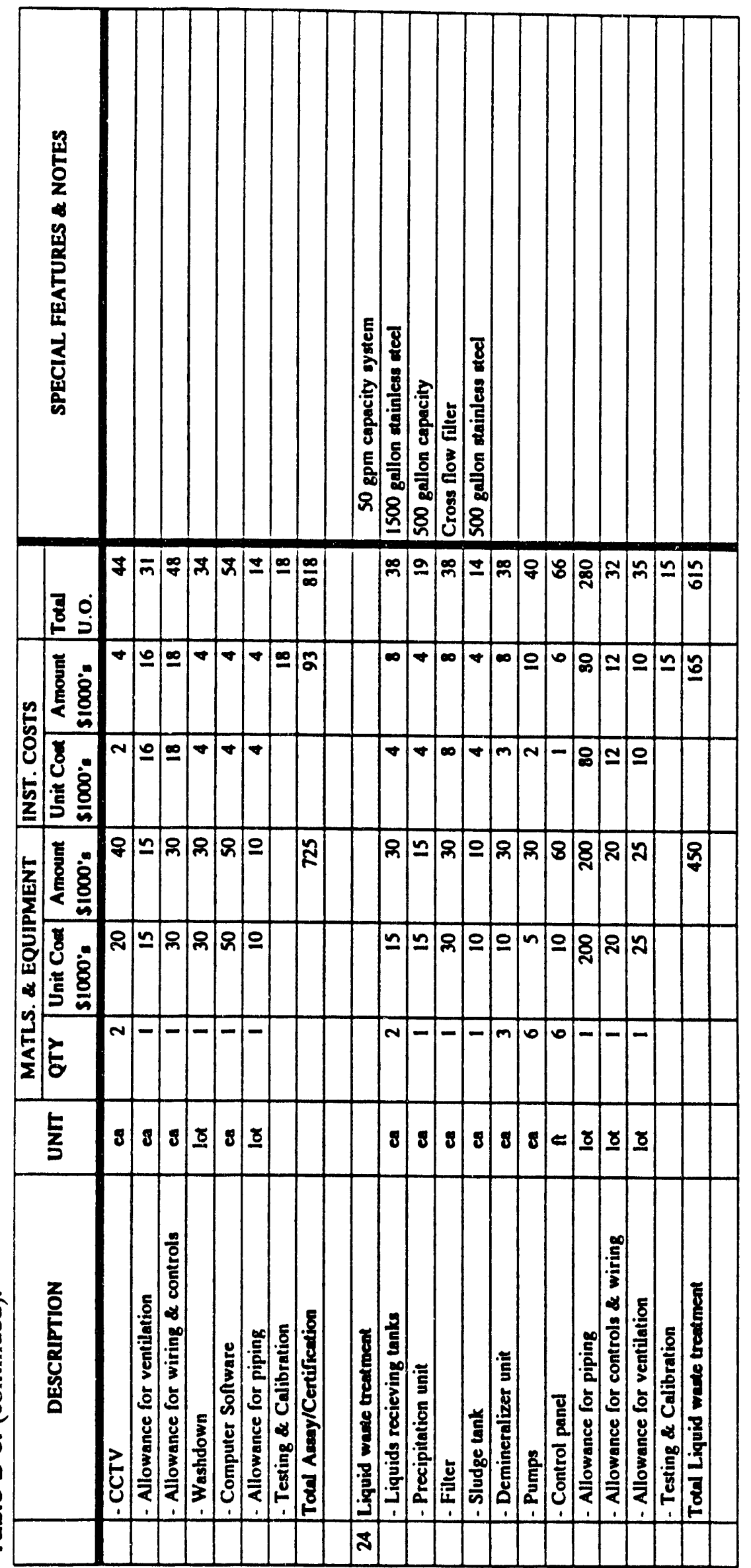

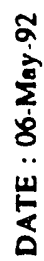
0

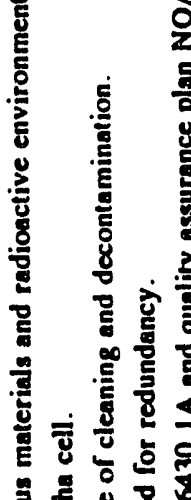

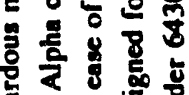
. 5 훙

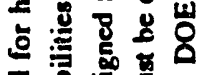

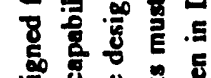
卷

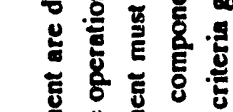

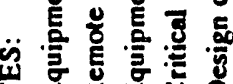

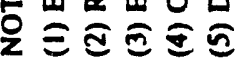




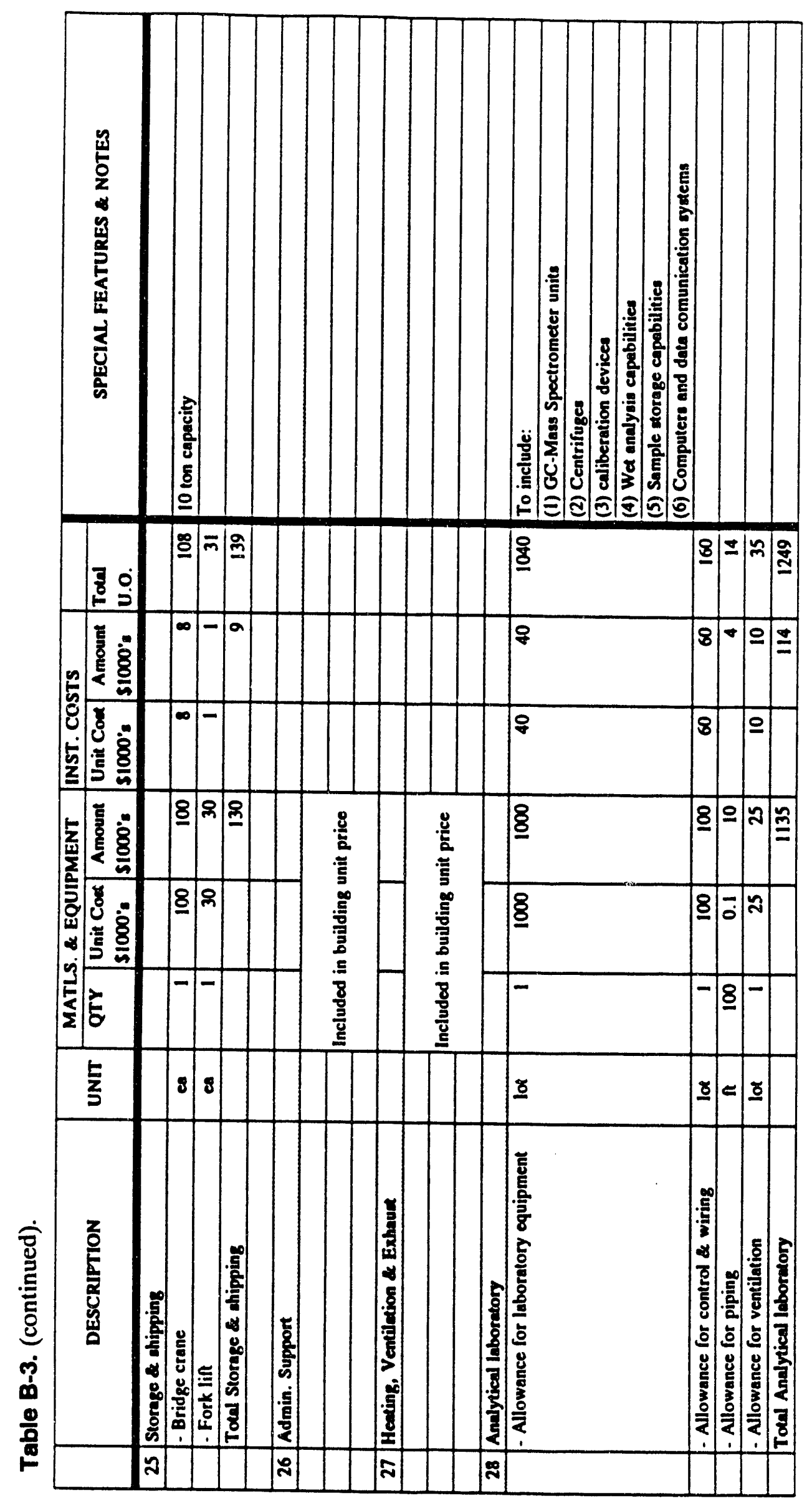

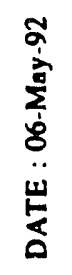

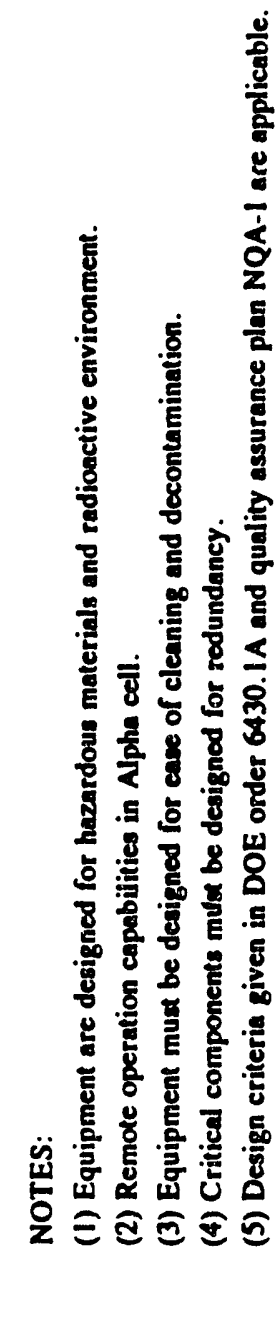

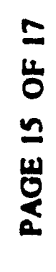

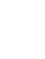

لِ 

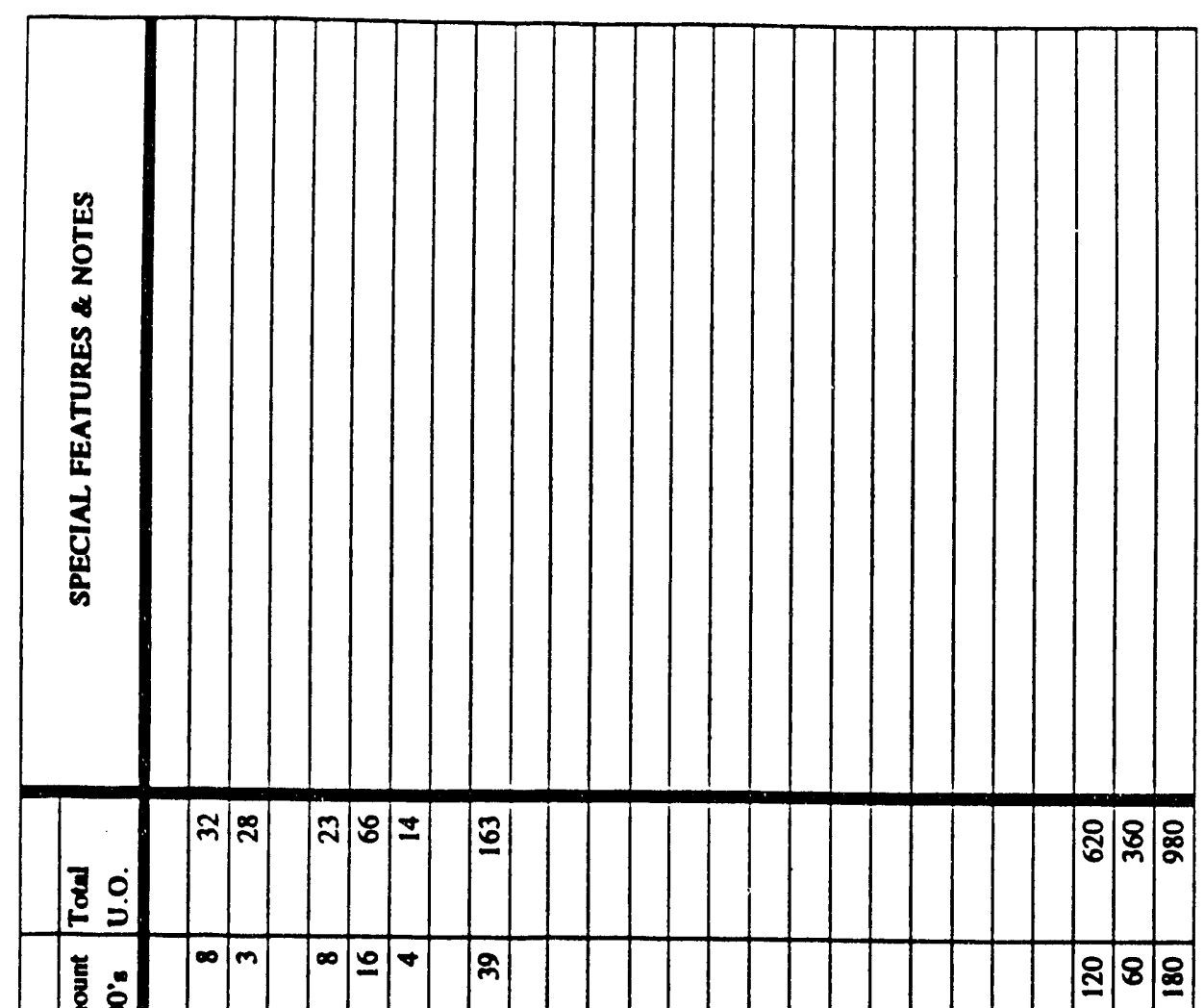

点

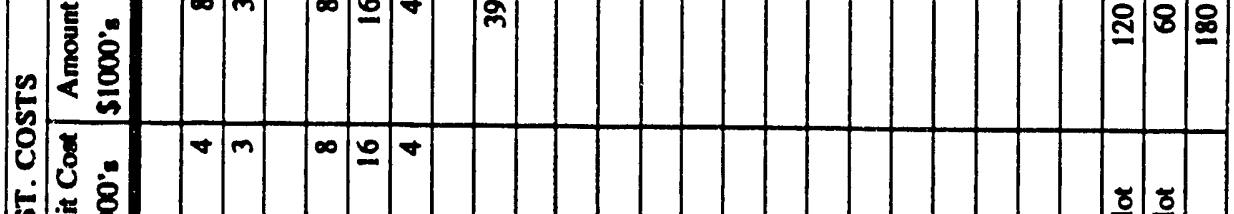

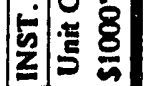
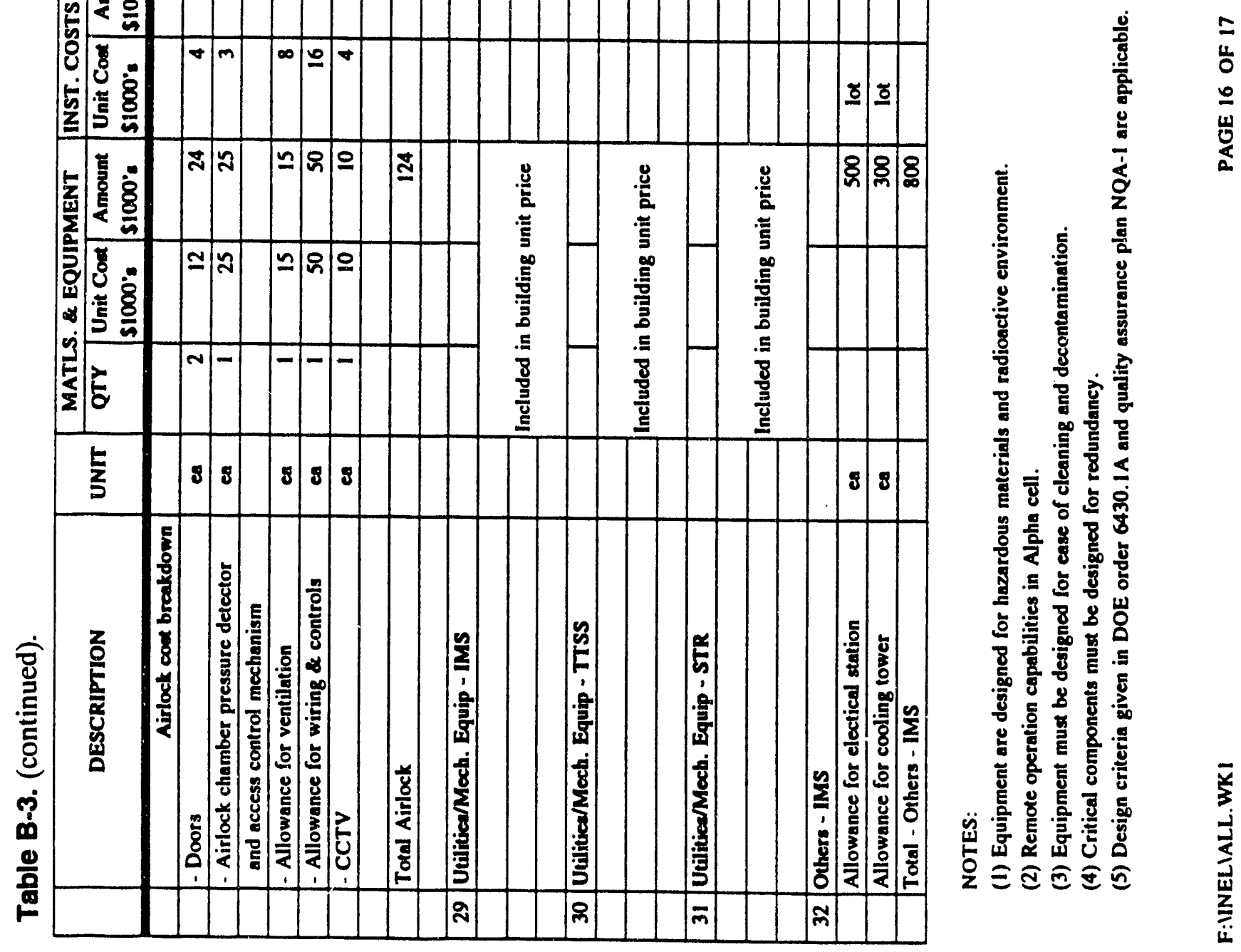


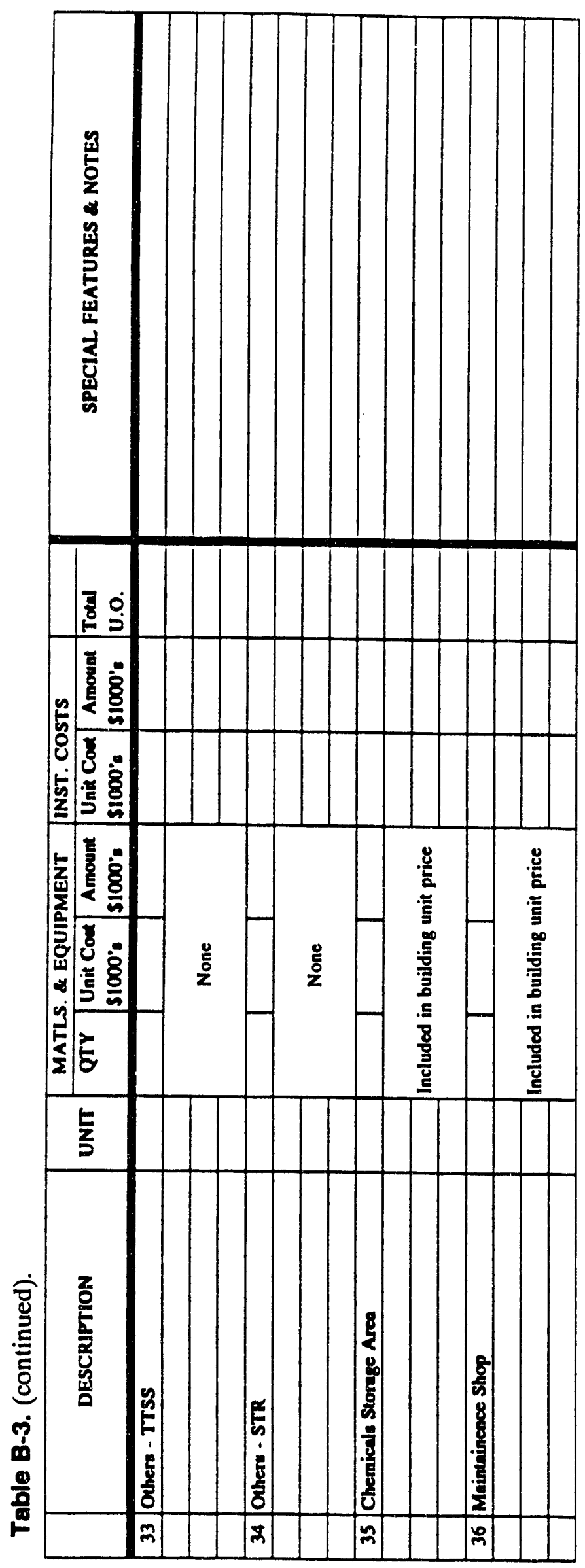

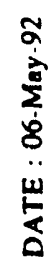

$=$
0
$=$
$u$
$\frac{0}{0}$

文 


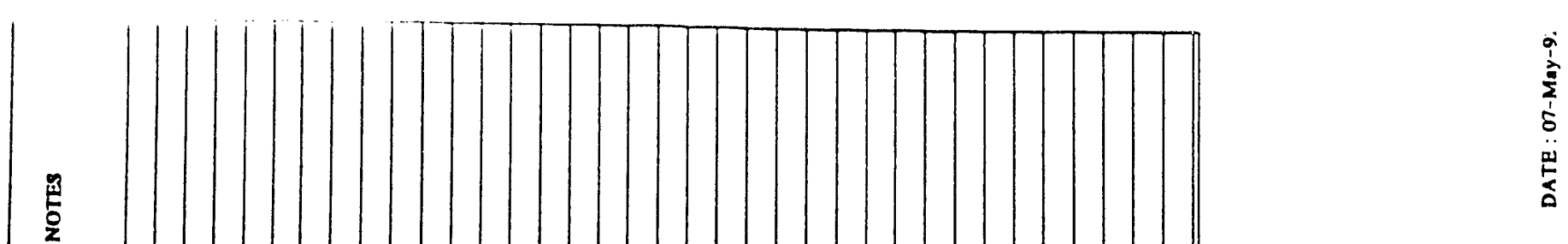

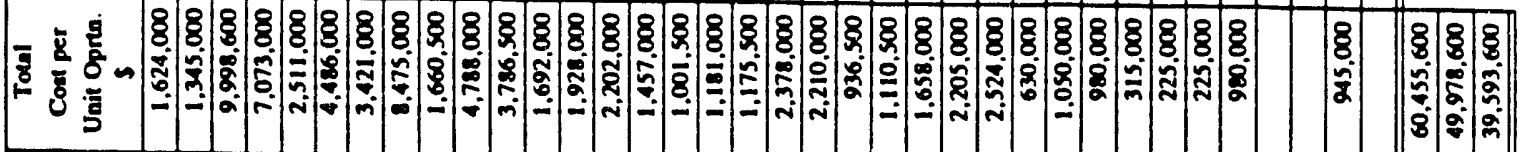

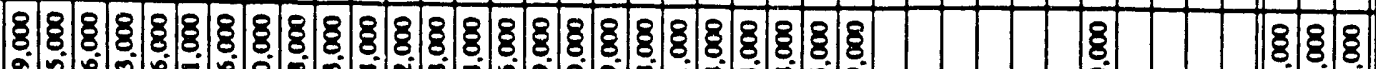

票吾

8

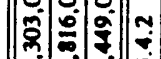

की

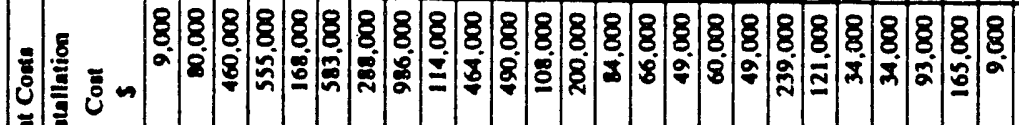

存

空

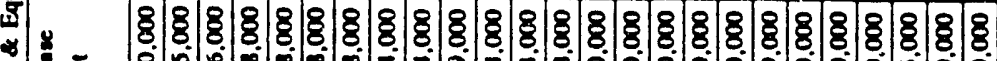

至 帘

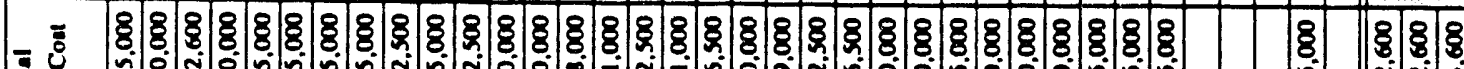

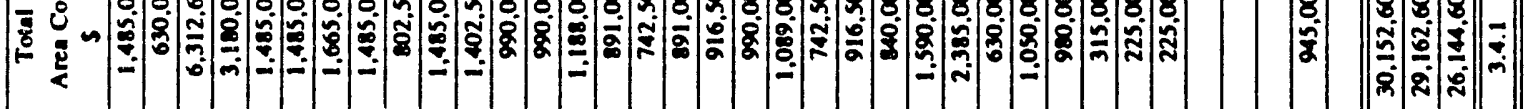

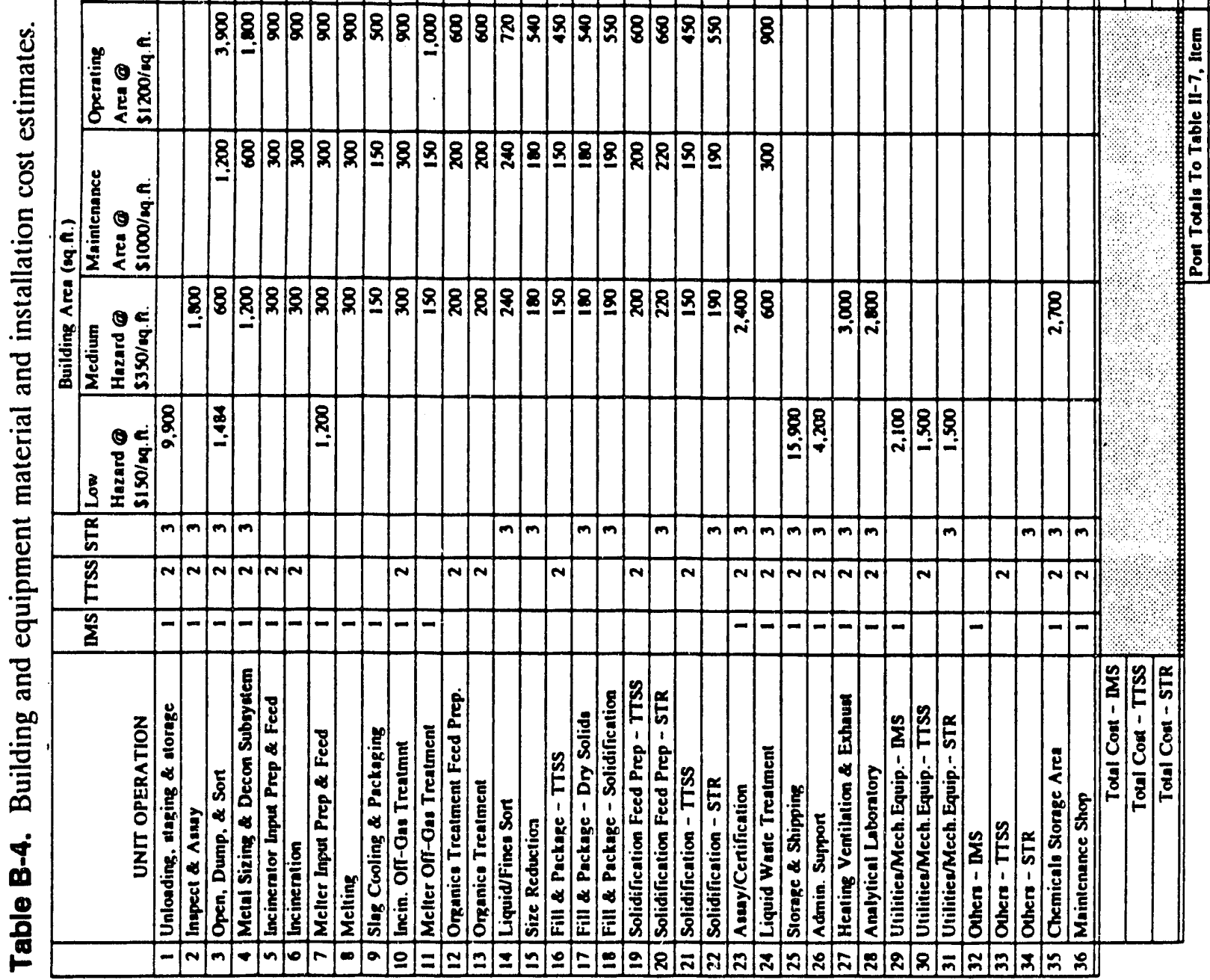




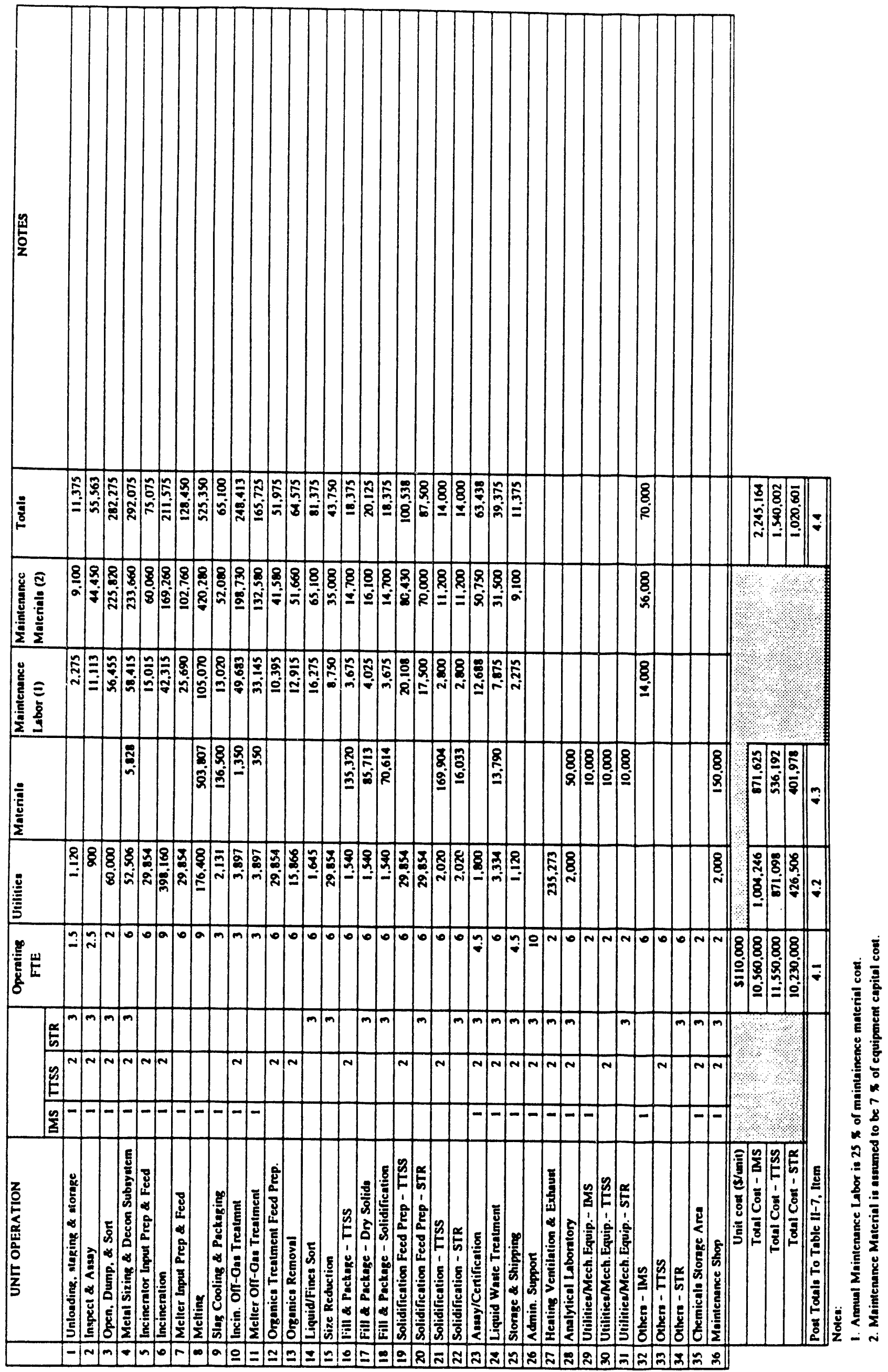

产 


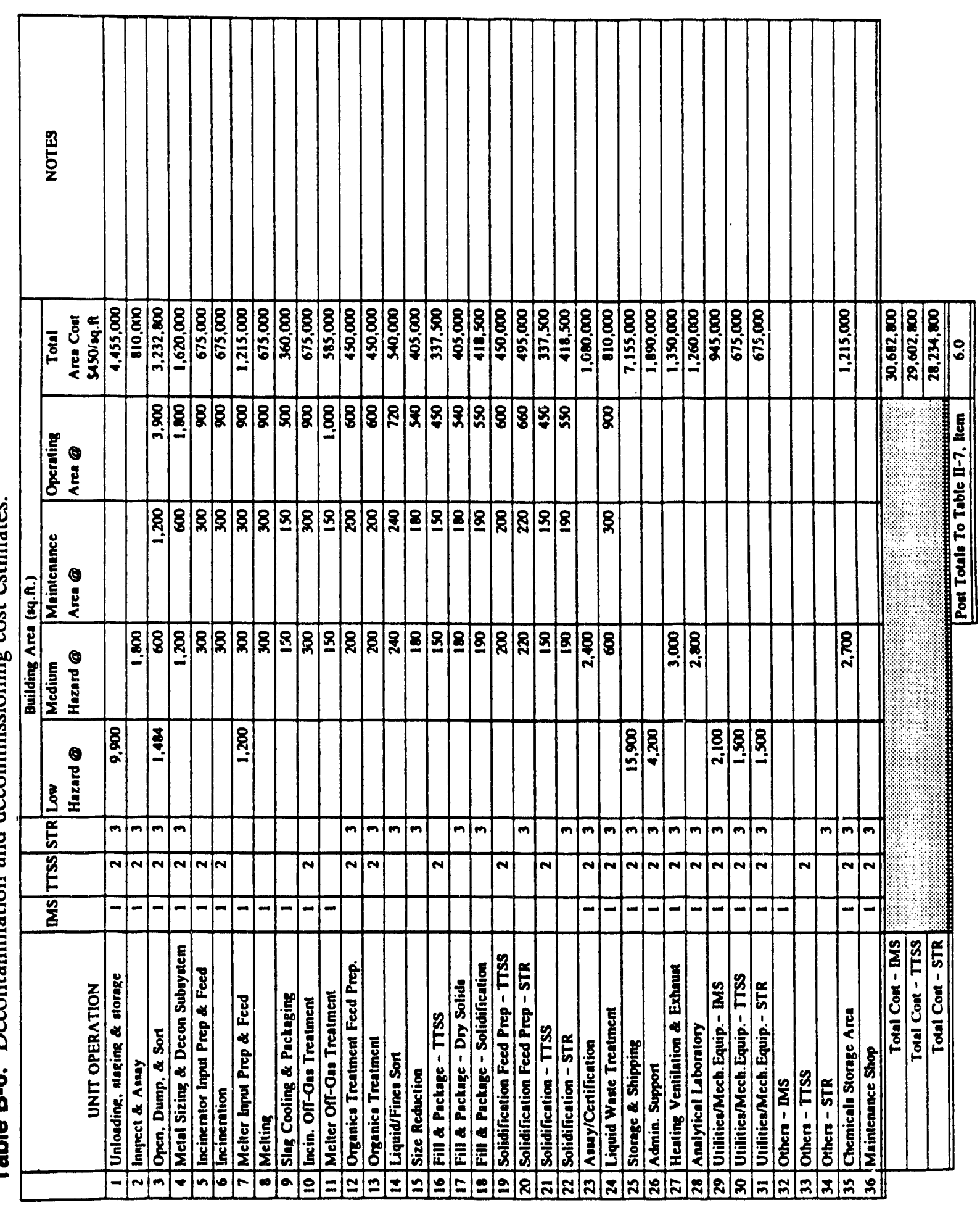

章 
Table B-7. ROM life-cycle cost estimate summary for LL-TRU system concepts.

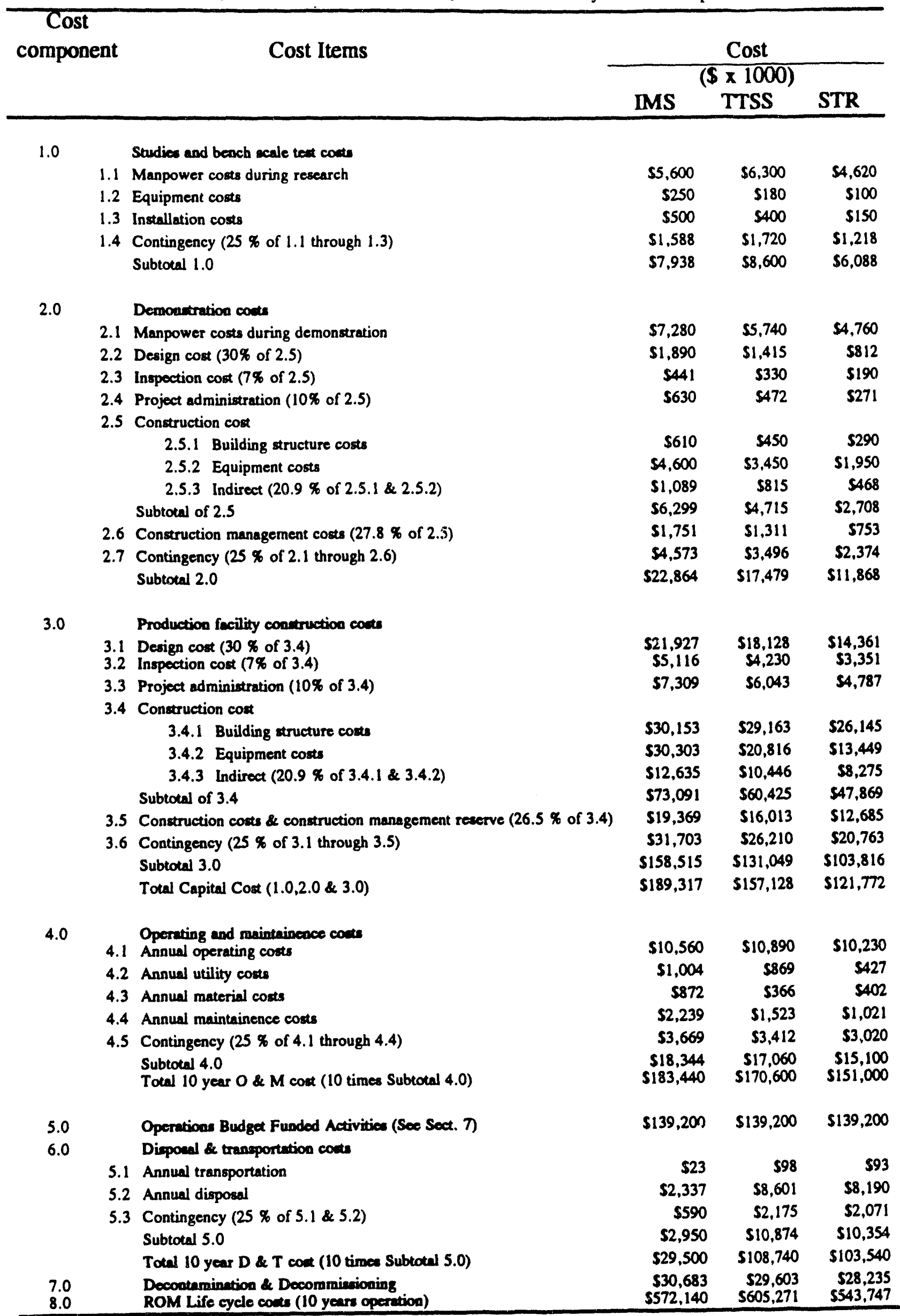



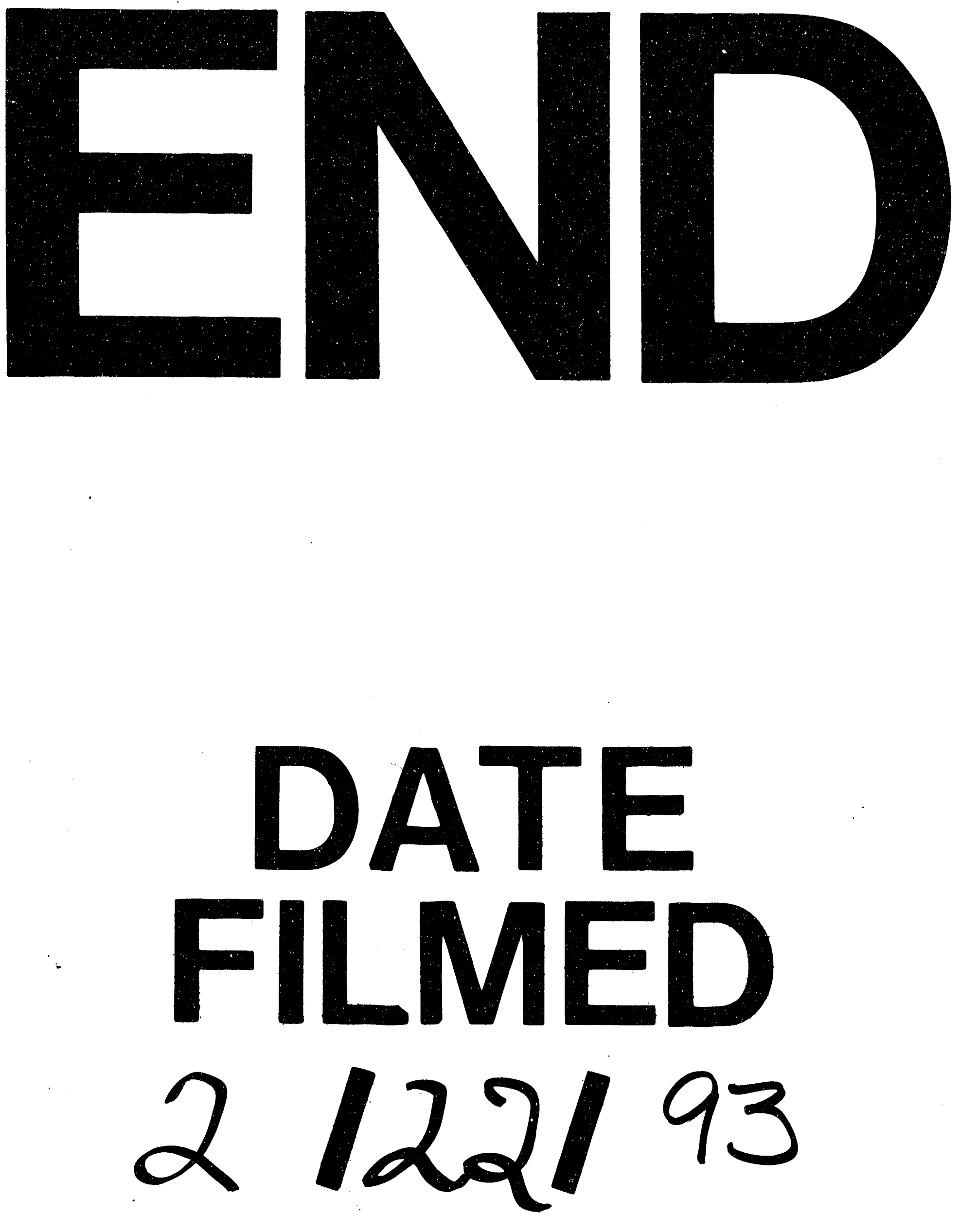
